\title{
LA QUERELLA DE LA LENGUA EN ARGENTINA
}

(1828-1928)

TESIS DOCTORAL

LIC. FERNANDO ALFÓN

Dirección: HORACIO GONZÁLEZ

Codirección: MARCOS RUVITUSO

LA Plata - 2011 
PRESENTACIÓN $\quad$ VI

INTRODUCCIÓN

PRIMERA PARTE

I. LOS PRECURSORES: CASTICISTAS Y ROMÁNTICOS (1828 - 1838) 7

I. 1. El idioma patrio de Juan Cruz Varela

I. 2. Larra en Buenos Aires

I. 3. Florencio Varela: casticismo y literatura nacional

I. 4. La generación del 37: invención de la nación

I. 5. La lengua de Echeverría

I. 6. La nacionalización de la lengua en Alberdi

I. 7. Gutiérrez, la emancipación de la lengua y el despertar de la querella

I. 8. La emancipación de Alberdi

II. SARMIENTO: LA POLÉMICA CON BELLO Y LA REFORMA ORTOGRÁFICA (1841 - 1870)

II. 1. La polémica Sarmiento-Bello

II. 2. La reforma ortográfica de Sarmiento

II. 3. Repercusión de la Memoria sobre ortografía castellana

II. 4. Andrés Bello y el purismo no supersticioso

II. 5. Espectros idiomáticos de Sarmiento

II. 6. La alarma de Juan Valera: antecedente de los correspondientes

II. 7. El idioma del presidente

III. LA INTERVENCIÓN DE LA REAL ACADEMIA EN AMÉRICA

$(1870-1880)$

III. 1. Las Academias Correspondientes y la reacción de Alberdi

III. 2. El rechazo de Gutiérrez: polémica entre Berra y Pelliza

III. 3. Polémica entre Gutiérrez y Martínez Villergas

III. 4. Alberdi piensa el rechazo de Gutiérrez

III. 5. Las confesiones de Alberdi

III. 6. El idioma nacional de Vicente G. Quesada

III. 7. Zeballos, Hernández, Sarmiento y la polémica

III. 8. López, el primer Groussac y el último Sarmiento 
IV. ACADEMIAS CORRESPONDIENTES Y DICCIONARIOS (1889 -

IV. 1. Polémica entre Argerich y Obligado: la academia y el diccionario

IV. 2. Polémica entre Del Solar y De Vedia (Juan Cancio)

IV.3. El juicio de Martí y la exhortación de Mansilla

IV. 4. La circular de Carballido y la lengua de Groussac

IV. 5. El Congreso de 1892

V. CONTRA EL PURISMO: DE LENZ A CUERVO (1893 - 1900)

V. 1. La advertencia de Rodolfo Lenz

V. 2. El sobrecastellano de Unamuno

V.3. Ernesto Quesada y El problema del idioma nacional

V. 4. La carta de Eduardo Wilde

V. 5. Polémica entre Cuervo y Valera. Primera parte

SEGUNDA PARTE

I. POLÉMICAS EN TORNO A LAS TESIS SEGREGACIONISTAS DE ABEILLE Y CUERVO (1900 - 1903)

I. 1. El Idioma nacional de los argentinos, de Lucien Abeille

I. 2. Secuaces y primeros antagonistas de Abeille

I. 3. Groussac y Cané: la teoría del reencauzamiento

I. 4. La antinomia de Abeille y el idioma patrio de González

I. 5. Polémica entre Cuervo y Valera. Segunda parte

I. 6. Quesada y el autor de Nastasio: en torno al criollismo

I. 7. Cuervo y el castellano en América

II. DEL VIRAJE DE UNAMUNO A LA TESIS DE LA ESCISIÓN MORAL, DE MENÉNDEZ PIDAL (1903 - 1918)

II. 1. El viraje de Unamuno

II. 2. Las Notas de Monner Sans

II. 3. Oyuela y el espíritu nacional en la lengua

II. 4. Selva y Terán: la evolución de la lengua

II. 5. El idioma patrio de La restauración nacionalista

II. 6. Los diccionarios del Centenario

II. 7. Rossi, el heredero de Abeille

II. 8. Lugones y la lengua gaucha

II. 9. Rojas: la lengua nativa y de conquista

II. 10. Toro y Gisbert y Menéndez Pidal: la tesis de la escisión 
moral

III. PRIMERAS PERIODIZACIONES: COSTA ÁLVAREZ, QUESADA Y

142

ROJAS (1922 - 1923)

III. 1. Primera periodización: Nuestra Lengua, de Costa Álvarez

III. 2. Segunda periodización: La evolución del idioma nacional, de Ernesto Quesada

III. 3. La lengua de Eurindia

III. 4. Los Disparates de Monner Sans y el casticismo de Groussac

IV. LA QUERELLA AL IRRUMPIR EL INSTITUTO DE FILOLOGÍA (1923 - 1926)

IV. 1. El Instituto de Filología

IV. 2. Albor de la polémica entre Costa Álvarez y el Instituto de Filología

IV. 3. Castro contra el dialecto argentino; Lugones en pro del idioma de los héroes

IV. 4. El «nuevo idioma de la Argentina» de Del Valle Inclán y el diccionario de Montoliu

IV. 5. «La mala suerte» de Costa Álvarez

IV. 6. Henríquez Ureña y la tesis del descontento y la promesa

V. De Grossmann a LA NACIÓN (1926 - 1927)

V.1. Elpatrimonio, de Grossmann

V. 2. Primeras glosas de El patrimonio

V. 3. Polémica entre La Gaceta literaria y Martín Fierro

V. 4. Xul Solar y sus «Apuntes de neocriollo»

V. 5. El futuro idioma en Borges y el «estado de gracia» de Castro

V. 6. La Nación y los nuevos horizontes de Tirso Lorenzo

VI. DE LA TESIS CONVERSACIONAL DE BORGES AL ÚLTIMO LIBRO

DE Costa Álvarez (1928)

VI. 1. Borges y la tesis conversacional

VI. 2. La prédica de Rossi

VI. 3. Carriegos, un nuevo heredero de Abeille

VI. 4. La Babel de Capdevila

VI. 5. Costa Álvarez y El castellano en la Argentina 
RESUMEN

CONCLUSIONES

BIBLIOGRAFÍA 


\section{PRESENTACIÓN}

La presente tesis es un estudio en torno a la historia política de la cuestión de la lengua en Argentina, desde sus inicios en 1828 hasta la conclusión de una etapa del debate en 1928. El plan de tesis fue presentado en el Doctorado de Historia de la Facultad de Humanidades y Ciencias de la Educación de la Universidad Nacional de La Plata en junio de 2008 y aceptado en agosto de ese mismo año.

Quiero agradecer, por tanto, a Horacio González, que me ha dirigido durante la realización de la tesis, orientando y sugiriéndome muchos de los textos que aquí se someten a estudio; al doctor Marcos Ruvituso, que me codirigió con suma dedicación; a mis padres, sin los cuales nada hubiera sido posible; y a José del Valle, por su amistad y por la conversación amena en torno a sus recientes trabajos.

La reunión de libros, periódicos, folletos y cartas la realicé, fundamentalmente, peregrinando por la Biblioteca Nacional, la Biblioteca Pública de la UNLP y la Biblioteca de la Facultad de Humanidades. Todos los bibliotecarios, en especial los de la Biblioteca Pública, me atendieron con tanta dedicación que no puedo, en este agradecimiento, dejar de nombrarlos. 


\section{INTRODUCCIÓN}

La formación identitaria de la Argentina se ha erigido, en buena medida, a partir de la querella en torno a la lengua que hablamos los argentinos. En la presente tesis pretendo mostrar, en principio, que esta querella consta de dos períodos. El primero se inicia en 1828, con el ensayo de Juan Cruz Varela sobre «Literatura Nacional», y tiene sus motivos más característicos durante el siglo XIX. El segundo viene de la mano del siglo XX, con Idioma nacional de los argentinos (1900), de Lucien Abeille, y sus estelas llegan hasta el día de hoy. Abeille puede considerarse una bisagra entre la vieja forma de estudiar las lenguas — ligada a la herencia del romanticismo y a la ciencia decimonónica - y la nueva forma, de carácter lingüístico ya en sentido más contemporáneo, que en España se desarrollaba en los albores del siglo XX y encuentra en Ramón Menéndez Pidal a su patriarca. Aunque Abeille no llega a pertenecer a esta escuela, se trata del primer intento de formar un programa filológico (con gramática y léxico incluidos) para el idioma argentino.

Estos dos períodos, no obstante, tuvieron como horizonte común dilucidar — ya sea desdeñándolo, ya sea enarbolándolo- el idioma nacional, el idioma patrio, la lengua argentina... modos alternativos con que se ha aludido siempre a un mismo problema: la cuestión de la lengua en Argentina.

He compuesto la presente tesis en torno a la crónica de estas dos vertientes, que llegan, en la década de 1920, a su máxima expresión. Tomo como punto de partida el año 1828, porque es allí cuando aparecen los primeros artículos que estimo relevantes. Concluye en 1928, cien años más tarde, por ser el año más activo de la querella (cuatro libros de enorme relevancia se publican este año), luego del cual aminora, como si se tratara de la paz que deja tras de sí el último estampido de una extendida batalla.

Presentar la tesis en términos de querella me ha permitido formular las siguientes hipótesis.

PRIMERO: Argentina ostenta —no de modo excluyente pero sí de modo singular - una cuestión (digamos también, un debate nacional) al que podemos llamar «la querella de la lengua». Bajo nombres como «idioma nacional», «idioma patrio», «nuestra lengua» etc., se ha pretendido dilucidar la identidad cultural de la república.

1 Borges 1928a; Capdevila 1928; Costa Álvarez 1928b; Henríquez UREÑA [1928]. 
SEgundo: Es el recelo a España lo que origina en Argentina la preocupación por un idioma distintivo, por un idioma argentino, no español. Para la nueva generación de Mayo, España solo tenía para ofrecer costumbres medievales, políticas monárquicas y gramáticos casticistas, autorizados únicamente en Madrid para enseñar a hablar correcto a los americanos. Esto ocasionó que la Argentina republicana y romántica enfatizara su identidad cultural señalando no tener nada que ver con la España absolutista. Es asunto de otra discusión si el juicio que se tuvo de España (mayoritariamente adverso) es justo o no. Argentina sintió el «derecho moral» de incidir en el idioma del mismo modo que incidían los castellanos, surgiendo, entonces, esa bizarría a partir del veto puesto a España, por su pasado, por sus costumbres, por sus pretensiones de cuidado y mando de la lengua. De modo que podríamos decir que la pretensión de un idioma argentino - expresión con que a menudo se presentó la cuestión de la lengua- ha sido otra de las consecuencias de la presencia de España en América.

TERCERO: Cuando una nación atraviesa un período de gran actividad cultural y expresivo, dos tendencias antagónicas, la neologista y la conservadora, experimentan, a la vez, un momento de gran repercusión y entusiasmo. La lengua recibe, entonces, una enorme presencia de voces y giros extraños; es aquí, a la vez, cuando los puristas actúan más enérgicamente en pro de detenerlos u ordenarlos. La Argentina tuvo esos momentos: la generación del 37, la Argentina de fin del siglo XIX, las dos primeras décadas del siglo $\mathrm{XX}$. La causa del idioma nacional a menudo ha resurgido en esos momentos.

Para nominar al libro, pude haber apelado al concepto de idioma nacional, al igual que cualquiera de sus variantes, por las siguientes razones. El concepto de idioma nacional designó, en Argentina, tanto una lengua privativa, como su contrario: la lengua común de todas las naciones de habla hispana; a menudo se empleó para referir una mera entonación rioplatense, a menudo como sinónimo de gauchesco, lunfardo, cocoliche o cualquiera otra jerga; también fue una variante de castellano y de español, como lo usa Ricardo Rojas. Muchas de las diatribas contra el idioma argentino, entendido ahora como una lengua privativa, llevan por nombre esta misma forma o formas parecidas: «idioma nacional» (Vicente G. Quesada), «lengua nacio- 
nal» (Miguel de Toro y Gisbert), «nuestra lengua» (Costa Álvarez)... como si el esmero por refutar la existencia de algo no pudiera prescindir de que, al menos, ese algo tiene un nombre. Creo, por tanto, que el título La querella de la lengua en Argentina pretende ser fiel al planteamiento de estos problemas.

Uso, a menudo, el vocablo español tanto como el de castellano, indistintamente, no porque ignore la historia y diferencia de cada uno de ellos, sino porque los textos que indago preferían uno u otro. No obstante, se notará que castellano es voz que aparece más en la primera parte, mientras que español se impone al final de la segunda.

Casi la totalidad de los textos que intervienen en esta querella hablan de idioma argentino como si se tratara del idioma de toda la Argentina. Una simple ojeada a la tesis, no obstante, revelará que esos mismos textos surgen en el ámbito geográfico y cultural del Río de la Plata, o bien remiten a la realidad de esta región. He aquí un problema, pero puesto que indago en la expresión idioma nacional por las luchas que lleva inscripta, ese problema no es fácilmente resoluble, aunque puede ser delimitado. Esta irresolución justifica la construcción de un libro como el presente. Que Buenos Aires presuma que sus problemas son los problemas de la nación entera es, en buena medida, la historia de la Nación Argentina.

\section{III}

La cuestión de la lengua en Argentina ostenta una historia textual que podemos calificar como una de las más valiosas de la república, por el número de las intervenciones que inciden en ella y, ante todo, por la calidad y trascendencia de las mismas. Puesto que esta historia textual consta de varias fuentes aún dispersas o tratadas de manera muy fragmentaria, la presente tesis también pretende reunirlas, situarlas en la tradición histórica que atraviesa la cuestión idiomática y hacerlas dialogar al punto que revelen el drama cultural idiomático acaecido en la Argentina durante el período 1828-1928.

Luego de 1928, no obstante, al progresar los estudios lingüísticos, la querella en torno a la lengua sigue, aunque en menor medida, generando sucesos de cierta relevancia, como son la polémica de Roberto Arlt con Ricardo Monner Sans; la tesis porteñista del idioma recreada por Raúl Scalabrini Ortiz en El hombre que está solo y espera; las reflexiones telúricas de Ezequiel Martínez Estrada en Radiografía de la pampa; las síntesis confeccionadas por Ángel Rosenblat en distintas publicaciones periódicas; las pretensiones de Vicente 
Rossi de demostrar un «idioma rioplatense»; el ensayo de Amado Alonso, «El problema argentino de la lengua», que reescribirá Américo Castro en 1941, bajo el nombre de La peculiaridad lingüistica rioplatense y su sentido bistórico, y al cual Borges le dedicará unas páginas aún polémicas («Las alarmas del Doctor Américo Castro»).

En cuanto a la periodización que despliego en la presente tesis, advierto que existen algunos trabajos similares pero que no llegan a dar cuenta integral de la misma por los motivos que resumo a continuación.

En 1922, el filólogo Arturo Costa Álvarez publica el libro de ensayos Nuestra Lengua, primer intento de biografiar la discusión en torno a la lengua en Argentina, discusión que, para ese año, ya está a punto de cumplir un siglo. El libro es sistemático y pretende cerrar el ciclo de estudios sobre la cuestión, porque, precisamente, la encuentra perimida. Costa Álvarez ignoraba que, poco tiempo después, en la Facultad de Filosofía y Letras de Buenos Aires se estaba por fundar, de mano de Ricardo Rojas, el Instituto de Filología, que encontrará como problema de la lengua en Argentina a la misma obra de Costa Álvarez, al que considerará —es opinión de la mayoría de sus integrantes: Américo Castro, Amado Alonso, etc.- un lingüista de la vieja escuela, o más precisamente, de método inadecuado. Costa Álvarez no pertenecía a la escuela de Menéndez Pidal y pagó eso con el destierro que le aplican sus colegas españoles en Argentina. Nuestra lengua, por tanto, es parte de la historia política de la lengua, no su resumen ni su juicio final.

La empresa de periodización desplegada en Nuestra lengua conmueve a Ernesto Quesada al punto de que acomete una reescritura $^{1}$ a partir de lo que considera omisiones y distracciones de aquella. Compartiendo en lo substancial las tesis de Costa Álvarez, el ahora director de la Academia Correspondiente de la Española se pone a corregirla. Quesada aprueba en general el libro de Costa Álvarez, para luego observarlo en varias de sus páginas en particular. Quesada, como a su modo Costa Álvarez, tampoco se afilia a la escuela fundada por Menéndez Pidal y se constituye, como aquel, en un mojón más en la genealogía de textos sobre la cuestión. Cuestión que, a principios de la década del veinte, aún no conocía sus momentos cumbres.

Tres años más tarde, en 1926, y en este mismo camino emprendido por Costa Álvarez y Ernesto Quesada, el germanoargentino Rudolf Grossmann emprende un nuevo trabajo ${ }^{2}$ de histo-

${ }^{1}$ Quesada, Ernesto $1923 \mathrm{c}$.

${ }^{2}$ Grossmann 1926. 
rización sobre la lengua en Argentina, cuyo objetivo, a diferencia de sus predecesores, es dotar a la periodización de aspectos específicamente lingüísticos.

En 1983, después de varias décadas en donde no se registran trabajos similares, Alfredo V. E. Rubione compila una serie de escritos En torno al criollismo", cuyo texto principal es «El criollismo en la literatura argentina», de Ernesto Quesada. En su estudio preliminar, Rubione revisa desde una perspectiva de la historia política los antecedentes de la discusión en torno al idioma, pero prefiere limitarse a relevar los acontecimientos que van de 1899 a 1903, años a los cuales pertenecen los textos que recopila.

Estos cuatro trabajos, de evidente relevancia sobre el área temática que investigo, carecen, ya sea por el momento histórico en que fueron escritos, ya sea por el período específico que abordan, de una perspectiva histórica integral de la cuestión de la lengua en Argentina. Mi pretensión es, por tanto, revisar este legado textual, reordenarlo y narrarlo desde una perspectiva de la historia política de las ideas idiomáticas.

\section{IV}

Existen otro tipo de trabajos que abordan el problema de la lengua en Argentina desde una perspectiva histórica, y que encuentro de enorme interés para la reconstrucción integral desde una nueva perspectiva que sitúe lo histórico-político como eje central: el de Jan Blommaert (1999); José Del Valle y Luis Gabriel-Stheeman (2002); Ángela Di Tullio (2003); y Juan Ennis (2008). Los comentaré brevemente, a modo de sugerir la relevancia y pertinencia de los planteos a los fines de elaborar un nuevo estudio sobre el tema.

El libro editado por Blommaert —aunque no versa sobre el caso argentino- intenta un análisis exegético de las «ideologías» actuantes en la configuración y reconfiguración constantes de una lengua. Blommaert parte de la premisa que lo connatural en el desarrollo de una lengua es la disputa polémica de sus sentidos y sus usos. La lengua, en tanto proceso dinámico, deviene en proceso ideológico. Así, en el enfoque blommaertiano, el conflicto y la tensión constituyen el principal elemento para la observación del lugar y la función de la ideología en la lengua.

El objeto de estudio en Blommaert, en este sentido, no procura trazar una historia de las ideas, sino una historia de los conflictos ideológico-lingüísticos. Logra, de este modo, que el enfoque apunte

${ }^{1}$ RUBIONE 1983. 
a la indagación de los elementos «extralingüísticos» en la historia de la lengua, a la dimensión política de la misma, completando, así, un hueco patente en los estudios lingǘsticos: el que corresponde al examen de la producción y reproducción históricas de las «ideologías lingüísticas».

En esta perspectiva de estudio, el estudio de los debates no comprende exclusivamente una lectura de los textos, sino una lectura a partir del contexto de producción y los mecanismos a través de los cuales esos textos devienen en textos prestigiados o desprestigiados, es decir, el modo en el cual pueden llegar a constituir parte del saber y del sentido común.

El libro que compilan Del Valle y Gabriel-Stheeman procura reunir una serie de estudios referidos al debate ideológico de le lengua hispánica. El estudio que puntualmente escriben juntos («Nationalism, hispanismo, and monoglossic culture») dota al resto de los trabajos de un marco introductorio, problematiza la cuestión de la estandarización del español y advierte la preponderancia de trabajos que claman por la unidad y conservación de la lengua. Conceptos fundamentales en este trabajo son los de «hispanismo», «hispanoamericanismo» y «panhispanismo». En la configuración del hispanismo en América, España habría procurado hacer primar lo español por sobre lo americano, incidiendo sobre la lengua en primer lugar. La intelectualidad española, y los españoles residentes en América, inciden, así, en la disputa por la variación y unificación lingüística, cuestión central en lo que Del Valle y Gabriel-Stheeman llaman the battle over spanish. Aquí, las posiciones idiomáticas como las de Bello, Sarmiento, Cuervo y Valera adquieren una dimensión político-ideológica más que pedagógico-lingüística.

Desde el punto de vista de la hispanidad, a la hora de discutir estos temas —señalan Del Valle y Gabriel-Stheeman- habrían ocupado una voz de mayor autoridad los técnicos, es decir, las voces esgrimidas desde una perspectiva de la especialización y la profesionalización. El poder legitimador del cientista habría sido decisivo en la configuración de los debates ideológico-lingüísticos.

El trabajo de Ángela Di Tullio se ocupa de los debates surgidos a partir del problema de la inmigración masiva hacia el Río de la Plata, entre fines del siglo XIX y principios del XX. Esta realidad inmigratoria generó el problema de la incorporación de estos nuevos actores a la vida política y social de la Argentina, aún en definición y en disputa por su identidad cultural. Conceptos fundamentales en este trabajo son los de «nación», «lengua», «inmigración»y «educación». Este último concepto es de superlativa importancia, 
pues, en torno a la «educación», el Estado Argentino habría estructurado un programa de unificación lingüística.

El trabajo de Di Tullio - he aquí su enorme aporte- presenta la cuestión del idioma nacional en dos etapas: una ligada al programa emancipatorio de los románticos y, básicamente, del siglo XIX; otra ligada a los debates ideológico-lingüísticos entre fines del siglo XIX y principios del XX, período en donde el Estado Argentino procura, desde el sistema de educación estatal, dominar la discusión y ganar la batalla del idioma en Argentina, esto es, unificación y centralidad de la lengua.

Di Tullio configura un panorama textual que ordena en un período de cien años, cuyos puntos cruciales son 1840-1850, 19001915 y que, a su vez, puede dividirse en los textos polémicos (obras literarias y ensayísticas) y los textos de política lingüística, que comprende desde órganos oficiales del Ministerio de Educación, hasta libros de texto escolares.

Decir la lengua, por último, es el nombre con que Juan Ennis presenta su tesis doctoral, escrita esencialmente en el Instituto de Romanística de la Martín-Luther-Universität de Halle-Wittenberg. Por el período que abarca (desde 1837 hasta fines del siglo XX) y por la cercanía con mis propias investigaciones, amerita observarla con más detalle. Se trata de una tesis que entiende que el pólemos es, también aquí, el padre de los debates ideológico-lingüísticos desarrollados en Argentina desde el siglo XIX. Ennis no ignora, por tanto, que los avatares de la lengua son avatares políticos, y acaso su pretensión más lograda haya sido poner de manifiesto la dimensión política de los mismos; propósito que alcanza reuniendo trabajos y textos que exceden el perímetro de la lingüística.

Dividida en tres partes bien justificadas (la primera centrada en los métodos teóricos; la segunda ocupada en los debates ideológicos-lingüísticos en el Río de la Plata; la tercera abocada al terreno empírico, las conclusiones y la bibliografía) es en la segunda donde Ennis expone lo más nutrido e interesante de sus investigaciones. Indaga en ella la relación de Argentina con la antigua metrópoli, período que resume en el título «Todo menos España: una nueva nación, una lengua distinta». Luego se detiene (y consagra todo un capítulo) a Lucien Abeille, al que llamará «dueño del escándalo». La empresa de Abeille desemboca, en la tesis de Ennis, en un proceso tendiente a «defender las murallas de la lengua». Es en medio de este proceso donde irrumpen voces como las de Borges, Alonso y Castro, que Ennis completa con un capítulo dedicado al lunfardo y otro al cocoliche; es decir, «la voz del otro». Esta segunda parte se 
cierra —alcanzando el libro en este punto, quizá, uno de sus momentos más intensos- con la descomposición de la obra de María Beatriz Fontanella de Weinberg, «en cuyos textos se observa la prolongación de los debates, aunque dentro de una serie textualdiscursiva que vela en gran parte su presencia, asumiendo la forma del discurso científico de la lingüística moderna»'.

Ninguno de los protagonistas principales en estos debates falta en Decir la lengua. Además de los mencionados, son escrutadas las posiciones de Echeverría, Alberdi, Sarmiento, Bello, Gutiérrez, Quesada, Obligado, Wilde y Arlt; además de las del Instituto de Filología, la Academia Porteña del Lunfardo y la Academia Argentina de Letras. Son escrutadas, quizá, hasta el punto de evidenciar la médula de esto que Ennis llama debates de carácter lingüístico e ideológico de la lengua. Su tercera hipótesis de trabajo, referida a estos mismos, contiene en ciernes lo que se explayará en el resto del libro:

Los debates ideológico-lingüísticos constituyen una instancia decisiva en la historia de la lengua española. Estos debates encuentran su lugar dentro de la definición del sujeto de los fenómenos de cambio y/o mantenimiento lingüístico. La arquitectura diasistemática de la lengua no se despliega sobre un plano horizontal, de igualdad, sino que está organizada de acuerdo a patrones jerárquicos; le es inherente una asimetría fundamental entre sus componentes. Esa asimetría fundamental está influida (y determinada) por discursos sociales vinculados a la construcción de identidades y organización de jerarquías dentro de una comunidad específica. Así, un discurso dominante instalado en instituciones de difusión de la norma, como por ejemplo la escuela, puede contribuir a la modelación de la conciencia lingüística de los hablantes, y al privilegio de una variante sobre otra en determinados contextos. Los debates en torno a la lengua se constituyen en objeto de estudio de la historia de la lengua y la investigación del cambio lingüístico en la medida en la cual es a través de ellos que se definen cuáles serán los discursos dominantes al interior de una comunidad específica. ${ }^{2}$

El siguiente interrogante: «It is not easy to step back far enough to ask the fundamental question: why does language change arouse such violent feelings?» 3 planteado por William Labov es el que intenta responder Ennis en sus conclusiones, respuesta que,

\footnotetext{
${ }^{1}$ ENNIS 2008, 317.

${ }^{2}$ ENNIS 2008, 47-48.

${ }^{3}$ LABOV 2001, 4.
} 
asevera, «residiría precisamente en la historicidad, agentividad y efectividad de los debates, tanto en los procesos de cambio lingüístico como en la contrapartida que éstos obtienen en la delimitación hacia el exterior y el interior de una comunidad, que siempre es

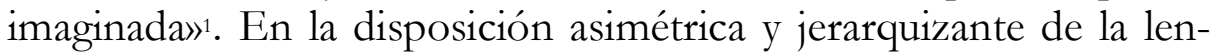
gua - esto completa las conclusiones de la tesis - se advierte como amenaza los procesos de cambio, pues estos presuponen una nueva configuración del poder, que excede incluso el ámbito estricto de la lengua. Todos los debates analizados por Ennis proceden, aunque a menudo refieran sus intenciones de forma subrepticia, en función de reconfigurar espacios y niveles de poder; esto es, designar y delimitar lo que se establece como legítimo e ilegítimo. Por tanto:

[...] los resultados de esos debates, sobre todo en lo relativo a los procesos de estandarización, no muestran la prevalencia absoluta e inobjetable de una posición y una normatividad, sino el resultado precisamente de una tensión, de un enfrentamiento, que si bien puede tener una parte triunfante, el paso del agonista no es uno que no deje rastro. ${ }^{2}$

Un enorme interés parecen estar atravesando los debates en torno a la lengua en Argentina; prueba de ello es el tenor de los títulos que Decir la lengua menciona al respecto y con los cuales dialoga, constituyéndose así, por la robustez de sus propias aseveraciones, en uno no menor entre ellos. Estos libros, que ya forman una constelación de flancos reconocibles, se consagran a uno de los asuntos más caros al sentir de los argentinos. Este libro de Ennis no busca cerrar la discusión, ese es otro de sus méritos.

\section{V}

Estos trabajos que acabo de reseñar brevemente han colaborado mucho en la presente tesis, sobre todo a la hora de aspirar a una visión holística de la historia política de la lengua en Argentina. También me han ayudado a realizar una reunión amplia de lo publicado respecto a la problemática de las distintas políticas de la lengua en la República Argentina. Pero han colaborado, en especial, a analizar el corpus textual de tal modo que se establezca un diálogo crítico de las fuentes, a partir del cual poder formular nuevas hipótesis acerca del período analizado.

\footnotetext{
${ }^{1}$ ENNIS 2008, 368-369.

${ }^{2}$ ENNIS 2008, 369.
} 
Mi investigación contó, en este punto, con la enorme ventaja de disponer, en la ciudad de La Plata, más precisamente en la Biblioteca Pública de la Universidad Nacional, la Sala Arturo Costa Álvarez (S.A.C.A), en la cual se puede hallar muchas de las fuentes que utilizo.

Por la naturaleza de la investigación que he realizado, enmarcada en lo que a grandes rasgos podemos llamar genealogía de las ideas, estimé que la metodología más pertinente era adoptar un acercamiento al problema desde cuatro acciones complementarias. En primer lugar, seleccionar y ordenar las fuentes más relevantes. En segundo lugar, analizarlas de tal modo que establezcan un diálogo crítico y doten de sentido su reunión sistematizada. En tercer lugar, contextualizar históricamente dichas fuentes como para que la cuestión idiomática se enmarque en la realidad político-cultural de la república, en el período delimitado en la presente investigación. Por último, reconfigurar nuevas hipótesis acerca del período analizado.

Estimé apropiado, por tanto, concebir la genealogía de las ideas en torno a la lengua como una actividad intelectual donde se arriba a conclusiones a partir de un diálogo establecido entre los aportes filológicos, lingüísticos, sociológicos e historiográficos. La investigación pretendió dar con una parte sustancial de la historia intelectual de la Argentina, para la cual se torna indispensable indagar en fuentes diversas. Una lectura eficaz de esas fuentes requiere dotar al análisis de una dimensión atenta a distintas tradiciones metodológicas.

La intención general, por último, fue establecer una genealogía de las diferentes voces que se interpelan en esta historia política de la lengua nacional, rastreando sus procedencias y linajes y, a la vez, sus modos y momentos de emergencia discursiva. De este modo, intenté una hermenéutica que, por su enfoque, adquirió una forma interdisciplinaria. Estos pasos de aproximación crítica a las fuentes requirieron, por tanto, una teorización abierta a las convergencias, discrepancias y tensiones que afirman los textos y, acaso, que responden a su propia lógica de producción. En esta tensión entre lo dicho, lo deducido y lo silenciado se ubica esta historia política de la querella de la lengua en la Argentina. 
Las lenguas, como las religiones, viven de las herejías.

Miguel De UNAMUNO

¿Se rechazará la carabela en nombre de la jangada?

PAUl GROUSSAC

El castellano es un idioma medio asfixiado al que nosotros hacemos respiración artificial. PABlo Rojas PaZ

Cuando se nos pregunta de pronto qué lengua hablamos los argentinos, vacilamos mucho en responder. Arturo Costa Álvarez

El pretendido «idioma argentino» en formación es, por ejemplo, una fantasía. LANACIÓN 
PRIMERA PARTE 


\section{LOS PRECURSORES: CASTICISTAS Y ROMÁNTICOS}

(1828 - 1838)

\section{1. El idioma patrio de Juan Cruz Varela}

La querella del idioma en Argentina no surge del intento por deslindar el castellano americano del peninsular, más bien de lo contrario. Antes que los románticos comenzaran a hablar de independencia idiomática, Juan Cruz Varela, a mediados de 1828, llama la atención sobre el mal trato del castellano en Argentina e inaugura un problema: el del idioma nacional. La aparición de una expresión semejante, si bien ya la tenemos en 1817, en la Gramática y ortografía de la lengua nacional, de Antonio J. Valdés; y en 1821, en el Compendio gramatical de le lengua nacional, llamada castellana, de José Catalá Codina, no había adquirido, hasta Varela, un carácter querellante.

Este hombre nos es hoy menos ignoto por la biografía que Juan María Gutiérrez le consagra en el Estudio sobre las obras y la persona del literato y publicista argentino D. Juan Cruz Varela (1871), donde lo presenta como un patriota neoclásico, un poeta de talla, un alma porteña de formación francesa, un traductor dotado y el mejor, hasta el momento, en lengua española, de los dos primeros libros de la Eneida, los únicos que alcanzó a traducir antes de morir en el exilio, en enero de 1839. Gutiérrez conjetura que, de seguir con vida, Juan Cruz Varea hubiera puesto en consideración la novedad de los románticos. Me interesa aquí, más que su obra poética, su proyecto de dilucidar el carácter de la «Literatura Nacional». Así tituló al ensayo que, en cinco entregas, publicó en el diario porteño El Tiempo, a mediados de 1828; y que, o bien no llegó a concluir, o bien su continuación se halla aún perdida. La expresión idioma nacional, preanunciando ya todas sus incógnitas y aristas, se expone por primera vez en este ensayo.

Aunque Juan Cruz Varela siente la urgencia de reflexionar sobre la literatura nacional posterior a la Revolución, no cree que exista, aún, algo semejante. Se hallan trozos sueltos, dice, de diferentes géneros y de un número reducido de autores; defectuosos, a veces, a veces buenos, pero «muy pocos que merezcan el nombre de perfectos». La huella, que de algún modo se empieza a demarcar, no es ni clara ni constante. Argentina no tiene, agrega, mayoría de edad, y sus mayores obstáculos son sus «hábitos nacionales». Varela esperaba un movimiento cultural, una pléyade o un conjunto de obras que llegaría, finalmente, con los románticos, aunque estos perderán 
un poco el afecto a las columnas y los dioses del arte clásico. Para fines de la década del 20 no hay, aún, nada de esto, y Varela siente que esta inmadurez intelectual pronto se acabará, por lo que se propone, en este ensayo por entregas, enseñar los escollos que retardan ese desarrollo.

La primera de estas notas aparece en el número 36 de El Tiempo (14 de junio de 1828). Es indispensable, escribe allí, para formar una literatura nacional, empezar a conocer a fondo «el idioma en que hablamos». Su primera impresión es que en los nuevos estados americanos, todas las instituciones útiles se resienten de la «impotencia de la infancia». Afanados en los quehaceres bélicos de la independencia, los americanos postergamos las cuestiones que hacen a nuestra vida institucional e intelectual. Un vínculo, sin embargo, útil y precioso, se mantiene aún entre la antigua metrópolis y la América de habla hispana: la lengua española, que —estima- debemos agradecer y custodiar. La encuentra sencilla, armoniosa, enérgica en cuanto al trato con las ideas y a la altura de cualquiera de las otras lenguas europeas, «pero este tesoro es, en nuestras manos, lo que son los metales preciosos, mezclados con las demás substancias minerales, en manos de quien no sabe beneficiarlas ${ }^{1}$. Este es el punto central que quiere destacar en esta primera nota: el mal uso americano del español peninsular; español que, para él, se agota en el castizo. El idioma, así como es generoso por su naturaleza, se adultera en bocas que ignoran su índole, sus recursos y su pureza. El idioma nacional argentino - esta es la primera conclusión que se infiere- para Varela no es sino el idioma español «genuino» y «puro», conceptos que entrecomillo pues serán sus sentidos, justamente, los que se encontrarán prontamente en litigio.

Lo más curioso de esta observación, sin embargo, es que Varela no culpa a los americanos de este mal trato, sino que se lo imputa a la misma España: «nuestros opresores nos legaron su idioma como los campos de que eran dueños: fecundísimo pero inculto» ${ }^{2}$. La argumentación que esgrime para sostener esto último es que España, iniciando con el reinado de Felipe II un proceso de enorme enriquecimiento, atrajo el interés y la intromisión de otras naciones en sus asuntos y en sus tierras. Entre estas intromisiones descolló Francia, cuya influencia abrumadora estremeció toda la cultura española, y en especial su lengua. Así, el español «fue perdiendo progresivamente su belleza primitiva, y esta fuente copiosa y cristalina

\footnotetext{
${ }^{1}$ VARELA J. 1828, 46.

${ }^{2}$ VARELA J. 1828, 47.
} 
se enturbió al fin con mil substancias heterogéneas» ${ }^{1}$. Esta degradación llegó a costas americanas, cuyos hablistas no supieron ni pudieron detener el mestizaje, sino que lo agravaron a costa del afán por ilustrarse. Esta devoción americana por aprender, además, no fue en busca de libros españoles, que escaseaban en todo lo que atañese a las ciencias, sino que fue tras los libros franceses. El panorama, entonces, ante los ojos castos de Varela, es desolador. Se lamenta de que todas las bibliotecas particulares de Buenos Aires se colmen de libros franceses, en desmedro de los españoles, y que sean casi todos galos los libros que sirven de texto en la universidad. «¿Quién podrá desconocer que esta precisión de consultar diariamente los escritos extranjeros produce el descuido del idioma patrio, acostumbrándonos a mirarlo con indiferencia?» $\rangle^{2}$ Este desinterés por la lengua materna, concluye —y aquí tenemos lo que deduce-, obtura el desarrollo de una literatura nacional.

Ahora bien, al deslindar literatura nacional de lengua nacional, y profesar que debe haber un carácter nacional de aquella, sin haberlo en esta - recordemos que para Varela el idioma no debe mestizarse- promueve un debate que resolverán los románticos de otra manera: a una independencia política, dirá tanto Gutiérrez como Alberdi, corresponde independencia cultural y de la lengua.

Varela completará su visión purista con otro aspecto que hallará de enorme ventaja: la unidad idiomática de la América española. Esta unidad, afirma, agiliza el progreso y evita la amenaza del «contagio» con otras lenguas extrañas. A esta bendición de la unidad (el término no es de él, pero le pudo haber cabido) la cree, sin embargo, vulnerada por los hábitos nacionales que mencionó al inicio, entre los cuales halla el siguiente: «Es generalísimo entre nosotros, pero muy principalmente en los niños, el alargar las sílabas finales de los imperativos, y aun el agregarles una letra, diciendo, v. gr., tomá por toma; corré por corre; vení por vens ${ }^{3}$. Es innecesario, aquí, ahondar sobre el desacierto de remitir el voseo a caprichos de extensiones y adiciones; basta señalar que Varela lo considera un mal extirpable.

Finalmente, Varela concluye advirtiendo que no quiere ser confundido con un proscriptor de lenguas, las que aconseja estudiar con ahínco, aunque insiste en que no deben alterar, ni preferirse, a la lengua nacional. El énfasis rigorista de Varela también lo deduce Juan María Gutiérrez, a partir de las columnas de El Patriota, otro

\footnotetext{
${ }^{1}$ Varela J. 1828, 47.

${ }^{2}$ VARELA J. 1828, 47.

${ }^{3}$ VARELA J. 1828, 49.
} 
de los emprendimientos de Varela donde, además de verter algunas de sus producciones poéticas, «censuró en los periodistas, sus colegas, las incorrecciones de la prosa o los pecados contra el buen gusto y el oído en los renglones desiguales» ${ }^{1}$.

De modo que la pregunta por el idioma, en Argentina iniciada con el ensayo de Juan Cruz Varela-, viene, por un lado, adosada al problema del carácter nacional en la literatura; y, por otro, a un ideario de pureza y unidad. Para la misma época, no obstante, y de la mano de Mariano José de Larra, se gestaba una forma opuesta de pensar la lengua, que confluirá una nueva tradición idiomática: la romántica.

\section{2. Larra en Buenos Aires}

Este mismo año, 1828, pero en Madrid, Mariano José de Larra publica el diálogo «Donde las dan las toman», donde los personajes defiende una concepción del idioma distinta a la de Juan Cruz Varela. Dice Don Ramón al Duende:

Las palabras sirven, representando las ideas, para entenderse los que las usan; estas palabras, reunidas en cada país, en que los hombres usan unas mismas, forman lo que se llama la lengua de aquel país; de aquí se deduce que los hombres no reconocen en sus lenguas respectivas más legislador que su convención tácita de entenderse, y que cuando usan de una voz y se entienden por medio de ella, esta voz queda reconocida una de las de su lengua. De donde se infiere que el uso es el único legislador de las lenguas. ${ }^{2}$

Ciertas palabras, sugiere Larra, no por resultar nuevas al léxico español lo manchan. Menos aun cuando este necesita alojarlas para ensanchar sus horizontes de expresión. Pretender fijar una lengua, por otro lado, le resultará a Larra una extravagancia. Luego, aunque también profesará el cultivo del idioma y el empleo hábil de sus recursos, no encuentra una amenaza la fricción de este con otras lenguas.

El que una voz no sea castellana, repetirá unos años más tarde en «El álbum», es para nosotros, «que ni somos ni queremos ser puristas $^{3}$, objeción de poquísima importancia. Este y otros artículos

\footnotetext{
${ }^{1}$ GuTIÉRREZ 1918, 259.

${ }^{2}$ LARRA 1828, 61.

${ }^{3}$ LARRA 1835, 363.
} 
de Larra, donde se entremezclan visiones sobre la lengua, interesan aquí porque son las tesis idiomáticas que recogerán los románticos del Río de la Plata. Larra encuentra que no existe ningún pacto ni con la divinidad ni con la naturaleza que prescriba usar tal o cual combinación de sílabas para explicarse: «desde el momento en que por mutuo acuerdo una palabra se entiende, ya es buena...» ${ }^{1}$, agrega. A sus herederos porteños, entonces, ya no les será extraño juzgar virtuosas aquellas lenguas cuyo mérito principal es hacerse entender, alojando abiertamente aquellos vocablos de los que carecen, pues no quedarán mudas ante ninguna realidad. No busco ser excluyente al postular a Larra como el primer influjo del romanticismo porteño en lo que respecta a la lengua - antecesores más remotos podemos hallar, incluso, en el manchego Juan de Valdés, que también estima ser de poquísima importancia que algo sea o no de su tierra para adoptarlo como propio-; pero en el Plata es notoria la influencia de Larra, y artículos enteros de Alberdi y Sarmiento fueron construidos sobre la base de artículos del madrileño.

En enero de 1836, Larra publicó otro artículo de sumo interés sobre este asunto. Lleva por nombre «Literatura» y, además de versar sobre lo que promete en su epígrafe: «una rápida ojeada sobre la historia e índole de la nuestra», aduce que la literatura es la expresión del progreso de un pueblo, así como sus palabras son la representación ideal del mismo. Pero aclara:

Ahora bien, marchar en ideología, en metafísica, en ciencias exactas y naturales, en política, aumentar ideas nuevas a las viejas, combinaciones de hoy a las de ayer, analogías modernas a las antiguas, y pretender estacionarse en la lengua, que ha de ser la expresión de esos mismos progresos, perdónennos los señores puristas, es haber perdido la cabeza. ${ }^{2}$

Este Larra, a gusto con la movilidad natural de las lenguas, volverá sucesivamente a través de un linaje que llegará hasta Miguel de Unamuno. Lo único que pueden exigir los puristas, insiste Larra, es que, al adoptar voces, giros y frases nuevas, se siga un criterio que respete en lo posible el tipo, la índole, las fuentes y las analogías de la lengua.

Larra entiende que, al tiempo que España imaginó una detención de la lengua en pos de custodiar un ideal de pureza, otras naciones europeas vieron expandir sus lenguas al no preguntar si este

\footnotetext{
${ }^{1}$ LARRA $1835,363$.

${ }^{2}$ LARRA 1836, 431.
} 
o aquel vocablo era o no castizo, sino si servía para algo. «Y medítese aquí que el estar parado cuando los demás andan no es solo estar parado, es quedarse atrás, es perder terreno.» ${ }^{1}$ De los pasajes de Larra brotan perfiles que explican por qué España imaginó posible detener el tiempo. Esta detención no solo traerá consecuencias de índole cultural, ni ellas se confinarán al territorio peninsular; será el malestar que se recogerá en Argentina para diferenciarse de todo lo español, o bien hacer énfasis en las diferencias. De modo que, mientras Larra piensa una Joven España; en Argentina, la Joven Generación gesta algo de dimensiones parecidas: trascender la España medieval, desatar los amarres de la expresión y aprender el lenguaje de las ciencias modernas.

\section{3. Florencio Varela: casticismo y literatura nacional}

Con fecha del $1^{\circ}$ de enero de 1835 , desde Montevideo, Florencio Varela, hermano de Juan Cruz, remite una carta a Juan Thompson y a Juan María Gutiérrez ${ }^{2}$, comentándoles el entusiasmo que le produjeron las poesías de Echeverría publicadas bajo el nombre de Los Consuelos, y los pocos lunares que, aunque indeseables, no deslucían ni afeaban el rostro de la obra. Estos lunares atañen a cuestiones métricas, sintácticas y a vocablos que Florencio Varela encuentra poco castizos: «lóbrego» y «fecundo» cree que jamás debieron convertirse en «lobregoso» y «fecundoso»; «imponente» es galicismo; «filoso» no cree que sea vocablo castellano; «pálida» no es adjetivo adecuado para referirse a la conciencia; así como «insensata» no lo es para el sustantivo «mano». «El autor de Los Consuelos —lamenta luego- suele pecar contra la pureza de la lengua.... ${ }^{3}$ La carta es relevante porque, al mismo tiempo que se alista en las filas casticistas de Juan Cruz, que también aplaude la aparición de Los Consuelos, parece desertar de ellas al referirse al carácter nacional en la literatura. Me explicaré.

Al final de la carta, Florencio Varela discrepa con un artículo de Juan Thompson, publicado en el Diario de la Tarde, que juzga poco nacional a las tragedias de Juan Cruz Varela, por ser, sus héroes, los de Grecia y Roma, no los de América. «No, amigos míos. Yo no

\footnotetext{
${ }^{1}$ LARRA 1836, 431.

${ }^{2}$ Esta carta de Florencio Varela, inédita durante tiempo, la publica Juan María Gutiérrez en 1873, en la Revista del Río de la Plata, Tomo VII, No 28. Buenos Aires, pp. 501-524. Sigo la edición de Juan María Gutiérrez (Cf. VARELA 1835). ${ }^{3}$ VARELA F. 1835, XXIII.
} 
creo que para que la literatura sea nacional, es necesario que tome en la Patria todos los asuntos que trate, que copie solamente nuestra naturaleza, que refleje siempre nuestros caracteres, nuestras costumbres. Los dominios del poeta son ilimitados...» ${ }^{1}$ Aquí Florencio Varela parece ser otro, más permisivo, menos purista. Le basta con que la literatura surja de un ingenio de la patria, para que sea nacional, así «tome los objetos y los originales donde quiera». Esto nos permite preguntar: ¿pueden ser los héroes extranjeros, pero no las voces?; ¿puede ser el templo helénico, pero la forma jamás debe ser francesa?

También Juan María Gutiérrez creerá que la literatura nacional puede prescindir de temas nacionales: «Nuestros poetas son llevados por la mano de Virgilio como lo fue Dante a la región donde se castigan los grandes delitos, sin que deje por eso de ser la Divina Comedia la creación más original y patriótica de la Europa en los crepúsculos de la Edad Media»². Pero Gutiérrez ya no verá como un problema que también el léxico se impregne de lo extranjero, pues tampoco eso horadará su carácter nacional.

\section{4. La generación del 37: invención de la nación}

La Generación del 37 dotó a la querella de nuevas realidades, pues los jóvenes románticos estaban atravesados por algunas preocupaciones primordiales. Primero: el encono contra España, alimentado por dos vertientes: la memoria de la guerra de la independencia, que aún no se disipaba, y el creer bárbaro y absolutista todo lo que fuera español. Segundo: el auge, entre ellos, de principios tendientes a postular al pueblo soberano en todo, incluso de su lengua. Tercero: la estima de aquellos idiomas permeables a los neologismos, estima adversa al casticismo. Cuarto: el imperativo por americanizar la cultura, cuyo elemento principal es la lengua. Quinto: la urgencia por emancipar la expresión de todas sus ataduras, anhelo propenso a despojar el pasado de su abrumadora autoridad. Sexto: la conjetura de que, así como en Europa se formaron lenguas neolatinas luego de concluir la centralidad romana, en América, desprendida ya del dominio peninsular, se formen las lenguas neoamericanas. Todo este ideario, a Alberdi, por ejemplo, lo incita a escribir: «Nuestros padres nos dieron una independencia material; a nosotros nos toca la con-

\footnotetext{
${ }^{1}$ VARELA F. 1835, XXXV.

${ }^{2}$ GUTIÉRREZ 1918, 178.
} 
quista de una forma de civilización propia: la conquista del genio americano».

Habría un séptimo aspecto a tener en cuenta: la disputa interna entre unitarios y federales, que los románticos intentan trascender, pero que impacta en la lengua a partir de la unidad o diversidad del idioma hablado en Argentina. Esto es, a partir de de las visiones centralizadoras del idioma, o aquellas que subrayan la diversidad dialectal de las regiones. Este último punto, sin embargo, no adquirirá suficiente relevancia hasta las postrimerías del siglo; pues, durante el siglo XIX, la querella por la lengua se libró entre Buenos Aires y Castilla, o bien entre América y España, y no tanto entre Buenos Aires y el interior. Habrá que esperar hasta los albores del siglo XX para encontrar en la querella protagonistas que no sean exclusivamente España y su Real Academia. En 1900, por ejemplo, con la publicación de Idioma de los argentinos, de Lucien Abeille, las presencias españolas ya no son exclusivas.

\section{5. La lengua de Echeverría}

En 1834, en unas «Notas» finales a Los Consuelos, Echeverría advierte que, si queremos conquistar una poesía cuyo valor equipare al que tuvo la poesía en la antigüedad y tienen hoy las naciones cultas, es preciso que aparezca revestida de «un carácter propio y original». Exhorta a los poetas a observar el suelo americano y sus costumbres, así como a expresar sus propios modos de sentir y pensar. «Solo así — agrega-, campeando libre de los lazos de toda extraña influencia, nuestra poesía llegará a ostentarse sublime como los Andes.... ${ }^{2}$ Se ha discutido bastante qué significa este «libre de... extraña influencia», pero - ya que él mismo se constituye en este tipo de influencia, al regresar de Europa europeizado- debemos deducir que implica ahondar en la naturaleza americana para dar con su cariz más íntimo. Echeverría busca despertar en los americanos una expresión que brote de los ecos de su propia idiosincrasia, una expresión que se hidrate de los ríos de América, se nutra de sus campos y ornamente con sus flores. Unos años más tarde, al prologar las Rimas (1837) ahondará sobre esta misma idea: «El Desierto es nuestro, es nuestro más pingüe patrimonio, y debemos poner nuestro conato en sacar de su seno, no solo riqueza para nuestro en-

\footnotetext{
${ }^{1}$ AlBERDi 1837, 20.

2 ECHEVERRía 1834, 308.
} 
grandecimiento y bienestar, sino también poesía para nuestro deleite moral y fomento de nuestra literatura nacional» ${ }^{1}$.

Juan María Gutiérrez, al reunir los papeles de Echeverría y publicar sus Obras completas (1870-1874), bajo el nombre de «Fondo y forma en la obras de imaginación» agrupó una serie de fragmentos sobre estética y crítica literaria de enorme interés para el presente estudio. Pertenecen a los primeros borradores del autor, destinados a constituirse en un ensayo mayor y más acabado. Allí, al versar sobre «Estilo, lenguaje, ritmo y método expositivo», hallamos el siguiente párrafo que podemos postular como el epítome idiomático de Echeverría:

La América, que nada debe a la España en punto a verdadera ilustración, debe apresurarse a aplicar la hermosa lengua que le dio en herencia al cultivo de todo linaje de conocimientos; a trabajarla y enriquecerla con su propio fondo, pero sin adulterar con postizas y exóticas formas su índole y esencia, ni despojarla de los atavíos que le son característicos. ${ }^{2}$

Este «sin adulterar» habilitó a una lectura tan ambivalente que tanto integristas como secesionistas de la lengua se disputarán para sus filas a Echeverría. También Gutiérrez gestará un párrafo de ambigüedad similar, y las consecuencias serán las mismas.

A punto de publicarse el Dogma Socialista (1846) — esto es, la segunda edición de los principios de la Asociación de Mayo (Palabras Simbólicas), precedidos por la primera edición de la Ojeada retrospectiva - Echeverría agrega, a último momento, una nota para referirse, e impugnar, un artículo titulado "Consideraciones sobre la situación y el porvenir de la literatura hispano-americana», publicado por el Comercio del Plata los días 24, 25 y 26 de julio de 1846. Su autor, el literato español Dionisio Alcalá Galiano, postulaba que las antiguas colonias españolas, aun habiendo consolidado la independencia a lo largo de veinte años, no lograban sacar a su literatura de las «mantillas» en que se encontraba; y atribuía la menoría a lo «renegados» que estaban los americanos de su antigua y legítima raza: la española. No nos proponemos imitar imitaciones, escribe Echeverría en el alegato, ni España puede dar a América el influjo que esta necesita. El arte español, agrega, observa ante todo las «formas» y el «estilo»; mientras que el americano, aunque no los desconoce, busca primordialmente un verbo que se inspire y armonice con la

\footnotetext{
${ }^{1}$ ECHEVERRÍA 1837, IV.

${ }^{2}$ ECHEVERRía 1874, 118.
} 
naturaleza del nuevo continente, virgen, aún, y velado. No es indispensable aquí ahondar en esta polémica; la traigo a colación porque en uno de los párrafos vuelve Echeverría a formular su tesis sobre el idioma, casi en los mismos términos: «El único legado que los americanos pueden aceptar y aceptan de buen grado de la España, porque es realmente precioso, es el del idioma; pero lo aceptan a condición de mejora, de transformación progresiva, es decir, de emancipación» ${ }^{1}$. El Comercio del Plata estaba, entonces, dirigido por Florencio Varela y acaso haya sido a este, por autorizar la publicación, a quien Echeverría quiso refutar.

No existen muchas referencias más sobre la querella de la lengua americana en Echeverría, no al menos con la profusión que aparecerán en las obras de Alberdi, Gutiérrez y Sarmiento. Debemos completar, sin embargo, su cosmos idiomático a partir de lo que destilan sus versos y el resto de su prosa. Allí se termina de afianzar esta idea de defender el legado del idioma, a través de su ampliación y enriquecimiento.

\section{6. La nacionalización de la lengua en Alberdi}

En julio del año 37, en Buenos Aires, se publica el Fragmento preliminar al estudio del derecho, donde Alberdi se propone ahondar en los elementos constitutivos de la legislación y, más precisamente, en la filosofía y razón de ser del derecho. Lo desvela el deseo de dotar a la Argentina de una filosofía propia, que respalde su emancipación y la acreciente. El ensayo podría haberse soslayado en este estudio si en su «Prefacio» no afloraran, ya en su esplendor, las tesis alberdianas sobre el idioma.

Alberdi afirma que la emancipación gestada en 1810 ha dejado a los argentinos la enorme tarea de forjar una nación. Pero esta nación no surgirá si no se ahonda, a partir de una conciencia propia, en la realidad argentina. A la emancipación de España por la fuerza debe seguir la emancipación por el espíritu, cuyo resultado final será la silueta de una nación nueva. Esta es, dice Alberdi, la misión que a ellos le compete, pero esta nación no deberá ser el reflejo de ninguna otra. «Es preciso, pues, conquistar una filosofía, para llegar a una nacionalidad. Pero tener una filosofía, es tener una razón fuerte y libre; ensanchar la razón nacional es crear la filosofía nacional, y, por tanto, la emancipación nacional.» ${ }^{2}$ No precisamos seguir leyen-

\footnotetext{
${ }^{1}$ ECHEVERRÍA 1846, 140.

2 Alberdi 1837, 17.
} 
do para deducir que esa razón nacional deberá expresarse, también, en un idioma nacional. No habrá un pensamiento propio si no se escribe y conversa en una lengua propia. Ahora bien, debemos examinar esta idea de idioma propio para advertir sus alcances.

Alberdi estima que la misión de su generación es teñir de color local, americano, a todos los elementos culturales que constituyen la nación. Anhela originalidad e incluso replegarse sobre nosotros mismos. Clama depurar nuestro espíritu de todo color postizo, de todo traje prestado, de toda parodia, de todo servilismo. A la frase $e l$ estilo es el hombre, añade el hombre es también su tiempo y espacio. De modo que desestima a los que piensan que, entre americanos, se trata de escribir español castizo y neto, que en Alberdi implica conducir al estilo a la insipidez y la impotencia.

Los argentinos, agrega, hemos tenido dos existencias: una colonial y otra republicana. La una nos las dio España; la otra, Francia. Pasamos de ser hijos de aquella, a ser hijos de esta, que envuelve, con su influjo, todo nuestro espíritu, nuestras instituciones, nuestra expresión. "Si la lengua no es otra cosa que una faz del pensamiento, la nuestra pide una armonía íntima con nuestro pensamiento americano, más simpático mil veces con el movimiento rápido y directo del pensamiento francés, que no con los eternos contorneos del pensamiento español.» ${ }^{1}$ Ahora bien, no pide, por esto, imitar lo francés; señala que acusar una prosa americana de poco castiza, o de muy galicada, es ignorar con creces el espíritu preferido por el americano. El galicismo no sería barbarismo, sino síntoma de progreso. Alberdi, que ya había recibido reproches por su lengua, no cree que esta deba identificarse con la lengua española, pues no se siente español, sino argentino. La existencia de esta entidad, Argentina, basta para que todo se impregne de su naturaleza distintiva. A cada nación, una lengua. La lengua de Argentina no es, entonces, la lengua de España; es hija de ella, como lo es toda la nación, sin ser por eso la nación española. «Una lengua es una facultad inherente a la personalidad de cada nación, y no puede haber identidad de lenguas, porque Dios no se plagia en la creación de las naciones.» ${ }^{2}$

Esta tesis que abraza Alberdi será refutada, tiempo después, por Ernest Renan (1882), que demostrará, invocando a Suiza, Egipto, Gales y a la misma España, que no hace a una nación la detentación exclusiva de una lengua. No está, sin embargo, el vigor del universo idiomática de Alberdi en esta nacionalización a ultranza, sino en postular nuevas pautas para establecer lo adecuado: «ंTu lengua-

\footnotetext{
${ }^{1}$ ALBERDi 1837, 46.
}

2 Alberdi 1837, 47. 
je penetra, convence, ilumina, arrastra, conquista? Pues es puro, es correcto, es castizo, es todo» ${ }^{1}$. Este es el fondo alberdiano, la intuición que el joven nacido el año de la Revolución sintió desde el primer momento. La personalidad lingüística que busca y que aconseja para América, en última instancia, debe atender a esto, al impulso; pues el resultado de esa expresión impulsiva será bueno si brega por ensanchar la libertad. Los americanos que buscan, en cambio, legitimar sus estilos de hablar y escribir en los dictámenes de la Real Academia vulneran la soberanía americana, que tiene al pueblo, no al rey, por único dictador. Llega a hablar, incluso, de «alta traición» a la patria si se escribe a la española. Ahora bien, Alberdi no reniega de las academias —idea que lo llevará a confrontar con Gutiérrez, cuando este rechace ser parte de la más célebre-, sino que rechaza que una nación tenga como propia la academia de otra. Si América no tiene su propia academia de la lengua americana, debería tenerla; pero no a la vieja usanza peninsular, sino acorde al nuevo espíritu americano, es decir, democrático.

Quizá Alberdi no hubiera puesto tanto énfasis en el divorcio con España -énfasis que será también el de Gutiérrez, el de Sarmiento- si ella no se le representara como el despotismo, el atraso y la brutalidad. Buscar denodadamente una mirada sobre lo propio y una emancipación completa, acaso haya sido un intento por despojarse de lo español. No está prescripto que una nación, al dejar de ser colonia, repudie invariablemente a la nación que obedecía. La causa de la querella idiomática en Argentina, como ya mencioné, también hay que buscarla en España.

En el Fragmento, por último, campea una sobrestimación del fondo de la lengua, por sobre la forma que eventualmente adquiera; una exaltación de lo que ella sea capaz de decir, por sobre el ornato que elija para decirlo. Alberdi no ve urgente dar con un estilo, sino con una substancia. Esta, de alcanzarse, ya de por sí es un estilo. Al final de la obra, en las «Notas», al disertar sobre las corrientes estéticas que atravesaron a la humanidad, impugna, para su presente, tanto al clasicismo de Boileau, como al romanticismo de Hugo. Destinado el arte, escribe, a satisfacer la necesidad progresiva de la naturaleza, no debe ser más que «progresista». Este concepto, entonces, no apelaba más que al espíritu cambiante de la realidad social; y ser progresista, en Alberdi, solo invocaba estar atento a las mutaciones sociales, que eran de gran singularidad histórica. Esta aspiración afianzó en él la idea de subordinar la forma de la lengua a las urgencias de los acontecimientos. La expresión y la lengua deben

${ }^{1}$ AlBERDi 1837, 47. 
marchar, casi sin miramientos, hacia las conquistas sociales; de aquí que aconseje no demorar en la incorrección. Basta con que las palabras adquieran el ímpetu del acontecer político y social. La infancia, dirá, es la edad de las formas, de los colores, de los símbolos; pero ya no somos niños y es preciso buscar la substancia de las cosas. Será con una metáfora épica, entonces, con que Alberdi hallará el mejor modo de respaldar sus tesis idiomáticas y responder a sus antagonistas:

Brilla más la tierra que oscurece la cólera de un héroe en los campos de batalla, que todo el oro que disfraza la corrupción de un cortesano. Pues bien: detener un libro que combate por las libertades de la humanidad, para enseñarle los vicios de sus frases, es detener a un guerrero en medio de su furia para advertirle que sus galones no van limpios. ${ }^{1}$

\section{7. Gutiérrez, la emancipación de la lengua y el despertar de la querella}

Juan María Gutiérrez es un caso especial. Su discurso durante la apertura del Salón Literario, a mediados del año 37, publicado poco antes que el Fragmento preliminar, es el que abre la querella de par a par. Lo abre, al menos, en cuanto a la repercusión pública, pues las intervenciones anteriores, aunque relevantes, en su momento fueron voces confinadas y, prácticamente, sin réplicas. El discurso de Gutiérrez, en cambio, provocará una serie de reacciones que se extenderán hasta muy entrado el siglo XX. Lo observaré de cerca.

Gutiérrez parecería tener plena conciencia del momento histórico que le toca vivir a su generación y del protagonismo que a ella le compete. De modo que su preocupación fundamental es el carácter que debe adquirir la cultura y en especial la literatura argentinas, preocupación que lo lleva a revisar el pasado de las mismas. La primera conclusión a la que arriba es que América, cuyas culturas precolombinas se desarrollaban como cualquier otra cultura de esplendor, se conmovió ante la Conquista e interrumpió su desenvolvimiento intelectual autóctono. Pasó a convertirse en hija adoptiva de España, de quien tomó sus costumbres, su ciencia, su literatura y su lengua. Pero España, se lamenta Gutiérrez, no ha dado un solo hombre de nota, un solo descubrimiento memorable, una sola idea que le pertenezca o que sea útil. Es esta misma España la que, des-

${ }^{1}$ Alberdi 1837, 210. 
deñando el saber, queda absorta ante el escenario natural y social de América: todo le resulta exótico, todo inconmensurable. El español ni estudia ni comprende el suelo americano: lo posee y lo ignora.

Con la literatura española sucede lo mismo. Gutiérrez no encuentra libros gestados e impresos en lengua castellana que despierten interés a un espíritu culto. «Por inclinación y por necesidad he leído los clásicos españoles, y mi alma ha salido de entre tanto volumen, vacía y sin conservar recuerdo alguno, ni rastro de sacudimientos profundos.» ${ }^{1}$ Salva, de la justiciera hoguera que imagina, al teatro español, a las odas de León y de Herrera, al Laberinto de Juan de Mena, y a la elegía que Manrique consagra a su padre. Nada más. $\mathrm{El}$ resto puede inflamarse.

Ante este diagnóstico, Gutiérrez clama divorciarnos de la tradición española, así como nos divorciamos de su política monacal. Incita a declararnos jlibres! de esta herencia infausta; aunque aclara:

Quedamos aún ligados por el vínculo fuerte y estrecho del idioma; pero este debe aflojarse de día en día, a medida que vayamos entrando en el movimiento intelectual de los pueblos adelantados de la Europa. Para esto es necesario que nos familiaricemos con los idiomas extranjeros, y hagamos constante estudio de aclimatar al nuestro cuanto en aquellos se produzca de bueno, interesante y be$110 .{ }^{2}$

Esta aclaración, que muchos han encontrado ambigua, se constituirá en un acertijo para todos los que han intentado desentrañar la discusión idiomática en Argentina, y vieron en Gutiérrez, y en especial en este discurso, la punta de lanza de toda la querella.

Gutiérrez no invoca en este «aflojarse de día en día» la inobservancia. No cree que la idea de apertura suponga degradación. Sin embargo, así como se ha llegado a postular a Gutiérrez como el más castizo de los hablistas, se lo ha condenado por ser el responsable de la corrupción idiomática e, incluso, de ser el padre intelectual del idioma nacional, invocado aquí en sentido despectivo. Veamos las primeras reacciones.

Gutiérrez envía los discursos pronunciados el día de la apertura del Salón a Florencio Varela, exiliado en Montevideo, y este le responde con una carta donde se refiere, primero, a la flamante inauguración: «preveo un término no muy remoto a la institución del

\footnotetext{
${ }^{1}$ GutiÉrRez 1837, 153.

${ }^{2}$ GutIÉRREZ 1837, 154.
} 
Señor Sastre» ${ }^{1}$. Cree que los hombres que se congregaron en esa empresa persiguen, unos, los intereses que los otros combaten. Después enjuicia los discursos de Sastre y de Alberdi, a los que no otorga relevancia. Finalmente se referirá a Gutiérrez, aludiéndolo en tercera persona, acaso porque el juicio tampoco es favorable: «Juzgo también muy exagerado lo que el doctor Gutiérrez dice acerca de la falta absoluta de buenos libros españoles $»^{2}$. No acompaña a Gutiérrez en su juicio sobre la literatura española, pero hay algo que le molesta más: «...quiere que no leamos libros españoles, de temor de impregnarnos de sus ideas menguadas; quiere que nos hagamos menos puristas, y que relajemos algo la severidad respecto de la admisión (o importación como ahora se llama) de ciertas frases extranjeras en nuestra habla» ${ }^{3}$. ¿Qué significa esto?, se pregunta Varela, pues no puede creer que, por leer en castellano, vaya el lector a deformar su inteligencia, así como no cree que, para expresar las ideas con claridad, vigor y belleza, sea necesario tomar frases o vocablos del extranjero. «Amigo mío, desengáñese usted: eso de emancipar la lengua no quiere decir más que corrompamos el idioma.» ${ }^{4}$

Este es el modo en que Varela leyó el ambiguo párrafo de Gutiérrez; esta es, a su vez, la tesis idiomática de Varela que, para respaldar, tomó lo primero que tuvo a mano, la prosa del hombre a quien le escribe:

El doctor Gutiérrez mismo ha mostrado en su discurso, que no juzga acertados los principios en este punto; porque ha escrito con toda la corrección y pureza posibles, sin que se advierta una sola frase extranjera, ni tampoco la novedad de sintaxis que él ha elogiado en otros y que yo ni he comprendido ni deseo. ${ }^{5}$

Miguel Cané (hijo) parecía conocer esta observación de Florencio Varela, y en oportunidad de componer, en 1876, un prólogo a la segunda edición del Juan Cruz V arela, la reescribió diciendo que pocos escritores españoles tienen la pureza de estilo y la corrección gramatical del doctor Gutiérrez y «para cualquiera de nosotros, yo el primero, que no escribimos en español, sino en un dialecto especial, en el que el vocablo es más o menos castellano y la forma siempre francesa, causa no poca sorpresa encontrar un libro que no parece

\footnotetext{
${ }^{1}$ VARELA F. 1837, 289.

${ }^{2}$ VARELA F. 1837, 290

${ }^{3}$ VARELA F. 1837, 291.

${ }^{4}$ VARELA F. 1837, 291.

${ }^{5}$ VARELA F. 1837, 291.
} 
salido de nuestras prensas» ${ }^{1}$. Esta observación será recogida por Alberto del Solar en 1889 y luego también por otros que encuentran en ella un poderoso antídoto contra toda pretensión de argumentar en favor de una autonomía idiomática.

El 2 de agosto de 1837, el Diario de la Tarde publica un artículo que trata burlescamente los discursos del Salón y las nuevas ideas que allí se cotizan. Lo firma Un Lechuguino, que probablemente sea el señor Pedro de Ángelis, a quien buena parte de los intelectuales porteños lo tenía por chancero. «He trabajado el siguiente discurso - dice el encabezado - que quisiera ver traducido a la lengua de la Pampa, por ser la más nacional que tenemos; de modo que pueda presentarse como un ser particular y propio, que participe del esencialismo de la invención, aun cuando todo él no valga un comino.» ${ }^{2}$

Una semana después, el 9 de agosto, también a través del Diario de la Tarde, tomará la posta el español Felipe Senillosa, residente en Buenos Aires, socio del Salón, pero distante de las posiciones allí esgrimidas durante su apertura. Senillosa ya tiene leído, y amonestado, el Fragmento preliminar, de Alberdi, al que se referirá con desdén, trato que no adopta para con al discurso de Gutiérrez, del que también disiente en relación a sus apreciaciones sobre la gloria de España. En cuanto a la lengua española, y esto es lo que quiero destacar, agrega que

[...] solo el que no la haya cultivado, solo el que no la posea, solo el que no pueda hacer uso de su riqueza, de su hermosura, de sus encantos, podrá atreverse a ultrajarla hasta el punto de decir que es pobre, estéril, insuficiente para expresar las nuevas ideas, los grandes pensamientos, las nuevas vistas, las concepciones originales de los filósofos, de los metafísicos modernos. ${ }^{3}$

Senillosa cree natural, luego, que la lengua castellana, como todas las que pretenden estar vivas, se nutra de neologismos. No anhela el purismo, al que juzga improcedente — y esto es lo curioso, pues, en el fondo, no disiente de Gutiérrez en cuanto al rumbo que debe tomar el castellano en América-, solo que cuando este dijo «aclimatar» la lengua a lo extranjero, Senillosa, como Varela y el Lechuguino, también escuchó acribillarla.

\footnotetext{
${ }^{1}$ CANÉ 1876, 12-13.

${ }^{2}$ Un LECHUGUINO 1837, 299.

${ }^{3}$ Senillosa, Felipe, «Remitido. Un juicio sobre el Salón», en Diario de la Tarde, $\mathrm{N}^{\circ}$ 1835. Buenos Aires, 9 de agosto de 1837. Página II. Cf. ECHEverríA, Esteban, Dogma Socialista... Página 304.
} 
Desde París, con fecha del 29 de octubre de 1837, el joven poeta Florencio Balcarce envía una carta a Félix Frías, donde, además de narrarle sus impresiones sobre la cultura en Francia, augura un triste y pronto final para el Salón Literario, y observa una cuestión del lenguaje por demás interesante, tratándose de un joven de apenas 19 años. Balcarce estima que el eje del discurso de Gutiérrez es «la formación de un lenguaje nacional», unión de conceptos que no sabe bien en qué consiste, pero que calificaría de «solemne disparate» si no estuviera anunciada por el mismísimo Gutiérrez.

Comprendería yo, si dijesen literatura nacional; porque significaría una poesía que reprodujese nuestras costumbres, nuestros campos y nuestros ríos; pero salir de buenas a primeras queriendo formar un lenguaje dos o tres mozos apenas conocidos en un pequeño círculo por algunos escritos de gaceta, es anunciar una presunción ridícula, es atribuirse una influencia que solo ejercen los talentos de primer orden. ${ }^{1}$

Balcarce, como Senillosa, acepta que una nación tome los vocablos que otra nación ha inventado para designar lo que descubre, aunque cree que esa adquisición no debe ser atolondrada. Nótese que también Balcarce habría acordado con las impresiones de Gutiérrez sobre la lengua, si no se hubiera impresionado tanto, como sus predecesores. Por otra parte, Balcarce afirma que el castellano se diversifica allí donde empieza a expresar el ámbito local y familiar. En este sentido, expresa una desesperanza en la unidad del idioma mucho más pesimista que la de Gutiérrez y Alberdi:

El lenguaje americano en esta parte es ya tan distinto del español que merece ser designado con diferente nombre. Vea usted una prueba de esta verdad en el lenguaje de la campaña, donde la naturaleza de objetos y costumbres desconocidos en España, ha hecho inventar un idioma incomprensible para un castellano. ${ }^{2}$

Por último, halla en la prosa de Gutiérrez lo mismo que halló Varela y que hallará Cané: locuciones tan españolas «que son ya inusitadas entre nosotros».

\footnotetext{
${ }^{1}$ BALCARCE 1837, 296.

${ }^{2}$ BALCARCE 1837, 297.
} 


\section{8. La emancipación de Alberdi}

En marzo de 1838, aún en Buenos Aires, Alberdi publicó en La Moda un artículo que tituló «Álbum alfabético». La afinidad con «El álbum» de Larra es notoria, no solo en el nombre. Alberdi se vale ahora de Dante para ampliar los argumentos idiomáticos a su favor. Entiende que el poeta tomó de las calles de Florencia el idioma que hoy habla Italia y que hizo lo que debía hacer: «obró como hombre de genio; aceptó, como buen republicano, lo que el pueblo, omnipotente en todo, había sancionado» ${ }^{1}$. Dicho esto, establece el parentesco con Buenos Aires, donde estima que circula un castellano modificado por el pueblo porteño, que ya no puede ser llamado el castellano de Madrid, pues pueblos tan diferentes «no podrán hablar un mismo idioma». El artículo sigue, luego, enfatizando la proposición de que la lengua es la nación, idea que será muy recurrente durante todo el siglo.

Con el título de «Emancipación de la lengua», en septiembre, aparece otra nota, ahora en El iniciador. Se encuentra dividida en tres puntos. En el primero, con citas de Fortoul, Hugo y Villemain, que le sirven de ayuda, Alberdi declara que la lengua, en Argentina, luego de 1810, no hace más que acompañar la revolución social ante la cual todos los intentos por detenerla son vanos e inútiles. Necesario es, agrega, abandonar la estructura española de la lengua que hablamos, y darle una forma americana y propia, cuya traza aún ignoramos, pues no está dada, como no está dada, aún, la traza de nuestra sociedad. «Sería una vergüenza que la España misma, que todos los días tratamos de esclava, retrógrada, añeja, viniese a darnos lecciones en esta parte...» Después vuelve al adagio: «hemos tenido el pensamiento feliz de la emancipación de nuestra lengua». En el segundo punto, Alberdi intenta explicar por qué en Buenos Aires la lengua de ciertos jóvenes de talento se va afrancesando cada vez más; para lo cual ensaya un panegírico a la lengua de Hugo, que, por el tiempo histórico que atraviesa, estima asociada a la perfección del pensamiento y a la emancipación del espíritu. El francés llegó, no siendo privativo de él, a la mayor simpleza, la exactitud, la brevedad y la elegancia. A eso aspiran los jóvenes porteños galicados. «La lengua, lo hemos dicho ya, es una faz del pensamiento: perfeccionar una lengua es perfeccionar el pensamiento, y recíprocamente: imitar una lengua perfecta es imitar un pensamiento perfecto, es adquirir lógica, orden, claridad, laconismo, es perfeccionar nuestro pensa-

\footnotetext{
${ }^{1}$ AlbERDI 1838a, 207-208.
}

2 ALBERDi 1838b, 226. 
miento mismo.» ${ }^{1}$ Conviene ser diestros, concluye, en la adopción de todo lo que ella tenga para ofrecernos de bueno, pues, de lo contrario, nuestra lengua no será ni argentina ni francesa, será imitación. En el tercer punto, vuelve a asociar el español peninsular a una expresión insípida y estrecha. Castiza y neta, pero mezquina. Y exhorta a escribir «claro, profundo, fuerte, simpático, magnético», inspirándose en el Larra que pregunta a todo libro: «¿Nos enseñas algo? ¿Eres la expresión del progreso humano? ¿Nos eres útil? Pues eres bueno» ${ }^{2}$. Luego pronostica algo que en parte fue profético, pues no faltarán en Argentina los que propongan al francés como lengua oficial: «Ya no hay casi un solo joven de talento que no posea el instinto del nuevo estilo y le realice de un modo que no haga esperar que pronto será familiar en nuestra patria el lenguaje de Lerminier, Hugo, Carrel, Didier, Fortoul, Leroux» ${ }^{3}$.

El tercer artículo se publica en noviembre bajo el nombre «Enseñanza del idioma», también en El iniciador; se trata de una parodia, en la que Alberdi imagina la prédica de un casticista extremo, ante un público de hablistas americanos: «¿Queréis escribir vuestro idioma? No escribáis el idioma que habla vuestro país, porque vuestro idioma, no es vuestro idioma. Vos debéis escribir como nadie habla ni escribe aquí: y si escribís como se habla y escribe aquí, no sabéis escribir» ${ }^{4}$. El rigorista de Alberdi lamenta que la lengua americana no sea americana, sino propiedad de España, y que así como nos la dio un día, sin más ni más, otro día nos la puede quitar y nos deja mudos. Se lamenta por el pueblo que, hablando castellano, confunda alguna vez la $s$ con la ₹ porque, además de estar próximo a caer en servidumbre, mañana confundirá también la justicia con la injusticia, la verdad con la mentira, la virtud con el crimen. «iPara qué queréis una libertad escrita con $v$ en vez de $b$ ? ¿Para qué sirven la riqueza y la paz escrita con $s$ en vez de ₹?:» Alberdi busca, así, ridiculizar este tipo de prédica.

Estos serán los temas de Sarmiento a partir de los años 40, de quien me ocuparé a continuación, soslayando el alegato de Alberdi de 1841 (Certamen poético), pues, en lo que respecta a la querella de la lengua, no hace sino volver sobre las tesis ya expuestas.

\footnotetext{
${ }^{1}$ AlBerdi 1838b, 229.

${ }^{2}$ LARRA 1997, 433.

${ }^{3}$ Alberdi 1838b, 231.

${ }^{4}$ Alberdi 1838c, 220.
} 


\section{SARMIENTO: LA POLÉMICA CON BELLO Y LA REFORMA ORTOGRÁFICA}

$(1841-1870)$

\section{1. La polémica Sarmiento-Bello}

En 1841 encontramos a Domingo Faustino Sarmiento desterrado en Chile. Luce treinta años de edad, aún no es considerado un escritor, ni siquiera un polemista, pero sus primeras intervenciones en la prensa local empiezan a generar cierto asombro. En La Bolsa, el 15 de enero, escribe que América, al separarse de la España medieval, a la que llama «abuela en común» de estos pueblos, quedó atada en lo que respecta a las ideas, la literatura, la lengua y la ortografía, que ya resultan algo extrañas a los americanos. Luego agrega algo que tomó de Chateaubriand, probablemente del Essai sur la littérature anglaise: «Los idiomas en las emigraciones, como en la marcha de los siglos, se tiñen con los colores del suelo que habitan, del gobierno que rigen y las instituciones que las modifican. El idioma de América deberá, pues, ser suyo propio, con su modo de ser característico...» ${ }^{1}$ Es el Sarmiento que está preparando un terreno fértil para presentar uno de los programas más sistemático de independencia cultural con respecto a la Península Ibérica: «Una vez dejaremos de consultar a los gramáticos españoles, para formular la gramática hispanoamericana, y este paso de la emancipación del espíritu y del idioma requiere la concurrencia, asimilación y contacto de todos los interesados en él» ${ }^{2}$. Antes de querellar sobre la cuestión ortográfica, lo hará sobre una controversia filológica.

La polémica principia con un opúsculo anónimo (se trata del ex profesor del Instituto Nacional, Pedro Fernández Garfias) publicado en el Mercurio, de Valparaíso, el 27 de abril de 1842. Lleva el nombre de «Ejercicios populares de lengua castellana» e intenta reunir aquellas palabras que el uso americano ha adulterado o dotado de nuevos sentidos, diversos a los de España. Fernández Garfias pone en evidencia, entonces, la autonomía americana de la lengua. Sarmiento, componiéndole al opúsculo algo así como un prólogo de bienvenida, en la misma edición del Mercurio, lo acompaña en la siguiente reflexión:

Convendría, por ejemplo, saber si hemos de repudiar en nuestro lenguaje hablado o escrito, aquellos giros o modismos que nos ha

\footnotetext{
${ }^{1}$ SARMIENTO 1841, 184.

${ }^{2}$ SARMiento, 1841, 184.
} 
entregado formados el pueblo de que somos partes, y que tan expresivos son, al mismo tiempo que recibimos como buena moneda los que usan los escritores españoles y que han recibido también del pueblo en medio del cual viven. ${ }^{1}$

Hasta aquí, adquiere la forma de una observación discreta, pero Sarmiento no quería decir solo esto, sino descoyuntar el tema de su tronco lexicográfico y rearticularlo en uno más político. De modo que agrega la idea de que el pueblo es soberano en las cuestiones del idioma, y lanza su célebre diatriba contra los gramáticos, a los que compara con el senado conservador, creado para resistir los embates populares, para conservar la rutina y las tradiciones. Asoma así, entonces, no solo la opinión, sino también el tono irritante con el cual Sarmiento querellará en cuestiones idiomáticas. Los gramáticos, agrega:

Son a nuestro juicio, si nos perdonan la mala palabra, el partido retrógrado, estacionario, de la sociedad habladora; pero como los de su clase en política, su derecho está reducido a gritar y desternillarse contra la corrupción, contra los abusos, contra las innovaciones. El torrente los empuja y hoy admiten una palabra nueva, mañana un extranjerismo vivito, al otro día una vulgaridad chocante; pero, ¿qué se ha de hacer? Todos han dado en usarla, todos la escriben y la hablan, fuerza es agregarla al diccionarios, y quieran que no, enojados y mohínos, la agregan, y que no hay remedio, y jel pueblo triunfa y lo corrompe y adultera todo! ${ }^{2}$

A algunos lectores, esta sentencia los ofendió. Sarmiento no ignora las consecuencias de sus palabras y se prepara para las escaramuzas. Los pilares de su concepción idiomática ya están casi definidos; estima que los pueblos corrompen naturalmente las lenguas, de modo que los vicios dejan de ser cuando es todo un continente el que los comete. Las discusiones del año 37 en el Río de la Plata se reavivan, ahora, en el país trasandino.

Luis Montt, al reproducir esta polémica en el tomo primero de las Obras de D. F. Sarmiento, nos informa que una correspondencia suscrita por Un Recoleto, aparecida el $1^{\circ}$ de mayo, en el Mercurio, impugna los Ejercicios; y otra firmada por las iniciales T.R.E.S, el día 3 de mayo, los corrige diciendo: «Suplicamos a ustedes, señores editores, en nombre de nuestro hermoso idioma castellano, en nombre del sentido común y del buen gusto rudamente ultrajados por nues-

\footnotetext{
${ }^{1}$ SARMIENTO 1842a, 209.

${ }^{2}$ SARMIENTO 1842a, 209.
} 
tro ejercitante, no presten sus columnas a ulteriores publicaciones de este género» ${ }^{1}$. También reproduce, y esto es lo relevante, un artículo publicado en el Mercurio del 12 de mayo, firmado por Un quídam, detrás del cual, asevera Montt, se esconde el políglota Andrés Bello. El quidam objeta al redactor del Mercurio (a Sarmiento) la pretensión de atribuir al pueblo la plena soberanía del lenguaje; y juzga, además, irreverente su opinión sobre los gramáticos. Bello cree que, antes que un senado conservador, los gramáticos son el cuerpo sabio que evita, por propio mandato popular, que cada uno hable como «se le dé la gana». Son, por tanto, los custodios filosóficos de la lengua.

De lo contrario —agrega—, admitidas las locuciones exóticas, los giros opuestos al genio de nuestra lengua y aquellas chocarreras vulgaridades e idiotismos del populacho, vendríamos a caer en la oscuridad y el embrollo, a que seguiría la degradación; como no deja de notarse ya en un pueblo americano, otro tiempo tan ilustre, en cuyos periódicos se ve degenerado el castellano en un dialecto español-gálico $[. . .]^{2}$

¿A quién se refiere Bello al aludir a «un pueblo americano»?: a la Argentina, y más precisamente a la región del Río de la Plata, donde preanuncia, acaso por el clamor de «una libertad románticolicenciosa de lenguaje», la confusión babélica de las lenguas.

Sarmiento responde en la edición del Mercurio del 19 de mayo, preguntándose a qué razón obedece este temor por los extranjerismos, tan a flor de piel en los que agitan la bandera de un español puro; preguntándose, además, si se quejan los franceses o ingleses de los españolismos que se introducen en sus idiomas respectivos. Sarmiento ve que los españoles que no son puramente gramáticos, no estudian los modelos de su literatura, sino que se van a estudiar las literaturas extranjeras; luego, está convencido que «se escribe en las versiones de los libros que más se leen», y esos libros no suelen ser españoles, que de serlos, no habría terror por la influencia gala, británica o germana. Es así que, en todos los rubros del saber, los que quieren hablar español, sin dejar de pertenecer a su siglo, deben mendigar en otros idiomas lo que les niega el suyo. «Un idioma es la expresión de las ideas de un pueblo, y cuando un pueblo no vive de su propio pensamiento, cuando tiene que importar de ajenas fuen-

\footnotetext{
${ }^{1}$ Cf. SARMiento 1887, 248.

${ }^{2}$ BeLlo 1842, 253.
} 
tes el agua que ha de saciar su sed, entonces está condenado a recibirla con el limo y las arenas que arrastra en su curso.... ${ }^{1}$

En la edición del 22 de mayo, puesto que una nota no le bastó, retoma los puntos de la contestación. Sarmiento no puede creer que Bello, siendo americano, esto es, miembro de repúblicas democráticas, haya plasmado ideas tan naturales a los gobiernos aristócratas:

En las lenguas como en la política —había escrito Bello-, es indispensable que haya un cuerpo de sabios, que así dicte las leyes convenientes a sus necesidades (las del pueblo), como las del habla en que ha de expresarlas; y no sería menos ridículo confiar al pueblo la decisión de sus leyes, que autorizarle en la formación del idioma. ${ }^{2}$

Esto es lo que Sarmiento quiere discutir: qué es lo que atañe al pueblo, o al menos al pueblo, como el americano, que ha decidido ser dueño de su gobierno. Los pueblos, afirma, modifican el idioma a su antojo, guiados por la necesidad y no por las sanciones académicas que, en última instancia, aguardan las mutaciones que aquellos efectúan. Los diccionarios recogen las palabras, no las inventan; son como archivistas de lo que el vulgo produce. El siguiente párrafo, dirigido a los rigoristas y culteranos, condensa la visión que Sarmiento predicará hasta sus últimos días:

Pero cambiad de estudios, y en lugar de ocuparos de las formas, de la pureza de las palabras, de lo redondeado de las frases, de lo que dijo Cervantes o fray Luis de León, adquirid ideas de donde quiera que vengan, nutrid vuestro espíritu con las manifestaciones del pensamiento de los grandes luminares de la época; y cuando sintáis que vuestro pensamiento a su vez se despierta, echad miradas observadoras sobre vuestra patria, sobre el pueblo, las costumbres, las instituciones, las necesidades actuales, y en seguida escribid con amor, con corazón, lo que se os alcance, lo que se os antoje, que eso será bueno en el fondo, aunque la forma sea incorrecta; será apasionado, aunque a veces sea inexacto; agradará al lector, aunque rabie Garcilaso; no se parecerá a lo de nadie; pero bueno o malo, será vuestro, nadie os lo disputará. ${ }^{3}$

Se suele plantear como un enigma la identidad real del quidam, aunque Luis Montt, que los conocía personalmente a todos, asevera

\footnotetext{
${ }^{1}$ SARMIENTO 1842b, 216.

${ }^{2}$ BELLO 1842, 254.

${ }^{3}$ SARMIENTO 1842c, 223.
} 
que se trata de Bello. El mismo Sarmiento así lo cree y, al final de la contestación del 22 de mayo, lamenta que en Chile no exista el ostracismo, pues lo hubiera pedido para «un gran literato que vive entre nosotros» ${ }^{1}$. ¿A qué podemos adjudicar esta reacción tan radical? ¿Por qué llegar a desear que Bello se erradique de Chile? El tema no es menor; estamos ante uno de los artículos más relevantes de Sarmiento. En países como los americanos, sin literatura, ni ciencias, ni artes, y que apenas empiezan a adquirir rudimentos estilísticos, Sarmiento cree que irles con la gramática, el casticismo y las reglas es como encorsetar lo único que ostentan de grandioso: la espontaneidad y la libertad de los albores. ¿A qué llenar de ortopedias a un niño que empieza a caminar, temiendo que no lo sepa hacer naturalmente? Bello había dicho que Argentina estaba degenerando en un dialecto español-gálico; Sarmiento se pregunta: ¿escribe Chile más versos que la Argentina? En absoluto, responde, e imputa a ese culto por los modelos que reina en Chile la imposibilidad de gestar algo viviente. El temor a equivocarse conduce a la inacción. Es el respeto riguroso a la gramática lo que tiene agarrotada la imaginación chilena, que devino, a fuerza de purismo, en una expresión estéril. «No hay espontaneidad, hay una cárcel, cuya puerta está guardada por el inflexible culteranismo, que da sin piedad de culatazos al infeliz que no se le presenta en toda forma.» ${ }^{2}$ No es que Sarmiento no pretenda crítica de estilo, corrección y consagración de modelos literarios, solo que no encuentra que eso sea apropiado, por el momento, para América. Acaso haya sido por esto que deseó que Bello se marchara. Lo veía campear mejor y más a tono en Europa. «Se lo habríamos mandado a Sicilia, a Salvá y a Hermosilla que con todos sus estudios no es más que un retrógrado absolutista, y lo habríamos aplaudido cuando lo viesemos revolcado en su pro-

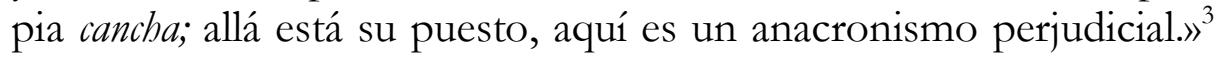
(Nótese que el «retrógrado absolutista» recae sobre Hermosilla, no sobre Bello.)

Esta imprecación de Sarmiento, entonces sí, acarreó que no se volvieran a enfrentar. Bello habrá sentido que no es en esos términos que se deba contrastar temas idiomáticos y no volvió - aunque es probable que exista una correspondencia inédita con Sarmiento- a enfrentarse con él en la prensa. Los que perpetúan la discusión son, o bien discípulos directos de Bello, o bien meros bellistas.

\footnotetext{
${ }^{1}$ SARMIENTO 1842c, 224.

${ }^{2}$ SARMIENTO 1842 c, 223

${ }^{3}$ SARMIENTO 1842c, 224.
} 
Interviene así, en la polémica — según anota Luis Montt—, un tal José María Núñez, que sale en defensa de Andrés Bello y firmará: Otro quidam. Sarmiento, en una proclama en favor del arte polemikós y la función querellante que debe cumplir la prensa, responde el 3 de junio ${ }^{1}$, y vuelve a la carga, dos días más tarde ${ }^{2}$, denunciando que no es forma de refutar a un polemista pedirle sus cartas de nacionalidad (Núñez se las había pedido), pues eso es herencia de la España despótica y propensa a mirar con recelo todo lo que sea extranjero. La voz que Sarmiento adopta en Chile es americanista, por eso fue inoportuno recordarle que era de otro país. En la concepción sarmientina de la lengua, además, casi no existe la articulación idioma nacional, y cuando aparece, refiere al idioma español americano.

La discusión continúa con una serie de notas de Sarmiento, donde revivirá el programa idiomático de Mariano José de Larra. Pero ya no queda nadie que le quiere hacer contrapeso. La querella, por el momento, se desvanece.

\section{2. La reforma ortográfica de Sarmiento}

En enero de 1842, el entonces Ministro de Justicia, Culto e Instrucción Pública de Chile, Manuel Montt, nombra a Sarmiento en el cargo de Director de la Escuela Normal, recientemente fundada, y le encarga la composición de un método sencillo y eficaz para que los niños aprendan a leer. Abocado a estudiar el tema, Sarmiento descubre que los libros están impresos con distintos criterios ortográficos, y que no es coherente enseñar distintos criterios de lectura. Advierte, luego, que la diversidad de criterios convierte a la ortografía en algo irracional. Esta ortografía se le representa al hablista español, y más gravemente al americano, como una ciencia oculta, o como un acertijo que solo develan los filólogos. A partir de antiguas reformas, entonces, compone una reforma ortográfica signada por la adopción del único criterio que estima válido: el fonético; esto es, escribir las palabras tal cual se pronuncian.

Sarmiento sabe que su criterio fonetista se remonta a Quintiliano, a Nebrija, a Mateo Alemán, y llega, a través de distintas revisiones, hasta reformistas contemporáneos como Mariano José Sicilia, José Mariano Vallejo, A. M. de Noboa, el canónigo Francisco Puente y la misma Real Academia española, inclusive, que adopta

\footnotetext{
${ }^{1}$ SARMIENTO $1842 \mathrm{~d}$.

${ }^{2}$ SARMIENTO 1842e.
} 
en la octava edición de su Diccionario (1837) cambios ortográficos regidos por el criterio fonético. Sarmiento conocía bastante bien estas intervenciones, pero se nutre, en especial, de las «Indicaciones sobre la conveniencia de simplificar i uniformar la ortografía en América», que Andrés Bello y el colombiano Juan García del Río habían publicado en Londres en 1823, en el primer número de La biblioteca americana. Las conclusiones de este trabajo, veinte años anterior al de Sarmiento, consisten, por un lado, en revitalizar la tesis de M. Fabio Quintiliano y Antonio Nebrija, que enuncia que cada letra debiera tener un sonido distinto y cada sonido representarse por una sola letra; por otro, en ordenar la ortografía a partir de la pronunciación, no del uso corriente ni el origen de las palabras, que son los que la desordenan y la tornan contradictoria. Bello, que no prefería ser tan drástico como lo será Sarmiento, propone reformar la ortografía castellana en dos etapas. En la primera:

$1^{\circ}$ Sustituir la $j$ en todos los casos en que se pronuncia $j:$ jeneral, almoraduj, etc.

$2^{\circ}$ Sustituir la $i$ a la $y$ en todos los casos en que esta haga las veces de simple vocal: rei, lei, $i$ (conjunción), etc.

$3^{\circ}$ Suprimir la $b$ muda: ombre, onor, etc.

$4^{\circ}$ Escribir con $r$ todas las sílabas en que exista el sonido fuerte que corresponde a esta letra: rrei, prórroga, Enrrique, etc.

$5^{\circ}$ Sustituir la zen lugar de la $c$ suave de $c e$, ci: zienzia, az̧er, etc. $6^{\circ}$. Desterrar la $u$ muda que acompaña a la q: qerer, qiso, etc.

Luego, en una segunda etapa:

$7^{\circ}$. Sustituir la $q$ a la c fuerte: qama, qilo, etc.

$8^{\circ}$. Suprimir la $u$ muda de gue, gui: gerra, giso, etc.

El 17 de octubre de 1843, heredero autoproclamado de esta reforma bellista, Sarmiento presenta su propia Memoria sobre ortografia americana ${ }^{\prime}$, en la Facultad de Filosofía y Humanidades de la República de Chile, de la que ya es miembro. Mencionaré los pormenores de la Memoria y en qué se diferencia de la de Bello.

Sarmiento veía que la mayor parte de los idiomas modernos no parecían revelar parentesco con la forma en que se plasmaban por escrito. ¿A qué se debía este hecho? Durante los siglos bárbaros eran muy pocos los hombres que escribían, pero los escritos quedaban como únicos modelos. Cuando llegó la era en que muchos quisie-

\footnotetext{
${ }^{1}$ SARMIENTO $1843 \mathrm{a}$.
} 
ron aprender a escribir, el primer obstáculo que hallaron fue que los referentes, los literatos, escribían, por no haber querido romper los modelos, como el pueblo hablaba hacía más de quinientos años. Cambiaba el habla, pero permanecía inmóvil la forma de graficarla. El desajuste, luego, se convirtió en un hecho aparentemente irreparable. Aprender a escribir era escribir como los literatos, pues eran las autoridades de la lengua. Lo que Sarmiento encontraba curioso era que los españoles siempre habían andado muy liberales en sus formas de estampar las palabras, y que amoldaban bastante bien lo escrito a lo pronunciado, hecho que atribuía más a la ausencia relativa de literatos íberos — sin los cuales no hay modelos que respetar-, que a la improbable singularidad de que los españoles hayan acertado en lo que todos los demás pueblos habían errado. Así es el modo en que Sarmiento plantea la cuestión ortográfica durante la polémica sobre los «Ejercicios populares...»; y así lo refrendará en la Memoria, donde agrega que la inquisición española generó una paradoja: «Durante tres siglos no ha habido en España un solo hombre que piense» ${ }^{1}$, de modo que, al fijarse la ortografía, no hubo - como sí hubo en Inglaterra y Francia- grandes bibliotecas que reescribir ni escritores que corregir. Es la única concesión que le hace al aporte cultural español: su brutalidad, facilitadora de ajustar la ortografía a la pronunciación durante el proceso de fijación de la escritura. «La España, en fuerza de su barbarie pasada, ha podido presentar la ortografía más aproximativamente perfecta, al mismo tiempo que la Francia y la Inglaterra, por su mucha cultura, tienen la ortografía más bárbara y más absurda.»²

Sarmiento advierte que Bello, así como Puente, que fue otro reformador de la ortografía en Chile, soslayaron lo principal del problema, que es la diferencia entre la pronunciación española y la americana. De ahí que encuentre necesario dejar de escribir la ₹: «¿Hay sonido z en el idioma hablado en América? No, absolutamente no. Se ha perdido desde Méjico hasta Chile, y esto es, señores, para siempre jamás» ${ }^{3}$. Bello, en cambio, juzgaba el seseo como un vicio de dicción. La segunda discrepancia, en lo que respecta a lo estrictamente gramatical, es que mientras Bello aconsejaba diferenciar la pronunciación de la $b$ suave, de la $v$ fuerte, Sarmiento entiende que en América, y aun en España, existe una sola pronunciación de esta consonante, y que, incluso, jamás hubo otra $b$ que no sea la suave.

\footnotetext{
${ }^{1}$ SARMIENTO 1843a, 12.

${ }^{2}$ SARMIENTO 1843a, 12.

${ }^{3}$ SARMiENTO 1843a, 16.
} 
De modo que la reforma sarmientina propone: $1^{\circ}$ Olvidar que existen en el alfabeto estas cuatro letras: $h, v, z, x .2^{\circ}$ No usar la $c$ sino unida a las vocales $a, o, u .3^{\circ}$ No usar la $y$ sino en las sílabas $y a$, $y e, y i, y o, y u$; en los demás casos usar $i .4^{\circ}$ Usar, por algún tiempo que, qui, gue, gui, «por no ofender los ojos llorosos de los literatos españoles y de los rutineros....».

Después reprochará a Bello no haber aplicado cabalmente en sus propios escritos las reformas que enseñaba, pues, no habiendo autoridad suficiente en ninguna corporación académica, es a través de las innovaciones de los escritores de nota que los cambios se contagian. ¿A qué se debe esa apostasía, se pregunta entonces, y ese pasarse «al bando de la rutina irracional de la ortografía dominante» ${ }^{2}$ ?

Como mencioné, Sarmiento pronuncia todo esto en la Facultad de Filosofía y Humanidades, es decir, ante un público universitario, entre el que se encuentra el mismísimo Andrés Bello, entonces rector de la Facultad, de quien podemos conjeturar que lo habrá escuchado entre indolente y azorado. Indolente porque no era el fonetismo, para él, algo de lo que no tuviera noticia; azorado, porque Sarmiento arremete como un toro enojado frente a algo que Bello no advirtió, o prefirió no advertir: el carácter americano de la pronunciación. El tono polemista y secesionista de Sarmiento, además, no existía en Bello, que entendía que estos temas llevan tiempo y ameritan una discusión serena.

La década del cuarenta es un momento oportuno para presentar una reforma de este tenor, por tres razones principales: en primer lugar, no existe una ortografía uniforme; en segundo lugar, la Real Academia aparenta estar sensiblemente inactiva; por último, la Universidad de Chile, recientemente creada, estaba a punto de convertirse en un centro desde el cual se compusieran y propalaran una cantidad inestimable de libros. De modo que, dado este escenario, Sarmiento suma, a su urgencia por racionalizar la ortografía, el visceral encono hacia la Academia de España y el anhelo de que los próximos libros surtidos desde el sur ostenten ya la independencia ortográfica americana.

La reforma de Sarmiento, al radicalizar las diferencias americanas, expone su principal punto de escisión con el pensamiento de Bello, cuyo anhelo es, por el contrario, la unificación entre España y América. El ideal de Bello es la unidad panhispánica de la lengua; la de Sarmiento, en cambio, la independencia total y la unidad, solo,

\footnotetext{
${ }^{1}$ SARMIENTO 1843a, 31.

${ }^{2}$ SARMIENTO 1843 a.
} 
panamericana. Este prefiere una América bien lejos de España; aquel, bien cerca. Bello tomaba muchísimos recaudos en sus planteos gramaticales, por no desalentar su ideal integrador; Sarmiento, en cambio, vaticinaba: «ni ahora ni en lo sucesivo tendremos en materia de letras nada que ver, ni con la Academia de la lengua, ni con la nación española» ${ }^{1}$. Bello aprecia a la Real Academia; Sarmiento la ridiculiza y repudia. De aquí que, para neutralizar el desorden ortográfico que campea a uno y otro lado del océano, el simplificar de Bello tiene el sentido de unificar idiomáticamente las naciones de habla hispana; en Sarmiento, en cambio, el simplificar está ligado a diferenciar América de España. Existe un acuerdo, sin embargo, entre ambos: el estado actual de la composición gráfica de los libros no facilita ni la escritura ni la lectura: retrasa el avance de la civilización.

En la Memoria, no obstante, Sarmiento deja deslizar un dejo de desesperanza, pues siente que la independencia de España, pujante en lo político, científico y económico, halla un límite en lo idiomático, pues aún se cree que en eso la única voz autorizada es la Real Academia. Por eso Sarmiento entendió que, por cómo están planteadas las relaciones con la Academia, cualquier intento de reforma debía ser drástico. En discusión con el dramaturgo español Rafael Minvielle - que estuvo entre los académicos que escucharon atentos la lectura de la Memoria, pero luego la repudiaron en la prensa-, Sarmiento le escribe: «Para introducir innovaciones útiles es, pues, necesario tomar el martillo que destruye, el hacha que destroza, y no la lanita que suaviza y hace cosquillas» ${ }^{2}$.

\section{3. Repercusión de la Memoria sobre ortografia castellana}

Luego de que Sarmiento leyera su Memoria, Andrés Bello, por ser el rector de la Facultad y tener que decidir algo al respecto, dispuso que el texto pasara a una comisión encargada de informar su contenido a toda la institución. Al secretario - cuenta Sarmiento en la Gaceta del Comercio del 23 de octubre- le pareció que el rector era la persona más idónea para esa labor, pero Bello en seguida se negó, aduciendo que el autor de la Memoria lo recusaría. El decano, presente en la discusión, acaso para evitar que el mal momento se agravara, mocionó que se enviara el documento a la imprenta, y que fuera la opinión pública quien lo juzgase. Nadie objetó más nada.

\footnotetext{
${ }^{1}$ SARMIENTO 1843a, 13.

${ }^{2}$ SARMiENTO 1843b, 59.
} 
Entre los que aceptaron que la Memoria se publicara se encontraba Rafael Minvielle, quien ya mencioné y quien, a pesar de consentir la publicación, no dejó de hallarla repudiable. La condenó a través de la prensa. Los argumentos de Minvielle, que conozco solo por los extractos que hace su antagonista, no parecen ser tomados muy en serio por Sarmiento: «A toda la serie de hechos que he reunido, ¿no tiene usted más que la palabra Sarmintier para probar su falsedad o su incongruencia...? ?» ${ }^{1}$ Ocho cartas compone Sarmiento, que le envía entre octubre y noviembre de 1843, y que refuerzan su tesis principal: «...todo mi sistema está montado, plagios aparte, en un solo hecho, y es que en América nosotros los criollos no pronunciamos el sonido zy no hacemos silbar la $s$ como ustedes» ${ }^{2}$.

Algo más importantes son las dos notas ${ }^{3}$ que Sarmiento publica en el Progreso, los día 22 y 23 de noviembre de ese mismo año. Discute con una opinión publicada en el Mercurio, que plantea el temor de fomentar, en caso de escindirse la ortografía, la propagación de dialectos de la lengua hispánica, o bien su adulteración. Sarmiento no cree en la teoría de la adulteración; por el contrario, la única suerte que puede correr el español en América es adiestrarse en aspectos ligados a la libertad y las instituciones republicanas. Por lo que responde al Mercurio diciendo que, si se desarrollan o disipan uno o varios dialectos en el continente, ello no dependerá de lo que publique el diario. Los dialectos, agrega, se forman si están dadas las condiciones. Es el caso del inglés (la cita la toma de Chateaubriand) cuya enorme expansión tuvo el costo de teñirse del color comarcal de las tierras más lejanas. « $\mathrm{Si}$ esto le sucede al inglés, que es un idioma vivo ¿qué porvenir le estará reservado al castellano, que es un cadáver sin vida, y que se mantiene de las ideas que pide de limosna a la puerta de todas las naciones? ${ }^{4}$

La polémica sigue en las ediciones del Progreso, de los días 24, 25, 27 y 29 de noviembre de 1843, donde Sarmiento contesta a «un profesor de gramática», siempre en torno a su obsesión: las lenguas se hablan, luego se escriben. Y cierra esta discusión lamentando que, en América, «estamos dispuestos a mirar como castizo, puro, propio, todo lo que en España es reputado como tal; mientras que los hechos generales que aparecen entre nosotros los llamamos vicios, y ni aun les hacemos el honor de estudiarlos» ${ }^{5}$.

\footnotetext{
${ }^{1}$ SARMIENTO 1843c, 70.

${ }^{2}$ SARMIENTO 1843d, 88.

${ }^{3}$ SARMIENTO $1843 \mathrm{e}$ y SARMIENTO $1843 \mathrm{f}$.

${ }^{4}$ SARMIENTO 1843f, 96.

${ }^{5}$ SARMIENTO 1843g, 113.
} 
Otras cinco notas (2, 3, 4, 5 y 7 de diciembre), publicadas también en el Progreso, siguen la discusión con el Mercurio, al que Sarmiento achaca haber leído idioma, jerga y dialecto, donde la Memoria solo decía reforma ortográfica. Sarmiento confiesa no serle de su interés la postulación de un idioma nacional, expresión que, insisto, casi no tiene relevancia en sus tesis sobre la lengua. Este es el tono de las notas:

El Mercurio habla de unidad del idioma cuando yo solo hablo de mejorar, de perfeccionar la ortografía, y para realizar este gran pensamiento, para mantener a todos los pueblos que antes eran españoles, reunidos alrededor de un centro común, por poco no piden que vayan en romería a visitar el arca misteriosa donde está contenido el idioma español, la tierra santa donde solo hay seres racionales, y donde crecen, como aquí las papas, la sonoridad, la armonía, las voces, las frases, la lozanía y el donaire. ${ }^{1}$

En esta polémica con los redactores del Mercurio, Sarmiento adopta, en temas idiomáticos, el parecer general de los románticos; de modo que si el idioma en América se llegara a diferenciar alguna vez del de España, afirma, «no nos metamos nosotros a trazarle el camino para el porvenir, que ha de ir por donde le dé la gana y se ha de reír de nosotros» ${ }^{2}$. Sarmiento debió de vivir esto como un dilema, ya que, por un lado, desestima el poder de las corporaciones sobre la lengua; pero, por otro, supo que estas, en buena parte, la gobiernan, más aún si se trata de la lengua castellana.

Finalmente, se pronuncia la Comisión de la Facultad de Humanidades, que había sido creada para discutir la Memoria, expidiendo un Informe que se constituirá en otro antagonista más de Sarmiento. La Comisión desaprueba varios puntos de la Memoria y teme, ella también, que escribir como se pronuncia genere tantas ortografías como hablantes tiene la lengua; por lo que sugiere estimar como único criterio ortográfico el uso común y constante. Sarmiento, anonadado, responde al Informe el 19, 20, 21 y 22 de febrero de 1844, donde vuelve a defender su posición fonetista e insiste en que ha sido nuevamente mal interpretado, ahora por quienes debieron estudiar mejor el tema. Este nuevo anatema que recibe Sarmiento termina siendo oportuno para que se explaye en algo que su Memoria, solo atenta a la regular pronunciación americana, no había atendido: la diversidad que existe en esa pronunciación. De

\footnotetext{
${ }^{1}$ SARMIENTO 1843h, 126.

${ }^{2}$ SARMIENTO 1843h, 132.
} 
modo que este temor de la Comisión al desbande gráfico le servirá para postular que la pronunciación que debe tomarse como horizonte, ante la disparidad, es aquella que adoptan los sectores cultos. Sarmiento, en el fondo, y aunque no al punto de Bello, es un integracionista; no busca promover que cada región americana hable su dialecto, ni anhela una ortografía por cada pluma.

Cuando se llama, pues, a la pronunciación principio, no se entiende en manera ninguna que cada lugareño, cada ceceoso ${ }^{1}$, como el Mercurio tuvo el candor de estamparlo en sus páginas, se forme una ortografía que represente su manera de hablar, sino para que los escritores, los literatos, las academias de la lengua y otras corporaciones científicas, formulen la ortografía que ha de servir para pintar las palabras. ${ }^{2}$

La polémica tiene algunos avatares más. Algunos periódicos de Chile adoptan, con salvedades, la reforma ortográfica que adquirió el nombre de chilena. Sarmiento sigue publicando en el Progreso, según Luis Montt, sin estampar su firma, y acaso existan otros pugilatos que no constan en el Tomo IV de sus Obras (1909), lugar de donde me nutro para la recreación de este litigio. La reforma ortográfica, luego —y aunque dejó sus marcas — fracasó. Sarmiento no dejó pasar oportunidad para afirmar que se trababa de las garras de España sobre América, especie de continuación del virreinato en lo lingüístico.

El pensamiento idiomático de Sarmiento no nos debería llevar a pensar que se trata de un recelo por todo lo español. Lo que revela su obra, como la de Bello, como luego la de Cuervo o la de Rodolfo Lenz, es una vocación americana por cuestiones idiomáticas; vocación, por momentos, mayor que la de la propia España. Nos revela que en América, finalmente, se estaba haciendo una apropiación, no ya solo de la lengua, sino del estudio y comprensión de la lengua. Veamos el caso de Andrés Bello.

\footnotetext{
${ }^{1}$ Debió estamparse seseoso.

${ }^{2}$ Sarmiento, Domingo Faustino, «El informe presentado a la Facultad de Humanidades», en Progreso. Santiago, 21 de febrero de 1844. Se encuentra en Obras de D. F. Sarmiento, Tomo IV: Ortografía, Instruccion Pública 1841-1854. Paris, Belín Hermanos, 1909. Página 164.
} 


\section{4. Andrés Bello y el purismo no supersticioso}

Contrario a la idea de que las lenguas son como ríos que el hombre no puede domeñar, Andrés Bello publica en Santiago de Chile, en abril de 1847, su Gramática de la lengua castellana, destinada al uso de los americanos, que pasará a constituirse en la principal obra de referencia idiomática, no solo para americanos. La había tramado para ordenar y conservar la lengua en su más posible pureza, pues encuentra al castellano como un medio providencial de comunicación y vínculo de fraternidad entre todas las naciones que lo hablan; pero, advierte, «no es un purismo supersticioso lo que me atrevo a recomendarles» ${ }^{1}$. Bello conoce al dedillo la querella idiomática y busca evitar ser recusado por casticista.

No se crea — continúa diciendo en el «Prólogo»— que recomendando la conservación del castellano sea mi ánimo tachar de vicioso y espurio todo lo que es peculiar de los americanos. Hay locuciones castizas que en la Península pasan hoy por anticuadas y que subsisten tradicionalmente en Hispano-América. ¿Por qué proscribirlas? 2

Su comprensión de la lengua le impide objetar el crecimiento del léxico a partir de la absorción de vocablos extranjeros o nuevos, y se limita a pedir criterio y buen gusto para las invitaciones. Encuentra vicioso, en cambio, prestar acepciones nuevas a palabras y frases conocidas, multiplicando, así, las anfibologías. Pero no está en esto su temor principal:

[...] el mayor mal de todos, y el que, si no se ataja, va a privarnos de las inapreciables ventajas de un lenguaje común, es la avenida de neologismos de construcción, que inunda y enturbia mucha parte de lo que se escribe en América, y alterando la estructura del idioma, tiende a convertirlo en una multitud de dialectos irregulares, licenciosos, bárbaros; embriones de idiomas futuros, que durante una larga elaboración reproducirían en América lo que fue la Europa en el tenebroso período de la corrupción del latín. ${ }^{3}$

¿Es esto un temor que Bello infiere a partir del estado real de la lengua en América, o a partir del tono que van adquiriendo las posiciones independentistas? ¿Existe, a mitad de siglo XIX, indicios

\footnotetext{
${ }^{1}$ Bello 1847, 11.

${ }^{2}$ BELLO 1847, 12-13.

${ }^{3}$ BELLO 1847, 12.
} 
fuertes como para pensar que las naciones que componen América se inclinan hacia una dialectización, segregándose, no solo de Castilla, sino entre ellas mismas? Continúa diciendo:

Chile, el Perú, Buenos Aires, México hablarían cada uno su lengua, o por mejor decir, varias lenguas, como sucede en España, Italia y Francia, donde dominan ciertos idiomas provinciales, pero viven a su lado otros varios, oponiendo estorbos a la difusión de las luces, a la ejecución de las leyes, a la administración del Estado, a la unidad nacional. ${ }^{1}$

El diagnóstico no es insólito, pues es al que arribará Rufino Cuervo a punto de cerrarse el siglo, y es la realidad que da por hecho el gramático Lucien Abeille el mismo año en que comienza el siglo XX. Por este temor es que Bello compone su Gramática, y la doctrina que en ella se plasma será, quizá, el mayor pilar sobre el que se asentarán las tendencias unificacionistas del idioma.

\section{5. Espectros idiomáticos de Sarmiento}

En alguna oportunidad Sarmiento admitió sentir que la estirpe de Rosas era también la suya: las obras de ambos se constituyen, a veces, de fuerzas contrarias; sus pensamientos, a menudo, querellaban contra sí mismos. Todo esto constituye una misma constelación, pues de otro modo no es posible comprender que unos años más tarde hallemos a un Sarmiento más purista; algo irreconocible al de unos años atrás. Al publicar Manuel Rivadeneira, en Chile, la Biblioteca de autores españoles, Sarmiento ve que en ella se reúnen los autores de las épocas en que la literatura española, y el idioma en que ella fue escrita, "prestó señalados servicios a la cultura de la inteligencia». Encuentra a la Biblioteca de inestimable valor y la cree necesaria para conocer esa tradición literaria, sin la cual se esfumaría lo mejor del casticismo. El 25 de marzo de 1849, la comenta en Crónica. La nota es de sumo interés para este estudio. Principia aseverando que la América española presenta, en esa época, una nueva realidad para las colonias, pues tienden estas a separarse cada vez más de la nación que antes fue su metrópolis. Esa diferenciación, que atañe a las instituciones, las ideas y los gustos literarios, induce al idioma a soslayar las glorias de su tradición.

\footnotetext{
${ }^{1}$ BeLlo 1847, 12.
} 
En América, entre las personas que cultivan la inteligencia, circulan con más abundancia que las españolas, las obras de los autores franceses, en historia, bellas letras y política. Esta necesaria transformación, y aquella desviación de las antiguas tradiciones nacionales, trae sin embargo un inconveniente, y es la inevitable adulteración de las formas del idioma, si al mismo tiempo que se beben las ideas de otras naciones más avanzadas, no se cuida de depurarlas de todo limo extraño, por el estudio de las peculiaridades de la lengua castellana. ${ }^{1}$

Parecería ser otro Sarmiento el que escribe, pero es el mismo; quizá enriquecido, quizá aún mucho más complejo. La empresa de Manuel Rivadeneira, cree, servirá de auxilio para los españoles, pero más para los americanos, que necesitan tenerla a mano para consultar los antecedentes necesarios del idioma, y "como correctivo indispensable de los vicios de lenguaje que pudiera ir deponiendo la labor del tiempo, la distancia, y aquella falta de comunidad de intereses y de vida política que ha creado la independencia americana» ${ }^{2}$.

¿Qué sucedió en España, en América o en la propia vida de Sarmiento para adoptar estas nuevas alarmas sobre la lengua? Quizá se hayan sosegado los ánimos que lo dividían de Bello, quien también había elogiado, meses atrás, la obra de Rivadeneira, casi por las mismas razones; es decir, por las virtudes de esa obra en cuanto a la enseñanza de la tradición idiomática. El siguiente fragmento de Bello, por su tono y filosofía, debe de haber sido del agrado de Sarmiento:

Multiplíquense cuanto se quiera las clases de gramática: ellas darán, a lo sumo, un lenguaje gramaticalmente correcto [...] ¿Pero darán la posesión del idioma? ¿Podrán suministrarnos el acopio necesario de palabras y frases expresivas, pintorescas, de que tanto abunda? Para adquirir este conocimiento, la lectura frecuente de los buenos escritores es indispensable. El señor Rivadeneira ha hecho un apreciable servicio $[\ldots]^{3}$

En 1853, en Madrid, se inicia la publicación de la Revista española de ambos mundos, cuyo anhelo, inscripto en el título, remite a establecer un nuevo vínculo con América. «Destinada a España y América — reza el «Proemio» del primer tomo— pondremos particular esmero en estrechar sus relaciones. La Providencia no une a los

\footnotetext{
${ }^{1}$ SARMIENTO 1849, 331-333.

${ }^{2}$ SARMIENTO 1849, 331-333.

${ }^{3}$ BELLO 1848, 738.
} 
pueblos con los lazos de un mismo origen, religión, costumbres e idioma para que se miren con desvío y se vuelvan las espaldas...» ${ }^{1}$ Dos años más tarde, en 1855, en Buenos Aires, se publica la Ortografía Completa, de Marcos Sastre, quien siguió atentamente las discusiones reformistas vividas en Chile e imprime, influido por Sarmiento, algo similar en su propia obra pedagógica: «Este tratado es un fragmento del curso de estudios que yo había meditado para la enseñanza de la lengua nacional...» ${ }^{2}$, pero aún no adquiere, la expresión «lengua nacional», la dimensión separatista que adquirirá en Abeille, sino que equivale a idioma hablado en América o, en casos, es simplemente sinónimo de español.

Al publicarse en Buenos Aires el tomo XXIX de las Obras de D. F. Sarmiento, casi a fin de siglo, aparece un texto inédito de gran interés, titulado «Una crítica española» ${ }^{3}$, que debió de ser escrito en la década del 60. Allí, como ya lo habían hecho Gutiérrez y Alberdi, Sarmiento advierte que en América toda persona que recibe un tinte de educación aprende ante todo francés, inglés e, incluso, alemán. Este hecho no lo lleva sino a postular la necesidad de generalizar los libros en castellano, so pena de dejar morir de inanición la lengua. Es el Sarmiento que vuelve sobre la tesis de que Cervantes es un hecho ajeno a España, que lo descubrió recién después de que otras naciones se lo pusieran ante las narices. Es el Sarmiento que no concede a España, ni siquiera, el descubrimiento de América, continente al que se chocó, afirma, buscando la India.

\section{6. La alarma de Juan Valera: antecedente de los correspon- dientes}

Un hecho aparentemente irrelevante sucede el 16 de marzo de 1862, en España: el escritor español Juan Valera lee su discurso de recepción en la Real Academia Española. Versa sobre el estado del castellano actual, pero me detendré en lo que el propio Valera enfatiza: las amenazas que aquejan a este idioma. El flamante miembro encuentra que un enorme caudal de voces e ideas llegan a España desde otras naciones, beneficiando al castellano y barbarizándolo, a la vez; de tal modo que es indispensable y urgente hacer algo para preservar su pureza y unidad. No llama a armarse en defensa de un casticismo xenófobo; le basta con advertir la amenaza que implica

${ }^{1}$ REVISTA ESPAÑOLA DE AMBOS MUNDOS 1853, VI.

${ }^{2}$ SASTRE 1855 , III.

${ }^{3}$ SARMIENTO 1899. 
que esas influencias lleguen sin control y encuentren al idioma sin custodias. «El lenguaje, que es la obra más instintiva del espíritu nacional, crece o puede crecer, pero sin alterarse en la esencia, ni aun en la forma.» ${ }^{1}$ Un idioma, agrega, llega a un momento de perfección en el cual no es posible un mayor crecimiento orgánico y verdadero: comienza a colmarse de una excrecencia inorgánica, un aluvión de voces bárbaras venidas sin orden ni concierto, y sobrepuestas y abrazadas a él. Este aluvión empañaría su «tersa y pulida belleza», secaría su frescura y consumiría su vida. Valera busca demostrar que, pasados ciertos períodos de civilización, es difícil que un idioma se mejore: o conserva su ser, con leves alteraciones, o decae y se corrompe. Este es el dilema, estima, en el que se encuentra el castellano de su época.

Pero la unidad del español, para Valera, no solo está amenazada en España; por estarlo allí, lo está en todas las naciones herederas de su cultura. Luego, como la perpetuidad de una nación, entiende, está atada a la suerte de su lengua, al hallarse en peligro el castellano, lo que peligra es la cultura española, sus ideales, sus anhelos y vigencia. Los pueblos que han influido poco al mundo, o que no han tenido grandes escritores y poetas, no tendrían tanta obligación de guardar su idioma; pero no cree que sea el caso del pueblo español, cuya obligación sería superlativa: «El habla es el sello de nuestra nacionalidad y de nuestra raza, uno de los títulos de nuestra nobleza, y vosotros sois sus custodios y defensores» ${ }^{2}$.

Dicho todo esto, recuerda aquellos versos del Duque de Frías que vaticinaban que América «verá la cruz del Gólgota plantada / y escuchará la lengua de Cervantes», ya que teme que ese vaticinio no se cumpla, pues no parece probable «que se conserve en América lo que en España se desdeña y destruye» ${ }^{3}$.

El mensaje, cuanto menos, se da en el lugar apropiado, pues Valera cree que la Real Academia puede hacer algo para revertir la tendencia. De aquí que busque persuadir a los académicos del momento crucial que atraviesa la lengua, para que direccionen la atención hacia el problema de la unidad lingüística y los vínculos con América.

Alguien podría pensar que un discurso así, pronunciado en España, en el seno de una institución monárquica, en nada afectaría a los hablistas del otro lado del Atlántico, ajenos, en esos años, al protocolo real; pero sucede que alarmas como las de Valera influirán

\footnotetext{
${ }^{1}$ VALERA 1864, 269.

${ }^{2}$ VALERA 1864, 279.

${ }^{3}$ VALERA 1864, 281.
} 
muchísimo a la corporación, al punto de comenzar a madurar en ella la necesidad de hacer algo tendiente a custodiar más enérgicamente la unidad panhispánica. La maduración de esta conciencia, algunos años más tarde, llega al punto de nombrar académicos correspondientes en América y buscar la fundación de sucursales americanas de la corporación madrileña. Aludiré en detalles a este problema más tarde (Cf. Primera Parte, III. 1.).

\section{7. El idioma del presidente}

Tres años después de la alarma de Valera, en 1865, es Sarmiento el que brinda un discurso de recepción, pero en los Estados Unidos, en la Sociedad Histórica de Rhode Island (Providence), de la que fue nombrado miembro. Se trata de una exposición extensa, ardua y cuyo tema central es «La doctrina Monroe». Allí encontramos líneas como estas: «Las imprentas del idioma español están en París, Bruselas y Nueva York; el primer hablista de la lengua castellana, Andrés Bello, venezolano, reside en Chile, no ha estado nunca en España, aunque haya sido nombrado miembro de la Real Academia de la Lengua.... ${ }^{1}$ Sarmiento, entonces, encuentra una nueva oportunidad para definir a la Real Academia como una suerte de tribunal anacrónico, erigido a sí mismo en aduana de los vocablos que quieren ingresar, por derecho y movimiento de las ideas, al lexicón offcial. «En la Nueva Inglaterra —agrega - sin hablarla mejor que el griego o el latín, está Mr. Ticknor, el erudito literato actual de la lengua española, tratada así por los extraños como lengua clásica, pero muerta.» ${ }^{2}$ Para afianzar esta consideración, Sarmiento, que en algún momento concedió a España reconocerle al menos el Quijote, ahora, ante este nuevo público, juzga que esa novela más bien se trata de una especie de aerolito, caído en tierra manchega como pudo haber caído en una geografía opuesta. Cervantes se trataría de un genio humano extraño a las influencias de la raza y la geografía españolas. Es por esto que no pertenece, cree Sarmiento, a ninguna nación, y es reclamado, a su vez, por todas. «Creó a su paso en la tierra un idioma, porque los ángeles del cielo perfeccionan todo lo que tocan. Este idioma se llama el idioma de Cervantes, y ha sido momificado en su honor.» ${ }^{3} \mathrm{El}$ discurso que estoy analizando - en los pasajes que se refieren a la lengua - es de primordial importan-

\footnotetext{
${ }^{1}$ SARMIENTO 1865, 215.

${ }^{2}$ SARMIENTO 1865, 216.

${ }^{3}$ SARMIENTO 1865, 217.
} 
cia, y hace falta leerlo con cuidado para no desprender, de lo expuesto, que Sarmiento postula algo así como la erradicación del idioma español de América. No está contrariado con la lengua, sino con el estado actual de la lengua. Como orador en Estados Unidos, exhorta a que se enseñe el castellano como segunda lengua, y señala a los norteamericanos que es esta lengua, y no otra, la que tienen por delante. Leemos al final del discurso: «Y el español es, sin embargo, la clave de la América del Sur».

El 22 de noviembre de 1866, desde Nueva York, al enviar una carta al «Señor Presidente y miembros de la Sociedad Rural Argentina», Sarmiento vuelve sobre las limitaciones que percibe en la lengua:

Me parece que el castellano mismo se ha de resistir a repetir en su lengua bozal algo que sea útil. Si fuera versos, o declamaciones vacías o pomposas, declaraciones de liberalismo, pase; pero agricultura en castellano, geología en castellano, hablar de cercos y de inventos... jun diablo! se ha de volver mudo o decir las cosas al revés, para que el ánima de Cervantes o de Góngora no rabie. ${ }^{1}$

Durante su gestión como presidente de la República (18681874) y aunque ahora abocado a los asuntos del Estado, Sarmiento no deja de inquietarse por la cuestión idiomática. En carta al Señor D. J. Rojas Paul, Ministro de Relaciones Exteriores de los Estados Unidos (11 de abril de 1870), explayándose en los consejos sobre educación, le pregunta: «iCree V. E. que se pueden organizar y desenvolver sociedades civilizadas con una lengua que, por bella que sea, no es órgano de trasfusión del pensamiento moderno? $\rangle^{2}$ Esta fue otra de las obsesiones de Sarmiento: el tema de la habilidad del castellano para entenderse con las ideas novedosas. Todas sus querellas idiomáticas tenían este horizonte: dotar al idioma de la versatilidad suficiente como para convertirlo en una lengua viva. Sarmiento se refiere despectivamente a la lengua española porque la estima, y la quiere ver renovada. La provoca para que despierte. «Nosotros tenemos que destruir la espesa muralla que por el idioma nos separa de nuestro siglo, para abrir paso a las ideas, digan lo que quieran los que a Cervantes divinizan.» $\rangle^{3}$ En esta carta a J. Rojas Paul, reconoce la estima que en Venezuela se tiene a la lengua, lo mucho que «cuidan de su pureza, hasta suministrar a la Academia de la lengua sus

\footnotetext{
${ }^{1}$ SARMIENTO 1866, 109.

${ }^{2}$ SARMIENTO 1870, 22.

${ }^{3}$ SARMIENTO 1870, 22.
} 
más preclaros hablistas», lo que revela que, si bien hallamos en Sarmiento un celador de la pureza, esta no apela tanto a los valores de conservación y fijeza, sino a una pureza ligada a la apertura y la expansión. Una lengua que se conmueva ante la presencia de otras; y que, para seguir siendo lo que fue en boca de Cervantes, se erosione si es necesario. Toda nota purista que se halle en Sarmiento tiene esta naturaleza; hecho que podemos deducir del análisis de su propia prosa, que es, acaso, el lugar más definitivo para juzgar su pensamiento en torno al idioma.

En 1872, consagrado a la «desagradable tarea de gobernar perversos y mal criados», insiste en su cruzada contra el idioma español de los últimos tres siglos. En carta a José Posse, del 5 de septiembre, confiesa que la lengua de Cervantes «es un viejo reloj rovillé, que está marcando todavía el siglo XVI. No saldrá de ahí. No se publican libros en España, y la América está dividida en doce tribus que no dan quinientos lectores, para cada uno, porque no se entienden en castellano» ${ }^{1}$.

\footnotetext{
${ }^{1}$ SARMIENTO 1872, 223.
} 


\section{LA INTERVENCIÓN DE LA REAL ACADEMIA EN AMÉRICA}

$(1870-1880)$

\section{1. Las Academias Correspondientes y la reacción de Al- berdi}

En 1870 la Real Academia Española, preocupada por el divorcio que se está produciendo entre América y España, crea una Comisión de Academias Americanas con el fin de evitar una segregación idiomática y custodiar la pureza del idioma; y en junta del 24 de noviembre de 1870 acordó autorizar la creación, del otro lado del Atlántico, de academias correspondientes suyas. Al reseñar más tarde la iniciativa, Puente y Apezechea, entonces secretario de la Comisión, presenta los principios que entonces los guiaba.

En primer lugar, parece estar muy interesado en demostrar que los objetivos que persigue la Academia no son políticos, tal como quedó plasmado en el artículo 11 que firma la Comisión: «Siendo, como lo es, puramente literario el fin para que se crean las Academias correspondientes, su asociación con la española se declara completamente ajena a todo objeto político» ${ }^{1}$. La Academia da por perdida la reconquista militar de América, cree que los lazos políticos se han roto para siempre; cree, incluso, que la tradición histórica misma puede desmembrarse y que, por desgracia, la hostilidad ha llegado a que se desarrolle cierto odio entre España y la América hispana:

[...] pero una misma lengua hablamos, de la cual, si en tiempos aciagos que ya pasaron, usamos hasta para maldecirnos, hoy hemos de emplearla para nuestra común inteligencia, aprovechamiento y recreo. ${ }^{2}$

La Academia llega hasta conceder que las repúblicas del otro lado del Atlántico se hayan independizado, pero reclama se le reconozca la maternidad cultural. Luego, como ve que estas repúblicas independizadas tienen más trato y comercio con extranjeros que con españoles, estima que

[...] si pronto, muy pronto, no se acude al reparo y defensa del idioma castellano en aquellas apartadas regiones, llegará la lengua,

\footnotetext{
${ }^{1}$ Puente y Apezechea 1873, 281.

${ }^{2}$ Puente y APEZECHeA 1873, 275.
} 
en ellas tan patria como en la nuestra, a bastardearse de manera que no se dé para tan grave daño remedio alguno. ${ }^{1}$

El interés de la Academia por reanudar los vínculos «violentamente rotos», además del carácter político que Puente y Apezechea niega, tiene otro interés de carácter geopolítico que no procura solapar, pues la recomposición de esos vínculos «va, por fin, a oponer un dique, más poderoso tal vez que las bayonetas mismas, al espíritu invasor de la raza anglo-sajona» ${ }^{2}$.

Como se ve, ya en 1870 las alarmas de Juan Valera comienzan a desplegar todo su poder persuasivo. El 6 de marzo de 1871, el periódico América Latina publica el documento de la Academia y motiva la reacción, en primer lugar, de Alberdi, quien elabora desde Londres un documento que titula «De los destinos de la lengua castellana en la América antes española», y en el que denuncia que eso de recolonizar la literatura americana como medio eficaz para defender la lengua castellana no es más que un nuevo desatino de la Real Academia. Desatino porque, en primer lugar, América se emancipó, no solo en política, sino también en literatura y en lengua. Alberdi encuentra absurdo este dictamen y se pregunta si España no se enteró, aún, de que América ya no depende en nada de ella. En segundo lugar, Alberdi insiste en que las lenguas no son obras de las academias, sino del pueblo; aquellas solo las registran y protocolizan. «Si hay un terreno en que el dogma de la soberanía del pueblo haya existido desde que existen sociedades, es el idioma.» ${ }^{3}$ Las lenguas pueden, además, vivir sin las academias, y sobre todo, sin un diccionario académico, pues viven sin él los ingleses, los franceses y otros tantos pueblos, que solo reconocen los diccionarios de tal o cual sabio en el que confían.

El documento de Alberdi que estoy mencionando está dividido en ocho partes. La cuarta es de suma importancia para comprender íntegramente su posición sobre la lengua. Si antes había dicho que cada nación tiene su lengua, ahora, al repetirlo, agrega que, aunque dos naciones hablen el mismo idioma, jamás será el mismo. No niega que el español sea la lengua de varias naciones; solo que cada una tendrá una forma natural de practicarlo y de dictaminar qué es lo puro e impuro, cuál es su léxico natural, qué giros son más o menos legítimos, etcétera. De aquí que el nacionalizar la lengua no implique, necesariamente, exiliarla de su tronco común,

\footnotetext{
${ }^{1}$ Puente y APEZEChea 1873, 277.

2 Puente y APEZECHEA 1873, 279.

${ }^{3}$ Alberdi 1871, 171.
} 
sino desistir de la idea de que exista un centro privilegiado desde el cual se discipline todas sus formas regionales. En esta misma parte del texto afirma que, cuando un sudamericano solicita el honor de ser nombrado miembro de la Academia - miembros que ya existían cuando España busca, además, crear academias correspondientes-, no por eso abdica de su soberanía intelectual ni se convierte nuevamente en colono. Recordemos que Alberdi no reclama el cierre de las academias, ni encuentra objetable participar en ellas, simplemente demarca sus límites, más aún cuando son monárquicas.

Alberdi deja asentado, por último, tres cosas: «No puede un país soberano dejar en manos del extranjero el magisterio de su lenguas ${ }^{1}$; que es otro de sus lemas, profusos ya en el tapiz que conforma su ensayística. En segundo lugar, pide a la Academia que atempere su temor al bastardeo del tesoro castellano en América, pues las lenguas, como las razas, se mejoran por el cruzamiento. «Babel inmensa y universal, rendez-vous de todas las naciones del globo, la América tiene por papel providencial mejorar las razas, las instituciones y las lenguas, amalgamándolas en el sentido de sus futuros y mejores destinos solidarios.» ${ }^{2}$ Por último aconseja a España que, si quiere conservar su autoridad literaria en Sud-América, trate de procurársela primero en la Europa misma, exhibiendo pensadores como Bacon, Descartes, Locke, Kant, y descubrimientos y progresos científicos y literarios capaces de rivalizar con aquellos que ostenta, en la faz del nuevo mundo, la Europa del siglo XIX, extraña al habla castellana.

\section{2. E1 rechazo de Gutiérrez: polémica entre Berra y Pelliza}

El 11 de diciembre de 1872, la Real Academia Española decide nombrar como miembro de la corporación, en calidad de correspondiente extranjero, a Juan María Gutiérrez, entonces rector de la Universidad de Buenos Aires. El diploma se remite un año después (30 de diciembre de 1873) y recién dos años más tarde (29 de diciembre de 1875), el cónsul de España en Argentina lo pone en manos del diplomado, consumando una demora que Gutiérrez atribuirá al arcaísmo natural de la Academia. El insigne documento llega acompañado del Reglamento de la institución y de sus Estatutos, cuyo punto primero afirma que los miembros de la corporación bregan por «cultivar y fijar la pureza y elegancia de la lengua castellana». A Gu-

\footnotetext{
${ }^{1}$ Alberdi 1871, 174.

${ }^{2}$ Alberdi 1871, 178.
} 
tiérrez lo desconcierta la invitación a convertirse en fijador y purista y, contrariamente a los tres años que tardó el diploma en llegar a sus manos, emplea apenas horas en responder ${ }^{1}$. No escatima agradecimientos, pero informa al Secretario accidental, Aureliano F. Guerra y Orbe, y a través de él a toda la Academia, tres inconvenientes que le impiden aceptar el nombramiento.

En primer lugar, porque en América todos sus habitantes cultivan la lengua heredada de España, pues se expresan en ella; pero «no podemos aspirar a fijar su pureza y elegancia», por razones que nacen del estado social que ha deparado a los americanos la emancipación política de la antigua Metrópoli. América, luego de su emancipación, abrió las puertas no solo a españoles, sino también a otros europeos y con ellos al influjo de toda Europa, a la recepción de sus costumbres, sus ideas y sus lenguas, las que, sin ningún tipo de vallado, se desplegaron conviviendo unas con otras. Por tanto, las calles de Buenos Aires hablan todas esas lenguas, como en muchas lenguas se imprimen sus diarios y se leen y discuten sus libros y sus leyes. Ninguna pureza puede brotar de semejante mezcla, que resulta más bien deseada. Las gratas condiciones que a ella deparan las circunstancias americanas la hacen más dócil, menos rígida e impoluta; por tanto no puede ni debe bregar esta ciudad por la pureza. Estimando que en España se sabe poco del trajín de Buenos Aires, Gutiérrez afirma que estos sonidos y modos de expresión «cosmopolitizan» el oído del porteño y « nos inhabilitan para intentar siquiera la inamovilidad de la lengua nacional» ${ }^{2}$. Luego se pregunta:

¿Estará en nuestro interés crear obstáculos a una avenida que pone tal vez en peligro la gramática, pero puede ser fecunda para el pensamiento libre? [...] ¿Qué interés verdaderamente serio podemos tener los americanos en fijar, en inmovilizar, al agente de nuestras ideas, al cooperador en nuestro discurso y raciocinio? ¿Qué puede llevarnos a hacer esfuerzos por que al lenguaje que se cultiva a las márgenes del Manzanares, se amolde y esclavice el que se transforma, como cosa humana que es, a las orillas de nuestro mar de aguas dulces? ¿Quién podrá constituirnos en guardianes celosos de una pureza que tiene por enemigos a los mismos peninsulares que se avecinan en esta Provincia? ${ }^{3}$

\footnotetext{
${ }^{1}$ GUTIÉRREZ 1876a.

${ }^{2}$ GuTIÉRREZ 1876a, 69.

${ }^{3}$ GUTIÉRREZ 1876a, 71.
} 
En segundo lugar, Gutiérrez sigue estimando que el idioma tiene íntima relación con las ideas, y no puede bastardearse en países que procuran ser inteligentes y progresar. En su concepción idiomática, el pensamiento se abre por su propia fuerza el cauce por donde corre, y esta fuerza es la salvaguardia verdadera y única de las lenguas, «las cuales no se ductilizan y perfeccionan por obra de gramáticos» ${ }^{1}$, sino por obra de los pensadores que se sirven de ellas.

Lo último que alega Gutiérrez para rechazar el diploma es que encuentra peligroso, para un sudamericano, la aceptación de un título dispensado por la Academia Española. Su aceptación, entiende, lo ligaría y ataría «con el vínculo poderoso de la gratitud». Sabe que no lo van a someter a las opiniones de la institución, pero al menos deberá respetarlas, y no cree ser capaz de eso. España no representa, aún, para Gutiérrez, el pensamiento libre y científico; mucho menos lo representa la Academia. También se siente distante de los intelectuales americanos que ya han aceptado fundar academias correspondientes en América:

La mayor parte de esos americanos se manifiestan afiliados, más o menos a sabiendas, a los partidos conservadores de la Europa, doblando la cabeza al despotismo de los flamantes dogmas de la Iglesia romana, y entumeciéndose con el frío cadavérico del pasado, incurriendo en un doble ultramontanismo, religioso y social. ${ }^{2}$

Esta carta, que se ha constituido en una de las piezas más preciosas dentro de la discusión en torno al idioma en Argentina, ni bien se publica es reproducida, grafica y oralmente, en cada rincón del Río de la Plata. La irreverencia de Gutiérrez atiza nuevamente la querella. Es casi la reedición de su encendido discurso inaugural del $37 \mathrm{y}$, como antaño, vuelven a esgrimirse adhesiones y diatribas.

En la edición del 14 de enero de 1876, La Nación publica una carta titulada "La lengua castellana», dirigida al director, firmada en Montevideo por Francisco Antonio Berra, un abogado y pedagogo que repartía su vida entre Argentina y Uruguay. Berra decide hablar del rechazo de Gutiérrez no por el hecho en sí, sino por lo que puede generar la doctrina que acompaña ese rechazo; es decir, por las consecuencias nefastas que pueden traer a la Argentina si triunfan las ideas de Gutiérrez. Berra no puede concebir que el pueblo sea, por el solo hecho de servirse del idioma, quien lo organice y dirija, pues - concediéndole a Gutiérrez que un idioma está íntimamente

\footnotetext{
${ }^{1}$ GutiÉRrez 1876a, 72.

${ }^{2}$ GUTIÉRREZ 1876a, 73.
} 
ligado al pensamiento de quienes lo hablan - si queda en manos del pueblo, será igual a como piensa el pueblo, es decir, un pensar imperfecto. Es, agrega Berra, «condenarnos a no expresar nunca correctamente lo que pensamos o, mejor dicho, a expresar confusa y trabajosamente lo que no pensamos». ${ }^{1}$. Por tanto, la perfección de un idioma, para Berra, no debe quedar a merced de «las preferencias inconscientes de un pueblo»; sino que debería ser resultado de la ciencia. Este traslado del idioma de manos incultas a manos científicas sería necesario para arribar a la lengua que estima necesaria: una lengua universal. El planteo es el siguiente.

Berra cree que las lenguas están atrasadas, que son como la economía de hace doscientos años atrás: «A las lenguas no les ha venido aún el Adam Smith que ha de hacerlas entrar en la corriente científica que hoy se extiende por todas partes $\rangle^{2}$. Gutiérrez, en este sentido, proclamaría la vieja concepción y, por tanto, su esfuerzo sería refractario a las tendencias del mundo moderno. Si los espíritus rutinarios y localistas tienden a defender las particularidades regionales, por un lado; el espíritu moderno, estima Berra, por el contrario, tiende a comunicar las lenguas al punto de tramar paulatinamente una lengua única. Cree, por tanto, que se trata de una lucha entre la vieja escuela y la nueva; un combate de fuerzas conservadoras contra fuerzas progresistas. De triunfar la concepción de Gutiérrez, la lengua castellana en Argentina habrá retrocedido hacia el albor del siglo XIX; si triunfan concepciones cientificas, entonces habrá trascendido ese siglo por completo. Berra no encuentra ninguna ventaja en que Argentina llegue a ostentar un idioma propio, solo encuentra eso como un obstáculo al progreso, concepto central en su planteo evolucionista. Con el tiempo, agrega, «el mundo adquirió el conocimiento de su fin racional y, con él, mejores ideas de sus relaciones morales. Comprendió que es necesario y conveniente el progresar, y que el progreso no se realiza en el aislamiento» ${ }^{3}$. El medio de comunicación y progreso por excelencia, por tanto, es la palabra, que debe ser entendida por todos, porque todos conformamos la humanidad, cuyo interés es la universalidad del pensamiento y de la lengua.

La doctrina del ilustrado Gutiérrez cohonesta esa localización y la recomienda, sin embargo, por no haberse apercibido, creo, de que ella es la rémora más poderosa de nuestros adelantos, porque nos

\footnotetext{
${ }^{1}$ BERRA 1876a, 1.

${ }^{2}$ BERRA 1876a, 1.

${ }^{3}$ BERRA 1876a, 1.
} 
aísla del resto de la humanidad, privándonos de todos sus progresos. ${ }^{1}$

Berra, entonces, no solo exhorta a detener el impulso nacionalizador, sino a colaborar en la tendencia generalizadora de la ciencia y el progreso, la cual terminará, finalmente, dándonos una lengua única. Su defensa del castellano radica, por tanto, en hallarlo más general que un castellano porteño. No lo defiende vía casticismo, ideología que repudia todo tipo de esperanto, sino por ser una zona intermedia entre un dialecto y un cosmolecto. Es más, Berra anhela que el castellano se universalice incorporando los aportes de América, para lo cual entiende necesario la fundación de academias corespondientes, que reúnan y envíen a Madrid esos aportes. Estas academias serían, además, las que realizarían el perfeccionamiento del lenguaje, las que lo harían cada día «más filosófico y más analítico», por la aplicación del criterio y de los métodos científicos.

Unos días más tarde, La Nación cede sus páginas a Mariano A. Pelliza, periodista, escritor e historiador argentino, amigo de Olegario Andrade y, aunque menos, de Bartolomé Mitre. Pelliza impugna la carta de Berra desde su título, pues lengua castellana no le parece sino una forma impropia de llamar a la lengua. Luego duda de la ciencia de Berra, quien no pasaría de ser «un utopista; un soñador; uno de esos apóstoles de la fraternidad humana que pide indiscretamente al progreso aquello, precisamente, que el progreso desbarata» ${ }^{2}$. Para Pelliza, la idea de una lengua única no es una tendencia hacia el futuro, sino hacia el pasado. Pertenece a la cuna de la humanidad, no a su porvenir. La unidad remite al génesis de los idiomas, no a sus desenvolvimientos. La ciencia de Berra, por tanto, en Pelliza no es más que inocencia. Al igual que Gutiérrez, Pelliza cree inútil velar por la pureza de la lengua, cuando la propia naturaleza de esta estriba en la mutación constante. Luego, considerando que la historia de las lenguas es la de generar variaciones, entrecruzamiento y fusiones, se pregunta - y le pregunta a Berra- si es racional pretender que las lenguas se unifiquen en una, al punto de que ya no sea necesario intérprete en el mundo. ¿Sobre cuál de los idiomas vivos se haría el entronque de la lengua universal?, se pregunta Pelliza, por un lado; y por otro, ¿las lenguas habladas en India, Egipto y China deberían ceder sin chistar en la lengua universal de Berra? He aquí el modo en que Pelliza, por tanto, leyó la carta de Gutiérrez:

\footnotetext{
${ }^{1}$ BERRA 1876a, 1.

${ }^{2}$ Pelliza 1876b, 1.
} 
¿Qué dijo este, en resumen, al secretario de la Academia? No acepto, señor, el encargo de guardar incólume esa lengua, aquí, en este país donde un millón de habitantes conspira a toda hora contra su pureza. ¿Es fundado o no lo que afirma el Doctor Gutiérrez? Con solo presentar el censo por nacionalidades queda resuelta la duda.

¿Qué más dice el señor Gutiérrez? Admite las consecuencias del hecho que se viene produciendo, porque ellas serán un producto de la libertad; y si la libertad es libre, preciso es dejarla hacer: ella nos dará un idioma con caracteres propios, con modismos, giros y construcciones no muy ortodoxos, pero sí peculiares; y por ese camino, sin vulnerar los fundamentos idiomáticos, tendremos una fisonomía particular en las letras. Porque, no emancipándonos de la gran lengua madre, siempre habremos de entendernos bien entre los distintos pueblos de la raza latina, que no permanezcan estacionarios y acompañen el movimiento civilizador, no en las reservas como la España, sino en los puestos avanzados como la República Argentina. ${ }^{1}$

Bajo el mismo nombre que la primera, «La lengua castellana», Berra publica, en el mismo diario, su segunda nota, este vez respondiéndole a Pelliza, quien habría entendido mal lo de «lengua universal». Berra cita como ejemplo de una lengua semejante la imaginada por el sacerdote español Sotos Ochando, que, a mediados del siglo XIX, la fabricó a base de una concepción matemática y un proceder mecánico.

Compartiendo con Gutiérrez y con Pelliza aquello de que en el Plata se está operando una transmutación de la lengua, Berra, no obstante, encuentra a esa operación como un problema, al que, lejos de estimular, hay que combatir y mitigar. Insiste en que la humanidad tiende a la perfección, a la racionalidad y al progreso; y que el deber de todos es colaborar en esa tendencia. De modo que la cuestión no es filológica, es esencialmente «filosófico-moral». Luego agrega:

El señor Pelliza ha sido poco feliz también en otro sentido. Ha traído a colación la historia, pero tomando de ella lo que menos podría revelarle la verdad; ha prescindido de la parte de esa misma historia española por él preferida, en que se descubre la aversión que el progreso tiene a los dialectos o idiomas locales, la aspiración

\footnotetext{
${ }^{1}$ Pelliza 1876b, 1.
} 
de la humanidad a un habla general en sus momentos de prosperidad intelectual, y la facilidad con que suele alcanzar este resultado. ${ }^{1}$

Berra le pide a Pelliza, en esta oportunidad, que sea más preciso y diga a qué se refiere al preanunciar que de la corrupción de la lengua en el Plata surgirán únicamente bienes. Para Berra, la realidad actual de las lenguas, precisadas de traductores para dialogar unas con otras, es penosa, y Argentina, de la mano de Gutiérrez, tendería a que esa pena sea mayor y aún más irreparable. Cree, por último, que Pelliza ha obviado referirse al punto central de su carta, que es la idea de «generalizar» la lengua, hecho que a Berra le resulta esencialmente bueno e inobjetablemente deseable:

Hablamos de la generalización como de una necesidad, como de un ideal; y de la tendencia humana como de un hecho que se realiza; y agregamos que la doctrina del señor Gutiérrez es contraria a aquel ideal y a esta tendencia. ${ }^{2}$

Al responder, Pelliza vuelve a formular lo que entiende como cuestión de fondo: ¿qué es lo que mejor conviene a le lengua que se está tramando en el Río de la Plata? ¿Es preferible desdeñarla y pensar en una lengua universal, sin nación? ¿Conviene llegar a una lengua semejante? Pelliza no cree haber errado al llamar a Berra un utopista, pues este se apareció con la lengua universal de Sotos Ochando, a la que, no por laboriosa y apriorística, deja de ser artificiosa e imposible. Las lenguas, agrega Pelliza, salen del taller de la historia, no de los laboratorios científico. Por eso acuerda en todo con Gutiérrez, porque la historia de la lengua española en el Río de la Plata, irrumpida ahora por presencias extranjeras y ajena a los dictámenes de la Real Academia, está operando de tal modo que solo se pueden esperar bienes de ella. Era al señor Berra, agrega, «a quien tocaba poner de manifiesto los males que nos produciría la independencia del lenguaje y el contacto con el mundo civilizado, después de la emancipación política y aislamiento parcial de España» ${ }^{3}$.

Este entredicho concluye con unas escasas líneas de Berra: «El señor Pelliza divaga... hasta perderse de vista. No es posible sostener discusiones con un adversario que apela en los casos extremos a

\footnotetext{
${ }^{1}$ BERRA 1876b, 1.

${ }^{2}$ BERRA 1876b, 1.

${ }^{3}$ Pelliza 1876b, 1.
} 
semejante táctica» ${ }^{1}$. Pelliza, acaso deduciendo que el divagador es el otro, decide no responder más.

\section{3. Polémica entre Gutiérrez y Martínez Villergas}

Al mismo tiempo que sucedía este altercado en La Nación, en otros periódicos polemiza el mismísimo Juan María Gutiérrez con el español Juan Martínez Villergas, publicista, epigramatario y literato que se encontraba, a la sazón, en Buenos Aires. Villergas ya era autor de un Sarmienticidio, imprecación que, según informa la portada de su edición francesa (Paris, 1853), puede llamarse, también, «A mal Sarmiento buena podadera...» Con las notas que publicará en su periódico semanario Antón Perulero, intentará ahora componer un Gutierricidio. Las compendiaré.

La primera nota se llama «Amor con amor se paga I». Creyendo que fue Gutiérrez el que demoró en responder y no la Academia en hacer llegar su diploma, Villergas afirma que la única explicación posible del rechazo, al no encontrar más que «peregrinas ocurrencias» en el descargo de Gutiérrez, es que debió de haber inferido alguna ofensa en el escrito del secretario de la Academia. Rumia luego, agrega Villergas, durante dos años esa ofensa y compone, a destiempo, el desaire que adjunta a la devolución del diploma. En esta hermenéutica, Villergas no sospecha ninguna raíz histórica, ninguna querella de antaño sobre la lengua, ni nada que no sea una afrenta anecdótica:

Gordo, pues, muy gordo debe ser el agravio que el señor Gutiérrez ha recibido; tanto que, además de aconsejarle lo que el mundo tomará por una ingratitud, y aun por una infracción de las leyes de la urbanidad, le ha trastornado el cerebro hasta el punto de hacerle decir cosas indignas de un hombre de indisputable talento $[. . .]^{2}$

La segunda nota es homónima de la primera. Villergas, que antes trató de adivinar por qué Gutiérrez rechazó el diploma, ahora intenta adivinar la reacción que tendrán los académicos, en Madrid, al leer la carta excusadora. Imagina que se pondrán muy tristes, taciturnos y melancólicos, al principio; luego, a medida que el secretario vaya leyendo la «carta magna impolitica, que así debemos nombrar a la

\footnotetext{
${ }^{1}$ BERRA 1876c, 1.

${ }^{2}$ Martínez Villergas 1876a, 76.
} 
de D. Juan Gutiérrez» ${ }^{1}$, irán serenándose, más tarde, consolándose, y por fin, alegrándose, hasta el extremo de acabar llorando de risa. Villergas, agregando como nuevo defecto de Gutiérrez el estilo impuro de su prosa, insiste en que la carta no es más que «pullas», esto es, una suma de sandeces y diversiones para el lector.

Una semana después, tocaya de las dos anteriores, aparece la tercera nota. Villergas, que leyó la cosmopolitización del oído porteño como la formación de una lengua segregada, rechaza la idea de que, por oír varios idiomas, vayan ellos a confundirse al punto de forjar uno nuevo. No cree que ello suceda en Madrid, ni en París, ni en Londres, ni en cualquier ciudad de los Estados Unidos. «El oír hablar diferentes idiomas puede dar a las personas de criterio ocasión para estudiados, pero no para confundidos.... ${ }^{2}$ Villergas cree que eso de formar un idioma nacional es extravagancia muy de argentinos, pues otros países no registran una pretensión semejante.

De esta última apreciación de Villergas podemos deducir que no estaba al tanto de lo que había sucedido en Estados Unidos con Noah Webster y su american tongue, que será antecedente de una efervescencia americanista y llegará hasta The American Language, de Henry Louis Mencken (1919). En el Río de la Plata hay una insistencia querellante con respecto a la lengua, pero no exclusividad. No obstante, no debió asombrarse Villergas de la querella argentina; raro hubiera sido que, habiendo existido una emancipación americana, nadie hubiera dicho nada en relación a la emancipación de la lengua.

Una serie de diez cartas publica el periódico porteño La Libertad, para responder a las de Antón Perulero, que van del 22 de enero al 6 de febrero de 1876. Hoy las conocemos como Cartas de un porte$\tilde{n o}^{3}$, título bajo el cual las compila Ernesto Morales a partir del apelativo con que las firma Gutiérrez. La idea de un porteño enfatiza una pertenencia no tanto geográfica cuanto espiritual.

En la primera carta ${ }^{4}$, para ahondar en las razones de su denuncia, Gutiérrez rememora el origen servil de la Academia para con el Rey de España, que, con sus académicos correspondientes, sus gramáticas y diccionarios, infiltra los barcos de guerra. No olvida que Cuba aún clama por su independencia ni soslaya el reciente desembarco español en Valparaíso, que, anunciándose con fines «científicos», terminó quemando la ciudad y tomando las islas de

\footnotetext{
${ }^{1}$ Martínez Villergas 1876b, 81.

${ }^{2}$ Martínez Villergas 1876c, 85-86.

${ }^{3}$ GUTIÉRREZ 1942.

${ }^{4}$ GUTIÉRREZ 1876b.
} 
Chincha. Para Gutiérrez, la distensión con España aún no ha llegado y, al fin y al cabo, él sigue siendo un hombre de la Revolución de Mayo, guerra que continúa librándose, ahora, por medios más filológicos, única vía que le queda a España para la Reconquista de América.

Puesto que Villergas piensa en la palabra babel, Gutiérrez, en su segunda carta, recoge esa invocación para desautorizar a su antagonista en temas lingüísticos: « ¿Con esa venimos ahora! ¡Con que el señor Perulero no puede explicarse la diversidad en las lenguas sino por medio de aquel cuento bíblico!» ${ }^{1}$ Gutiérrez, versado ya en las teorías de Müller y Bopp — que intuye no han llegado aún a España-, sintetiza el origen de la lengua española, para evidenciar que es otra la forma en que deben pensarse las cuestiones filológicas. Por otro lado, siente que, igual que al pronunciar su discurso del 37, ha sido nuevamente mal interpretado:

Ha creído Perulero que cuando el señor Gutiérrez hablaba de una lengua española enriquecida con elementos que le llegaban (en este país) con la industria y la actividad, y las costumbres de la inmigración, optaba por una jerga incoherente y descosida que solo hubiera de entenderse a las orillas del Plata $[\ldots]^{2}$

No hacía falta esta aclaración para inferir que Gutiérrez no desea un idioma propio en sentido estrecho. Insiste, no obstante, en que un pueblo cuyos órganos están en desenvolvimiento y progreso, el órgano de las ideas también lo está, y que fijarlo sería como parar un reloj para saber la hora a punto fijo.

Las notas de Gutiérrez continúan y Villergas respondió como pudo, pero al perpetuarse las aclaraciones y las nuevas imputaciones, la polémica comienza a desvariar y ya, en la décima intervención de Gutiérrez se lee: «Nuestras catas ya no tienen objeto» ${ }^{3}$.

\section{4. Alberdi piensa el rechazo de Gutiérrez}

Desde París, en febrero del mismo año (1876), Juan Bautista Alberdi compone un texto titulado «Evolución de la lengua española», donde observa, no tanto la concepción idiomática de Gutiérrez, con la cual no parece tener grandes discrepancias —ambos creen que el

\footnotetext{
${ }^{1}$ GUTIÉRREZ 1876c, 99.

${ }^{2}$ GutiérRez 1876c, 102.

${ }^{3}$ GuTIÉRREZ 1876d, 169.
} 
idioma es una realidad viviente, dócil y virtuosamente impura; y que cada pueblo tiene soberanía sobre él一, sino su percepción sobre la Academia. Alberdi, como mencioné antes, aunque cree limitado el poder de las instituciones de la lengua española, no las rechaza, e intenta persuadir a Gutiérrez de que ya no tiene sentido desdeñarlas. Lo que para uno entorpece el desarrollo del castellano en América, para el otro lo potencia. A Alberdi le interesa el asunto, no solo por estar involucrado un viejo compañero que respeta, sino porque a él también lo han nombrado miembro correspondiente de la Real Academia y no ha seguido su ejemplo. Veamos el texto en detalle.

En primer lugar Alberdi entiende que la Academia, aunque por naturaleza tiende a estabilizar la lengua, entiende su movilidad. Conviven en su seno dos fuerzas antagónicas y complementarias: la conservadora y la reformista. La Academia, para Alberdi, no ignorara que los pueblos son quienes gobiernan sus lenguas, pero no cree infecundo interferir en ellas. La lengua, así, es siempre la misma y es siempre distinta. El hecho de que los miembros de la Academia no sean todos oriundos de Castilla revelaría que la intención de la corporación no es sino la de dar cuenta de la diversidad; y el hecho de nombrar americanos como miembros correspondientes es prueba de ello.

En segundo lugar, al mismo tiempo que la Academia habla de «cultivar y fijar la pureza y elegancia de la lengua castellana», nombra, para que sean parte de su seno, hombres que ni la fijan ni la hacen elegante. Prueba de ello es haberlo nombrado miembro a él, que es sudamericano y habla como tal, esto es, distinto a como se habla en Castilla. La labor académica no se agota en purezas y fijaciones, también reflexiona en torno a la claridad, la concisión, la precisión, la adquisición de nuevas voces y giros, todo lo cual justifica nombrar hombres de todas partes del mundo. Esto lo entiende distinto Gutiérrez, quien cree que el buscar adherentes extranjeros no es más que un plan de reconquista por vía ortográfica. Alberdi, que termina consintiendo esta última presunción, se pregunta: «¡Ojalá en este sentido pudiera España conquistarnos hasta hacer un hablista como Cervantes de cada americano del Sud!» ${ }^{1}$ Ello, agrega, no lo ha logrado ni siquiera en su Península.

En tercer lugar no habría que temer el ingreso de gramáticas y diccionarios, pues no son estos sino el comercio y la inmigración los grandes propagadores de los idiomas. Mucho menos habría que temer si provienen de España, nación que tiene entumecido su comercio, su autoridad intelectual y, sobre todo, sus comunicaciones

${ }^{1}$ Alberdi $1876,190$. 
con América. (Tres años demoró el diploma en llegar a manos de Gutiérrez.) El poder de la Academia sobre las lenguas es relativo; da diplomas casi en sentido figurado, pues, cacaso es ella quien tiene el derecho de darlos? Alberdi, en definitiva, cree que Gutiérrez tendría que haber concebido el nombramiento como un gesto de cordialidad, y no el desenvaine de un sable de tinta. Luego estima que las fuentes que persuadieron a Juan María Gutiérrez deben de ser el inglés Herbert Spencer — hombre de la idea de que la lengua inglesa no debe su perfección, en ciertos puntos, sino a la ausencia controladora de una Academia - y el francés M. Littré —autor de un estimable Dictionnaire de la langue française.

Por último Alberdi objeta a los ingleses el hecho de que no se hayan asociado en torno a los asuntos de la lengua. Si en todos los órdenes sociales los hombres se asocian en pos de mejorar, ya sea el comercio, la industria, los cultos, se pregunta Alberdi ¿por qué no habrían de asociarse para beneficiar las lenguas?

Mientras tanto, en el mes de marzo de 1876, al mismo tiempo que Juan Martínez Villergas sigue escribiendo en su Antón Perulero sobre Gutiérrez, este envía una carta privada a un amigo de Chile:

¿Qué le parece mi cohete a la Academia? Tenemos un sílabus y un concilio en Roma; tendremos un Diccionario y una Academia que nos gobernará en cuanto a los impulsos libres de nuestra, índole americana en materias de lenguaje, que es materia de pensamiento y no de gramática. Tendremos una literatura ortodoxa y ultramontana, y no escribiremos nada sino pensando en nuestros jueces de Madrid, como los obispos que sacrifican los intereses patrios a los intereses de su ambición en Roma. Yo he cumplido con mi deber, cediendo a propósitos más altos que los que puede comprender el autor del «Deber» (Julio Simón) y el mismo Bello si viviera. He rechazado el diploma con que hasta Alberdi se engalana en el título de «Luz del día», como ha podido observar. Advierta Vd. que este amigo me criticaba amargamente mi respeto por la gramática y la ortografía de nuestro idioma, creyendo que estos cuidados eran nimiedades, y afectando tal adversión por ellos, que sus primeros éxitos le avergonzarán ahora cuando le caigan a la mano. ${ }^{1}$

\section{5. Las confesiones de Alberdi}

Algunos años después, en 1900, tenemos la publicación del tomo XV de los Escritos póstumos de Juan Bautista Alberdi, donde hallamos

\footnotetext{
${ }^{1}$ GutiÉRreZ 1876e, 976.
} 
«Mi vida privada...», autobiografía compuesta, austeramente, en las postrimerías de su vida. Resulta interesante, para el presente estudio, una serie de confesiones que hace Alberdi sobre su ideario de la lengua. Durante sus estudios de jurisprudencia, en Buenos Aires, allá por los años treinta, confiesa haber intimado con Juan María Gutiérrez y Esteban Echeverría, a quienes reconoce el enorme influjo que han ejercido en su pensamiento; aunque, mientras estos cultivaban la literatura, él se inclinaba más por los estudios filosóficos y sociales. La aversión entonces a todo lo español lo enemistaba con la lengua castellana, «sobre todo con la más pura y clásica», la que le resultaba insoportable por lo difusa. Alberdi atribuye entonces a la falta de esta cultura literaria el no haber podido sentir la belleza de la literatura española, que advirtió — y esto lo lamenta - ya muy entrado en años: «No hace sino muy poco que me he dado cuenta de la suma elegancia y cultísimo lenguaje de Cervantes» ${ }^{1}$.

Se suele leer esta confesión como una refutación al Alberdi que anhelaba la «Emancipación de la lengua». El hombre maduro que reprende al joven incauto. Pero la remembranza continúa y parecen ser otras las inferencias que debemos hacer.

Cuando en Madrid me encontré en el seno de algunas familias, más de una vez el habla de los niños y de las damas me distrajo de la música misma por la armonía de su acentuación. Alguna satisfacción creí encontrar de mis preocupaciones contra el viejo estilo castellano, en la confesión de Larra, de que si Cervantes viniese al mundo, en este siglo, se guardaría de usar de su lenguaje del siglo $\mathrm{XVII}^{2}$

Alberdi, septuagenario ya y libre de los nubarrones de la posguerra, despeja sus recelos del castellano peninsular y reafirma la naturaleza permeable del idioma. No vira hacia el casticismo, sino que, ahora más informado sobre el viejo estilo de Castilla, redime las advertencias neologistas de Larra.

En esta misma evocación, un poco más adelante, reconoce que en su juventud no frecuentó mucho los autores españoles, no tanto por su anti-españolismo, sino porque el curso de su formación lo llevó a buscar en el resto de Europa el Bacon, el Locke y el Montesquieu que no hallaba en España. Cuando más tarde se disipó su encono juvenil y no encontró obstáculos para informarse de los libros clásicos de España, estos ya no podían herir sensiblemente su

${ }^{1}$ Alberdi 1900, 295.

${ }^{2}$ AlBERDI 1900, 295-296. 
estilo de escribir y expresarse. De modo que Alberdi empieza a sentir una atracción por España cuando ella va abandonando la forma que a los románticos americanos aterraba; cuando crecen en su seno intelectuales como Ángel Ganivet, Miguel de Unamuno o Ramiro de Maeztu, que es lo que Alberdi aconsejaba a la Real Academia hacer para recuperar el castellano de América: dar a luz intelectuales modernos.

\section{6. El idioma nacional de Vicente G. Quesada}

Para los albores de 1877, el abogado, periodista y político Vicente G. Quesada ya tiene concluido un riguroso estudio sobre distintas bibliotecas de Europa y América Latina, destinado a iluminar la reforma y reorganización de la Biblioteca Pública de Buenos Aires, que entonces dirige. Resultan relevantes las observaciones que, incidentalmente, expone sobre la cuestión del idioma nacional. La lengua española, para Quesada, debe aspirar a la unidad y la pureza, aunque no desoiga las singularidades, ante todo léxicas, que brotan en cada nación que la habla. No puede España ni debe, por tanto, seguir editando un Diccionario y una Gramática, prescindiendo del aporte estudioso de hablistas americanos.

¿Le bastaría a la España la gloria de haber extendido su hermosa lengua en el Nuevo Mundo, para que desdeñe a aquellos pueblos y les niegue participación en obra que debe ser común a sus hermanos en sangre, costumbre y lengua, como dice el señor Hartzenbusch?1

Quesada saluda que un académico como Juan Eugenio Hartzenbusch desee establecer, en favor de la unidad idiomática, un puente inquebrantable de comunicación entre América Latina y España; solo que encuentra a esta última algo desatenta con las cosas que se escriben y se editan allende los mares.

Lejos de que la conservación castiza del idioma pueda ser un obstáculo para el desarrollo de la civilización en América, para Quesada sería un nuevo vínculo de unión, acaso el más poderoso, entre españoles y americanos: el común desvelo por la pureza de la lengua.

\footnotetext{
${ }^{1}$ QuesadA V. 1877b, 492.
} 
En vez de introducir una anarquía y un desorden en la ortografía y la gramática, y como consecuencia la corrupción en el idioma que sería propósito mezquino, bajo el frívolo pretexto de necesidades extrañas y nuevas a la metrópoli antigua-, la razón aconseja que estas, y las que fueron sus colonias, acepten las voces nuevas con que incesantemente se enriquecen y aumentan las lenguas vivas, para que se conserve en la estructura de la frase y en la ortografía la posible uniformidad: la pureza del idioma patrio, hermoso y rico, por otra parte, pero de ninguna manera estacionario. ${ }^{1}$

Esta visión del idioma, por lo que se desprende del resto del libro, no condena la inmigración, aunque advierte su influencia corruptora; no desalienta la lectura de obras extranjeras, pero subraya lo mal que nos acostumbran; no ignora que una lengua se ensancha día a día, pero repudia el neologismo. De modo que, en el ideario de mantener castiza a la lengua, al mismo tiempo que abierta a los avatares de un mundo vivo, Vicente Quesada encuentra en la labor de la Academia el antídoto a todos los males que surjan de esta oscilación entre la permanencia y el cambio, pues dictando la norma logra que las transformaciones no corrompan. Así, si bien achaca a España desinterés por las cosas de América Latina, celebra la «noble y dignísima» iniciativa de la Real Academia de crear academias correspondientes, y aplaude el «valor» de los americanos que, comprendiendo el interés en común por mantener unida y pura la lengua, comienzan a fundarlas. Estas academias, como la de Santa Fe de Bogotá, la de Quito y la de México, son hechos que lo complacen, porque servirían para desvanecer las preocupaciones engendradas por ciertas susceptibilidades, que habrían perturbado a «espíritus esclarecidos», al sostener que se ofende a las nacionalidades de América cada vez que se conserva la lengua de sus progenitores. Vicente Quesada no solo repudia el rechazo de Juan María Gutiérrez, sino que cree que son pocos e impertinentes quienes lo acompañan:

Pretender que la lengua española, solo por haber sido la de los conquistadores, deba convertirse en dialectos peculiares a cada república, es una idea atrasada y poco en armonía con las necesidades de la civilización moderna $[\ldots]^{2}$

Todas estas observaciones trabajan en función de respaldar lo que, para Vicente Quesada, resulta urgente: convocar a un congreso

${ }^{1}$ QuesadA V. 1877b, 492-493.

${ }^{2}$ Quesada V. 1877b, 497. 
lingüístico que reúna hablistas españoles y latinoamericanos, cuya misión sea plasmar en un nuevo Diccionario y en una nueva Gramática la misión conjunta de velar por el idioma.

Apenas nombrado, ese mismo año, Ministro de Gobierno de la Provincia de Buenos Aires, Vicente G. Quesada expide la primera circular oficial con respecto a la querella en torno a la lengua:

Marzo 5 de 1877: Persuadido que es necesario atender cuidadosa y esmeradamente la enseñanza de la lengua nacional, para impedir la anarquía que se va introduciendo en la ortografía, y conservar puro y correcto nuestro idioma, como cumple a todo el pueblo culto, recomiendo a usted, de una manera especial, preste la mayor atención a su enseñanza, e impida que por descuido del profesor o por indolencia de los discípulos, crean que es permitido a gentes bien educadas, escribir incorrectamente su idioma e ignorar la gramática. ${ }^{1}$

Algunos años después, en oportunidad de volver sobre la cuestión de la lengua, Vicente Quesada reconstruye, documento por documento, las medidas que adoptó España durante el período colonial para extinguir las lenguas autóctonas y así lograr la expansión e imposición de la lengua española. El objetivo era preciso: facilitar la administración y la catequesis cristiana. Para Quesada, este proceso, cuya punta de lanza fue la instrucción jesuítica, fue natural y necesario, y debería admirárselo como una de las empresas más nobles y civilizadoras de la Conquista.

No se hubiera obtenido nunca que las numerosas poblaciones indias, en sus propias comarcas, se aplicasen a estudiar y aprender la lengua de la raza que las dominaba por la conquista: que dejasen voluntariamente sus idiomas indígenas y cambiasen sus costumbres. Eso era propiamente una quimera: los indios no oían la lengua de los conquistadores sin recordar la humillación de vencidos, sentimiento que experimentan todos los pueblos en esa situación. Era inevitable obligarlos $[\ldots]^{2}$

Si España, agrega, terminó por comprender la necesidad de estudiar las lenguas indígenas fue para hace más eficaz la imposición de la lengua castellana; de modo que esas inquisiciones de lo autóctono cesaron una vez logrado el objetivo principal.

Vicente Quesada encuentra enormemente beneficioso que, desde el sur del continente hasta los confines mexicanos del norte,

${ }^{1}$ QuesadA V. 1877a.

${ }^{2}$ QuesadA V. 1903, 11-12. 
se hable una única lengua. Conservarla pura y unida, exhorta, es honrar ese legado y reconocer el enorme esfuerzo que hicieron los conquistadores para lograrlo. Esta es, para él, la única lengua nacional, cuya historia abnegada sintió la obligación de contar:

Aplaudo, pues, todos los esfuerzos que hizo el gobierno español para generalizar la lengua castellana en América, y es digno de elogio el resultado de que tal idioma constituya hoy, y en lo porvenir, el rasgo más característico de las naciones hispano-americanas.

Por todo lo que someramente he expuesto, juzgo de muchísima importancia estudiar los métodos adoptados por el gobierno español para generalizar el idioma de los conquistadores, a fin de extinguir los idiomas y los dialectos de los indios. Mengua fuera perder este precioso don de un lenguaje en común, permitiendo su corrupción y la formación de dialectos locales, de provincialismos poco castizos, de influencias regionales anárquicas en materia de tanta trascendencia e importancia. ${ }^{1}$

Esto último le resulta un peligro muy evidente, puesto que en el norte de América, advierte luego, predomina la lengua inglesa, lengua de una raza «invasora y absorbente», es decir, una raza conquistadora; de modo que aquí el amor de Quesada al ímpetu conquistador se termina.

\section{7. Zeballos, Hernández, Sarmiento y la polémica}

Volviendo a la década del 1870, poco antes de que finalice, el joven abogado y periodista Estanislao Severo Zeballos publica su ambicioso plan en torno a La conquista de quince mil leguas, un pormenorizado estudio para trasladas la frontera sur de la república hacia el Río Negro. Las intenciones del trabajo no se solapan: se trata de un informe integral para la intervención militar. Zeballos habla muy mal de los indios araucanos, pero no tan mal de su lengua, a la que encuentra encantadora, original y —aunque algo carente de palabras que signifiquen abstracciones y principios filosóficos- rica en denominaciones para los objetos físicos que van desde la tierra hasta el mar, y desde el mar a los cielos. Con esta lengua, a la que incluso llama preciosa, cree que sucede lo que con el castellano: cuando la hablan pueblos alejados de su lugar de origen, la corrompen.

\footnotetext{
${ }^{1}$ Quesada V. 1903, 27.
} 
De ahí que cuando oímos hablar a los pampas hay que corregirles y enseñarles lo que ellos desfiguran o ignoran.

$[\ldots]$

Es necesario corregirles también prosódicamente, como corrigen los españoles a los americanos, cuando dicen, verbigracia, tenés por tienes.

Para llegar a darse cuenta de estas circunstancias es menester comenzar primero por conocer a fondo la lengua araucana, tal cual se hablaba y habla en las serranías de Arauco, para poder estudiar corrigiendo la de los pampas, que ha degenerado gramaticalmente, y que ha aumentado su caudal de voces a causa de la nueva vida que el araucano hacía en la llanura. ${ }^{1}$

Al año siguiente, y desde un punto de vista distinto al de Zeballos, José Hernández publica La vuelta de Martín Fierro (1879). Acaso creyendo que la polémica lo alcanzaba también a él, Hernández justificó en el prólogo el lenguaje de su poema —al que, hallándolo incorrecto y bárbaro, encontraba a la vez afín al gaucho y necesario a toda escritura que hable de él.

El gaucho no conoce ni siquiera los elementos de su propio idioma, y sería una impropiedad, cuando menos, y una falta de verdad muy censurable, que quien no ha abierto jamás un libro siga las reglas del arte de Blair, Hermosilla o la Academia. ${ }^{2}$

También interviene Sarmiento en la polémica, aunque esta vez sin el brío de sus ya lejanos treinta años. En oportunidad de responder a Vicente Quesada y a su temor de que los avatares ortográficos estén generando una anarquía idiomática en el idioma nacional, Sarmiento vuelve sobre la cuestión de la soberanía idiomática (en este caso sobre la ortográfica) y se pregunta por la relevancia de la Real Academia entre los americanos «habiendo dado uno de nuestros hablistas sus razones para no aceptar de ella el título de miembro honorario» ${ }^{3}$. Pero en 1879 Sarmiento no tiene ya la misma percepción que años atrás sobre España, pues advierte que esta nación ya se mueve, al menos en materia editorial, en el sentido de todas las naciones civilizadas, difundiendo todas las ramas del conocimiento. Hallamos en este año, por un lado, a un Sarmiento que atemperó su pensamiento sobre el idioma castellano a la relativa expansión de libros editados en español; por otro lado, a un Sar-

${ }^{1}$ ZEBALLOS $1878,333-334$

${ }^{2}$ HERNÁNDEZ 1879, 4.

${ }^{3}$ SARMIENTO 1879a, 308. 
miento impugnando cualquier tipo de gestación dialectal o diversidad idiomática. El 22 de abril, en El Nacional, leemos una de sus nuevas tesis: «Uno de los mayores bienes de que goza una nación es la unidad del lenguaje de sus habitantes, y la mayor rémora para su civilización son las diferencias...». ${ }^{1}$. La diversidad de lenguas en una misma nación le resulta motivo de discordia y desencuentro, y es en esta misma nota donde desdeña la babelización y la juzga indeseable para el entendimiento de un pueblo.

\section{8. López, el primer Groussac y el último Sarmiento}

En 1880, con la publicación del Diccionario Filológico-Comparado de la Lengua Castellana, de Matías Calandrelli, la Universidad de Buenos Aires se jacta de estar a la vanguardia en temas lingüísticos. Vicente Fidel López, sintiendo que los espíritus de Grimm, Bopp y Max Müller revivieron en el trabajo de Calandrelli, le compone una «Introducción», donde lo juzga colosal y lo estima como honra para la ciencia nacional, porque no solo es el único de su especie en la lengua española, sino «el primero también, por el método y por el bagaje, que se emprende en tan vasta escala sobre las lenguas de la civilización moderna conocidas con el nombre de indoeuropeas» ${ }^{2}$.

Por el modo en que Fidel López traza el origen y desarrollo de las lenguas se puede deducir que no pugna por un purismo para el castellano de América, sino más bien por un estudio en profundidad de todas sus formas, incluidas las incaicas, que confluyen en él. López no era de la idea de atacar los dialectos, sino de tratarlos como un orfebre observa su pedrería:

Muchas veces la lengua oficial de una nación es mucho menos rica en acepciones que la jerga popular, y no puede reclamar más ventaja que la de haber tenido mayor fortuna, por su posición geográfica o por otros accidentes políticos más favorables que los que alcanzaron los otros hermanos abandonados en la baja clase de dialectos. ${ }^{3}$

López lleva contabilizados nueve emprendimientos filológicos a cargo de eruditos españoles, entre los cuales se encuentran la edición de 1726 del Diccionario de la Real Academia; los Orígenes de la

\footnotetext{
${ }^{1}$ SARMIENTO 1879b, 139

${ }^{2}$ LÓPEZ 1880, VI.

${ }^{3}$ LÓPEZ 1880, XXVIII.
} 
lengua española, compuesto por varios autores y recogidos por Mayans y Sicar (1787); el Diccionario etimológico, de D. Juan Peñalver, de 1805; y el equivalente de Felipe Monlau, de 1856. Ninguno, afirma, merece los honores de ser tenido por verdaderamente filológico.

Unos años más tarde, con la aparición de su Historia de la República Argentina (1883), Fidel López advierte la presencia incaica indeleble sobre el castellano, presencia que, estima, dulcificó, nutrió y singularizó el habla de los argentinos. López, que ni alentó la segregación de la lengua ni ejerció la devoción a la Real Academia Española, insiste en que las formas regionales que adquieren las lenguas no deben combatirse, sino comprenderse y estimarse. Está, en el fondo, más cerca de Littré y de Gutiérrez, a quien llama «amigo inolvidable», que de la Comisión académica y su programa de salvación del tesoro castellano.

En esos años, a principios de la década de 1880, encontramos a Paul Groussac en Tucumán, presidiendo una comisión encargada de redactar una Memoria de la provincia. Groussac se encarga de los primeros capítulos, a los que titula «Ensayo histórico sobre el Tucumán». Las observaciones que hace sobre la lengua de la provincia van en un sentido tan distinto a las que hará años más tarde que amerita mencionarlas. Groussac estima que, durante el siglo XVIII, los españoles conservan en Tucumán la pretensión de ser la aristocracia del país, pero los criollos comienzan a negarles ese derecho.

Los criollos blancos, producto de la mezcla de la sangre europea e indígena, en que el tipo superior comienza a prevalecer, adquieren los vagos lineamentos de una raza aparte, la raza argentina. ${ }^{1}$

Groussac cree, además, que esta raza ya ostenta costumbres notablemente distintas a las «razas progenitoras». En los ojos rasgados y bellísimos de las mujeres, en la finura aristocrática de sus extremidades, en la tez fresca y tersa, en la blancura y admirable regularidad de la dentadura, nota que se forma un conjunto «nuevo y soberanamente seductor». Pero la gran separación, agrega, la encuentra en la lengua. No niega que el idioma oficialmente hablado sea el castellano, ni cree que pueda decirse que sea un dialecto lo que se habla en Tucumán, "se introducen, sin embargo, en el vocabulario un sinnúmero de voces nuevas, pintorescas, que, mezcladas con restos de quichua, adulteran el aspecto exterior del lenguaje» ${ }^{2}$. Una modificación aún más profunda encuentra en la sintaxis, donde

\footnotetext{
${ }^{1}$ Groussac 1882, 128-129.

${ }^{2}$ Groussac 1882, 129.
} 
advierte la presencia de cierto giro general, incorrecto para la gramática oficial, pero «más vivo y fluido», que deforma o, más bien, reforma la lengua escrita. Pero la valla que se levanta verdaderamente entre criollos y peninsulares, agrega, «proviene de la pronunciación». Luego de enlistar las distinciones que encuentra entre la pronunciación española y la tucumana, afirma que «Hay una pronunciación argentina que hace distinguir al hijo de este país» ${ }^{1}$. Estas observaciones raciales e idiomáticas no serían tan significativas si Groussac no las concluyera previendo que se van a abrir paso hasta constituirse en una nueva oficialidad.

Tales son, indicados de prisa, algunos de los lineamientos que, a fines del siglo XVIII, revelan ya que una raza nueva se está elaborando lentamente en la sombra, hasta que crecidas las fuerzas y marcadas las idiosincrasias, pida atrevidamente su lugar al sol de la libertad. $^{2}$

Algunos años más tarde de estas reflexiones de Groussac en Tucumán, Sarmiento, quizá teniendo presente la discusión entre Berra y Pelliza, enuncia una de sus ideas más sostenidas en el tiempo: las condiciones expansivas del inglés. Acaso porque lo conocía bastante bien, acaso porque creía intuir el destino de las lenguas, jamás dejó de imaginar la lengua inglesa como una suerte de lengua universal; de modo que su reflexión sobre el castellano tuvo siempre la referencia desafiante de esta lengua. En junio de 1886, refiriéndose al volapuk, afirma que, teniendo el inglés conquistados cuatrocientos millones de habitantes, no es necesario imaginar otra lengua capaz de ser entendida y hablada por todo el planeta. Esa irradiación, agrega, no la tiene el francés, que se habla solo en Francia y tiende a desaparecer en Canadá; no la tiene el alemán, sonoro y vital para las ciencias, pero restringido a Alemania; no la tiene el italiano, fonético y candoroso, pero inepto para lo trascendental. Tampoco la tiene el español, pues

[...] si los gobiernos americanos han de acabar por ser los de ejércitos acuartelados en ciudades y aventureros audaces como se va generalizando, acabará por pasar a dialecto, o a lengua servil, como el quichua y el guaraní. La duración de las lenguas depende de las instituciones de gobierno. ${ }^{3}$

\footnotetext{
${ }^{1}$ GroussaC 1882, 130.

${ }^{2}$ GROUSSAC 1882, 132.

${ }^{3}$ SARMIENTO 1886, 351.
} 
Sarmiento es de la idea de que el sistema representativo y las instituciones libres terminarán de derramar el inglés por toda América, Europa y Australia, repitiendo, aunque en mayor dimensión, la experiencia del latín, que por sus instituciones desplazó al griego como lengua de expansión. 
IV. ACADEMIAS CORRESPONDIENTES Y DICCIONARIOS (1889 - 1892)

\section{1. Polémica entre Argerich y Obligado: la academia y el diccionario}

Si salváramos las distancias del siguiente parangón, que en breve detallaré, la nueva polémica que surge al cerrarse la década del 80 entre Rafael Obligado y Juan Antonio Argerich reedita la discusión sobre los académicos correspondientes y las academias sucursales de la española. Ahora es el publicista Argerich quien reedita el pensamiento rechazador de Gutiérrez; mientras que el poeta Obligado, a su vez, la aceptación de Juan Bautista Alberdi. Salvando las distancias digo, porque, entre las muchas que se podrían establecer, la más evidente es que, tanto Obligado como Argerich bregan por la pureza y conservación del idioma. Veamos las diferencias.

La polémica se origina el 4 de agosto de 1889, a raíz de una entrevista publicada en La Prensa, donde Rafael Obligado asevera que la soberanía del idioma pertenece a España, y rendirle pleito homenaje sería cumplir un deber filial. Todo lo demás sería hacer lujo de «ridícula independencia». Luego, aludiendo al problema de las academias correspondientes, afirma no encontrarlas indeseables.

Antonio Argerich, sorprendido por las opiniones del autor del Santos Vega, a quien creía un patriota, escribe una carta el mismo día y la envía a La Nación. Creyéndolo ahora un converso, le pregunta qué fue de aquel poeta que bregaba por la independencia intelectual argentina:

[...] hete aquí que de pronto el señor ministro residente de España concibe la idea de establecer entre nosotros una sucursal de la que «fija, limpia y da esplendor» y Usted, en el campo de la doctrina crítica, se pasa con armas y bajeles al campo contrario [... $]^{2}$

Argerich le advierte que la creación de una academia de la lengua española en América estaría destinada a morir por «falta de atmósfera», y por ser, al mismo tiempo que antipatriota, «inútil y descaminada». No obstante, dice todo esto sin querer que se lo confunda con un neologista; confiesa amar el idioma castellano y desear que se conserve incólume en América. Lo que Argerich objeta es, por un lado, la utilidad de las instituciones de la lengua; por otro, la

\footnotetext{
${ }^{1}$ Obligado 1889 a.

${ }^{2}$ ARGERICH 1889a.
} 
legitimidad de las mismas en tierras que ya no gobiernan: «Las Academias, puede decirse, sirven en resumen para muy poco, y si para algo sirvieran en países como estos deberían ser esencialmente nacionales y no factorías dependientes del negocio central» ${ }^{1}$. Luego llama a los idiomas «organismos vivos» que no están sujetos al dictamen de las academias, sino a la inclemencia del lugar, el tiempo y el pueblo que los modela. La pureza por la que aboga, por tanto, remite a una pureza americana, sin injerencia de España: «Con o sin academia, hablaremos de un modo distinto del empleado en España.... $\rangle^{2}$ Si ha de formarse una academia, para Argerich debe ser argentina, "sin vasallajes de preocupaciones extranjeras», y que España acoja o rechace, si le place, lo que esta diga. Luego, antes de terminar, le pide que le permita dos palabras:

Usted ha sido seducido y no se ha dado cuenta de que arriaba su bandera, pero nos quedan las batallas ganadas por Usted y contamos con las que todavía ganará como artista, aunque sea sucursalero. ${ }^{3}$

Rafael Obligado le responde enviando a La Nación cuatro cartas, que serán publicadas el 7, 8, 9 y 11 de agosto. En la primera rechaza la acusación de patriota en lo poético, traidor en lo demás, porque las opiniones en La Prensa solo si se las malinterpreta pueden conducir a pensar que se debe arriar, en cuestión idiomática, la bandera de la patria. Reconoce haber hablado de «autoridad» de España sobre la lengua, pero no de «soberanía»; y eso de «pleito homenaje» $\mathrm{y}$ «deber filial», conceptos que afirma no ser los suyos, le suenan a servilismo y adulación. A la autoridad española, en cambio, Obligado la encuentra evidente:

Fuera bien original y hasta ridículo que nosotros, o cualquiera república americana, que estamos balbuciendo una literatura propia, nos la echáramos de maestros ciruelas abrogándonos una supremacía que no nos hemos conquistado; porque esta autoridad se conquista, no con desearla, sino a fuerza de talento, prodigado en siglos de labor. ¡Quién nos diera a Cervantes, a Lope y a Calderón por acá, para decir a España: atrás, vieja inútil! ${ }^{4}$

\footnotetext{
${ }^{1}$ ARgERICH 1889a.

${ }^{2}$ ARGERICH 1889a.

${ }^{3}$ ARGERICH 1889a.

${ }^{4}$ Obligado $1889 \mathrm{~b}$.
} 
Obligado le concede a Argerich la idea de que los idiomas no se forjan en las academias sino en el pueblo, pero encuentra evidente que «se depuran en los buenos escritores», así como las palabras y locuciones se seleccionan, precisan y circulan en el «diccionario» de la lengua. Aquí es donde Obligado disiente con su amigo y antagonista, pues no cree que este lexicón deba estar compuesto por «Perico de los Palotes», pues, aun siendo este Perico un docto, jamás lograría un repertorio de palabras tan vasto como el que puede lograr una corporación.

Desdeña usted las labores académicas, y sin embargo, no me citará usted un diccionario español, que en sus aciertos no sea mera copia de la estigmatizada Academia, comenzando los desaciertos precisamente allí donde el autor ha pretendido burlarse o separarse de ella. ${ }^{1}$

De modo que Obligado encuentra al diccionario académico, incluso con sus falencias, superior a otros lexicones particulares; por tanto, prefiere aplaudir a la corporación y colaborar con ella, en vez de combatirla y ridiculizarla.

En la segunda carta, para ejemplificar la función que debería cumplir un miembro americano de la Academia Española, Obligado hace como si ya fuera portador de ese título. ¿Cuál sería su deber?, se pregunta: enviar a Madrid, encabezada por unas parcas líneas de formalidad, la lista de nombres, verbos, locuciones y modismos argentinos que deben incluirse en el Diccionario. Nada más.

¿Que la Academia no los acepta? ¡Peor para ella!... y no para mí, que los seguiré usando a destajo.

¿Que la Academia los selecciona? Me alegraré mucho, porque, eso sí, en materia de lenguaje gusto del oro purísimo. No por eso dejará de circular el cobre que por acá nos quede.

¿Que la Academia los incluye en su léxico? Confieso que los veré allí con orgullo patrio; porque, dejémonos de historias, querido amigo, jnadie, a menos de ser un bolo, puede ver sin agrado que aquello que nació de lo íntimo de su ser, ande honrado en labios de millones de hombres, y en servicio para la expresión de ideas, de millares de talentos!

En esto se agota, para Obligado, todo lo que los académicos correspondientes pueden y deben hacer. No implica, para él, con-

\footnotetext{
${ }^{1}$ OBLIGADO 1889b.

${ }^{2}$ Obligado 1889c.
} 
vertirse en traidor, ni dejar la puerta abierta de América para que España vuelva a apoderarse de ella.

Llegamos, así, a la tercera carta, donde Obligado confiesa haber buscado y rebuscado en la imputación de Argerich algo que le ayudara a entender por qué, siendo su oponente un razonador preclaro, cae en el error de creer que, al dar un manojo de voces para ser admitidas al léxico oficial, peligra la libertad intelectual de los argentinos. Si hay algo que lo explique, concluye, es el prejuicio de creer que la Academia de la lengua es una fuerza contraria a la evolución del idioma, que no permite que se usen palabras no alojadas en su Diccionario.

Felizmente no hay nada de esto. La Academia no impone la lengua: la recibe de los pueblos del habla castellana, no aturdida sino mesuradamente, como cumple a sus fines de velar por su pureza, y en prueba de que ello es verdad, de que desea enriquecer cada vez más el tesoro común del idioma, es la creación de esas mismas correspondientes que tanto alarman a usted. ¿Qué nos pide, en resumen, la Academia Española? ¡Nos pide argentinismos! ${ }^{1}$

A diferencia de Argerich, y sobre todo de Juan María Gutiérrez, Obligado siente que España se acerca a América afectuosamente, no con intención de reconquista. Le basta con echar un vistazo en lo que se ha convertido Buenos Aires: una ciudad moderna, poderosa y próspera, para reconocer que ya está en condiciones de dar, y no solo recibir insumos espirituales. Para Obligado, la soberanía de Argentina es algo bastante invulnerable como para creerla en peligro. ¿Qué lo puede asustar una corporación literaria, si ya no lo asustan naciones formidables, atestadas de soldados y cañones? Argentina, para él, no es solo «la primera nación de la América latina»; todos los pueblos, venidos de todas partes del mundo, que se fusionan y conviven en ella, están generando en ella un ambiente propicio para la creación y la expansión del espíritu: «Dante, Cervantes, Calderón, Molière, Hugo, el semidiós Shakespeare, Goethe el diáfano y Byron el luzbélico, están en germen aquí, y brotarán en su día en nuestras pampas» ${ }^{2}$.

En la última carta que envía Obligado a La Nación, intenta atenuar las diferencias que tiene con Argerich, pues no busca, al fin y al cabo, ni perder un amigo, ni hacer de una polémica el germen de una discordia. Ambos, aunque disienten en el modo de lograrlo,

\footnotetext{
${ }^{1}$ OBLIGADO 1889d.

${ }^{2}$ Obligado $1889 \mathrm{~d}$.
} 
pretenden que el idioma se conserve incólume en América. De modo que hay un último punto que Obligado quiere asentar y con eso cerrar el asunto: no cree, aunque lo desee, que la Academia Correspondiente Argentina se forme.

¿Y por qué no es posible? Por dos razones: la primera, porque somos asustadizos en materia de independencia literaria, cuando de España se trata, aunque doblemos el cuello mansamente a las demás naciones, especialmente a aquella que usted sabe; y la segunda, porque... vaya, porque somos así. ${ }^{1}$

Al responder Argerich, también por última vez, formula su conclusión del debate: «La sucursal está muerta: que en paz descanse» ${ }^{2}$. Luego cree que su antagonista está eludiendo lo neurálgico del tema, que es la ilegitimidad de que España se arrogue la soberanía idiomática. Se pregunta de dónde se deduce el derecho de que nos imponga, a modo de sentencia, apelable ante la posteridad, su manera de interpretar el idioma. Le resulta irrisorio postular que la Academia sea la más docta a la hora de confeccionar diccionarios y gramáticas; piensa, por ejemplo, en Andrés Bello, cuya Gramática, particular y americana supera todos los esfuerzos hechos por la corporación real. «Cuerpos conservadores, tímidos, llenos de plateados y dorados, son cuerpos de otras edades.») Para Argerich, un buen diccionario solo puede ser el resultado de un esfuerzo individual, y cita como ejemplos el de Littré y el de Webster. Acusa, finalmente, a Obligado de llevar su pretensión «conservadora de la lengua) a un extremo que cree inconveniente; $y$, preanunciando la sentencia que imprimirá Rufino Cuervo diez años más tarde, se pregunta:

¿Quién nos dice que no estemos en un momento histórico semejante, hasta cierto punto, al que siguió a la caída del imperio romano y que la corrupción del idioma, tan sonada, no sea, como es siempre la corrupción, una de tantas fuerzas de creación en la eterna transformación de los seres? ${ }^{4}$

\footnotetext{
${ }^{1}$ Obligado 1889e.

2 ARGERICH 1889b.

${ }^{3}$ ARGERICH 1889b.

${ }^{4}$ ARgERICH 1889b.
} 


\section{2. Polémica entre Del Solar y De Vedia (Juan Cancio)}

Unos días más tarde, el capitán chileno, ahora escritor y poeta, Alberto del Solar, envía una carta a La Nación, dedicada a Rafael Obligado, a quien quiere servirle de aliado. En ella da a entender que no le resulta una mancha ni una deshonra recibir un diploma extranjero, ni cree que se menoscabe o sufra el patriotismo americano porque en España se estimen y premien los talentos de la América. Del Solar entiende y hasta saluda que Argentina esté buscando dar con una literatura nacional, pero eso de fundar una lengua nacional,

[...] generalmente híbrida y enriquecida por barbarismos de la peor especie, y que reniegue de aquella que nos enseñaron nuestros padres y aprendimos a balbucear desde nuestra cuna, nos parecería lastimoso extravío. ${ }^{1}$

De modo que cree que lo se está discutiendo es la fundación de una «lengua nacional aparte». Aunque principia la nota advirtiendo la singularidad cultural argentina, desdeña luego que los argentinos pretendan una lengua, pues también podrían reclamar, con iguales derechos, una propia los chilenos, los venezolanos, los colombianos... ¿Por qué no reconocer — se pregunta— la autoridad de una cabeza que acoja y ordene, clasifique y depure el uso de todas estas peculiaridades de nuestro idioma local? Del Solar no encuentra problema en ello ni subordinación, sino beneficios, opinión que comparte con Obligado. No cree tampoco posible que cada nación, al rechazar una autoridad central que reúna y unifique el criterio para los americanismos, pueda dar con un diccionario nacional. Ni cree tampoco, y esto lo enfatiza, que América se encuentre en un momento similar al europeo durante las gestaciones de las lenguas romances. Encuentra, sí, un proceso de «corrupción» de la lengua, al que cree que habría que detener.

Por lo que toca a evitar la invasión de la corruptela en materia de lenguaje (no se confundan las dos voces transformación y corrupción), parece fuera de duda que se impone la necesidad de establecer en América una autoridad suprema que regule los términos familiares, que precise el lenguaje que han de entender en conjunto los ochenta millones de hombre que se sirven de él para expresar sus ideas,

\footnotetext{
${ }^{1}$ SOLAR 1889a.
} 
que armonice y simplifique, por decirlo así, el idioma común, «limpiándolo, fijándolo y dándole esplendor». ${ }^{1}$

Esta es, para Del Solar, la causa por la cual se han fundado las academias de la lengua; no para que cada nación arríe nuevamente su bandera de la independencia.

Unos días más tarde, bajo el seudónimo de «Juan Cancio», el periodista argentino Mariano de Vedia compone una carta al señor Alberto del Solar, donde fundamenta su voto en contra de las academias. De Vedia entiende que el vocablo idioma, como enuncia su sentido griego, remite a «propiedad», «índole»y «costumbres propias»; y, por tanto, no existe ni puede existir entre los viejos pueblos de Europa y los nuevos de América similitud en cuanto a estas realidades.

No tenemos aún idioma que refleje o exprese al exterior esa propiedad, esa índole, esas costumbres; no lo tendremos hasta que surja - y ha de surgir - el genio poderoso, hijo de nuestro medio, que debe dar unidad y vida artística a todos los elementos, completamente propios, que forman ya un lenguaje especial, con su genio, su fisonomía, sus giros. ${ }^{2}$

Para De Vedia, ese futuro idioma americano constará de seis décimas partes de español, repartiéndose las otras cuatro en la proporción de las influencias que se ejercen ya sobre el español de América. Luego, como cree que se trata de hechos fatales, niega la necesidad y la conveniencia de que se establezca una academia corespondiente de la española. En la instalación de estas academias De Vedia ve la pretensión de amoldar el genio americano al «idioma» español. ¿Qué beneficios, se pregunta además, acarrearía establecer una comunidad de idioma entre estos dos pueblos? A diferencia de Alberto del Solar, De Vedia no duda de que en América se produzca una dialectización progresiva; cree que sucederá «fatalmente». Alentar la unidad idiomática, vía academias o sin ellas, es invertir tiempo en algo que tarde o temprano se perderá. Por otra parte, las academias de la lengua, además de ir contra la tendencia natural de los idiomas, irían contra la soberanía idiomática de los americanos; pues no entiende que sea otra la pretensión española de intervenir en el castellano de América. Cree que estas instituciones sirven, no a los idiomas, sino al dominio español.

\footnotetext{
${ }^{1}$ SOLAR 1889a.

${ }^{2}$ VEDIA 1889a.
} 
La respuesta de Alberto del Solar no se hace esperar, $\mathrm{La} \mathrm{Na}$ ción la publica al día siguiente: «Pero qué es lo que, según usted, hablamos hoy, señor Cancio? ¿Es una lengua o es un idioma? ¿Es un dialecto o es un patua?» ${ }^{1}$ Del Solar insiste en que América no está ante una transformación de la lengua castellana, sino ante un momento extraordinario de corruptela, en la cual se dan cita neologismos inadmisibles y extranjerismos (en especial galicismos) innecesarios. Luego se pregunta qué pueblo obtendrá tanta influencia sobre los de origen español en América, como para alterar sustancialmente la forma del lenguaje patrio. Del Solar no teme tanto a la sustitución del castellano, sino al «injerto, por decirlo así, de vocablos e idiotismos entre lenguas de naturaleza completamente diversas ${ }^{2}$. Por último exhorta a su antagonista a conocer bien el castellano, antes de arrastrarlo entre el polvo.

«¿Qué es lo que hablamos?», repregunta De Vedia al día siguiente, y responde: «Una lengua, señor Del Solar» ${ }^{3}$. Una lengua, no obstante, de la cual no hay que enorgullecerse, agrega, porque es obra de España, es decir, ajena. De Vedia insiste en que América hará su propio idioma, pero no a base de otro idioma europeo que desplace al castellano, sino a partir del ser social que brote del suelo americano. Refiriéndose, luego, puntualmente al Río de la Plata, al que concibe como tierra de confluencia extraordinaria, agrega: «Aquí se hará también el gran idioma — el gran idioma, porque recibirá las más poderosas y sanas influencias que haya recibido cualquiera otro de la tierra» ${ }^{4}$. Luego de reafirmarse en estas tesis se ocupa de la labor de la Academia, la cual estaría, por tanto, empecinada en convertir al castellano en un museo, al que debería adorársele en su pureza. No creyendo De Vedia en las instituciones de la lengua, no puede consentir las idas de Obligado:

¿Para qué quiere España argentinismos? Guárdeselos, señor Obligado, no los regale, aunque de muchos sea usted padre; guárdeselos para nuestro idioma, que ya viene, y no los exponga a un desaire justificado. ${ }^{5}$

Al contestar, Alberto del Solar le objeta, en primer lugar, esa idea de no poder enorgullecerse de la lengua castellana, por haber

\footnotetext{
${ }^{1}$ SOLAR $1889 \mathrm{~b}$.

${ }^{2}$ SOLAR $1889 \mathrm{~b}$.

${ }^{3}$ VEDIA $1889 \mathrm{~b}$.

${ }^{4}$ VEDIA $1889 \mathrm{~b}$

${ }^{5}$ VEDIA $1889 \mathrm{~b}$.
} 
sido gestada sin nuestro consentimiento. De seguir con estos razonamientos, agrega, tampoco podríamos enorgullecernos de otras herencias, como las que provienen de nuestros padres. Del Solar no busca, por el tono que emplea, ridiculizar a De Vedia; pero lo logra al reproducir algunos de sus pasajes. Luego vuelve sobre la necesidad de instalar academias correspondientes, justamente para evitar el futuro idioma que se preanuncia:

[...] debemos, pese a los que nos impugnan, considerar al español como nuestra lengua única; y a toda la amalgama de elementos heterogéneos que a veces suele formar un guirigay o jerga ininteligible, tan frecuente, por desgracia, en Chile y Colombia, como en el Perú y la Argentina, desecharla, o, si no, clarificarla; despojarla de toda la borra, dejándole solo lo necesario. ${ }^{1}$

Este entrevero se agota, al menos en el espacio del periódico, al día siguiente, con la última nota de Mariano de Vedia ${ }^{2}$, la que resume las posiciones encontradas y deja formuladas una serie de preguntas que, años atrás, habían sido las de Juan María Gutiérrez: ¿Interesa a los americanos detener el flujo de voces e ideas que se entrecruzan y alteran en el Río de la Plata? ¿Conviene al progreso americano asociarnos en pos de fijar la lengua?

Digo que se agota en el periódico, porque Alberto del Solar creyó que debía responder, pero por extenso. Da una conferencia en el Ateneo de Buenos Aires y luego, el mismo año, 1889, la publica en forma de folleto bajo el nombre de Cuestión filológica. Ahora que tiene más tiempo se extiende, pero los temas son los mismos. Los aludiré sucintamente.

En primer lugar, Del Solar no cree que a las naciones de la América hispánica le espere la formación de dialectos, como sucedió en Europa al perderse el latín. Durante la independencia, estima, no hubo invasiones de nuevas razas, ni sustitución de costumbre, ni reemplazo de una religión por otra.

¿Por qué habría de degenerar el idioma patrio porque la patria cambiaba de forma de gobierno? ¿Por qué habría de abandonarse una lengua sabia y organizada por dialectos imperfectos, embrionarios y deficientes? ${ }^{3}$

\footnotetext{
${ }^{1}$ SOLAR $1889 \mathrm{c}$.

${ }^{2}$ VEDIA 1889c.

${ }^{3}$ SOLAR 1889d, 28.
} 
Del Solar encuentra que la lengua castellana permaneció intacta en América, es decir, que su natural evolución jamás alteró su esencia; pero luego habrían llegado los ánimos emancipatorios y a algunos hombres que los enarbolaban se les dio por tramar una lengua nacional, empresa que, excusándose en la necesidad del progreso y la libertad, no era más que una prédica en favor de la corrupción del idioma. Esta situación llega hasta fines de siglo; es la situación en que el mismo Del Solar cree encontrarse. Por todo esto, por el peligro, encuentra necesario volver sobre las advertencias de aquel Bello de 1847 que clamaba por la conservación unificada del castellano en América, sin que esto implique fosilizar la lengua. Es decir, aceptar las voces y giros necesarios; rechazar los superfluos y afectados. Abogar por el purismo de la lengua, mas no por un purismo supersticioso. So pretexto de aumentar la especie - agrega Del Solar- «no hemos de tolerar que se autorice el libertinaje» ${ }^{1}$. El crecimiento ordenado y vigilado del idioma no debe ser regido sino por el uso, que es el que fija, limpia y da esplendor. Pero lo que debe entenderse por uso, «nótese ello bien, no es el uso del vulgo» ${ }^{2}$. A su entender, el uso lo constituyen

[...] las inteligencias cultivadas, las opiniones de los buenos escritores, que conocen y han estudiado a fondo su lengua y que, según la expresión de un ilustre pedagogo, «deben considerarse, por lo tanto, como los depositarios de la lengua nacional». ${ }^{3}$

Luego de estas observaciones, Del Solar pasa a la cuestión $G u$ tiérrez, porque también él advierte la paradoja de que Juan María Gutiérrez, aunque algo irreverente con la Real Academia, escribe «en el más puro y correcto castellano». Lamenta, así, que predique con los conceptos lo que borra con la práctica castiza del estilo.

Meses más tarde, Rafael Obligado, Estanislao Ceballos y Carlos Guido y Spano son nombrados miembros de la Real Academia Española en calidad de académicos correspondientes extranjeros. Obligado se siente honrado y le escribe a Tamayo y Baus, secretario perpetuo de la Real Academia:

\footnotetext{
${ }^{1}$ SOLAR 1889d, 31.

${ }^{2}$ SOLAR 1889d, 32.

${ }^{3}$ SOLAR 1889d, 32.

${ }^{4}$ SOLAR 1889d, 32.
} 
Dígnese V. S. participar al Sr. Director de la Academia, mi aceptación del cargo, haciéndole presente a la vez, que considero un deber de patriotismo velar la pureza y enriquecimiento de nuestro magnífico idioma.

La República Argentina, como V. S. lo sabe, recibe anualmente miles de inmigrantes europeos, benéficos en sí mismos, puesto que son la principal fuente de su progreso, pero causa fatal de la mezcla de todas las lenguas, en detrimento de nuestra cultura literaria y artística.

Como argentino y como amante de nuestras tradiciones de raza, creo, en conciencia, cumplir un deber altísimo contribuyendo a mantener la unidad de la lengua de nuestros abuelos, de nuestros héroes y de nuestras madres. ${ }^{1}$

\section{3. El juicio de Martí y la exhortación de Mansilla}

Ese mismo año, 1889, en octubre, al reseñar un libro argentino, José Martí lanza su pertinaz «Gutiérrez, para no ser traidor, no quiso ser académico» ${ }^{2}$. Martí está asombrado de la transformación porteña y encuentra, a partir del libro de Juan Piaggio, la oportunidad para decirlo. Nunca ha visto una ciudad cambiar tanto como lo ha hecho Buenos Aires, en solo veinte años. Se sacó del costado, escribe, «el puñal de la tradición». Su juicio sobre lo que en ella está sucediendo es similar al que había expresado Gutiérrez al rechazar el diploma, pues advierte que la presencia extranjera, con sus lenguas, se cruza en Buenos Aires de tal modo que, valiéndose de la libertad y el progreso, produce beneficios espirituales. Esa reunión no es, para Martí, causa accidental y pasajera, sino voluntad de crear un pueblo donde se junten, bajo la presidencia latina, las fuerzas vivas del mundo. «Y se han juntado y confundido con las del país, pero sin invadirlo ni desfigurarlo.... ${ }^{3}$ No es corrupción lo que encuentra Martí en Buenos Aires, sino una sanísima fusión de fuerzas creativas. No se ha gestado, por tanto, sino la fisonomía de un nuevo país, que está a la vez forjando el arte y la literatura que esté a su altura, que dé cuenta de sus esperanza y su vitalidad. Martí no cree que Buenos Aires esté en peligro, por el contrario, entiende que es la ciudad que más a salvo está del atraso.

Esta confluencia extraordinaria no puede jamás consentir los anhelos académicos de fijar, pues la transformación idiomática que

${ }^{1}$ OBLIGADO 1890.

${ }^{2}$ MARTí 1889, 359.

${ }^{3}$ MARTí 1889, 359. 
vive la ciudad no solo supone la presencia de lenguas europeas, sino de lo indígena y lo exótico, al punto que el idioma español, que no cree deba ser suplantado, torna en una forma descastizada. Cito, a continuación, el párrafo que no es posible glosar.

Fue primero la lengua revuelta y excesiva, como en la primera confusión tenía que ser, más cuando era, en la pelea local de la carreta contra el ferrocarril, timbre de honor y patente de hombre aquel modo de hablar, y símbolo del advenimiento de la patria, sin miedos ni tutelas, al coro del mundo. Con los pueblos vinieron sus lenguas, pero ninguna de ellas pudo más que la nativa española, sino que le trajo las calidades que le faltan como lengua moderna, el italiano la sutileza, el inglés lo industrial y científico, el alemán lo compuesto y razonado, el francés la concisión y la elegancia. Y surgió en la Argentina, con la irregularidad y atrevimiento que vienen de la fuerza, ese mismo castellano que no huele a pellejo por obligación ni está sin saber salir de Santa Teresa y el Gran Tacaño, y ya se habla en España por los hombres nuevos, aunque sin el desembarazo y riqueza con que lo manejan en América sus verdaderos creadores. Mas no el castellano de crónica, adamado y pintoresco, que en espera de lances mayores, y por obra de la armonía y color de América, se escribe felizmente, con ligereza de pluma y matices de azulejo, en los países que no han entrado aún de lleno en la brega universal; sino otro que le lleva ventaja, aunque no se le vea ante el peine y el rizador, como que va poniéndole causas a todo lo que dice, $y$ nombres a todo lo que ha menester, y es franco, directo, breve, potente, vivo, sin que se note que prospera en él el vicio de que al principio lo acusaron, que fue el de caer de la jerga arcaica, a que se ha de hacer la cruz, en la jerga científica. ${ }^{1}$

Interesado por la querella y por la discusión del diccionario y las academias, Lucio V. Mansilla, también en 1889, le dedica al asunto una de sus causeries de los jueves, del periódico Sud América, donde exhorta a los hombres en disputa a llegar a un acuerdo con la Academia Española y dotar a la lengua, finalmente, de un Diccionario que, no por ser del español, deje de ser americano. Mansilla cree que escritores como Bello, Baralt, Caro o Vicente Quesada no han buscado —al auspiciar la limpieza, la purificación y el ennoblecimiento de la lengua - someter el castellano de América al veto de la Academia peninsular, sino, por el contrario, inducir a esta a ir lentamente incorporando en su Diccionario oficial el caudal de voces forjadas al calor de la idiosincrasia americana. La propia España ostenta erudi-

${ }^{1}$ Martí, José, en el mismo lugar. Página 360. 
tos que, siguiendo esta tendencia, y sin abandonar el ideal casticista, quieren asimilar voces nuevas.

La Academia Española no pretende ni puede pretender, en su purismo, que voces aceptadas por millones de hombres, no figuren en su Diccionario, en la oportunidad debida. Pero ¿cuándo llega esta oportunidad? Aquí está todo el quid de la cuestión. ${ }^{1}$

Mansilla entiende que los ingresos de voces americanas al Diccionario deben ser más oportunos, pues va en esta prontitud por comprender y aceptar lo americano, el poder aspirar a la unificación de la lengua española.

\section{4. La circular de Carballido y la lengua de Groussac}

Dos años más tarde, en 1891, heredera de aquella circular de Vicente G. Quesada que pedía «atender cuidadosa y esmeradamente la enseñanza de la lengua nacional» ${ }^{2}$, se publica una circular de Juan Carballido $^{3}$, entonces Ministro de Instrucción Pública del gobierno de Carlos Pellegrini. Este nuevo escrito oficial, destinado a explicar a los rectores de los colegios nacionales la reforma en el plan de estudios secundarios, advierte algunos problemas:

Tan violenta ha sido la avenida inmigratoria, que podría llega a absorber nuestros elementos étnicos. Están sufriendo una alteración profunda todos nuestros elementos nacionales: lengua, instituciones prácticas, gustos e ideas tradicionales. A impulso de este progreso spenceriano - que es realmente el triunfo de la heterogeneidad- debemos temer que las preocupaciones materiales desalojen gradualmente del alma argentina las puras aspiraciones, sin cuyo imperio toda prosperidad nacional se edifica sobre arena. ${ }^{4}$

El nuevo plan no quiere quedar impávido frente a esto que encuentra como problema: busca, así, redefinir la identidad nacional, ahora «hispanoamericana», pero cuya Madre Patria sigue siendo España.

\footnotetext{
${ }^{1}$ Mansilla 1889, 59.

${ }^{2}$ QuesadA V. 1877a.

${ }^{3}$ Paul Groussac se atribuye la redacción de esta circular. Cf. GroussaC 1900, 413.

${ }^{4}$ CARballido 1891a.
} 
Carballido asevera que, más que la raza y las instituciones análogas, la «lengua común» constituye el mayor vínculo de fraternidad con el resto de los países hispanoamericanos. Esta «lengua común», no obstante, está seriamente amenazada por un proceso de dialectización; y no habría otro país más expuesto que Argentina a este peligro. Estima, también, que puede ser una exageración prever que un día en nos fuera difícil entendernos entre hispanoamericanos, pero en tal caso «no lo sería asegurar que habríamos perdido, a no reaccionar, el hábito de la lengua tradicional...» ${ }^{1}$ La reforma, por tanto, decide intervenir en la dirección de la lengua.

Renunciemos a vanagloriarnos con nuestras incorrecciones: como lo repite expresamente el nuevo plan de estudios, no hay más idioma nacional que el castellano. ${ }^{2}$

La circular es aplaudida por Ernesto Quesada, hijo de don Vicente, y refrendada con una carta fechada el 26 de abril de 1891 que publica La Nación al poco tiempo. La polémica crece y aparecen, entonces, algunos de los escritos más relevantes, uno de los cuales paso a comentar.

Como mencioné en una reciente nota al pie, Paul Groussac se atribuirá la redacción de esta circular en «A propósito de americanismos», de modo que conviene leerla junto a este artículo y, a la vez, junto a las ideas de la lengua que encontramos en 1897, al presentar Del Plata al Niágara. En el «Prefacio», Groussac confiesa que su propósito es artístico y teme que se haya malogrado por insuficiencia, ya del artista, ya de su modo de esgrimir la lengua española, que no es su lengua natural. No busca justificar su «propia torpeza», sino que trabaja constantemente para acercarse a una "corrección gramatical, base y fundamento del estilo» ${ }^{3}$. Esta corrección, no obstante, no parece remitir a una idea casticista, pues le resulta imposible aceptar el castellano de su época como un instrumento adecuado al arte contemporáneo: «Sonoro, vehemente, oratorio, carece de matices, mejor dicho, de nuances - pues es muy natural que no tenga el vocablo, faltándole la cosa» ${ }^{4}$.

Groussac, previendo que la evolución del estilo tiende al análisis pormenorizado, a la sutileza y al cromatismo, encuentra al español actual similar a una trompeta de bronce, estrepitosa y triunfal,

${ }^{1}$ Carballido $1891 \mathrm{~b}$.

${ }^{2}$ CARBALlido $1891 \mathrm{~b}$.

${ }^{3}$ GroussaC 1897, XVII.

${ }^{4}$ GroussaC 1897, XVII. 
pero sin escala cromática. La lengua francesa, en cambio, al haberse reelaborado incesantemente, ostenta los mayores matices y la mayor aptitud entre las lenguas modernas.

La lengua española no ha sufrido ni admite este trabajo de transformación: se rige siempre e invariablemente por sus clásicos. Ahora bien: todo producto orgánico que se estaciona, se desvirtúa; y los que declaman sobre la riqueza presente de un instrumento secular, aplicando un concepto inmutable a un proceso esencialmente evolutivo, desconocen los términos de la cuestión. ${ }^{1}$

Luego, al modo en que lo habían planteado los románticos, Groussac advierte que la cultura española contemporánea no es aislable de la penetración cultural extranjera, viviendo, por su inferioridad, más del reflejo y de la copia que de la creación original. Encuentra, a la vez, algo ilógico en quienes aceptan dócilmente las cosas extranjeras, pero se oponen a sus palabras, que no son más que algo inseparable de aquellas. No es imposible probar que Groussac estaba iniciando una gran transformación en la prosa de habla hispana. La prueba está en sus libros. Este «Prefacio» que ahora comento preanuncia esta transformación. Entretanto, Groussac considera atendible cualquier esfuerzo encaminado al propósito de alcanzar un estilo literario más sobrio y eficaz «que nuestro campaneo verbal, a par que más esbelto y ceñido al objeto que la anticuada notación española» ${ }^{2}$.

Toda la empresa extraordinaria que lleva el nombre Del Plata al Niágara está enriquecida con valiosas observaciones sobre la lengua, sobre Andrés Bello, sobre la Real Academia Española. Al pasar por Lima, por ejemplo, Groussac alude de soslayo la polémica desatada por Gutiérrez:

En Lima se siente ahora como una recrudescencia de la palabrería pedantesca y vacía. Funciona solemnemente una «Academia de la Lengua», sucursal de la que elabora en Madrid tan exquisito diccionario. Para procrear una obra inspirada, para dar al fin con la originalidad y la vida, estos «excelentísimos» se cuelgan del pescuezo un abalorio y, puestos en cuclillas, formando rueda, teniendo cada cual en la mano su diploma de la academia matriz jse calientan al reflejo de una luna menguante! $!^{3}$

\footnotetext{
${ }^{1}$ GroussaC 1897, XVIII.

${ }^{2}$ Groussac 1897, XIX.

${ }^{3}$ GroussaC 1897, 96-97.
} 


\section{5. El Congreso de 1892}

Entre el 31 de octubre y el 10 de noviembre de 1892, en Madrid, convocado por la Asociación de Escritores y Artistas Españoles, se celebra un Congreso Literario que, aunque el 98 por ciento de sus miembros eran españoles, declama ser «hispanoamericano». Se conmemoraba el cuarto centenario del descubrimiento de América y la preocupación central era «sentar las bases de una gran confederación literaria, formada por todos los pueblos que aquende y allende los mares hablan castellano, para mantener, uno e incólume, como elemento de progreso y vínculo de fraternidad, su patrimonial idioma». El tema, entonces, es la unidad del «patrimonial idioma».

A partir de lo que se desprende de las treinta y una resoluciones referidas al idioma que publica el Congreso, se evidencia una fe, irrestricta y quizá muy elevada, en que España - y en especial la Real Academia - debe, casi por derecho natural, regir los destinos de esa unidad idiomática. Las resoluciones más curiosas — curiosas si no nos olvidamos que el Congreso era «hispanoamericano»- son la 14, 15, 16 y 17, donde se establece a dicha corporación, y a las instituciones por ella apadrinadas, la autoridad máxima en materia de lengua, y se invita, además, a defender la unidad idiomática a partir de un respeto universal a una única reglamentación gramatical (dictada, naturalmente, por la Real Academia). La resolución vigésima postula imprescindible para todos los pueblos de habla castellana un léxico común; pero más adelante advierte que el vocabulario de los americanos corrientes en el nuevo mundo «...se inserte, no en el cuerpo del diccionario de la Academia Española, sino por vía de apéndice...». De modo que el Congreso fue, cuanto menos, descortés, pues invita a América a almorzar en su histórico palacio, pero prefiere por el momento que lo haga en algún cuarto aledaño y menos iluminado.

Ernesto Quesada, que reproducirá las resoluciones en El problema del idioma nacional, y siendo él un miembro y, por momentos, ferviente defensor de la Academia, advierte cierta prepotencia española, por lo que lamenta que el Congreso haya estado impregnado del Alas Clarín que lanzó, alguna vez: «los españoles somos los amos del idioma». Si en Argentina se dio una enorme relevancia a la cuestión separatista en torno a la lengua, sugiere Quesada, España también es responsable. Al comentario de estas resoluciones, agrega:

${ }^{1}$ ASOCIACIÓN DE ESCRITORES y ARTISTAS ESPAÑOLES 1892, 1. 
[...] la Academia Española parece creer que basta enviar diplomas de individuos correspondientes, y enseguida olvidar a estos, pues ni mantiene relación con ellos, ni vínculo alguno, ni les envía siquiera sus publicaciones, de modo que parece considerarlos como simple elemento decorativo para dar a la corporación un ligero barniz de que no es exclusivamente española, sino que lo es, a la vez, americana. ${ }^{1}$

${ }^{1}$ Quesada E. 1900, 64. 


\section{CONTRA EL PURISMO: DE LENZ A CUERVO}

$(1893-1900)$

\section{1. La advertencia de Rodolfo Lenz}

A principios de 1890, y con solo 27 años de edad, llega a Chile el fonetista, filólogo y folclorista alemán Rodolfo Lenz. Junto con otros profesores germanos había sido convocado por el gobierno de Balmaceda para ejercer en el Instituto Pedagógico de la Universidad de Chile. Desde entonces comienza a estudiar casi todos los fenómenos del lenguaje en su nuevo país, aunque desde una perspectiva algo inédita en la región. El mismo año que se celebra en Madrid el Congreso Literario, compone en Santiago de Chile un interesante artículo sobre nacionalidad y lenguaje que será publicado al año siguiente, 1893, en Buenos Aires, y que es oportuno mencionar.

Es probable que Lenz conociera la conferencia de Ernest Renan sobre la nación (1882), porque parte de un modelo argumental parecido: demuestra que ningún elemento —ni la lengua, ni el gobierno, ni la religión — puede constituir por sí solo una nación.

La lengua, que en Europa es una de las características más determinantes de la nacionalidad, no lo es de ninguna manera en América, donde no menos de quince naciones hablan la misma lengua castellana. ${ }^{1}$

¿Qué elemento, por tanto, se presenta como absolutamente necesario para la constitución de una nación? Lenz responde que ese elemento no es más que «la conciencia de un individuo de pertenecer a una nación». Esta conciencia genera un sentimiento de pertenencia, una comunidad de identidad, sin la cual las naciones no son posibles. La nación, dirá al final, es más bien una voluntad política.

Estas aclaraciones liminares le sirven para pensar el vínculo entre lengua y nación, pues intenta desbaratar la idea de que cada nación requiere de una lengua propia. Las naciones, para Lenz, se forman y mutan ajenas al movimiento de las lenguas, o cuanto menos ajenas a un movimiento lineal. También le sirven estas aclaraciones para reflexionar sobre la distinción entre las naciones euro-

${ }^{1}$ LENZ 1893, 36. 
peas y las americanas, pues no cree que lo que sucedió con las lenguas en Europa vaya a suceder necesariamente en América.

Durante la Conquista, según el planteo de Lenz, el castellano que se introduce en América es una lengua muy formada, pero no completamente definida y acabada; de modo que, con cada nueva expedición europea, la lengua castellana se fue mezclando, y sus formas clásicas, literarias, fueron confundiéndose con las dialectales. Aunque el castellano, una vez en América, se haya impregnado también de voces indígenas - he aquí una de los aspectos más relevante en la tesis lenziana - no se ha formado en ninguna parte una lengua nueva producto de esa fusión. Distinto fue el proceso lingüístico en Europa, donde el arribo del latín a distintas regiones ha formado, con el tiempo, el castellano, el francés, el italiano.

Pero este análisis, que abona la tesis unificacionista del castellano en América, tiene ciertas salvedades: Lenz advierte que «hay ligeros principios» para pensar una futura dialectización, sobre todo en países como Argentina y Chile, donde el lenguaje vulgar se aleja progresivamente del castellano.

Se puede presumir que, dejadas sin instrucción pública estas regiones, y sin la influencia continua de la lengua literaria ya formada y usada constantemente por los instruidos, en algunos siglos se desarrollarían nuevas lenguas que estarían con el castellano en la misma relación en que este está con el latín. ${ }^{1}$

Que no haya sucedido aún tal cosa se debe, continúa diciendo Lenz, al vínculo ininterrumpido que la América hispana mantiene con España y Europa. Para que América viva un proceso de desmembramiento lingüístico similar al que vivió Europa, precisaría una invasión similar a la de los bárbaros; precisaría, por ejemplo, que las distintas culturas indígenas buscaran sobreponerse a la cultura hispánica, hecho cada vez más remoto. De modo que Lenz imagina las condiciones que deberían darse para que en América se formen nuevas lenguas, pero no anuncia la indefectible babelización del continente.

Unos Ensayos filológicos americanos publicados en Chile, al año próximo, 1894, aclaran bastante su posición. Lenz vuelve sobre la diferencia del proceso del latín en Europa y del español en América, pero ahora limita casi hasta extinguir la remota posibilidad de que se formen lenguas nuevas en el nuevo continente: «según todas las probabilidades, la lengua castellana nunca se disolverá en tantos

${ }^{1}$ LENZ 1893, 39. 
diferentes idiomas ni morirá en América, como, según se cree comúnmente, murió su vieja madre latina en Europa» ${ }^{1}$.

Muchos de sus coetáneos han cuestionado a Lenz por ver en sus estudios del folclore y del lenguaje vulgar chileno una abierta defensa de las formas dialectales. Ernesto Quesada llegó a decir que «Lenz es el Abeille chileno: el idioma nacional de los argentinos de este se convierte en el idioma patrio en Chile de aquel» ${ }^{2}$. Lenz se hace eco de estas acusaciones y pide ser juzgado como un lingüista, no como un maestro de escuela; diferencia muy bien la lengua culta de la vulgar; no duda que la culta es la lengua literaria, la que aspira y alcanza a menudo el ideal casticista; pero no es esa lengua la que le interesa, sino la que habla el bajo pueblo chileno, «el lenguaje de los huasos». Ambas lenguas, que así las llama, son formas distintas de un mismo idioma: el castellano. De haber creído que en Chile se estaba formando un nuevo idioma, de seguro hubiera estudiado sus peculiaridades sin agregar demasiados comentarios acerca de su moralidad.

Rodolfo Lenz es un avanzado en cuanto a estudios filológicos y lingüísticos en la región. Su resolución de los problemas no pretende ser polémica, sino empírica. Que un vocablo sea más o menos castizo le importa menos que la historia de su variación fonética. No se siente un jardinero, que retira la maleza para dar más espacio a las rosas, sino un botánico, que recoge con igual interés todo lo que tenga vida. De aquí que en sus ensayos invierta tiempo en diferenciar la actividad del preceptista literario del científico. Para Lenz son dos cosas absolutamente distintas trabajar en pos de hacer más culta una lengua que recoger todo lo vulgar que hay en ella. Su preferencia por estas formas vulgares de la lengua remite a que encuentra allí muchas más marcas regionales que en la lengua culta, tendiente a indiferenciarse en un castellano unificado por las letras.

Unos años más tarde, en 1899, en Santiago, publica un trabajo de carácter pedagógico, donde parece responder a quienes le recelan:

Los que desprecian los dialectos populares parten de una base enteramente falsa, creyendo que el lenguaje del pueblo bajo es una corrupción de la lengua literaria; ignoran que los dialectos son la forma primitiva y natural del idioma $[. . .]^{3}$

\footnotetext{
${ }^{1}$ LENZ 1894, 2-3.

${ }^{2}$ QuesadA E. 1902, 114.

${ }^{3}$ LENZ 1899.
} 
De haberse pronunciado sobre la querella de la lengua en Argentina, hubiera sido Rodolfo Lenz - y no Abeille, como sugeriré más adelante - el que inaugura una nueva etapa en la contienda; no porque él creyera en una próxima disgregación del castellano en América, sino porque ya razona con las nuevas concepciones lingüísticas, que aún no cuentan con un Saussure, pero ya disponen de un Franz Bopp, un Max Müller, un August Schleicher.

\section{2. El sobrecastellano de Unamuno}

Por estos años, algunos acontecimientos políticos dotan a la querella de un dramatismo que excede los problemas idiomáticos. En 1898 España pierde las últimas colonias que conservaba en América, dando lugar a que se inicie un proceso de revisión crítica de toda la cultura española, a uno y otro lado del Atlántico. Miguel de Unamuno es uno de los hombres que acogerá esta revisión y uno de los primeros españoles que, sintiendo el influjo de Sarmiento, ofrecerá una nueva interpretación sobre él y sobre la cuestión de la lengua en Argentina. Donde otros ven en el cuyano únicamente antiespañolismo y cerrazón, Unamuno ve anhelo de una nueva España, solo que este anhelo aparece bajo las formas del brío colérico. Larra, Sarmiento y Unamuno constituyen una tríada íntima, cuya veta española se deduce del recelo a algo íntimamente español: el purismo. Si hemos de conceder a Bartrina aquello de que «si habla mal de España, es español», la propensión a discutir en torno a un posible idioma argentino es, en parte, una preocupación de temperamento español.

En una serie de notas publicadas a fines del año 1899 en El Sol, de Buenos Aires, Unamuno embiste contra este purismo casticista y enuncia su clamor: «hay que hacer el español internacional con el castellano, y si este ofreciese resistencia, sobre él, sin él o contra él». Se trata de un clamor, a la vez, algo dramático, pues, siendo Unamuno vasco, postula la necesidad de que el vascuence muera en el castellano, para sobrevivir a través de él, del mismo modo que debía morir y sobrevivir el idioma nacional argentino. Estas muertes necesarias, sin embargo, debían suceder a condición de incidir en esa lengua mayor. La concesión de ser en otro debía hacerse para forjar un otro más vasto, un otro que deje de ser enteramente otro.

\footnotetext{
${ }^{1}$ UNAMUNO 1899a.
} 
El futuro lenguaje español no puede ni debe ser tan solo una expansión del castizo castellano, sino una integración de hablas regionales y nacionales diferenciadas sobre la base del castellano, respetando la índole de este, o sin respetarla, si viene al caso. ${ }^{1}$

Unamuno piensa en el latín a la hora de imaginar el destino del español castizo, pues cree que su muerte es solo aparente; el latín subsiste, enriquecido y diversificado en las lenguas romances. El énfasis autonomista de los americanos no se representa, en Unamuno, como una mera irreverencia, sino como un intento de poner en concordia la lengua de un pueblo con las ideas que en él se abren paso:

Hacen muy bien los hispano-americanos que reivindican los fueros de sus hablas y sostienen sus neologismos, y hacen bien los que en la Argentina hablan de lengua nacional. Mientras no internacionalicemos el viejo castellano, haciéndolo español, no podemos vituperarles los hispano-españoles y menos aun podrán hacerlo los hispano-castellanos. ${ }^{2}$

Unamuno pide para América, lo mismo que para España: imbuirse de Europa. Europeizar la lengua. De modo que todo tipo de casticismo le parecerá una broma anacrónica.

\section{3. Ernesto Quesada y El problema del idioma nacional}

A fines de este mismo año (1899), en Buenos Aires, la Revista Nacional publica, de Ernesto Quesada, la primera entrega de «El problema de la lengua en la América española», una serie que luego aparecerá en un solo volumen bajo el nombre de El problema del idioma nacional. Ernesto Quesada, hijo del ya mencionado Vicente y miembro correspondiente, a la sazón, de la Real Academia Española, señala aquí, ante todo, el profundo disgusto que le provocaron las tesis de Juan María Gutiérrez y se separa de ellas. Mientras que Quesada sintió el calor maternal de la Península; Gutiérrez, el fuego de sus cañones; uno cree que mantener lazos de cariño con ese tronco común no menoscaba la independencia; el otro percibe que esos lazos ofenden el legado de Mayo. En el lema académico fijar,

\footnotetext{
${ }^{1}$ UNAMUNO 1899a.

${ }^{2}$ UNAMUNO 1899a.

${ }^{3}$ QuESADA E. 1900.
} 
Gutiérrez leyó detener, Quesada, en cambio, entendió que allí se decía precisar lo verdadero, lo conveniente para la lengua.

Conociendo muy bien la discusión en torno al idioma nacional, Quesada acomete con premura lo que cree se trata de lo neurálgico: las tesis de Gutiérrez. No logra entender cómo, siendo este un eximio escritor en lengua española, haya promovido una lengua barbárica y corrupta. De modo que Quesada percibe: por un lado, que Gutiérrez es el padre espiritual de un idioma argentino ligado a lo abigarrado y mal cosido; por otro, que es progenitor de los que enarbolarán la causa separatista. Si concedemos que Gutiérrez advirtió, únicamente, los riesgos de tomar el legado español sin ningún reparo, no está tan lejos de las advertencias de Quesada. Las mismas españoladas que este reprocha al Congreso Literario de 1892, son las que encuentra Gutiérrez en su nombramiento como correspondiente. Luego de leer los postulados de Quesada sobre la lengua, uno podría concluir que, quizá, la única diferencia entre estos dos hombres es que uno pertenece al siglo XIX y el otro al siglo $\mathrm{XX}$; es decir, que uno aún siente que se está librando la guerra de la independencia y el otro, en cambio, el proceso de reencuentro con la Madre Patria.

Quesada intenta explicar la renuncia de Gutiérrez al Diploma sospechando razones personales, no de envergadura conceptual que fue la misma explicación que había adoptado Juan Martínez Villergas-: aduce que Gutiérrez se comportó como un loco. Pero Quesada no escribe entre comillas idioma nacional, pues entiende que este se trata, naturalmente, de un español castizo al que simplemente adjuntaría ciertos americanismos. Lo único que Quesada objeta a la Real Academia (a España en general) es su demora para considerar que América, la América culta y literaria, ya es fundamental en el desarrollo del castellano.

Hay aun dos aspectos más que deben destacarse en este estudio: por un lado, Quesada cree que la amenaza al idioma nacional no es la gauchesca ni ninguna otra forma de criollismo, sino al avance del inglés; por otro, y este aspecto es además su tesis, asevera que el idioma nacional, ese que tanto se discute, no es ni debe ser más que el que empuñan los hablistas cultos y escriben los escritores autorizados. 


\section{4. La carta de Eduardo Wilde}

Entre los lectores del trabajo de Quesada se encuentra el escritor y ministro argentino plenipotenciario en los Estados Unidos, Eduardo Wilde, que le remite en diciembre de 1900, desde Washington, una extensa carta, donde le concede la idea de que el español nacional sea el bien hablado, aunque difiere en lo se entiende por hablar bien. Para Wilde, idioma bien bablado es

[...] hablado como lo habla la jente culta en España, en América i en cualquier otro país cuyo idioma sea el castellano o español; en España con los modismo españoles, en América con los americanismos i en Filipinas con los propios del país, porque en cada parte será el uso hablar así y el uso es la lei. ${ }^{1}$

La ortografía de la carta comulga con lo que Wilde quiere decir, pues, no interesándole mayormente discutir con Quesada, busca auspiciar una reforma ortográfica y esmerarse en demostrar que la gramática española, tal cual está, es caprichosa, compleja y contradictoria. Cito solo una de las tantas quejas que amontona para justificarse: «No veo por qué no debiéramos decir yo tení, en lugar de yo tuve... ${ }^{2}$. La irregularidad de los verbos le parece viciosa, enfermiza y anormal. Luego, cree refutar a Quesada enumerando los moretones de la Academia Española, de Bello y de otros que colman su escritorio. Parecería que la carta busca convertir a las gramáticas existentes en bufones del idioma.

En lo que respecta a su reforma ortográfica, Wilde toma los principios fonetistas, solo que los presenta como si fueran una revelación original que le vino mientras se mataba de risa, en la cancillería, escribiendo a Buenos Aires, en contra de los que hacen ilógico el idioma. Lo que en un Bello o en un Sarmiento adquiere la forma de un tratado caviloso y convincente, en Wilde adquiere la forma de carnaval de pronombres, adverbios e interjecciones. De modo que, si el propósito de Wilde excede los límites de una epístola, carece, a la vez, de la envergadura suficiente como para constituirse en un programa de reforma gramatical. Con el mismo énfasis que defiende la polivalencia de nuestro recién, condena la del verbo precisar; acepta la expresión desde luego, pero repudia desde ya; da de azotes al que, por hallarlo un saltimbanqui; con el ánimo de festival que llama a simplificar la ortografía, insta a multiplicar las formas del posesivo

\footnotetext{
${ }^{1}$ WiLDE 1904, 106.

${ }^{2}$ WILDE 1904, 114.
} 
su, a quien llama bailarín, comodín y cortesana. En fin, pide amparo para los usos regionales del español, al mismo tiempo que exhorta a unificar y convertir en ciencia exacta la gramática que lo rija. Quesada advierte que la carta, aunque tramada en un ambiente protocolar, procura la humorada y a menudo la hipérbole. No la responde.

\section{5. Polémica entre Cuervo y Valera. Primera parte}

Pero este año, 1899, aun dispone de un hecho no menos relevante en la querella, y si se ha de juzgar por la serie de réplicas que genera, es sin duda el hecho más importante del año. El poeta argentino Francisco Soto y Calvo invitó a su casa al filólogo y lingüista colombiano Rufino José Cuervo, a quien le leyó, entre el agasajo y la conversación, su flamante Nastasio, una veintena de miles de versos que perfilan, sobre el escenario de la pampa, el drama de un gaucho payador al que, tras una vida dichosa, siguió la desgracia de perder su hogar, su mujer y sus hijos. Cuervo sintió, entre la emoción que le producía oír esos versos, algo de nostalgia por lo que ellos le revelaban sobre el futuro de la lengua en América. Esos versos, para entenderse cabalmente, debían leerse con el auxilio de un glosario criollista, que el mismo Soto y Calvo anexaría al final. De modo que Cuervo ve confirmadas ciertas intuiciones que últimamente venían asediándolo: el idioma español, en América, se terminará separando del español peninsular. La escucha del Nastasio fue, para el célebre colombiano, como despedirse definitivamente de aquella esperanza de ver unida a la lengua que estimaba como una de «las mayores glorias que ha visto el mundo...»

En la misma casa de Soto y Calvo, Cuervo le escribe una carta para expresarle la emoción que le causó su poema. En esas líneas, acaso sin prever la enorme repercusión que tendría, bosqueja una impresión que, al anexarse la carta como prólogo a la edición de Nastasio (Chartres, 1899), será el umbral de otra polémica. Cuando los pueblos americanos, escribe allí Cuervo, se hallaban aún en el regazo de España, esta los dotaba de los bienes culturales y el vínculo con ella era íntimo y natural; luego vino la emancipación; luego, al imbuirse cada nación en sus asuntos e ignorar los ajenos, incluidos los de España:

La influencia de la que fue metrópoli va debilitándose cada día, y fuera de cuatro o cinco autores cuyas obras leemos con gusto y

\footnotetext{
${ }^{1}$ Cuervo 1899, X.
} 
provecho, nuestra vida intelectual se deriva de otras fuentes, y carecemos pues, casi por completo, de un regulador que garantice la antigua uniformidad. ${ }^{1}$

Cuervo siente que el protectorado casticista por el que tanto había bregado ya no puede evitar que cada americano se apropie de lo extraño y extranjero como mejor le parezca. La idiosincrasia y el paisaje americanos, y las propias lenguas autóctonas horadan la pureza de la lengua al punto de precisarse glosarios, si es que se ha de expresar lo más íntimo, lo familiar y local.

Estamos pues en vísperas (que en la vida de los pueblos pueden ser bien largas) de quedar separados, como lo quedaron las hijas del Imperio Romano: hora solemne y de honda melancolía en que se deshace una de las mayores glorias que ha visto el mundo, y que nos obliga a sentir con el poeta: ¿Quién no sigue con amor al sol que se oculta?2

Cuervo no se siente solo al plantear la tesis segregacionista; lo respalda, desde Alemania, el lingüista Friedrich August Pott, quien había defendido esos presagios y sostuvo, con Cuervo, cierta corespondencia al respecto ${ }^{3}$. También está al tanto de las opiniones segregacionistas del gramático francés Louis Duvau, quien alienta desde París a su compatriota Lucien Abeille, instalado en el Río de la Plata y a punto de editar un extenso volumen destinado a probar que el idioma en Argentina se encontraba en vísperas de constituirse en una lengua nueva. Duvau y Abeille sostienen y anhela la secesión; Cuervo, en cambio, la cree irremediable y la lamenta: «hora solemne y de honda melancolía...» El aporte de Cuervo al programa unificacionista de la lengua hispana no había sido menor. Sus Notas (1874) a la Gramática de Bello, ni bien publicadas, se constituyeron en parte inseparable de esta y, hoy día, se leen como una única y misma obra, fruto de una misma inspiración y propósito.

Al publicarse en Francia el Nastasio, Francisco Soto y Calvo, como mencioné, adjunta la carta de Cuervo como prólogo. Las predicciones se hacen públicas y Juan Valera, aquel Valera del «Discurso de recepción», se atreve a replicarlas. El 24 de septiembre de 1900, Los lunes de El Imparcial, de Madrid, publica «Sobre la duración del habla castellana», donde asevera que Cuervo, al que juzga como

${ }^{1}$ Cuervo 1899, IX.

${ }^{2}$ Cuervo 1899, X.

${ }^{3}$ Cfr. Göttingische gelehrte Anzeigen de 24 de octubre de 1877; que es la referencia que dará el mismo Cuervo más tarde. 
el más «profundo conocedor de la lengua castellana» decidió, a deshora, largarse a divagar como un Jeremías, pronosticando «siniestros relámpagos, terribles avisos y ominosas señales» ${ }^{1}$. Valera no cree que España se haya desprendido realmente de sus colonias americanas: «por el habla, por las creencias y por las costumbres, la gente de allí [de América] seguirá siendo española antes de ser americana» ${ }^{2}$. Al leer el Nastasio, además, no halló un escrito testigo de la americanización de la lengua, sino una obra escrita en castellano «muy puro». No logra, entonces, entender el pronóstico de Cuervo, por lo que intenta disculparlo: «Quizás exprese D. Rufino J. Cuervo, pues ya se entiende que este es el autor de la carta, no ya una convicción, sino el temor, propio de quien mucho ama, de que aquello que ama desaparezca o muera» ${ }^{3}$.

Pero Cuervo no es un hombre senil o un advenedizo al que se lo pueda recusar por hipocondría. Valera lo sabe, por eso intentará darle batalla también en el terreno que aquel mejor conoce: el lingüístico. Las condiciones que generaron en Europa las lenguas neolatinas —esta es la réplica de Valera- no son las que existen en América, que no padece invasiones de pueblos de distintas razas, ni en su seno se fundan naciones de distintas lenguas, ni encuentra a su estirpe española despertando de un eclipse que demoró siglos.

El que haya cierto número de palabras propias de cada país para significar especiales y locales usos, costumbres, producciones naturales, trajes, etc., no basta para explicar que vengan a nacer distintas lenguas. ${ }^{4}$

Cuervo lee atentamente estas objeciones y se pone a elaborar una respuesta más extensa y filológica. Demorará en responder. Mientras tanto, el 2 de diciembre, en La Nación, Juan Valera vuelve a referirse al Nastasio y a la carta que le sirve de prólogo. Las opiniones son las mismas: «Absurdo es imaginar y esperar que, no bien desechamos el castellano, se renueve el milagro de la Torre de Babel...»

\footnotetext{
${ }^{1}$ VALera 1900a, 39.

${ }^{2}$ VALERA 1900a, 40.

${ }^{3}$ VALERA 1900a, 41.

${ }^{4}$ VALERA 1900a, 42.

${ }^{5}$ VALERA 1900b, 52.
} 
SEGUNDA PARTE 
I. POLÉMICAS EN TORNO A LAS TESIS SEGREGACIONISTAS DE

ABEILLE Y CUERVO

$(1900-1903)$

\section{1. El Idioma nacional de los argentinos, de Lucien Abeille}

La obra de Lucien Abeille, en 1900, constituye una escisión tal que amerita pensarla como el inicio de un nuevo período. Lucien Abeille fue, como tantos franceses allegados al Río de la Plata, un entusiasta de la argentinidad. Radicado en Buenos Aires desde 1889, poco antes de cumplir treinta años intuyó en su nueva patria el nacimiento de algo que aún no conocía bien, pero que cree poder develar: la expresión local. Profesor de lengua latina en el Colegio Nacional de Buenos Aires, de francés en la Escuela Superior de Guerra y miembro de la Sociedad de Lingüística de París, publica, en 1900, Idioma nacional de los argentinos. El libro, cuya tesis se puede inferir del título, presenta en el Prefacio la siguiente taxonomía:

Cuatro opiniones condensan las teorías diversas que se han creado acerca de la lengua hablada en la República Argentina. Hay los que creen que el idioma nacional es simplemente el castellano; los que afirman que es solo un dialecto; los que sostienen que es una lengua genuinamente argentina; los que velan por el purismo castellano. ${ }^{1}$

Abeille es de la idea de cobijarse en la tercera, a la cual consagra los trece capítulos de su extenso volumen, donde discurre como un lingüista comparatista: el sánscrito, el griego, el latín, el inglés, el alemán; la fonética, la sintaxis, los léxicos, todo le sirve para confluir en la tesis de que en la Argentina se está forjando una nueva raza, de vida intelectual y moral propia, cuyo cariz distintivo es la claridad del pensamiento y la adopción de un idioma nacional que armoniza con él. Si esta nueva raza se sirviera de la lengua que heredó, la castellana, como es insuficiente para la expresión diáfana de su pensamiento, la raza argentina no se desarrollaría plenamente, pues estaría en contradicción su alma y el modo en que ella se expresa. Este idioma, no obstante, por encontrarse aún en gestación, prefiere escribirlo en cursiva.

Abeille toma de Renan la idea de que una nación es un alma, para luego afirmar — tesis que Renan no hubiera acompañado-

${ }^{1}$ ABEILLE 1900, XI. 
que a cada alma patria le corresponde un idioma: «Una nación que carece de idioma es una nación incompleta» ${ }^{1}$. De aquí que su primer capítulo sea una disquisición sobre la vinculación entre «Lenguas y naciones», y cite, luego de Renan, a Humboldt: «...la ley interna de las diferentes lenguas es la consecuencia rigurosa de la diversidad que presenta el genio de las distintas naciones» ${ }^{2}$.

El libro es una empresa vasta y concienzuda, llena de méritos y descubrimientos, pero su idea matriz conlleva el germen de su desgracia. Una enorme cantidad de curiosidades, por lo demás, alienta la suspicacia. Mencionaré solo uno. Durante los siete años que dictó cátedra de francés en el Colegio Nacional, Abeille dice haber constatado varias veces que los alumnos, al traducir al idioma nacional, por ejemplo, la oración «Cet éclat n'a servi qu'a nous», escribían «Este esplendor no ha servido que a nosotros», hecho que lo llevó a deducir lo siguiente:

Al oír estas traducciones me preguntaba si era necesario corregirlas dándoles el giro castellano, o dejarlas pasar favoreciendo así la evolución del argentino. En honor de la verdad, debo afirmar que las he corregido por temor de la evolución demasiado vertiginosa ${ }^{3}$

Este tipo de procedimientos vulnera los logros del libro; Abeille, no obstante, los estima válidos y los agrega como hechos comprobatorios. Pero la mayor curiosidad de la obra tal vez sean los «Trozos» que Abeille selecciona para robustecer su tesis, pues las prosas de Fidel López, Mitre, Irigoyen, Cané, Guido y Spano, Mansilla, Ramos Mejía, Zeballos, Alberdi, Sarmiento..., que selecciona como casos de idioma nacional, no parecen auxiliarlo, sino más bien resistir todo su programa.

Hay algo que Abeille comparte con el germano Lenz, instalado en Chile casi contemporáneamente a la instalación de Abeille en Buenos Aires: ambos articulan la expresión idioma patrio, solo que en Lenz no remite más que a una forma oral y popular del castellano. Antecedentes de Abeille - aunque solo en cuanto a la idea de futuras lenguas en América- podrían ser Pott y Cuervo, pero a este último, si bien no lo escandalizaría la tesis autonomista de Abeille, quizá sí el modo en que la fundamenta. Los dos responderán a sus antagonistas de forma separada, y empleando recursos muy distintos. No hay solidaridad entre ambos; no hay misivas de mutuo res-

\footnotetext{
${ }^{1}$ ABeILLE 1900, 3.

2 ABEILLE 1900, 1.

${ }^{3}$ ABeiLle 1900, 285.
} 
peto; no se sabe, siquiera, si uno ha leído al otro, aunque me atrevo a decir que Cuervo conocía el Idioma... del francés.

La fundamental novedad que reporta Abeille, estimo, no es tanto su tesis cuanto el modo de tratar la cuestión del idioma nacional, pues intenta demostrarlo filológicamente. Nadie hasta el momento había hecho un esfuerzo en este terreno; o al menos nadie lo había hecho de forma tan decidida. Abeille retira la querella del ámbito donde la libraron los románticos y somete al idioma a un examen disciplinar: la lingüística. No habla como escritor, político o abogado; habla como un profesional del lenguaje.

Esta novedad conlleva una gran paradoja para la causa abeilliana, porque todo lo que ella auspiciaba genera la aparición de antagonistas que la desmoronan con sus mismas armas. Hasta 1900, la disputa parecía no ameritar exceder el periódico o el folleto; al irrumpir Abeille, muñido de un aparato científico y una extensión inéditos, genera la propagación de una prosa refutadora que culmina en hombres como Ramón Menéndez Pidal y Amado Alonso. Refutadas, luego, las ideas lingüísticas que sustentaban a Abeille tarea de la que se encargará la nueva escuela filológica-, se desplomarán las conclusiones a las que esas ideas conducían. Es Abeille, paradójicamente, quien comienza la devastación del «idioma nacional de los argentinos». La cuestión de la lengua no deja de ser una querella, solo que ahora comenzará a disponer de un corpus bibliográfico que prescinde de considerarla como una lucha por la expresión y la emancipación cultural. Ese corpus comienza a ser escrito por lingüistas, que en la búsqueda de su propia legitimación piden que sea interpelado desde una inscripción similar en el «campo del saber». La novedad de Abeille, en síntesis, no reside en postular un idioma nacional, sino en confinarlo a una cuestión técnica.

\section{2. Secuaces y primeros antagonistas de Abeille}

Entre los que se alistan explícitamente en defensa de la tesis de Abeille, se encuentra, en primer lugar, el doctor Louis Duvau, profesor y director de Gramática Comparada en la Escuela Práctica de Altos Estudios de París, quien le envía a Abeille una carta, fechada en octubre de 1899, saludando la pronta aparición del libro y manifestando estar en todo de acuerdo con las premisas lingüística que lo guían. Abeille a incorpora, luego, como introducción a su libro ${ }^{1}$.

\footnotetext{
${ }^{1}$ Duvau 1899.
} 
Luego saluda la tesis el ex presidente de la República, Carlos Pellegrini, a quien Abeille había dedicado el libro y citado, profusamente, como ejemplo de prosas escritas en idioma nacional de los argentinos. Carlos Olivera, después, elogiará a Abeille en Tribuna ${ }^{1}$, y se entusiasmará con la idea de ligar cada nación a una lengua privativa. Para él, como para Abeille, hay tantas lenguas como naciones. Tal es así que, en esos años, comenzó a circular la burla de que los latinoamericanos podían hablar más de veinte lenguas: el argentino, el uruguayo, el colombiano, el chileno, etc.: la tesis de soldar nación y lengua se tomó a la chacota. La dirección editorial de Tribuna, en manos de Mariano de Vedia, no censura la nota de Olivera, pero la impugna:

Aunque la naturaleza del asunto y la firma autorizada del artículo que va a leerse - firma que por otra parte es de la casa- harían innecesaria toda salvedad, cierta pasión por el tema nos obliga a decir que no estamos de acuerdo con nuestro distinguido compañero de tareas, Sr. Olivera, y que consideramos literariamente malsano e inconducente a sus fines científicos el libro del Dr. Abeille, anticipando esta nota a nuestro propio juicio sobre la obra en cuestión. ${ }^{2}$

También saludan la empresa de Abeille, dos años más tarde, un tal Ramón C. Linares ${ }^{3}$ y, desde las páginas de Caras y Caretas, Carlos Correa Luna, aunque este adopta el tono festivo:

Los gauchos son nuestros padres muy honraos, y el día que yo le oyera decir a un hijo mío que le gustaba el ZapaLLo, ó saliera á cabrestiarle á la pronunCiaCión, me lo acostaba de un bife y lo sacaba'é la escuela, comprendés?... Cada cual en su lái, hermano. Este tano habla en cocoliche porque no ha nacido en la casa'é gobierno, y yo hablo en crioyo porque soy crioyo, y los españoles en castiya porque pá eso los largaron en su tierra... Pero que me vengás vos, que ti has criao entre los ranchos comiendo choclos asaos y manejando el fiyingo, á hablarme'é la madre patria en tono'é lamentación... no siás sonso! Envainá el purismo, ché, como dicen en tu jujao, y dejám'e pistolerías $[. . .]^{4}$

\footnotetext{
${ }^{1}$ Olivera 1900.

${ }^{2}$ VEDIA 1900.

${ }^{3}$ LiNARES 1902.

${ }^{4}$ Correa LunA 1902.
} 
Nombro estas bienvenidas porque son enumerables. No lo son en cambio las diatribas, que se alistan contra Abeille con distintos tenores. En París, el hispanista francés Alfred Morel Fatio reseña el libro en Romania sin callar que encuentra equivocada la tesis principal, pues el divorcio que Abeille afirma entre Argentina y España no se puede constatar en la lengua: «toutes les alteraciones fonéticas argentinas se retrouvent par exemple dans l'espagnol du centre et du midi de l'Espagne» ${ }^{1}$. Ernesto Quesada, algo más enojado, reedita en un solo volumen sus entregas periódicas sobre «El problema de la lengua en la América española», ahora bajo el nombre El problema del idioma nacional, y agrega un proemio destinado a Abeille, al que acusa de francófilo: «Esta es sin duda la razón por la cual ese libro parece pensado y escrito en francés, y traducido al castellano con un descuido y abandono que pasman $»^{2}$. Pero me referiré a estos embates más en detalle a continuación.

\section{3. Groussac y Cané: la teoría del reencauzamiento}

Es casi una regla que los refutadores de Abeille ignoren el contenido de su libro o cuanto menos su nombre de pila exacto. Quizá no sea el caso de Paul Groussac, quien no obstante, en oportunidad de refutar en un artículo la autoctonía de ciertos americanismos, castiga a Abeille con el desprecio: «No merece mención una rapsodia reciente, en que la ignorancia absoluta del asunto (comenzando por el castellano) toma la forma de una baja adulación al criollismo argentino» ${ }^{3}$. Pero el artículo no agota en esta nota al pie lo que tiene para decir con respecto a la querella; luego de discurrir sobre ciertas etimologías, Groussac ensaya dos tesis en torno a ella: una intenta desbaratar, en favor de la conveniencia de persistir en el castellano, la idea de un idioma nacional; la otra, reencauzar a los románticos en la senda del casticismo.

La herencia atávica de España —afirma, para esgrimir la primera tesis- es un hecho indestructible. Negar este pasado histórico sería tomar los vicios del legado, no sus virtudes. Y la fidelidad a este legado español clama velar por la subsistencia del idioma español en América. «La herencia que aconsejo a los argentinos conservar con respeto religioso es la de la lengua, que es la tradición viva

\footnotetext{
${ }^{1}$ MOREL-FATIO 1900, 486.

${ }^{2}$ Quesada E. 1900, V.

${ }^{3}$ Groussac 1900, 387.
} 
de la raza...» ${ }^{1}$ Groussac confiesa, luego, haber sido el narrador de la circular del ministro Juan Carballido (1891), por pedido exclusivo de este; de modo que, al encontrar oportuno citarlo, buscando el respaldo de una autoridad, se cita a sí mismo, y el pasaje que elige reescribir es aquel que exhorta a renunciar a la vana pretensión de una lengua propia y aceptar, por el contrario, el beneficio de una lengua común a todo el continente.

Este Groussac de 1900 no niega que el castellano ha sido un instrumento más admirable en tiempos de Luis de León y Cervantes, pero lo halla ahora inhábil para interpretar la civilización contemporánea. «Admitamos que quede como instrumento perfecto para expresar las ideas de un pueblo que, desde entonces, no las tiene originales ni fecundas en ciencia, en filosofía ni en arte, caminando hace dos siglos a remolque de los que inventan y producen.» ${ }^{2}$ No obstante, y aunque anticuada, afirma que es la única lengua en Latino América, junto con la portuguesa, y aunque lamenta el estado entumecido del español, descree de la superioridad de una lengua autóctona: «¿Se rechazará la carabela en nombre de la jangada? $)^{3}$

Si bien algunos años antes había creído ver en Tucumán la formación de una nueva raza argentina, notable por la diferencia que su castellano manifestaba en relación al peninsular'; ahora Groussac desestima estas variaciones y menos aun las anhela:

No existe tal «dioma argentino» en formación; ni tendría importancia, aunque fuera más original y completo, cualquier patuá rústico que aquí coexistiese con la lengua culta, como ocurre en todas las provincias de Europa. Si tiene, al contrario, un rasgo evidente y plausible nuestra presente producción o reproducción literaria, es el de un esfuerzo hacia la propiedad del lenguaje - es decir, hacia el español castizo. El «gauchismo», antes celebrado y hoy anticuado y cursi, va desapareciendo con el gaucho. ${ }^{5}$

La segunda tesis, dicha un poco al pasar, sentará las bases para revisar el pensamiento idiomático de los románticos. Se trata del intento por librar a los prohombres de la patria de la paternidad autoctonista del idioma. Groussac estima que, al invocar el respaldo de un Sarmiento o un Gutiérrez para el propósito separatista, se ha

\footnotetext{
${ }^{1}$ GroussaC 1900, 413.

${ }^{2}$ Groussac 1900, 414.

${ }^{3}$ Groussac 1900, 414.

${ }^{4}$ Groussac 1882, 128-132.

${ }^{5}$ Groussac 1900, 414.
} 
confundido el estilo con el sentimiento; pues aquellos hombres, adversos a la influencia española, no habrían extendido la antipatía al idioma español. En Gutiérrez es evidente con solo leerlo; en Sarmiento, «si es harto visible que no dominaba la lengua, no lo es menos que jamás la ofendió deliberadamente» ${ }^{1}$.

También Miguel Cané, el mismo año, aboga por desligar a Juan María Gutiérrez de la genealogía que lo tendría como fundador principal del Idioma Nacional:

La acción del Doctor Gutiérrez ha sido generalmente mal entendi$\mathrm{da}$; gentes hay que piensan, de buena fe, que sus preceptos llegaban hasta sancionar los barbarismos y galicismos de que nuestro lenguaje escrito y hablado rebosa, y que los argentinos debíamos regirnos por la gramática del vení, vos y tomá. Nada más lejos de su pensamiento $[\ldots]^{2}$

Luego advierte sobre la conveniencia de que la lengua persista inmutable en su estructura esencial; y recusa a Abeille por su condición gentilicia: «Paréceme que si el Sr. Abeille, a más de tener todo el cariño que muestra por nuestra tierra, y que creemos sincero, fuera hijo de ella, sentiría en el alma algo instintivo que le enderezaría el razonamiento en esta materia» ${ }^{3}$. Previamente, habiendo percibido localismo en el rótulo «Curso de Idioma Nacional», estampado por los programas oficiales de la lengua castellana, Cané se pregunta si ello llevará — también por ímpetu independentista - a nacionalizar el catolicismo y las matemáticas.

\section{4. La antinomia de Abeille y el idioma patrio de González}

En noviembre de 1900, en el Círculo Militar de Buenos Aires, Abeille brinda una conferencia homónima de su libro, Idioma nacional de los argentinos, pero le agrega un subtítulo: Antinomia lingüistica insoluble. Se dispone a hablarles, ahora, a aquellos que creen que se debe conservar puro el castellano en Argentina y suplican al Diccionario, a la vez, que haga un lugarcito a las voces y giros especiales del país. Les habla como si fueran el último bastión que se resiste al evidente triunfo de su tesis autonomista. ¡Ríndanse!, los exhorta, pues cree que la Academia jamás aceptará que voces que no sean españolas,

\footnotetext{
${ }^{1}$ Groussac 1900, 415.

${ }^{2}$ CANÉ 1900, 63.

${ }^{3}$ CANÉ 1900, 70.
} 
como poroto, choclo, chancho, gaucho, laucha, yacaré, sean consideradas nuevos integrantes de la lengua.

Y está bien que no los reconozca, agrega, porque no son voces españolas; las voces argentinas deben registrarse en un diccionario argentino, para lo cual debe aceptarse definitivamente la existencia de una lengua argentina. El idioma español es un gran monumento que se encuentra absolutamente concluido: no hay lugar en él para las novedades que se producen del otro lado del Atlántico. Esta es la tesis de Abeille, que vuelve a desplegarse en esta conferencia.

Solicitar de la Academia la carta de ciudadanía para las palabras y las locuciones argentinas es pedir lo imposible. La Academia no puede colocar estos vocablos y estas expresiones sino en el Apéndice de su Diccionario, así como se clavan las monedas falsas, en los mostradores de los bancos, para ilustrar al público a fin de que se precava. Para la Academia estos vocablos y estas locuciones son un veneno lingüístico: he ahí porqué los pone al final de su vocabulario: in causa venemum. ${ }^{1}$

De esto se trata la antinomia lingüística insoluble, pues ni la Academia española puede aceptar neologismo de otra lengua, ni la Argentina debe retrasar su evolución nacional y la gestación de su propia lengua.

He mencionado recientemente las réplicas que aparecen el mismo año 1900; Abeille las sigue por la prensa sin que ninguna le haga mella, pero en esta conferencia siente la necesidad de referirse a aquel pasaje en que Miguel Cané conjetura que, de seguirse los argumentos expuestos en Idioma nacional, también podría pedirse un «catolicismo nacional». Abeille toma en serio esa posibilidad y responde que Roma no admite que su doctrina experimente la menor alteración, y el día que esta doctrina sufra la más mínima variación, probablemente se produciría un cisma, y «Roma declararía que la Argentina no pertenece a la comunión católica. Al ejemplo de otras naciones, la Argentina sería entonces cristiana sin ser católica» ${ }^{2}$.

El mismo año 1900, Félix Lajouane edita un libro del político, pedagogo y escritor Joaquín V. González: Patria, cuyas pretensiones se sugieren ya en el título. La patria, para González, es la síntesis, unidad y máxima expresión espiritual que puede alcanzar un pueblo, el lugar hacia donde debe aspirar todo hombre y el ámbito de realización plena de lo humano. Se trata de un libro lleno de defini-

\footnotetext{
${ }^{1}$ Abeille 1901, 14

${ }^{2}$ ABeille 1901, 30.
} 
ciones grandilocuentes, donde el signo de admiración brota entusiasmado y encierra, repentino, los conceptos más rimbombantes.

En este llamado al patriotismo, González consagra un capítulo entero, el quinto, a señalar la relevancia que el idioma nacional tiene dentro del ideal de la patria. Para tal fin, le interesa plantear la cuestión idiomática en el ámbito de la educación y la escuela nacional, pues esta escuela debería basarse en la enseñanza de un idioma patrio, que se llama nacional «porque es el heredado de nuestros progenitores con la raza y la cultura, y forma el fondo del carácter y modalidad del pueblo argentino». Al igual que Abeille, González también habla del pueblo argentino en términos de raza y, en tanto raza, su prenda más vital y palpable es el idioma que la singulariza:

Que existe entre el idioma y la raza un vínculo tan estrecho, hasta el punto de ser difícil separar ambos conceptos, y que es él la forma en que se exteriorizan y evolucionan el espíritu y el carácter del hombre, es indudable. ${ }^{2}$

Pero este «idioma de la raza», advertimos luego, no es sino el castellano, al que encuentra irremplazable, hermoso, puro, vigoroso, etcétera. El llamado a nacionalizar la lengua, en González, es un llamado al casticismo. Se trata, por tanto, de un planteo que encuentra absolutamente relevante el cultivo del idioma castellano, a fin de conocer su naturaleza y potenciar su influencia, porque es allí, en la compresión y expansión del idioma, donde se desenvolvería el espíritu de la nación que lo habla.

La comprensión del idioma nacional a que aspira Joaquín V. González no solo es una forma de comprender la raza, sino de ahondar en su tradición. El idioma se revela, así, como el vínculo más duradero y firme con el pasado. Todo el ideal patriótico, González lo ve disminuirse al desdeñarse o prescindir de la enseñanza y uso del «idioma de la raza». De aquí que crea que el Estado debe ocuparse de las cosas del idioma por medio de la «escuela nacional», cuya misión es enseñar la gramática y las letras en que este idioma se manifiesta.

\footnotetext{
${ }^{1}$ GONZÁLEZ 1900, 58.

${ }^{2}$ GONZÁLEZ 1900, 59.
} 


\section{5. Polémica entre Cuervo y Valera. Segunda parte}

En marzo de 1901, desde Francia y por medio del Bulletin Hispanique, llega la demorada aunque gigantesca contestación de Rufino José Cuervo: «El castellano en América». Aquí Cuervo no siente que Quesada sea su nuevo antagonista, por el contrario, lo cita y elogia lo suficiente como para pensar cierta comunidad de ideas con respecto al futuro del idioma, aunque no la haya. Así como todos temieron a Cuervo, y en su lugar despotricaron contra Abeille; quizá Cuervo, a su vez, temió enfrentarse con Quesada, y prefirió alojarlo amablemente en sus disquisiciones.

En esta nueva intervención de Cuervo, el oponente es Juan Valera, al que cree molesto no tanto por la idea de la futura disgregación del castellano en América, sino por eso de que «fuera de cuatro o cinco autores cuyas obras leemos los americanos con gusto y provecho, nuestras vida intelectual se deriva de otras fuentes» ${ }^{1}$. Son, pues, las dos ideas que Cuervo intentará refrendar.

Comenzando por el estado del castellano en América, a partir de lo cual conjeturará su suerte venidera, Cuervo afirma que las lenguas, por el mero hecho de andar en el tiempo y dejarse influir por los hechos sociales, pueden evolucionar hasta modificarse y convertirse en otras:

De modo que el latín pudo transformarse también sin que hubieran intervenido los grandes trastornos que precedieron al nacimiento de las modernas nacionalidades; y la lengua castellana podrá seguir pasando por alteraciones sucesivas que aun paren en lenguas muy diferentes de la que hoy hablamos, sin que para eso se requiera, como supone el Sr. Valera, cosa parecida a la invasión de los bárbaros o al llamado letargo de la Edad Media, y menos todavía el que la lengua antigua sea sustituida por otra diversa, como si dijéramos el quechua o el chibcha. ${ }^{2}$

Suceden a este párrafo una dilatada y pormenorizada exposición de todas las variantes que atravesó el castellano a lo largo de su historia; que es el intento denodado por evidenciar que las lenguas, por su mero hecho de andar, revisten al cabo de algunos siglos formas notablemente distintas.

Debilitada, agrega Cuervo, la influencia que ejercía la antigua metrópoli para unificar la lengua en sus colonias y constituidas estas

\footnotetext{
${ }^{1}$ Cuervo 1899, IX.

${ }^{2}$ Cuervo 1901, 37.
} 
en naciones autónomas, no queda otra fuente de unidad lingüística que el cultivo de una literatura común, que se presenta en la escuela, se explica y se comenta en las cátedras de humanidades, y se lee y relee por todos con el propósito de mantener una unidad.

¿Bastarán estos medios artificiales, en caso de que lleguen a aplicarse, para conservar la unidad del castellano en América y conjurar los vaticinios funestos de los lingüistas, que dan por seguro sucederá con él lo que con el latín en el Imperio Romano?1

Esto, para Cuervo, es solo cuestión de tiempo, pues aún no ha pasado el necesario para que se evidencie un divorcio tan considerable como el que existe entre las lenguas romances. Aunque el proceso en América diste del europeo y la ruina del español literario se dé de otra forma, el terreno está igualmente dispuesto. La independencia y la inmigración extranjera pueden llegar a tener consecuencias parecidas a las que tuvieron la extensión del cristianismo y las invasiones de los pueblos septentrionales.

En La Tribuna, de México, el 31 de agosto y el 2 de septiembre de 1902, aparece la respuesta de Valera: «Me apesadumbra pensar que algunos espíritus extraviados en la Argentina y en otros puntos de la América del Sur sientan el prurito de inventar y de salir hablando lenguas nuevas» ${ }^{2}$. No lo nombra a Abeille, pero también escribe para él. Valera asume que el pronóstico de Cuervo entusiasmó a muchos hombres de la región. Entiende que hay un auge segregacionista y gente que aún postula que el castellano es lengua de estrechez para contener ideas de envergadura, pero no quiere discutir con nadie más que con Cuervo, al que encuentra «tan maravilloso filólogo, tan profundo conocedor de nuestro idioma» ${ }^{3}$. Valera no duda de la sabiduría de Cuervo, por eso le resulta difícil creer que desconfíe de la vitalidad y duración del habla castellana; pero no sabe si Cuervo teme o espera — «pues no veo claro si le mueve el temor o la esperanza» ${ }^{4}$ - que se descuelguen los hispanoamericanos algún día y terminen hablando nuevos idiomas, divorciándose por completo, no solo de España, sino entre ellos mismos.

Discutir con Cuervo, no obstante, para Valera, es como combatir contra Aquiles (impar congressus Acbilli), y no se hubiera atrevido

${ }^{1}$ Cuervo 1901, 58.

${ }^{2}$ VALERA 1902, 97.

${ }^{3}$ VALERA 1902, 98.

${ }^{4}$ VALERA 1902, 98. 
si su congoja no hubiera sido tan grande como su certeza de que no puede América salir hablando, de golpe, muy distinto de como se habla en España.

Los mismos argumentos que emplea Cuervo, dice Valera, de aplicarse al inglés, conduciría a postular su desaparición en Canadá, en los Estados Unidos, en Australia y en no pocas otras colonias inglesas esparcidas por el mundo.

¿En qué tierra ocupada hoy por ingleses no penetra en la lengua de ellos multitud de vocablos, de giros y de frases, tomadas de lenguas indígenas para significar cosas que allí se crean y se inventan? Tal aluvión de vocablos exóticos, no destruye ni corrompe con todo la lengua inglesa: lo que hace es enriquecer su léxico y añadir acaso algunas nuevas maneras de decir a los ya conocidos y empleados. ${ }^{1}$

El neologismo no es, agrega Valera, indicio para inferir la constitución de nuevas lenguas. Esta refutación, acaso, no sea válida, pues Cuervo no restringe sus observaciones a una mutación léxica, ni ignora que un ramillete de vocablos nuevos es incapaz de escindir una lengua. El filólogo colombiano, nuevamente, suspende de a ratos sus tareas ordinarias y compone una lenta y abrumadora respuesta final, que veremos más adelante.

\section{6. Quesada y el autor de Nastasio: en torno al criollismo}

Con la excusa de impugnar el Nastasio, al que estima como un mero poema localista, Ernesto Quesada embiste contra toda forma de idioma nacional que no sea el castellano o, mejor aun, contra la pretensión de que su versión criollista se erija como tal. Para tal fin, publica, en 1902, «El criollismo en la literatura argentina», donde intenta demostrar que la gauchesca es, ya para principios del siglo $\mathrm{XX}$, una impostura jergal, nada criolla (la cree andaluza) y mortecina.

Propiamente, pues, el género gauchesco, vale decir, el que emplea la fraseología de los gauchos, o sea lo que quiere presentarse como la única manifestación del criollismo en nuestra literatura, ha tenido cuatro representantes populares: Hidalgo, Ascasubi, del Campo y Hernández. Ninguno de ellos, por rara casualidad, fue de origen

\footnotetext{
${ }^{1}$ VALERA 1902, 100.
} 
gaucho ni vivió siquiera su vida en las estancias criollas, salvo Hernández, y eso en parte; fueron todos hijos de las ciudades [...] ${ }^{1}$

Luego remata diciendo que ese genio literario pertenece ya a la historia. El castellano, entendió Quesada, contuvo a esos artificios como excentricidades que entonces (alba del siglo XX) solo podían ofrecer, por arcaicos, el valor del extrañamiento. El cocoliche y el lunfardo, que estima fueron la continuidad cronológica de la gauchesca, le resultan aún más escandalosos, y les teme por su vigencia y auge en las letras argentinas. Pero al final del escrito atenúa su encono contra la gauchesca y reconoce que, aunque jergal, pertenece a los dominios argentinos; dicho esto, Quesada apunta su propia tesis:

Asunto nacional es todo asunto argentino, desde la vida miserable y original de los indios del sur, hasta la existencia suntuosa y casi europea de nuestra élite. En esta gama de diversidades puede ensayarse fácilmente nuestro espíritu, hasta encontrar su tonalidad propia. ${ }^{2}$

Vitorean epistolarmente a Quesada, Miguel Cané (1902), que augura en la educación obligatoria la función de terminar con el flagelo de toda forma de criollismo; y Carlos A. Estrada, que entiende que los esfuerzos deben consagrarse a «enriquecer el habla castellana y no a injertarle los estúpidos modismos de jergas tabernarias, ni el balbuceo semi bárbaro de la ignorancia gauchesca» ${ }^{3}$. El vitoreo sigue, y es la misma revista Estudios, donde Quesada publica, la que se encargará de describirlo y de ampliar la discusión ${ }^{4}$.

Algún tiempo después, Francisco Soto y Calvo, que ya leyó bastante crítica sobre su Nastasio, decide intervenir en la polémica; pero elige como único antagonista a Ernesto Quesada, a cuyo ensayo encuentra erudito y meritorio, y aun así equivocado en su punto central. En primer lugar, y como tesis que guía su réplica, estima que el criollismo no es una fuerza menor y degradada del lenguaje. Basta que la forma de la lengua sea la expresión de un sentimiento auténtico, para que sea apropiada. Para Soto y Calvo, la literatura nacional es una realidad incipiente y hay que juzgarla como tal, y disculparla, incluso, cuando procede como recién nacida. No es tiempo de censurar sus formas, sino de alentarlas. Muy a menudo,

${ }^{1}$ QuesadA E. 1902, 47.

${ }^{2}$ Quesada E. 1902, 113.

${ }^{3}$ Estrada 1902, 239.

${ }^{4}$ Cf. Estudios 1902. 
agrega, «los preceptistas han retardado, más bien que empujado, la penetración en el espíritu humano del conocimiento puro de la belleza» ${ }^{1}$. Y como preceptista hallará que se comporta el libro de Quesada, que pretende «encauzar la imaginación y constreñir las entrañas» de los hablistas; que, de haberse escrito durante el albor de la Edad Media y tomado al pie de la letra, las lenguas romances serían aún ilegales y criollistas. El «demiurgo argentino», así lo llama a Quesada, aconseja a los escritores:

[...] rebuscar nuestro lenguaje, almidonarlo a la castellana, y prepararnos con él, bien descaracterizados y bien incoloros, la blanda almohada de la indiferencia universal, y la molicie en que duermen, los agotados, el sueño entorpecedor de la decadencia. ${ }^{2}$

Soto y Calvo - que sitúa la discusión en el lugar que estaba en 1837, restituyéndole su tono romántico - halla absurdo recriminar la ausencia de una idiosincrasia nacional, al mismo tiempo que se cercena y repudia sus formas incipientes.

La tesis en favor del criollismo del autor del Nastasio supone una primacía de la expresión sobre la forma eventual que esta adquiera, pues «con cualquier instrumento se puede tocar cosas bellas». Las pasiones que el hombre arroja, palpitantes, a sus congéneres, valen por lo vital que en ellas hierve - agrega-, y es esto lo que hace inútil la cruzada de Quesada contra toda forma de criollismo, pues, aunque griten y hachen los preceptistas, el pueblo se expresa imponiéndose a todo. De modo que Soto y Calvo infiere que existe una «belleza nacional» que hace falta captar en su pureza y que es eso, a la vez, lo que la hace bella y respetable. Y esta lengua será como fuere:

[...] con gringuería, gauchismo y acicalamiento eufémico francés y restos de hurañía española; con el encantador variar con que transfórmalo todo el torrente de las edades; con nuestros inútiles galicismos (si el señor Cané nos deja alguno); con nuestros italianismos arrabaleros; con nuestros criollismos y cocolichismos, que por ley natural hubieran de perpetuarse en el lenguaje y la acción. ${ }^{3}$

\footnotetext{
${ }^{1}$ Soto y Calvo 1903, 289.

${ }^{2}$ SOTO Y CALVO 1903, 291.

${ }^{3}$ SOTO y CALVO 1903, 299
} 


\section{7. Cuervo y el castellano en América}

Insatisfecho con las conjeturas que se tejen en torno a las causas de su dramática conversión, Rufino José Cuervo decide explicarla él mismo en el quinto tomo del Bulletin Hispanique. En 1877, Friedrich August Pott reseña la segunda edición de las Apuntaciones críticas sobre el lenguaje bogotano ${ }^{1}$, de Cuervo, y augura, a partir de lo que le sugiere el libro, que las lenguas procedentes del Lacio, instaladas en América, no podrán escapar del destino inscripto en las leyes generales de la naturaleza. Para ese entonces, Cuervo no tenía mayor conocimiento del estado del castellano más allá de Colombia, y rechazó ese pronóstico segregacionista:

[...] es infundado el temor de que en la parte culta de América se llegue a verificar con el castellano lo que con el latín en las varias provincias romanas, pues la copiosa difusión de obras impresas, referentes todas más o menos a un mismo tipo, el constante comercio de ideas con la antigua metrópoli y el estudio uniforme de su literatura aseguran a la lengua castellana en América un dominio imperecedero. $^{2}$

$\mathrm{Al}$ investigar los usos de la lengua a lo largo y ancho del continente, a Cuervo, entonces, le nacen las dudas y al cabo de un tiempo muda de opinión.

Luego de esta aclaración, Cuervo se dispone a refutar cada uno de los párrafos vertidos por Valera en La Tribuna de México. En primer lugar cree necesario advertir que la dialectización progresiva del castellano no reside en los textos ni en el léxico, cuanto en la pronunciación de la lengua y en su la oralidad. No se puede conjeturar una separación idiomática comparando un libro editado en Madrid, en Méjico, en Lima y en Santiago; podrá hacérselo recién cuando escuchemos la lectura de un mismo libro, de boca de un madrileño, un mejicano, un limeño... Cuervo cree que Valera no ha advertido esta preliminar. Luego, detalla algunos cambios profundos que atravesó el castellano en su fonética, su morfología y su sintaxis, para evidenciar algo que estima demasiado obvio: las lenguas se transforman.

Si la lengua, pues, se altera siempre, y de ordinario sin que intervenga la voluntad humana, son ilusorios todos los consejos que se

\footnotetext{
${ }^{1}$ Cf. Göttingische gelebrte Anzeigen del 24 de octubre de 1877.

${ }^{2}$ Cuervo 1885, XXIV.
} 
den a españoles o americanos para que la conserven intacta o para que las alteraciones sean uniformes. ${ }^{1}$

Estas divergencias, agrega, desarrolladas en el curso de más de tres siglos, pueden aumentar, aunque aún no impidan que nos entendamos. El hecho de que se logre cierta cohesión entre los escritores, para sostener la unidad de una lengua escrita «extranacional», no detendrá — como no se logró detener durante la Edad Mediaque la lengua conversacional y corriente se desarrolle ajena a estas prescripciones e ingrese, finalmente, en la lengua literaria. Así el romance venció al latín; así, es probable, el habla popular americana termine por suplantar al castellano tradicional y autorizado.

Cuervo, por último, aduce que Valera no ha invalidado ninguno de los principios o pruebas que sustentan su tesis, ni aducido razón o investigación científica que esclarezca la cuestión. Por lo tanto, estima, el decoro lo obliga a guardar silencio.

${ }^{1}$ Cuervo 1903, 66. 

II. Del VIRAJE DE UNAMUNO A LA TESIS DE LA ESCISIÓN MORAL, DE MENÉNDEZ PIDAL

(1903 - 1918)

\section{1. El viraje de Unamuno}

La carta que Miguel de Unamuno envía desde Salamanca el 11 de enero de 1903 a Adolfo Casabal, entonces codirector de la revista Estudios, pretende reencauzar nuevamente la querella en torno al idioma nacional de los argentinos. Retomando las disputas nacidas a partir de la carta-prólogo de Cuervo y el estruendoso libro que publica Abeille, Unamuno retira el problema del recinto lingǘstico y lo resitúa en el lugar donde lo habían puesto los románticos: el moral, pues cree intuir, en el clamor autonomista de los argentinos, un deseo legítimo de hacerse escuchar. Retomando sus tesis de 1899, formula lo que quizá sea una bisagra en torno a la querella: el idioma argentino debe ser pensado como un problema ético.

La cuestión hay que ponerla, a mi juicio, en otro terreno, y es que los argentinos y todos los demás pueblos de habla española reivindiquen su derecho a influir en el progreso de la común lengua española tanto como los castellanos mismos, que no reconozcan en estos patronato alguno sobre la lengua común, como si se les debiera por fuero de heredad, que afirmen su manera de entender y sentir el idioma de Cervantes. Aquí está la raíz de la cuestión. ${ }^{1}$

Y aquí está la raíz del viraje. Unamuno, heredero en esto de Sarmiento, exhorta a que se piense el problema de la lengua partiendo del derecho que tienen los argentinos a su emancipación espiritual. Emancipación que no puede dictarse desde Castilla, ni mucho menos desde la Real Academia. Unamuno exhorta, además, a todos los dialectos del español a apropiarse de la lengua común, no a salir protestando cada uno su autonomía. Apropiarse del español para hacerlo a la medida de cada pueblo, y a la de cada ser que lo habla, si es necesario. Asirlo por la fuerza, si se resiste, para que resuenen en su interior todas sus variaciones. Pero si es posible postular la existencia de un idioma nacional, dirá, hay que buscarlo dentro del español.

A Unamuno lo desvela la cuestión del idioma, por momentos la causa argentina, pero interviene con serenidad. Conoce la lengua

\footnotetext{
${ }^{1}$ UNAMUNO 1903, 32.
} 
al punto de entrever sus posibles destinos. Descree de las tesis segregacionistas. A causa del desarrollo del comercio, la difusión del conocimiento de la lectura, la expansión de la imprenta y el interés de los pueblos por entenderse, augura que la suerte del idioma español será la unidad. Solo que esa unidad no deberá subyugar sus formas regionales. El español será una unidad en la medida que no sofoque sus distintas formas de esgrimirse, la argentina entre ellas, aunque no cree que sea muy distinta a la de España. No hay vocablo «argentinista» que él no haya escuchado campear de una punta a otra de la Península Ibérica. De modo que desdeña la cuestión del «idioma patrio» en cuanto se lo preconiza desde sus aspectos léxicos, sintácticos o fonéticos; no así en cuanto a lo que los argentinos quieren, aunque en forma desacertada, expresar al evocar la expresión idioma nacional.

Unamuno nos sugiere, a los argentinos, lo que les había sugerido a sus paisanos, los vascos, cuando les auguró que el vascuence moría, y debía morir, en el vasto español. La misión era hendir el español, hacerle una herida suficientemente aguda como para que no olvide que en sus entrañas sobrevive otro idioma. «Yo, escribiendo castellano, me creo tanto o más vasco que los más de mis paisanos que escriben en vascuence, y les llevo la ventaja de que mi palabra será más oída que la suya.» ${ }^{1}$ Tiempo después se le oirá repetir aquello de que quien no trate ser en los demás, dejará de ser en sí mismo.

\section{2. Las Notas de Monner Sans}

El catalán Ricardo Monner Sans adopta a la Argentina como segunda patria desde el momento que arriba, en 1889, al puerto de Buenos Aires. En 1903 ya cree estar en condiciones de publicar (y publica) sus Notas al castellano en la Argentina, apuntaciones en su gran mayoría de carácter recusante. Su condición de inmigrante no lo recató al momento de juzgar a los hispanoamericanos incapaces aún de hablar «como Dios manda»; ni fue un atenuante al presentar sus Notas como restauradoras de la pureza y la unidad del idioma. Gramático, maestro de escuela, paremiólogo, tradicionalista y lector de lápiz rojo en mano, Monner Sans se jacta de su casticismo y anhela ser llamado «el preceptor» de la lengua, o mejor, el «flagelador de nuestros vicios lingüísticos». Este y la totalidad de sus libros normativos parten de la tesis de que el idioma es sucesivamente

${ }^{1}$ UNAMUNO 1903, 34. 
bastardeado, y cree ver oscurecido el panorama cuando, faltando los Bello, proliferan los Abeille. Monner Sans también escribe contra el Idioma nacional de los argentinos, a quien lo cree una farsa para aislar, primero, a la Nación Argentina del resto de las naciones de habla hispana, y luego suplantar el castellano por el francés.

Hermanas de las Minucias lexicográficas (1896), las Notas están regidas por cuatro principios básicos.

Primero: la etimología imprime a las palabras un sentido prácticamente inmutable. Si abandonar entraña la idea de dejar en cierto desamparo a una persona o cosa abandonada, no se puede abandonar una ciudad para ir al campo. Tampoco se puede acentuar algo que no sea una vocal. Adherir solo lo logra «una cosa con otra». Flamear solo pueden las velas; las banderas ondean. Gauchadas solo hacen los gauchos. Así como tomar medidas solo toman los sastres.

Segundo: el idioma español llegó a tal definición, que cualquier neologismo sería muy fácil objetar, de haber ya un equivalente castizo. Inútil es el gálico acaparar cuando rige un auténtico y romancero monopolizar. Inútil es igualmente alienado, estando demente. Confortable, estando lleno de comodidades. Revancha, teniendo desquite. Ni siquiera es lícito decir joven soltera, en lugar de doncella o señorita; ¿por qué? porque jeune fille dicen los franceses. Así mismo, encuentra innecesaria la palabra kerosene, porque ya tenemos petróleo.

Tercero: toda forma de criollismo, para Monner Sans, resulta entre ramplona y usurpadora de voces preclaras. Atorrante se dice, «en buen castellano», haraposo, mugriento, o lleno de parásitos. Y por extensión, casi toda forma argentina o americana es adúltera: nuestro entrañable balero, es en verdad el boliche; ¿por qué?: porque así lo llamaban en España. Batirse en duelo es, en castizo: reñir en desafío. Boleto es billete; y el vuelto del billete es, en lengua pura, vuelta; así como nuestras veredas no son más que aceras o veredones. Es gálico que un argentino tenga un buen día, pues no lo tuvo aún (no lo escribió aún) ningún autor clásico; un bon jour solo tienen los franceses. Así como solo en Francia se tiene un papá, nosotros tenemos un solemne padre, y a los sumo un grave papa. Ni tenemos canillas, sino grifos; ni clubes, sino casinos y círculos; ni cortafierros, sino cortafríos; ni despedidos, sino despedidas. Ni siquiera nuestras flores pequeñas son florcitas, sino florecillas. ${ }^{1}$

El cuarto precepto que abraza Ricardo Monner Sans recela de la productividad de la lengua, esto es, sospecha que de un sustanti-

\footnotetext{
${ }^{1}$ Abeille, a quien Monner Sans cree un bárbaro, parece haber sido más agudo al advertir que el argentino prefiere no construir diminutivos en -illo, -illa, pues los reserva para un uso despectivo. Cf. ABEILlE 1900, 158.
} 
vo como oferta pueda derivarse la forma verbal ofertar, suponiendo que ofrecer ya cumple esa función. En la entrada jalonar se lee: «De jalón no ha nacido todavía jalonar, como de bito no nació bitar, porque aún no pasó a ser ley que todos los substantivos pudiesen engendrar verbos» ${ }^{1}$. La preceptiva de Monner Sans en este punto parece dar con una rebeldía en las propias Notas: en la entrada pajonal leemos: «Si de maíz hacemos maizal, y de trigo, trigal, ¿por qué de

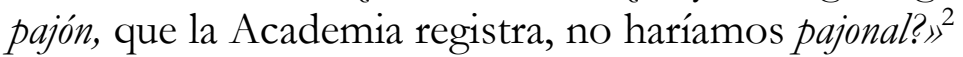

Estos cuatro principios, que Monner Sans ve vulnerados a menudo en estas regiones, lo condujeron a estimar que la lengua está corrompida. Creyó que su lucha preceptiva contra estas presencias extrañas era útil, pero ignoró que sería eterna, al menos mientras el castellano estuviera vivo. Encontró manchas hasta en el Diccionario, de la Real Academia; en el Diccionario de ideas afines, de Eduardo Benot; en las Apuntaciones, de Rufino José Cuervo; en la prosa de Benito Pérez Galdós, e incluso en los consejos de Rafael María Baralt, de Baldomero Rivodó y del jesuita P. Mir, a quienes, de todos modos, consideraba muy poco pecadores. Y ya que la lista sigue, podemos conjeturar que la única lengua que Monner Sans encuentra enteramente casta es la lengua que no se habla, pues hablar - a esto, creo, conduce su programa- supone incurrir en crimen de lesa hispanidad.

El idioma en Argentina, región enfatizada en sus Notas, ya es «híbrida confección, no de jacintos y perlas, como dijo Lope de Vega, sino de neologismos y barbarismos» ${ }^{3}$. Cree que son cuatro las causas que dan aliento al entuerto: $1^{\mathrm{a}}$ la inmigración; $2^{\mathrm{a}}$ la incesante lectura de obras francesas; $3^{a}$ los malos traductores; $4^{a}$ una mal entendida independencia de la autoridad académica. Causas que tendrían su sanación si fuera el uso quien gobernase la lengua, pero el uso de los doctos, y no de los doctos en general, sino de aquellos que reprueban el vos y el recién. Doctos como el señor Fernando Cruz, orador en el Congreso Literario Hispanoamericano de 1892, el cual se atrevió a decir:

Así como es indispensable que haya en la sociedad códigos de leyes que establezcan cuáles son los derechos y determinen cuáles son las obligaciones, que declaren lo que se puede hacer y lo que no se puede hacer, es igualmente forzoso que al hablar nos sujetemos a ciertas reglas que, al mismo tiempo que por los principios de la Fi-

\footnotetext{
${ }^{1}$ Monner Sans 1903, 231.

${ }^{2}$ MonNer SANS 1903, 278.

${ }^{3}$ Monner SAns 1903, 44.
} 
lología, o sea por el estudio crítico y filosófico de la lengua, sean también sancionadas por el uso de las gentes cultas ${ }^{1}$.

La idea la celebra el mismo Monner Sans y su tenor punitivo es el que pretendió para sus Notas.

Estanislao Severo Zeballos, aquel de La conquista de quince mil leguas, se entusiasma con estas Notas y les concede un extenso prólogo, cuya tesis señala que los barbarismos que se reúnen en catálogos regionales, cuando no son galimatías o meras adulteraciones del idioma castellano, son solo americanismos, voces de base castellana que se las puede hallar a lo largo y ancho del continente. La obra de los diccionarios locales le resulta una pérdida de tiempo y una curiosidad contraria a la ciencia, «pues no deben aspirar las naciones a aislarse, sino a comunicarse con la mayor facilidad...» ${ }^{2}$ Antes había adelantado que coleccionar localismos es «obra estéril de curiosidad y de desocupados» ${ }^{3}$. Zeballos, como Monner Sans, también es de la idea de que la lengua castellana ya está formada y definida.

Al editarse las Notas, Monner Sans se toma la molestia de enviárselas a algunos filólogos, escritores y gramáticos. Entre tanta lisonja que llega con los acuses de recibo, contrasta la respuesta de Unamuno (Salamanca, 23 de febrero de 1904) quien no prefiere llamar «enfermedades» del habla a simples y naturales variaciones, ni estimar a estas como autóctonas de Argentina, ni siquiera de América. La tendencia a mortificar la lengua es un fenómeno que se explica muy bien por medio de la analogía y es, en el Río de la Plata, la misma que en Madrid o en Salamanca. Unamuno disiente con las Notas: «Mi criterio es algo menos purista que el de usted. El castellano ha de enriquecerse por integración de las diferencias que de él surjan en los tan diferentes países en que se habla» ${ }^{4}$. El hombre de Bilbao ya había escrito sobre lexicografía e inferido ideas distintas a las de Monner Sans. Para Unamuno, un vocablo jamás calca el significado de otro: así como de fácil hacemos facilitar, de evidencia, evidenciar, y de agencia, agenciar, del sustantivo influencia hacemos influenciar, aunque hiera esto el oído de muchos, al creer que el verbo influir ya cumple esa función. Producida la dualidad de forma, deviene la dualidad de sentido. De modo que influir e influenciar son cosas tan distintas como esperar y esperanzarse, como lo son resolver de solucionar.

\footnotetext{
${ }^{1}$ Cf. MONNER SANS 1903, 52.

${ }^{2}$ ZeBallos 1903, 21.

${ }^{3}$ ZEBALLOS 1903, 14

${ }^{4}$ Cf. Monner Sans, 1903, 379.
} 
«Meter palabras nuevas, haya o no otras que las reemplace, es meter nuevos matices de ideas.»»

Las Notas al castellano en la Argentina, que se reeditan corregidas y ampliadas en 1917, alumbrarán, en 1941, un retoño de la misma calaña: La peculiaridad lingüística rioplatense y su sentido histórico, de Américo Castro, cuya tesis es la misma: los argentinos profanamos la lengua. Es célebre la réplica de Borges (1941).

\section{3. Oyuela y el espíritu nacional en la lengua}

El mismo año que Monner Sans presenta sus Notas (1903), el escritor y crítico literario argentino Calixto Oyuela diserta en el Colegio Nacional Norte sobre el espíritu nacional en la lengua y en la literatura. En esa ocasión, y por el estado que está tomando la querella, Oyuela cree oportuno destacar tres peligros en torno al castellano en Argentina.

El primero remite al manifiesto desdén o antipatía con que buena parte de los argentinos han mirado cuanto se relacione con la gramática, la homogeneidad y el casticismo de la lengua. El fenómeno, cree Oyuela entender, se debe a un equívoco surgido al calor de la guerra de la independencia y arrastrado de generación en generación. Ese equívoco, agrega, no fue más que haber creído que esta lucha, antes que un conflicto familiar de emancipación, fue una guerra contra una nación extranjera y usurpadora, como si descendiéramos de los indios americanos y no de los mismos conquistadores. Este equívoco acentuó la antipatía con España, viendo en la lengua la marca, aún, de la presencia invasora. Andando los años y ni bien comenzado a recomponerse el vínculo de filiación, resurgió

[...] aquel espíritu de patriotismo casero y municipal, estrecho y meticuloso, de que os he hablado, y dio en el peregrino subterfugio de quitar al castellano su tradicional nombre de pila y cambiárselo por el de idioma nacional, eufemismo con el cual se le designó por años en nuestros planes y programas. Luego esto pareció todavía poco patriótico, y se le llamó idioma patrio. ¡Cuánta puerilidad!2

El segundo peligro, estima Oyuela, nacido del descuido e indiferencia con respecto a las cosas de la lengua, atañe al abuso de neologismos. Acaso en la misma línea de pensamiento que Monner

\footnotetext{
${ }^{1}$ UNAMUNO 1901.

${ }^{2}$ Oyuela 1903, 226.
} 
Sans, encuentra absurda la adopción aluvial de voces bárbaras. El enriquecimiento y ensanche del idioma, que aun así lo cree necesario, se debería dar por asimilación lenta, razonada y orgánica. De modo que exhorta a hacer con los pensadores modernos lo que los grandes escritores españoles del siglo XVI hicieron con los raudales del pensamiento platónico y del pensamiento aristotélico: «absorberlos íntegros, sin detrimento de la limpidez y la hermosura de la lengua.... ${ }^{1}$

El tercer y último peligro que enfrenta la lengua en Argentina, consecuencia que encuentra «pueril y viciosa» de los peligros anteriores, es

[...] cierta propaganda, inspirada en un mal entendido espíritu nacional y en falsas analogías, destinada a mostrar como cosa inevitable, provechosa y casi realizada ya del todo, la corrupción y fermentación del castellano, y su transformación en una lengüita argentina, para nuestro uso particular y exclusivo. ${ }^{2}$

Se refiere a Abeille, al que prefiere no nombrar, y a su programa lingüístico, al cual cree se lo forjó con una pomposa y falaz base científica, convocando en su auxilio la comparación forzada de lenguas, la supuesta formación de un tipo argentino surgido del producto de la inmigración, y el apoyo de escritores europeos, sobre todo franceses, que sabiéndonos enamorados de París, ven con simpatía todo lo que tienda a separarnos de España.

Oyuela no concibe la tesis de un idioma nacional ni lo desea. En castellano, agradece, celebraron nuestros poetas las victorias de la independencia; en castellano están escritas nuestra Constitución y nuestras leyes, las obras de Echeverría y Gutiérrez, de Mármol y de Andrade, de López, de Sarmiento y de Estrada; en castellano nos ensañaron a hablar nuestras madres y hemos enseñado a hablar a nuestros hijos. Este hermoso y magnífico idioma, agrega, está esencialmente fundido en las raíces mismas de nuestro ser nacional, al punto que atentar contra su unidad fundamental, concluye, no solo es un acto de barbarie, sino además un crimen contra la patria.

Censervémosle, según el voto de Echeverría; perfeccionémosle en lo posible; estudiémosle con amor para preservarle de corruptelas funestas, para conocer su índole y aprovechar sus recursos; deses-

\footnotetext{
${ }^{1}$ OYUELA 1903, 234.

${ }^{2}$ OyUela 1903, 238-239.
} 
timemos las lisonjas y consejos de los amables huéspedes que nos repiten al oído seréis como dioses» ${ }^{1}$

\section{4. Selva y Terán: la evolución de la lengua}

Tres años más tarde, en 1906, Juan B. Selva reúne en forma de «librejo» (el calificativo es de él) una serie de conferencias bajo el nombre El castellano en América: su evolución, inspirado en El darvinismo, de Emilio Ferrière. Arriba a la siguiente conclusión: el castellano en América tiende fatalmente a mantener su unidad. Selva, sugestionado no solo por Ferrière, sino también por Haeckel y Spencer, ejerce el hábito de juzgar el destino de las lenguas con el mismo principio con que otros juzgan la suerte de las plantas y los animales. Este hábito es el que luego condenará Menéndez Pidal en Cuervo, a quien su fatalismo lo condujo, curiosamente, a sostener lo contrario que Juan B. Selva. Treinta y ocho años después (1944), no desembarazado aún del enfoque spenceriano, volverá con un tomo al que le estampa por título: Evolución del habla.

Pero volviendo a la primera década del siglo, en 1908, en Tucumán, el historiador y publicista Juan B. Terán interviene en la querella idiomática al publicar Estudios y notas. En el capítulo que lleva por nombre «Naturaleza del lenguaje», Terán se afilia a la lingüística heredera de Max Müller, Michel Bréal y William Dwight Whitney y explicita las premisas que lo han convencido: el lenguaje no es una revelación divina, sino una obra social. Sus leyes, por tanto, pueden conocerse siguiendo las de cualquier otro fenómeno social, es decir, las leyes de la evolución social. La lengua es, además, lo que más fielmente refleja y se acomoda a los movimientos del alma colectiva. Todo intento por detener este acomodamiento tiene algo de improcedente, algo de tendencia a estancar el despliegue espiritual de un pueblo.

Para Terán, como se ve, el lenguaje sigue las vicisitudes del espíritu social, y sean estas buenas o malas, no dejan de ser inevitables. No estará en la mano humana modificarlo como no lo está modificar las leyes que rigen la circulación de la sangre. Los cambios que atraviesa una lengua, pues, no son irrupciones bárbaras cuanto pruebas de vitalidad. Cuando el espíritu de un pueblo permanece inactivo y aislado, agrega, «su lenguaje se inmoviliza; cuando nuevas ideas lo despiertan y el contacto con otros pueblos lo

\footnotetext{
${ }^{1}$ OyUela 1903, 241.
} 
anima, su lenguaje se enriquece y flexibiliza» ${ }^{1}$. Estas premisas son contrarias a un ideario purista de la lengua, al cual Terán estimó ajeno a la lingüística moderna. Por tanto, encontró más oportuno invocar aquella idea de Max Müller de que «una lengua compra su imperio en el tiempo, al precio de su ruina inevitable», solo que donde el alemán dice «ruina», el argentino lee algo similar a la redención. Esto será, para Terán, el faro a partir del cual hay que guiar la discusión por la lengua en Argentina.

Ahora bien, esta redención está distante tanto del casticismo pretendido por Monner Sans, cuanto del autonomismo predicado por Lucien Abeille. Terán presiente una forma argentina de esgrimir el castellano, tendiente a una mayor delicadeza y transparencia en el vocablo, a una justeza del adjetivo y una sensible sugestión de la idea, pero esa forma no puede ser llamada idioma nacional, al que juzga temerario, inexistente e imaginado por Abeille a partir de «locuciones bárbaras de la gente rústica o la jerigonza cosmopolita de algún barrio suburbano» ${ }^{2}$. Esta forma argentina no vulnera ni hace peligrar la unidad del castellano, ni es deseable que lo haga. No constituye un nuevo idioma, pues no impide la inteligencia y la comunicación con otros pueblos de habla castellana.

La intuición de Terán acerca de la suerte del castellano en Argentina, sin embargo, terminará siendo más osada que la de Abeille, pues se pregunta si toda la inmigración europea que está llegando a la Argentina, formando un genio propio, no terminará llevando al castellano nacional, nutrido de todos esos aportes neolatinos, a reavivar cierto carácter dormido de la vieja latinidad. La tendencia literaria argentina al casticismo, por tanto - tesis que le concede a Paul Groussac-, más que una vocación purista, quizá esté informando de una emanación de lo nuevo, a partir de la redención de formas arcaicas de raigambre latina, que persisten en el habla americana, memoriosa de la lengua de los conquistadores, y en los nuevos afluentes europeos. Así, en Terán, el espíritu nacional, representado en su lengua, tendería a lo románico.

Por la magnitud de las conclusiones, la exposición argumentativa resulta escueta, algo inasible y hasta sibilina. Es imposible descifrar si esa forma argentina pertenece al ámbito de la lengua oral o al de las obras literarias cultas. La tesis de la romanización, sin embargo, adquiere su momento más diáfano en estos tres párrafos con que cierra su ensayo:

\footnotetext{
${ }^{1}$ TERÁN 1908, 135.

2 TERÁN 1908, 148.
} 
¿Este esfuerzo de castización no demuestra un vigor intelectual mayor, que endereza el surco de la labor hacia el campo fecundo de los orígenes latinos, para renovar la savia de las ramas secas?

¿No es también nuevo lo viejo que se anima con un soplo sano y juvenil?, ¿no será nueva la lengua castellana esclarecida, iluminada con el renacimiento del verbum latino?

Después de dispersado en las lenguas romances, y al cabo de muchos siglos, parece que tentara una recomposición ideal, por un proceso inverso al de dispersión — de síntesis_- para fundar el nudo de un nuevo ciclo trascendental en este lejano país, en que se reúnen, como en una cita histórica, los hijos de la civilización latina y herederos de su genio. ${ }^{1}$

\section{5. El idioma patrio de La restauración nacionalista}

Durante la presidencia de José Figueroa Alcorta (1906-1910), y por orden del mismo presidente, se le encomienda a Ricardo Rojas la tarea de estudiar el régimen de la educación en las escuelas europeas. Argentina está cerca del Centenario de la Revolución y crece la preocupación por actualizar el carácter nacional de la república. Rojas viaja a Europa y, luego de comparar sus distintas formas de educación, llega a la conclusión de que el sistema argentino es «deplorable» y necesita, de manera urgente, una reorientación sobre la base de una conciencia nacionalista, que aquí significa una reforma que restablezca el vínculo perdido con la tradición nacional. Compone, para este fin, un extenso informe crítico que se convirtió, con el tiempo, en uno de sus libros más discutidos: La restauración nacionalista. Este informe, al buscar constituirse en las bases para una reforma en el estudio de las humanidades modernas, se pronuncia sobre cuestiones históricas, geográficas, morales e idiomáticas. Me detendré en lo que respecta a este último aspecto: el idioma.

Rojas creyó desde el primer momento que en el idioma patrio estaban los elementos espirituales más duraderos de la tradición nacional, el puente espiritual más firme con los antepasados y con España. La conservación de ese idioma era, por tanto, necesaria para la unidad espiritual e histórica a través del tiempo y para lograr el instrumento adecuado en la persecución de la hegemonía cultural en América. No duda en llamarlo idioma patrio; a veces utiliza el concepto de idioma nacional o el de idioma tradicional, que son, en esta obra de Rojas, todos equivalentes, todas formas alternativas de idio-

\footnotetext{
${ }^{1}$ TERÁN 1908, 150-151.
} 
ma español, forma que, en cambio, evita por considerarla un error. Su revalorización de lo indígena y de las voces indígenas, que en $L a$ restauración ya ocupa un lugar relevante, no implica ceder absolutamente nada en la idea de que la lengua de Argentina es y debe ser el español. El problema no está en lo autóctono, sino en lo foráneo: en el francés, en el inglés, en el italiano. Pero Rojas, aunque aún muy joven, revela conocer muy bien el funcionamiento de las lenguas, de modo que no niega la formación de nuevos vocablos, la aparición de nuevas acepciones a las ya conocidas, la necesaria adaptación de ciertos barbarismos o los cambios oportunos de sintaxis en favor de la claridad: todo esto le resulta evolución natural de una lengua:

Mas lo que pasa entre nosotros por influjo de la horda cosmopolita, en su mayoría analfabeta, es la deformación de las palabras castizas, el abuso del extranjerismo estridente, el empleo absurdo de las preposiciones, la introducción de sonidos extraños a la música de nuestra lengua. ${ }^{1}$

El enemigo número uno de la restauración que pretende Rojas es, entonces, el cosmopolitismo, entendido como la presencia extranjera que resiste argentinizarse. No pide la expulsión del inmigrante, pide que resigne su lengua materna ni bien pise suelo argentino.

¿De qué servirá, asimismo, que el maestro enseñe su gramática, y diga que el castellano es el idioma del país, si el alumno, al regresar de la escuela, ve las aceras llenas de letreros en francés, en inglés, en alemán? Los comerciantes e industriales pueden ser extranjeros; pero cuando vienen a hacer su granjería en nuestro territorio, tenemos el derecho de imponerles la lengua del país, que es uno de los signos de nuestra nacionalidad. ${ }^{2}$

\section{6. Los diccionarios del Centenario}

Coincidiendo con los festejos del Centenario de la Revolución de Mayo se funda, por un lado, la Academia Argentina de la Lengua; por otro, se publica una serie de diccionarios que, si bien son trabajos lexicográficos, se desprende de ellos un nuevo episodio en la querella. Tobías Garzón, en Barcelona, presenta el primer Diccionario

\footnotetext{
${ }^{1}$ Rojas 1909, 368.

${ }^{2}$ Rojas 1909, 450.
} 
argentino (1910); Ciro Bayo, en Madrid, reedita su Vocabulario criolloespañol sud-americano (1910); Lisandro Segovia, en Buenos Aires y bajo los auspicios de la Comisión Nacional del Centenario, publica su Diccionario de argentinismos, neologismos y barbarismos (1911); Diego Díaz Salazar, aunque con un ejemplar más discreto, aporta lo suyo en el Vocabulario argentino (1911). El espíritu de estos trabajos no es anunciar la creación de un idioma argentino, y sus autores incluso creyeron necesario aclararlo en los respectivos prólogos. No obstante son justificaciones que ofrecen algunos interrogantes.

Garzón, por ejemplo, confiesa que comenzó haciendo un vocabulario de barbarismos, pero resultaron ser estos tan numerosos y generalizados, incluso entre la gente culta, que dejó de considerarlos bárbaros. Luego, al ver que muchas voces en Argentina se escribían distinto, o tenían otro sentido, o directamente no aparecían en el Diccionario académico, se preguntó:

¿Será posible, me decía, que este idioma nuestro, nacional, castellano por su índole analógica y sintáctica y casi en su totalidad por sus elementos prosódicos y ortográficos, pero cada día más distinto del que se habla en la península por su vocabulario o expresión de las ideas madres-, carezca de un diccionario propio, que registre las palabras, frases y modismos usados en la República Argentina $[\ldots]$ ?

Como se deduce de esta cita, Garzón se atreve a afirmar la existencia de un «idioma nuestro, nacional» solo en cuanto al vocabulario, pues «no hay una lengua argentina sino castellana» ${ }^{2}$, dirá más adelante. La idea de un «diccionario argentino» le produjo algunos dilemas, pues así como no se trata de un diccionario de la lengua argentina, ni de un diccionario integral del español en Argentina, tampoco es un diccionario de argentinismos, pues muchas de las voces que constata campean por igual en otras regiones del continente. La idea de un «diccionario argentino», por tanto, remite únicamente a que pertenece a la Argentina o tiene relación con ella.

A párrafo siguiente, este aseverar que «no hay una lengua argentina sino castellana» parecería desmoronarse al afirmar que se ha propuesto demostrar el estado actual de la lengua en la República Argentina, donde «no se habla ya el idioma que se habla en España» ${ }^{3}$; aunque aclara, más abajo, que un nuevo mundo exige una nueva

\footnotetext{
${ }^{1}$ GARZÓN 1910, VI.

${ }^{2}$ GARZÓN 1910, VI.

${ }^{3}$ GARZÓN 1910, VII.
} 
lengua, pero con «nueva» no debe entenderse una lengua radicalmente distinta, sino simplemente una lengua renovada, enriquecida en cuanto a su léxico. Garzón busca ser claro en esto, porque sabe de la querella en torno a estos temas y no le interesa atizarla; encuentra igual de útiles para su empresa tanto los trabajos de un Lucien Abeille como los de un Ernesto Quesada, ambos con «prolijas y luminosas disquisiciones sobre el idioma de los argentinos» ${ }^{1}$.

A Ciro Bayo parece haberlo asaltado la misma contradicción que a Garzón, en cuando al estado de la lengua en América. Bayo reedita su «Vocabulario de provincialismos argentinos y bolivianos» (1906), ahora en forma de libro y bajo el nombre Vocabulario criolloespañol sud-americano (1910). El prólogo esta vez está sensiblemente recortado, de modo que tenemos que ir a la versión de 1906 para comprenderlo cabalmente. Dos visiones antagónicas parece tener Bayo sobre el estado de la lengua en América y, particularmente, en Argentina. Por un lado se convence de la unidad:

Lograron las naciones americanas sacudir el férreo yugo de la Metrópoli; han podido darse nuevas leyes, adoptar exóticas costumbres, y hasta posible es que abracen otra religión, pero ya no les es dable formarse un idioma privativo nacional. ${ }^{2}$

Estima que el americano ilustrado, lo quiera no, hablará y escribirá en lengua española, de modo que «las fantasías de Sarmiento y demás corifeos hispanófobos» de expresarse en criollo, agrega, no pasarán de alardes inocentes. El pretendido lenguaje criollo, excepto algunos modismos y términos dialectales, no pasa de ser un «bodrio de barbarismos, solecismos, arcaísmos y demás fealdades gramaticales $\rangle^{3}$. Pero por otro lado, y luego de enumerar los distintos peligros que sufre la lengua española en América, Bayo teme una disgregación, de modo que

[...] milagro será que no se confirme en plazo no muy largo la opinión de Bello, quien dice que «a no evitarse esta anarquía de lenguaje se hablará con el tiempo en América una jerga desconocida».

Ya va sucediendo en Sur-América lo que en la España romana con el latín del Lacio. ${ }^{4}$

\footnotetext{
${ }^{1}$ GARZÓN 1910, XI.

${ }^{2}$ BAYO 1906, 241.

${ }^{3}$ BAYO 1906, 241.

${ }^{4}$ BAYO 1906, 243.
} 
Al reeditar su «Vocabulario...», Bayo presenta un prólogo sensiblemente más austero, cobrando mayor protagonismo este temor de secesión idiomática. Esta nueva versión comienza diciendo: «Sabido es que en la América española se habla un castellano que necesita traducirse al español. Ya va sucediendo...» ${ }^{1}$.

Menos alarmado que Bayo, Lisandro Segovia confiesa tender con su obra una mano amiga hacia la madre España y hacia las repúblicas hermanas (incluido el Brasil), invitándolas a que «unidos todos, trabajemos por la depuración y acrecentamiento del patrimonio común, sin olvidar que el porvenir del castellano está en América...» ${ }^{2}$ Diego Díaz Salazar, aunque lamenta que algunos están obstinados en «hacer un idioma argentino», cree que, por el momento, no hay que temerle a esa futura disgregación, y aun menos habría que temerle «si nuestra Academia hubiese tomado en consideración el propósito de don Juan Valera, de dar cabida en nuestro Diccionario oficial a muchos americanismos.... $\rangle^{3}$

\section{7. Rossi, el heredero de Abeille}

La soledad en la que se encontraba Abeille desde que salió su Idioma se ameniza también en 1910, año en que Vicente Rossi presenta su Teatro nacional rioplatense. Aunque uruguayo emigrado en Argentina, más precisamente en Córdoba, Vicente Rossi prefirió ser llamado hombre del Río de la Plata. En esta región - difícil de delimitar por los elementos que el propio Rossi proporciona- había entrevisto, no solo el origen del teatro, sino los perfiles de un idioma nacional.

Cuentista, primero, y fugaz historiador después, Rossi desliza a partir de este trabajo de 1910 una concepción del idioma que tiene a Lucien Abeille como precedente principal. Al promediar el libro, en oportunidad de buscar saldar la discusión en torno a la definición de la palabra gaucho, no vacila en postular que

[...] el profesor Dr. Abeille es quien, indiscutiblemente, ha encontrado la definición exacta y lójica de esta palabra, gracias a sus profundos conocimientos científicos. La ha publicado en su valioso libro El idioma Nacional de los Arjentinos [...] ${ }^{4}$

\footnotetext{
${ }^{1}$ BAYO 1910, 5.

${ }^{2}$ SEgovia 1911, 12.

${ }^{3}$ Díaz SALAZAR 1911, 10.

${ }^{4}$ Rossi 1910, 116.
} 
Cree, además, tan ciegamente en el trabajo de Abeille, que, al tramar el capítulo «El lenguaje», de su Teatro, lo presenta como única referencia. Este capítulo amerita una atención.

Rossi entiende que el lenguaje que ha adoptado el teatro nacional rioplatense es el del Río de la Plata; luego, como en el teatro se habla, le resulta lógico que el habla sea la de la región. Por tanto, el casticismo le resulta inapropiado: «Si el Teatro Nacional Rioplatense hablara en "castizo" con pronunciación nacional, sería falso y ridículo» ${ }^{1}$. De modo que Rossi establece una frontera muy definida entre lo auténtico y lo afectado, en cuanto al lenguaje del teatro. Si el teatro, agrega, pretendiera hablar y pronunciar «castizo», precisaría dotarse de hombres y mujeres que supieran hacerlo, dotes que encuentra raras en el Río de la Plata.

A Vicente Rossi lo desvela la disputa con los puristas, que están, a su parecer, sitiando los escenarios en pro de hacerlos entonar de otra manera. Con ellos discute; a ellos ataca. «El "casticismo" entre nosotros es la "castellanomanía", y esta es una desorientación científica, es la ilójica de un criterio retardatario y pretencioso.» ${ }^{2}$ Es de absoluta novedad, a esta altura de la querella, el concepto de castellanomanía, pues liga el casticismo a un vicio intelectual, a una extravagancia.

La distancia que Rossi siente de España es, a veces, más virulenta que la distancia sentida por los jóvenes románticos. De ellos toma, siempre a través de Abeille, sus premisas idiomáticas. De aquí que Rossi no pueda entender por qué habría que velar celosamente por una pronunciación extranjera.

Cultivamos la hipocresía lingüística, dándole a la niñez textos con terminolojías «castizas», que apenas son aceptados en el cuarto de hora de su exposición, y que jamás se respetan. Cultivamos la hipocresía intelectual, escribiendo como no hablamos, como no sabemos hablar. ${ }^{3}$

Todo esto lo conduce a esgrimir un concepto de gran relevancia en su obra - sobre todo por el modo en que lo desarrollará en sus próximas publicaciones-: el «idioma en jestación». Rossi entiende que la lengua en el Río de la Plata está en un período de babelización, que no encuentra indeseable, y del cual surgirá una lengua robusta y madura.

\footnotetext{
${ }^{1}$ Rossi 1910, 120.

${ }^{2}$ Rossi 1910, 121.

${ }^{3}$ Rossi 1910, 122.
} 
Por último, concluye el capítulo saltando de la exposición argumental, a la proclama y la admiración:

Sí, estamos obligados moral y cívicamente a formar y sostener un Idioma Nacional. Es deuda contraída; con nuestros antecesores, que nos hicieron la patria; con el cosmopolitismo que nos hace población e "influyendo en todo" no puede sustraerse a eso; con nosotros mismo, que debemos edificar lo nuestro sobre lo nuestro. [...] ¡Idioma Nacional para el Teatro Nacional! Esa es la terminante exijencia de nuestros pueblos, de nuestra alma nacional, de nuestra raza nacional!

Como se advertirá en las citas transcriptas, Rossi adopta una nueva ortografía, pues entendió que también allí debía encararse su gesta patria en pro de una nacionalización del idioma. Fonetista, como Bello y como Sarmiento, su ortografía incluye la sustitución de la $j$ en lugar de $g$ (lójica, jénero, arjentino), la apócope de la $d$ final en algunas palabras (bondá) y un sistema de acentuación que irá variando en obras posteriores, donde expondrá más expansivamente su programa de reforma ortográfica.

\section{8. Lugones y la lengua gaucha}

Como se ve, los festejos del Centenario de la Revolución llegaron con muchos acontecimientos lingüisticos. Al mismo tiempo que Manuel Ugarte imagina el porvenir de la América española en términos de patria única y asevera la unidad del idioma «que nos legó la madre patria» ${ }^{2}$, Leopoldo Lugones concluye y publica su Didáctica, obra en torno a la instrucción nacional en la que se afirma que el castellano, en Argentina, es una de las asignaturas enseñadas con mayor deficiencia. Las razones de esta deficiencia remiten a dos causas principales:

$1^{\circ}$ Los profesores, si son criollos, hablan y escriben incorrectamente, por lo regular; y si son españoles, tienden a enseñar un castellano que aquí no se usa. $2^{\circ}$ El espíritu esencialmente gramatical de la enseñanza, conforme a las atrasadas ideas de la Academia Española, cuyo texto oficial es un dechado de imprecisión y descuido, co-

\footnotetext{
${ }^{1}$ Rossi 1910, 126.

${ }^{2}$ UgARTE 1910, 212.
} 
mo que ni siquiera concuerda en muchos puntos con las prescripciones de su propio diccionario. ${ }^{1}$

Lugones parte de la premisa de que existen dos castellanos: el de España y el de América. Esto le resulta una realidad evidente por el solo hecho de que una lengua, en tanto organismo vivo, adquiere la forma del medio donde vive. Estos dos castellanos se distinguen, además, por una doble tendencia:

En España se atiende con preferencia a la construcción. Aquí a la brevedad de la expresión hablada y escrita. Aquello es más estético. Esto más utilitario. Lo uno, más tradicional y dogmático; lo otro, más moderno y evolutivo. ${ }^{2}$

La gramática entendida como dogma es, para Lugones, un residuo escolástico, concepción que invirtió un orden natural, convirtiéndola en un dictamen preexistente al idioma que describe y que, por tanto, convierte en su vasallo. Luego, la gramática devino en majestad.

Pero no es en 1910 cuando aparece desplegada la mayor cosmovisión lugoniana de la lengua nacional, sino en las seis conferencias porteñas de 1913. De regreso de Europa, y ante un público notable, Lugones expone, en el teatro Odeón, seis lecturas de carácter ensayístico. Aunque iniciáticas y fragmentarias, las corrige, las amplía y las da a la estampa tres años más tarde (1916), bajo el nombre de El payador, una obra de propósito doble: por un lado, develar el sentido épico del Martín Fierro; por el otro, trazar una genealogía hercúlea para la raz̧a argentina. Así como Virgilio intuyó una ascendencia helénica para refundar el mito del pueblo romano, Lugones establece una ascendencia similar para refundar el suyo, aunque su trama partirá de un sustrato estético, antes que sanguíneo:

Ahora bien, nosotros pertenecemos al helenismo; y entonces, la actividad que nos toca en el proceso de la civilización ha de estar determinada por la belleza y por la libertad para alcanzar su mayor eficacia; puesto que ambas son nuestros móviles naturales. ${ }^{3}$

El payador establece una estética como vínculo fundamental de la raza, pues concibe a la belleza como el único valor inmutable, a lo

\footnotetext{
${ }^{1}$ LugONES 1910, 246.

${ }^{2}$ LugONES 1910, 246-247.

${ }^{3}$ LUGONES 1916, 262.
} 
largo de los tiempos, capaz de establecer un puente inconmovible entre dos pueblos.

No es posible obviar la mención de esta tesis, pues en medio de ella Lugones enhebra, haciéndolas armonizar, sus apreciaciones sobre la lengua en Argentina. En primer lugar, persiste en advertir dos castellanos: uno español, otro americano; ambos perfectamente distinguibles. Esta es la base para postular que el castellano del gaucho, adaptado al suelo americano, constituye una lengua signada por una forma arcaica. Pobre en su vocabulario, debido a la vida humilde y campestre, tendió a la concisión y al laconismo, al realismo de la expresión y la filosofía práctica, a la elipsis y la simplificación de sus frases; vivificando la destreza derivativa de la lengua, convirtió en verbo todo aquello que necesitó verbalizar, y al faltar una literatura que imponga una preceptiva, discurrió con mayor libertad, y desarmó el humanismo que había latinizado y culteranizado al idioma. Con esto, agrega Lugones, el lenguaje gaucho

[...] fue más activo como instrumento de expresión, más vigoroso y más conciso; mientras que el otro, subordinado desde entonces a la tiranía académica, a la estética del canon, fue paralizándose en esterilidad sincrónica con el desmedro de la libertad peninsular. ${ }^{1}$

Ya desde el siglo XVI, en los primeros historiadores de América, Lugones encuentra un castellano más dúctil, no por usar americanismos, sino porque la despreocupación literaria de estos hombres los hacía escribir el mismo idioma que palpitaba en sus bocas. Muchos de ellos, últimos paladines de Europa, se hicieron rebeldes, independientes y sublimes en América. Sus obras son los legados del castellano americano, cuyas peculiaridades no debieron juzgarse como barbarismos, sino como elementos preciosos de una lengua más genuina e, incluso, hasta más vigorosa.

Nuestro castellano, menos correcto que el de los españoles, aventájalo en eficacia como instrumento de expresión, al resultar más acorde con las exigencias de una vida más premiosa: que tal, y por la misma exigencia ineludible de progreso, fue, desde la conquista, la vida americana. ${ }^{2}$

La sola virginidad de América obligó a convertir a la lengua en un instrumento creador, no pesando en ella la tradición que oprimía

\footnotetext{
${ }^{1}$ LUGONES 1916, 135-136.

${ }^{2}$ LUGONES 1916, 136.
} 
a España. Así como la España humanista se dio en latinizar el idioma, el gauchismo, al simplificarlo, lo modernizó, conservando en él, paradójicamente, formas originales del castellano viejo. Es primordial para las tesis que conlleva El payador relevar este proceso lingüístico, pues subrayar las marcas arcaicas del castellano de América no es más que establecer su filiación con el castellano anterior al siglo XVI, unido aún al ámbito cultural de la lengua latina que encarnó los principios del ideal caballeresco, el culto a la mujer y el heroísmo. La intimidad con que se fundieron, en la lengua latina de los llamados tiempos oscuros, elementos tan distintos como los arábicos, los germanos, los anglosajones, los vascos y los eslavos, que componen el germen más activo de la baja latinidad, comporta, para Lugones, una prueba de civilización superior. Así es que se restauró en el fondo silencioso de las pampas, en un nuevo molde, por efecto de la libertad y las tendencias étnicas, un proceso civilizatorio evidente en los diversos aportes de todas las lenguas romanas.

El castellano paralítico de la Academia, corresponde a la España fanática y absolutista, «nuestra madrastra», como decía con tanta propiedad Sarmiento; y en eso, como en todo lo demás, solo le debemos atraso y desolación. Estamos, así, tan separados de ella, como ella misma del espíritu que animó a los primeros conquistadores. Lo que nosotros restauramos y seguimos restaurando, es la civilización por ella perdida; de manera que todo esfuerzo para vincularnos a su decadencia, nos perjudicaría como una negación de aquel fenómeno. Es ella quien tiene que venir a nosotros, la raza nueva, «hija más hermosa que su hermosa madre», pero sin ningún propósito de influir sobre nuestro espíritu, más fuerte y más libre que el suyo. América no será jamás una nueva España. ${ }^{1}$

\section{9. Rojas: la lengua nativa y de conquista}

Un año antes de que Lugones leyera sus conferencias, Ricardo Rojas inaugura en la Facultad de Filosofía y Letras de Buenos Aires la primera cátedra de Literatura Argentina (1912), labor pedagógica e investigativa que confluye en la publicación de su Historia de la Literatura Argentina, obra cuatripartita que comienza a ver la luz en 1917, con «Los gauchescos»; y sigue en 1918, con «Los coloniales»; en 1920, con «Los proscriptos»; y en 1922, con «Los modernos». La obra es vasta y excede los estudios literarios, o como prefirió razo-

${ }^{1}$ LugONES 1916, 141-142. 
nar su autor, abarca la literatura entendida como «todo el contenido de la conciencia como expresión y del universo como representación» ${ }^{1}$.

Ya desde el segundo parágrafo de la «Introducción», Rojas entiende que el idioma argentino, aunque trasplantado, no se corrompió, sino que, al adquirir una forma americana, se renovó y se abrió a una edificación próspera. A Rojas le interesa definir el alcance de este idioma y de la argentinidad, pues necesita establecer los propios alcances de su historia de la literatura argentina. No ignora que El peregrino en Babilonia, de Tejada, la Representación de los hacendados, de Moreno, el Triunfo argentino, de López y la Oda al Paraná, de Lavardén, son todos libros anteriores a la Revolución: ¿son, por tanto, obras argentinas? No ignora, tampoco, que tanto el Facundo, como las Bases y La gloria de don Ramiro fueron escritos en el extranjero: ¿están, por esto, fuera de la nación? Sabe bien que tanto Amadeo Jacques, como Paul Groussac, ambos europeos, se fundieron a nuestro patrimonio cultural: ¿se los puede llamar argentinos? Sabe, también, que el paraguayo Ruy Díaz de Guzmán, el uruguayo Florencio Sánchez y el nicaragüense Rubén Darío quedarían incomprensibles si se los apartara del ambiente intelectual argentino: ¿son nuestros escritores? La idea de literatura nacional es tan vasta y generosa para Rojas, que todas estas obras y estos nombres tienen un lugar en su Historia. Veamos, ahora, qué tan vasto es su idioma nacional; o mejor dicho, completemos las ideas sobre la lengua ya vertidas en La restauración nacionalista.

Al igual que Vicente Fidel López y Juan María Gutiérrez, Rojas se interesa por las lenguas nativas y afirma que fueron suplantadas por el castellano, que ni puede ni debe ocultar las marcas de aquellas. Luego, para esgrimir un buen castellano, por el cual Rojas aboga, conviene no ignorar la naturaleza americana que ha adoptado en estas tierras. Veamos en detalle el volumen «Los gauchescos», donde Rojas se ocupa de la lengua, tanto de la nativa como de la del conquistador.

Los indios americanos hablaban distintas lenguas al llegar los españoles, cuyo castellano vivía, por entonces, un florecimiento literario y se expandía triunfal por sobre los demás dialectos peninsulares. De modo que la América del desembarco vive, desde el punto de vista filológico, el siguiente proceso dual. Por un lado, la formación de un castellano erudito —el de los poemas del Renacimiento y las leyes del Imperio - en pugna con un castellano vulgar, que era el hablado por los conquistadores. Por otro lado, la extinción paula-

\footnotetext{
${ }^{1}$ Rojas 1917, 35.
} 
tina de los idiomas indígenas más débiles en favor de los más fuertes como el quichua, el guaraní y el araucano, que, al sobrevivir, impregnaron el castellano del conquistador.

La tesis del desembarco en América de un castellano vulgar la deduce Rojas del hecho de que el conquistador no es el hombre de Castilla, sino el aventurero extremeño, vasco, andaluz, lusitano, únicos que aceptan reclutarse y embarcarse hacia el Nuevo Mundo. Estos osados navegantes no son, por tanto, cortesanos, sino hombres cuyas lenguas son las del vulgo y cuyas regiones de origen no son más que las de algún dialecto. El idioma que se trasplanta no es, pues, el refinado de Góngora, Cervantes y Quevedo, sino el sermo vulgaris. Luego, hallando remoto que los nativos aprendieran el castellano, el conquistador termina aprendiendo, en pro de la colonización, los idiomas nativos. Aquí hay un primer elemento para delimitar los orígenes del idioma nacional.

Todo esto se detalla en el tercer capítulo del primer tomo de «Los gauchescos», donde versa sobre «La lengua nativa». Allí Rojas resume, en diez puntos, la evolución filológica de los cuatrocientos años de nuestra historia:

$1^{\circ}$ desaparición de los pequeños dialectos indígenas regionales, los cuales nos han dejado numerosos topónimos; $2^{\circ}$ adopción de las tres lenguas indígenas más evolucionadas; $3^{\circ}$ decadencia paulatina de estas últimas en actual proceso de extinción; $4^{\circ}$ suplantación progresiva de las lenguas indígenas por el castellano; $5^{\circ}$ adopción de este idioma como lengua nacional del estado argentino e instrumento exclusivo de su literatura; $6^{\circ}$ diferenciación acentuada del castellano vulgar de los conquistadores, que sobrevivió como idioma gauchesco en las campañas, y del idioma académico, que se siguió cultivando en las ciudades; $7^{\circ}$ enriquecimiento de la lengua conquistadora a expensas de las lenguas conquistadas; $8^{\circ}$ paralelismo de este proceso argentino con la evolución filológica que han seguido todos los pueblos hispanoamericanos; $9^{\circ}$ solidaridad mental de nuestra América por el idioma común de sus diversas nacionalidades; $10^{\circ}$ posibilidad de conservar la autonomía de nuestras respectivas literaturas nacionales sin acatar el canon de sus academias, ni romper los lazos que nos ligan a la patria de origen en nuestro idioma. ${ }^{1}$

Al llegar al sexto capítulo, «El idioma de los conquistadores», Rojas procura especificar mejor de qué se trata el idioma argentino, pues es el idioma en que se escribe la literatura argentina. Ya había

\footnotetext{
${ }^{1}$ ROJAS 1917, 90.
} 
dicho que al llegar el castellano a América se encuentra en proceso de consolidación, pero al traerlo el conquistador, es decir el sermo vulgaris, se trata de un castellano que conserva aún muchas de las formas medievales, mucho de su vigor primitivo, anterior al Renacimiento, que es el modo en que vivía la lengua lejos de Castilla. De aquí que el castellano argentino esté lleno de arcaísmos y vulgarismos que afloran, por ejemplo, en la poesía gauchesca, poesía que Rojas encuentra genuinamente nacional. A este castellano aún medieval que llega a América se suma, luego, tras un proceso de canonización y latinización del idioma, el castellano culto, el sermus eruditus, reuniéndose ambos en la pluma de los escritores argentinos, quienes, al ensamblarlos, componen la literatura argentina. Hay, por tanto, en la lengua nacional, una vertiente popular y una culta. No cree que una valga más que la otra; cree, sí, que en la armonía de ambas reside «la plenitud de una cultura». Esta tesis volverá en Eurindia, libro del que me ocuparé más tarde.

\section{10. Toro y Gisbert y Menéndez Pidal: la tesis de la escisión moral}

No debo aún alejarme de los albores de 1910, pues en esos años, Miguel de Toro y Gisbert publica en París sus Americanismos, cuyo primer capítulo embiste «contra los fanáticos partidarios de una estrafalaria emancipación lingüística, que quisieran convertir el español de los argentinos en una lengua análoga al francés de los haitianos...» ${ }^{1}$. Esa estrafalaria emancipación remite principalmente al Idioma nacional de los argentinos. Toro y Gisbert conjetura que Lucien Abeille es conducido por tres impresiones funestas: la que lo sorprende ante los fenómenos de la lengua en Argentina; la que lo induce a engaño por mal interpretar lo gauchesco; y la que lo hace desdeñar, como es propio de los franceses, todo lo que provenga de España. Luego, afianzado en esta triple ofuscación, Abeille se empeñaría en demostrar que hacen bien los argentinos en destrozar la lengua de sus antepasados. Tomando de referencia la reseña de Alfred Morel Fatio (1900) sobre Idioma nacional de los argentinos, Toro y Gisbert encuentra que las variaciones que releva Abeille en la lengua argentina son equivalentes a las que podemos hallar, no solo en el español de cualquier país hispanoamericano, sino en el de la misma España.

\footnotetext{
${ }^{1}$ TORO Y GISBERT [1912], 6.
} 
Deben pues desengañarse los partidarios de la Babel sudamericana. Hablan español y de España les vino su lengua, con todos sus defectos, así como con sus elementos de progreso. ${ }^{1}$

Sin embargo, Toro y Gisbert sabe que, en cuanto a la cuestión del divorcio idiomático entre América y España, no solo hay que refutar a Abeille, sino a Rufino Cuervo, a quien consagrará el segundo capítulo, «La lucha de las lenguas y el separatismo lingüístico», ensayo que atenderá dos causas distintas: una lingüística, otra política. En cuanto a la primera, no cree pertinente comparar la ruina de la lengua latina con los avatares de la lengua en América. Valiéndose ahora del libro de Albert Dauzat, La vie du langage (Paris, Colin, 1910), adscribe a la idea de que el camino evolutivo de las lenguas no sucede igual en unas que en otras, ni son equiparables sus fatalidades. La invasión de elementos extraños, condición imprescindible para corromper una lengua, no resulta decisivo en aquellas lenguas que ostentan vigorosidad y altas defensas. El español, por el número de seres que lo hablan en América y por sus propias virtudes, tiende a expandirse aún más, no a retroceder y disgregarse en dialectos. Es tan capaz de absorber como de asimilar las voces ajenas. De modo que se pregunta:

¿Qué nos reserva el porvenir? ¿El aumento de las ligeras divergencias que separan una lengua de otra, o la unificación de ambas? Prefiero por mi parte adoptar esta última suposición. Ya es hora de que cese la leyenda del divorcio entre España y América. ${ }^{2}$

En cuanto a la segunda causa, despachados los argumentos que invalidan la gestación de lenguas nacionales en Hispanoamérica, Toro y Gisbert cree que, en el fondo, es un antiguo rencor hacia España lo que aviva al separatismo, rencor que, por lo remoto, debiera dejárselo en paz. "Ya no hay opresores ni oprimidos, y si nuestros bisabuelos se batieron por las causas igualmente nobles de la libertad y del respeto a las leyes, no debemos nosotros continuar mirándonos con ojeriza.» ${ }^{3}$ Asumida ya la autonomía nacional entre España y Argentina, entiende que persiste una unión de raza — más firme que la nacionalidad - que traza un puente venturoso, no solo en cuanto a la lengua, sino también en cuanto a la literatura de am-

\footnotetext{
${ }^{1}$ TORO Y GISBERT [1912], 25.

${ }^{2}$ TORO Y GISBERT [1912], 48.

${ }^{3}$ TORO Y GISBERT [1912], 49.
} 
bos pueblos. Cuando el celo provinciano de los argentinos cese, concluye, se verá los beneficios de afianzar este vínculo hispano.

Esta segunda causa que menciona Toro y Gisbert —la causa moral del separatismo- será refrendada años más tarde por Ramón Menéndez Pidal, al enviar una carta — fechada en Madrid, en diciembre de 1917 - a sus amigos Aurelio M. Espinosa y Lawrence A. Wilkins, de los Estados Unidos, a quienes saluda por el primer número de la revista Hispania, que impulsan a través de la American Association of Teachers of Spanish. Los buenos augurios no vienen solos, traen adosadas dos tesis referidas a la querella. La primera - atendiendo al hecho de que la Asociación pretende ahondar en el estudio del español - se ocupa de la distinción entre el habla de España y el habla de Hispanoamérica; distinción que, para Menéndez Pidal, solo se encuentra en el habla popular, pues el habla culta está unificada a uno y otro lado del océano. Todas las hablas populares, agrega, abundan en variaciones regionales, hecho que no debe conducir a estimarlas como lenguas nacionales. Las diferencias existentes en el habla popular de Hispanoamérica, por otra parte, son considerablemente menores a las que existen en España. El llamar «española» a la lengua remite, para Pidal, a esta superación de las variedades locales.

¿A qué responde, se pregunta entonces, la pretensión de aspirar a una lengua argentina? Lo responderá en su segunda tesis, donde advierte que la pretendida escisión argentina es ajena a todo basamento lingüístico. Para Pidal existe un resabio de antipatía con la antigua metrópolis, que conduce al argentino a pensar que su lengua es argentina, nunca española. Jefe representativo de esta corriente cismática, y de esta generación antipática, sería Domingo Faustino Sarmiento, quien, interpretando el momento histórico de América, daba prioridad a la adquisición de ideas, antes que a las formas con que expresarlas. Esta actitud sarmientina habría sido mal interpretada para fundar, de su exageración, un movimiento separatista basado en esos resabios de antipatía. Este sentimiento, luego, «quiso presentarse bajo una apariencia sistemática y científica en el libro que publicó en 1900 el francés Abeille, elevando a la categoría de “idioma nacional" todos los vulgarismos argentinos»". La idea de que Sarmiento ha sido tergiversado la debe de haber tomado Menéndez Pidal del artículo de Groussac, «A propósito de americanismos» (1900), pues a él remite para sentenciar que otro francés, ahora más eminente, se encargó de fustigar a Abeille y echar por tierra la causa del idioma nacional.

${ }^{1}$ MenéndeZ Pidal 1918, 7. 
A lo que yo he podido averiguar entre los escritores de toda clase de las generaciones jóvenes argentinas, la idea del idioma nacional está muerta y enterrada siete estados bajo tierra. Y téngase entendido que en ninguna otra república americana ha habido un movimiento semejante al de la Argentina. ${ }^{1}$

Hay otro aspecto relevante en esta carta de Menéndez Pidal, inscripto en su título, pues, a partir de lo que en ella se argumenta, cada vez será menos indistinto el modo en que se la llame a la lengua: «puestos a escoger entre los dos nombres de lengua española y lengua castellana hay que desechar este segundo por impropio» ${ }^{2}$. ¿Dónde reside la impropiedad? Pidal sabe que llamar a la lengua española data de la Edad Media, pero entiende que esta denominación no se hace tan justa y necesaria sino a partir del Siglo de Oro, cuando la nación contaba ya con los reinos de León, Castilla, Aragón y Navarra. Siendo Castilla el alma de esta unidad, entiende que los otros reinos colaboraron en el perfeccionamiento de la lengua literaria. Previo a esta unidad, y siendo aún lenguas literarias el leonés y el aragonés, no hubiera sido un desatino llamar castellana a la lengua de Alfonso el Sabio o a la del Arcipreste de Hita; pero sí lo hubiera sido en el caso del Quijote. Se ha españolizado tanto la lengua, que Pidal ya no ve bien que la Academia la siga llamando castellana, pues «induce erróneamente a creer, dado su valor geográfico restringido, que fuera de Castilla no se habla la lengua literaria sino como una importación...» ${ }^{3}$

Si seguimos este aspecto geográfico del planteo, para principios del siglo XX, cuando Pidal remite su carta a los Estados Unidos, la lengua tampoco debería llamarse española, pues también induciría erróneamente a creer que fuera de España no se la habla. Pero el aspecto geográfico no tiene tanta relevancia como el lingüístico; Menéndez Pidal no cree que las lenguas americanas hayan aportado algo tan relevante como lo han hecho, a partir del siglo XV, el leonés, el aragonés y el navarro. La Real Academia no verá insuficiencia alguna en estas sugerencias de Menéndez Pidal y las tomará como si se tratara de una revelación: abandona el adjetivo castellana y llamará, a partir de la decimoquinta edición de su libro (1925), Diccionario de la lengua española. Según confesará su «Advertencia», la nueva edición pone mayor atención al aporte de las «múltiples re-

\footnotetext{
${ }^{1}$ MenÉndez PidAl 1918, 8.

${ }^{2}$ Menéndez Pidal 1918, 3.

${ }^{3}$ Menéndez Pidal 1918, 3.
} 
giones lingüísticas, aragonesa, leonesa e hispanoamericana» ${ }^{1}$. Reemplazar el calificativo castellana parece lógico, pues no solo se estamparán voces de Castilla; como tampoco se estamparán solo voces de España ¿cómo se explica que, no obstante, se quede en española? Para algunos, el problema es los españoles estiman que Hispanoamérica aún es una región de España. Más adelante veremos cómo este rebautizo genera una nueva polémica, ahora por el nombre.

${ }^{1}$ ReAl ACADEMia Española 1925, VIII. 


\section{PRIMERAS PERIODIZACIONES: COSTA ÁlVAREZ, QUESADA Y \\ ROJAS}

(1922 - 1923)

\section{1. Primera periodización: Nuestra Lengua, de Costa Álva- rez}

En 1922 el filólogo platense Arturo Costa Álvarez publica una serie de ensayos bajo el nombre de Nuestra Lengua, algunos de los cuales destina a biografiar la querella de la lengua en Argentina. Se trata, entonces, del primer intento de periodización, justo cuando la controversia está a punto de cumplir un siglo y ya hay algunos (acabamos de ver el caso de Menéndez Pidal) que la dan por muerta.

El libro busca la ecuanimidad científica, aunque monta en cólera de a ratos. Flexible y generoso por momentos, deviene en retador y preceptista en otros. Resolutivo y categórico en algunas de sus páginas, se torna frágil y provisional en muchas otras. Siempre pendenciero. Siempre misceláneo. Algunos lo han llamado maciz̨o; otros, heroico, erudito, discreto, sopesado, trascendente... y hay a quien se le escapó un divino. Luego de un prólogo, donde confiesa haber hecho confluir en la empresa veinticinco años de meditación y compostura, Costa Álvarez diserta, en las casi trescientas cuarenta páginas restantes, sobre el arte de discutir, traducir, hablar, escribir y lexicografiar en castellano.

Nuestra lengua consta, así, de cuatro cuerpos principales: «Los Idiomólogos», «Los Traductores», «Los Diccionarios» y «Las Lenguas». El primero, del que me ocuparé sucintamente, ostenta un nombre impronunciable, invención del mismo Costa Álvarez, castigador infatigable (junto a Monner Sans) de los neologismos. Es un nombre, además, ambivalente, porque idiomólogo alude tanto a los que se han pronunciado sobre el idioma en América, como a los que postularon la existencia de un idioma nacional.

El idiomólogo es un tipo de escritor que no existe sino en la tierra americana descubierta, conquistada, colonizada y explotada por los españoles. Se distingue de todos los escritores de la humanidad por este rasgo característico: predica la sustitución de la lengua en que escribe, y el castellano le sirve para decir que el castellano no sirve. ${ }^{1}$

\footnotetext{
${ }^{1}$ Costa Álvarez 1922, 91.
} 
En el sentido no despectivo del concepto idiomólogo —es decir, en tanto alusión a todos aquellos que simplemente se ocuparon del idioma-, Costa Álvarez sería uno de ellos, me atrevo a decir: el idiomólogo por antonomasia.

Esta primera parte del libro, de cuyo nombre no quiero abusar, despliega una genealogía, la primera en su especie, de la polémica en torno al castellano en Argentina. Consta de nueve ensayos que ameritan ser referidos:

El primero se titula «Echeverría y la lengua». La primera empresa de Arturo Costa Álvarez es demostrar que Esteban Echeverría ha sido mal interpretado, intentando probar que, donde este dijo ampliar y enriquecer la lengua, otros han leído barbarizar y arruinarla. Echeverría — según esta exégesis - no impugnaba la lengua de los conquistadores, sino cuando esta lengua se disponía para la causa monárquica, arcaica y rutinaria. Todo el matiz americanista con que Echeverría forjó su lengua no debería presentarse, por tanto, como antecedente de la gauchesca ni de ninguna parla singular.

Demostrada la tergiversación que se hizo de Echeverría, que Costa Álvarez realiza exponiendo todos los párrafos en que el poeta habla de la lengua, empleará, en los ensayos siguientes, el mismo procedimiento con Alberdi, Sarmiento y Gutiérrez, pues cree que ellos tampoco han predicado la desnaturalización del castellano entre nosotros, sino que habrían sufrido la misma adulteración que sufrió Echeverría. Este será el propósito principal de estos iniciales capítulos: desligar a estos hombres de todo plan corruptivo de la lengua y quitarles el sayo de segregacionistas. Esta tesis, esbozada ya en los artículos de Groussac y Cané, ambos de 1900, es la que Costa Álvarez desempolva para reavivar y nutrir de ejemplos.

$\mathrm{El}$ segundo ensayo lleva por nombre «Alberdi y la lengua». $\mathrm{Si}$ al ideal idiomático de Echeverría lo reencausa, al de Alberdi lo disculpa. Costa Álvarez establece dos Alberdi, el joven y el maduro. Aquel ostenta unos treinta años; este ya es sexagenario. Uno está en la edad de la impaciencia, la intolerancia y el arrebato; el otro, en el rellano de la reflexión ecuánime. El joven, enemistado con todo lo español; el viejo, reconciliado. Declamador patriotero, guerrillero y ditirámbico en loor francés, el pequeño; sereno y sabio, el grande. El uno quiere formar una lengua nueva para los argentinos; el otro, clama por custodiar la unidad del idioma español.

Dos Alberdi son, entonces, los que denuncia Costa Álvarez, pero solo el primero incurriría en confusiones funestas al creer que a cada nación corresponde una lengua y que esta cambia al mutar el gobierno de la nación; se confunde al enseñar que la lengua vulgar 
debe enarbolarse como lengua nacional y que el idioma español es un desgraciado porque en él solo se escriben desgracias; se confunde al sostener que una revolución en literatura no es tal sin una revolución en la lengua y que el progreso del castellano depende de su sumisión al francés; se confunde, finalmente, al concebir que a determinada lengua, determinadas ideas (hablo español: pienso mal; hablo francés: pienso bien) y que pronto será familiar entre nosotros el lenguaje de Lerminier, Hugo, Carrel, Didier, Fortoul y Leroux.

Expuestas así como lo hace Costa Álvarez, estas ideas no enseñan de un pensamiento más que su aspecto estrafalario. ¿Qué juicio acomodar a un exegeta que presenta al Alberdi del Fragmento y de La Moda como un ridículo y un necio? El mismo Costa Álvarez debió de haber sentido que sus apreciaciones eran algo petulantes, de modo que, al final, lo disculpa:

Entre los pinitos flojos y vacilantes de la criatura, y el tranco nervioso y rítmico del conscripto; y el andar firme y elástico del adulto, y el paso lento y cauteloso del anciano, no hay contradicciones sino períodos distintos de la evolución biológica. ${ }^{1}$

El tercer ensayo versa sobre «Sarmiento y la lengua». En el caso de Sarmiento, habría embestido contra el castellano por encontrarlo responsable del espíritu rutinario, preceptista y servil de los que escriben valiéndose de él. Estos malos escritores, así, serían la causa de que los pueblos de América, recientes conquistadores de la libertad de acción, no puedan alcanzar también la libertad de pensamiento mediante libros escritos en castellano. Esta observación - achacar a la lengua los pecados de quienes la usan - ya la había objetado en Alberdi; por lo que, cuando Sarmiento escribe lengua anota Costa Álvarez- debe leerse literatura.

Este Sarmiento que estremece al idioma a principios de los años cuarenta, en Chile, tendría algo en común con el Aberdi que, desde Montevideo, había hecho otro tanto: ambos son jovencitos. Ambos, desterrados y rencorosos de España, acuerdan en que la lengua es el último lazo a romper para que la emancipación se complete.

Pero la visión de Sarmiento se diferencia de la de Alberdi en dos rasgos principales: primero, la de Alberdi nace de la voluntad persistente, la de Sarmiento de una veleidad momentánea; segundo,

${ }^{1}$ Costa Álvarez 1922, 42. 
Alberdi da por hecho ya, por existente, un idioma particular argentino, Sarmiento predice un idioma general hispanoamericano. ${ }^{1}$

Otros aspectos, además, diferenciarían a ambos: Alberdi funda su emancipación de la lengua en la razón política y en ciertas leyes evolucionistas; Sarmiento, en cambio, no daría ninguna razón científica. A Costa Álvarez, todas las disquisiciones sarmientinas le resultan vaguedades filosóficas, en clave metafórica, ininteligibles, además, por los errores de sintaxis.

De todos modos, Costa Álvarez intentará luego demostrar que también hay dos Sarmientos: uno que vota por la autonomía de la lengua hispanoamericana; otro, por la unidad de la lengua. Si uno es idiomólogo; el otro, purista. Cita los fragmentos en que Sarmiento es uno y otro, y elige el que le resulta más bello y razonable: el que aboga por la unidad del castellano. ¿A qué razón responde esta partición del cuyano? Pues a que Costa Álvarez no puede concebir un Sarmiento en permanente disputa. Su propensión a creer que debe existir un determinado tipo de orden lógico en el pensamiento lo induce a convertir el huracán verbal sarmientino en una brisa que sopla siempre en un mismo sentido. Así, lotea el cosmos idiomático de Sarmiento y enseña solo un puñado de estrellas, una única constelación. Aquí está la prueba:

Tiene un valor puramente circunstancial todo lo que el gran hombre ha escrito contra la Academia por su ortografía arbitraria, y contra los puristas por su aversión al neologismo; y quedan como anhelos fijos suyos, objeto de su predicación constante, en primer lugar la adopción definitiva del castellano como lengua común para todos los pueblos americanos de origen español, y en segundo lugar el uso debido de esta lengua a los efectos de mantenerla pura. ${ }^{2}$

Domadas, así, las tesis idiomáticas de Sarmiento, ya no ofrecen casi ningún interés.

En el cuarto ensayo («Gutiérrez y la lengua»), compuesto con la misma lógica que los tres anteriores, se ocupará del acto quizá más célebre de Gutiérrez: el rechazo del diploma. Costa Álvarez cree que, para que no resulte insólita y desconcertante la actitud de Gutiérrez, es necesario distinguir entre el rechazo del diploma, acto de orden personal y pasional; y el rechazo de la intervención académica, acto de orden público, que obedece a razones de interés

\footnotetext{
${ }^{1}$ Costa Álvarez 1922, 50.

${ }^{2}$ Costa Álvarez 1922, 56.
} 
general, fundadas en las particularidades de nuestra lengua. Las razones primeras, las pasionales, las habría explicitado el mismo Gutiérrez: él no podía servir a una causa monárquica; y temía, además, una trapacería de España, que intentaría recobrar su dominio en América, aunque más no sea un dominio espiritual, rindiendo a sus pies, con títulos honoríficos, las voluntades de los intelectuales. Las razones segundas, las de orden público, las llama «razones improvisadas», a las que Gutiérrez habría recurrido para velar discretamente aquellos móviles personales y pasionales. Esta tesis la completa agregando que no se habría comprendido esta dimensión dual del célebre rechazo y se habría tomado estas «razones improvisadas» como un programa orgánico y acabado en pro de un autoctonismo idiomático.

Esta nueva tergiversación la habría originado Francisco A. Berra, en aquella polémica con Mariano A. Pelliza; y la habrían recogido, en 1889, Mariano de Vedia, que, en favor de un idioma americano, cita párrafos de Gutiérrez; y ese mismo año, Alberto del Solar, que ve a Gutiérrez como un autonomista. El mismo Ernesto Quesada, en 1900, hace de «El Porteño» un idiomólogo; igual que lo hace Menéndez Pidal en la carta que envía a sus amigos Espinosa y Wilkins, en diciembre de 1917. Costa Álvarez, no obstante, afirma que

No hay tal tesis ni tal doctrina en Gutiérrez. Si el error en este punto se ha generalizado es porque nadie estudió el caso debidamente: De Vedia sugestionó a Del Solar, estos dos escritores influyeron en Quesada, y este pasó la palabra a Menéndez Pidal, quien, a su vez, la ha comunicado a Julio Casares, que en Crítica efimera (I, 267) trascribe esa afirmación sin corregirla. En 1900, Miguel Cané en La Nación y Paul Groussac en los Anales de nuestra biblioteca nacional tratan de librar a Gutiérrez de ese sambenito con que la pasión patriotera, necesitada de una autoridad, lo revistió desde el primer momento; pero, para destruir el error no basta declararlo, hay que demostrarlo. ${ }^{1}$

Y es esto lo que intenta demostrar Nuestra lengua, que Gutiérrez rechaza el purismo y la intervención de la Real Academia en América, pero, siendo un escritor muy castizo, no auspicia la formación de un idioma patrio. Dos pasajes de las famosas cartas porteñas le bastan para demostrarlo:

Ha creído Perulero que cuando el señor Gutiérrez hablaba de una lengua española enriquecida con elementos que le llegaban (en este

${ }^{1}$ Costa Álvarez 1922, 65. 
país) con la industria y la actividad, y las costumbres de la inmigración, optaba por una jerga incoherente y descosida que solo hubiera de entenderse a las orillas del Plata, quedándonos segregados del comercio hablado y escrito con todos los pueblos de nuestra raza. ${ }^{1}$

Consta, esta cita, en la segunda carta de Gutiérrez, publicada en La Libertad, el 23 de enero de 1876. La cita siguiente, se encuentra en la sexta carta, publica en el mismo medio, el mismo año, el día 28 de enero:

En ella [en la carta de Gutiérrez] se trata sencillamente de revolucionarse contra toda traba que en nombre de intereses que representa y sirve la Academia matritense, pudieran impedir el ensanche, en todo sentido, del lenguaje que se usa o usare en lo futuro, no a orillas del Manzanares, sino a las orillas del Río de la Plata. ${ }^{2}$

Llegamos así al ensayo «La disciplina académica y la lengua», en el que, una vez encauzadas las opiniones de los cuatro románticos, Costa Álvarez procura demostrar que los cuatro proclamaron, en definitiva, que nuestro idioma no es más ni menos que el castellano, al que debemos limpiar de las impurezas con que lo afea, en la lengua vulgar, la inmigración cosmopolita; $y$, en la lengua culta, la lectura continua de libros extranjeros. Estos hombres, agrega, han sido, por un lado, mal leídos; y, por otro, ellos habrían sugerido a través de la «prosa incorrecta» un combate contra el casticismo. Porque los cuatro, agrega, fieles al castellano en teoría «rendían culto en la práctica al barbarismo y al solecismo: Gutiérrez por momentos, Echeverría a cada instante, Sarmiento por temporadas, Alberdi toda la vida». ${ }^{3}$

Estamos ante otra dualidad, tan recurrentes en los análisis costalvareanos. Esta actitud bicéfala: pensar en favor de la pureza, escribir aferrado al barbarismo, sería una idiosincrasia muy argentina y marca evidente en los románticos. Esta fusión entre «lengua vulgar» y «lengua culta», esperando que surja de la reunión una lengua más propicia, sería, para don Arturo, la doctrina que, en materia de lengua, recomiendan Echeverría, Alberdi, Sarmiento y Gutiérrez. De modo que estamos, no ante un reajuste de su tesis, sino, creo yo, ante una nueva.

Más adelante, Costa Álvarez enumera doce puntos, que serían los doce extravios a partir de los cuales se hizo, de estos cuatro hom-

${ }^{1}$ GUTIÉRREZ 1876c, 102.

${ }^{2}$ GuTIÉRREZ 1876d, 128.

${ }^{3}$ Costa Álvarez 1922, 71. 
bres, «una piqueta para demoler el castellano, y un cemento para construir un idioma privativo en su reemplazo» ${ }^{1}$. Los resumo: $1^{\circ}$ Ver en España la dependencia y el atraso. $2^{\circ}$ Creer que escribir un castellano correcto es escribir la lengua de otra nación: España. $3^{\circ}$ Tender al rechazo de toda sujeción o norma. $4^{\circ}$ Aspirar a tener un idioma privativo, creyendo que la distinción reside en la forma de la lengua, y no en el pensamiento. $5^{\circ}$ Entrever en el gauchesco el germen de este idioma autóctono. $6^{\circ} \mathrm{La}$ idea de que la literatura francesa debe su prestigio a la lengua francesa; lengua que, por tanto, deberíamos imitar. $7^{\circ}$ Un interés por la novedad y una repugnancia por lo habitual, situación que los induce al neologismo. $8^{\circ}$ Una vanidad por aparecer versados en lenguas extranjeras. $9^{\circ}$ Cierta convicción en que la lengua es el habla, y que por tanto se aprende sola. $10^{\circ}$ La negligencia gubernamental, que, al descuidad el estudio de la gramática en la escuela y permitir el estudio de escritores incorrectos, desdeña la unidad de la lengua. $11^{\circ} \mathrm{La}$ adquisición de traducciones baratas e ignorantes del idioma castellano. $12^{\circ} \mathrm{El}$ natural desprecio que profesan al castellano los escritores plebeyos de «nuestra prensa populachera».

Cierra el capítulo quinto preanunciando que en la Argentina reina una «incultura populan», signada por el desinterés en la gramática, la ausencia de modelos literarios propios y la imposibilidad de asentar una academia argentina de la lengua. De esto se ocupa el capítulo sexto, de «La incultura popular y la lengua», pues el siglo XIX en Argentina, para Costa Álvarez, termina con el triunfo y la apoteosis de la incultura popular en el lenguaje, donde la corrupción del idioma se habría hecho sistemática en los dos últimos decenios en pos de lograr un fin patriótico: «nacionalizar el habla». Esta apoteosis plebeya coincide con el auge del criollismo, mixtura lingüística a la que llama bodrio y artificial, y en cuyos albores está el Santos Vega, el Martín Fierro y el Juan Moreira, es decir, la propensión al coraje, la patriada y el espíritu indómito. El criollismo es, para Costa Álvarez, la escuela que propone despertar y fomentar el amor a la patria con «cualquier» tipo de recurso; y bajo esta bandera, se habrían cobijado los ardorosos buscadores del idioma nacional. Con el concurso de los escritores plebeyos, concluye Costa Álvarez, la propaganda de los idiomólogos entra en auge y cobra relevancia el clamor por un idioma privativo. En este concierto de voces es que surge el libro de Lucien Abeille, al que llama «monstruoso endriago», y al cual se consagra el próximo capítulo, titulado «El libro de Abeille y la lengua».

\footnotetext{
${ }^{1}$ Costa Álvarez 1922, 73.
} 
Luego de llamar a Abeille «doctor en teología», Costa Álvarez afirma resultarle evidente que esta obra persigue tres objetivos: plantear una tesis, ostentar erudición y hacer zalamería. Luego, acusa a Abeille, entre otras cosas, de plagio, por robar en tres oportunidades del Vocabulario Rioplatense Razonado, de Granada; y por saquear, íntegro, el folleto de Gaston Maspero sobre el lenguaje gauchesco. A estas dos obras «ni una sola vez cita Abeille en su libro». Pero no cree relevante ocuparse de esto, sino de la tesis ofrecida en Idioma nacional de los argentinos, cuya idea estaría planteada a priori, sustentada en razones, no en hechos. Abeille, afirma Costa Álvarez, entiende que debe haber un idioma nacional, pero no puede demostrarlo.

En el ensayo siguiente, «El buen sentido y la lengua», que es el octavo, Costa Álvarez cita en extenso el artículo de Groussac, «A propósito de americanismos», de 1900, pues encuentra en él, condensada, toda la buena doctrina en relación al problema de la independencia idiomática. Es el reconocimiento al hombre que lo inspiró a escribir la mayor tesis de Nuestra lengua: reencauzar a los románticos. Luego, vuelve a trazar la genealogía del pleito sobre el idioma nacional, acaso para reiterar que se trata de un pleito superado.

El último ensayo de esta primera parte, entonces, llevará por nombre «La lengua misma». Valiéndose de la Historia de la literatura argentina, de Ricardo Rojas, Costa Álvarez expone los orígenes de la lengua en Argentina, a los que pretende completar con una descripción del estado actual de esta lengua. Lo desvela un hecho que estima lamentable: «Cuando se nos pregunta de pronto qué lengua hablamos los argentinos, vacilamos mucho en responder» ${ }^{1}$. Costa Álvarez cree vana esta dubitación, pues ni el galimatías de los inmigrantes, en las capitales y los puertos; ni la subsistencia del castellano arcaico, en pueblos, llanuras, sierras y familias tradicionales; ni la gauchesca de los viejos campesinos del Plata; ni el lunfardo de los suburbios; ni el guirigay compadrito de los arrabales; ni el guaraní de Corrientes; ni el quichua de Santiago; ni ninguna otra parla singular debería torcer la convicción de que en Argentina hay un único idioma nacional: el castellano general y culto.

Para respaldar esta convicción, Costa Álvarez cree necesario distinguir la lengua general de una nación, de las hablas regionales y las jergas; pues mientras estas suelen ser varias y variadas, y las hay en todas las lenguas; aquella corresponde a la lengua oficial, la lengua de los himnos, de las leyes y códigos, de los textos impresos

${ }^{1}$ Costa Álvarez 1922, 141. 
correctamente, de los prosistas y poetas que respetan la gramática y las buenas costumbres. Esta lengua general, en el caso de la Argentina, es y debe seguir siendo el castellano.

Llegamos, entonces, a la tesis final de Costa Álvarez, que, al mismo tiempo que postula la indisputabilidad del castellano como único idioma argentino, agrega que se halla íntegro y definido. La causa por el idioma nacional se encontraría destruida, y estas notas que constituye Nuestra lengua serían su biografía definitiva. Nuestro filólogo no podía intuir, entonces, que su esmerado trabajo constituiría un jalón más de la querella — que sobreviviría a otros tantos funerales más-, ni podía intuir que así como él compuso un réquiem para el pleito del idioma, otros lo compondrían para Nuestra lengua. Será, este entrevero en que distintas escuelas filológicas se decretan mutuamente la muerte, asunto de un capítulo posterior.

\section{2. Segunda periodización: La evolución del idioma nacio- nal, de Ernesto Quesada}

La empresa desplegada en Nuestra lengua convence a muchos: algunos la elogian en la prensa, otros la festejan en el estrado. A Ernesto Quesada lo motiva a tal punto que acomete una reescritura, enfatizando todo aquello que considera omisiones y distracciones. Esta reescritura — que la revista Nosotros publica a principios de $1923^{1}$ y la imprenta Mercatali reimprime el mismo año en forma de folleto- lleva por nombre La evolución del idioma nacional. Compartiendo en lo substancial las tesis de Costa Álvarez, el ahora director de la Academia correspondiente se pone a señalarle detalles, como si acusara a su antecesor de no haber consultado los 60.000 volúmenes (sic) que conforman su biblioteca. Quesada aplaude en general a Nuestra lengua, para luego objetar varias de sus páginas en particular. Todo el opúsculo quesadiano, así, adquiere la forma de una dilatada nota al pie, atestada de referencias bizantinas y anécdotas no exentas de cierta vanidad. Entre las primeras se encuentra la mención de artículos y cartas que solo el hijo de Vicente G. Quesada ostenta; entre las segundas, la mención de todas las voces que festejaron sus trabajos de 1900 y 1902, algunas de las cuales lo llaman sabio, erudito y un ser de la más recta doctrina.

Costa Álvarez apenas escribió un libro sobre la lengua en Argentina, Quesada le recrimina todo lo que le faltó para ser uno sobre la lengua en América. Aquel solo pretende ocuparse de los que invocaron la expresión idioma nacional; este le objeta haber olvidado

${ }^{1}$ Quesada E. 1923a; Quesada E. 1923b. 
los trabajos sobre lexicografía, morfología, sintaxis e, incluso, literatura argentina en general. Veamos no obstante, más allá del señalamiento de estas peccata minuta, qué otras novedades nos llegan con esta segunda periodización que compone Quesada.

La idea de Costa Álvarez de quitar el sayo de segregacionistas a los románticos empieza a ejercer influencia y convierte, en primer lugar, al mismo Quesada, que, si antes había hecho a Gutiérrez el promotor principal de un idioma local, ahora cree naturalmente que esa prédica contra la lengua española era solo resabio del odio contra todo lo godo: «ninguno de aquellos cultos argentinos - como lo demuestra acabadamente Costa Álvarez- en realidad soñó con la suplantación del castellano por un dialecto cuasi indígena» ${ }^{1}$. Luego insiste en que la querella por el idioma nacional ha sido superada; idea que escribe como si estuviera tallando un epitafio. Así, La evolución del idioma nacional procura señalar los tres momentos de este extinto pleito: nacimiento, desarrollo y muerte. El tono del ensayo es el de aquel que se refiere a algo remoto. Poco antes de finalizar el primer cuarto del siglo XX, la lengua nacional ya dejó de ser, para Quesada, un problema. La unidad de la lengua es un hecho que ya nadie discute. Luego de la querella suscitada en torno al criollismo, triunfantes las fuerzas unificacionistas y disipadas las tendencias «deliberadamente corruptoras del idioma», reina sin oposición «la buena doctrina» de la conservación y la pureza idiomática. Hay un único idioma nacional, vuelve a decir en este nuevo ensayo, y es el castellano, pero no el de la conversación pública o la sobremesa hogareña, sino el de «la lengua usada por los buenos escritores, en el libro o en el periodismo, lo que caracteriza el lenguaje nacional» ${ }^{2}$.

Como prueba de este triunfo definitivo, Quesada subraya el diarismo de la época, pues encuentra que la evolución del idioma nacional (el castellano culto) ha sido principalmente la obra de la prensa periódica. En la Argentina, no es tanto el libro como el diario el vehículo difusor de las ideas, por lo que es trascendental su labor para la purificación de la lengua. La prensa, entiende Quesada, ha tomado ciertos recaudos luego del pleito en torno al criollismo, y ha procurado quedar del lado del casticismo, pues cada diario ha cuidado de incorporar a su personal superior un técnico, generalmente español, hablista consumado, que revisa lo que publica el periódico, «limpiándolo de abrojos y malezas en punto a lenguaje». Luego, el público tiende a imitar la lengua del periódico, creándose así un círculo virtuoso. Quesada cree ser testigo de un cambio sus-

\footnotetext{
${ }^{1}$ Quesada E. 1923 c, 6.

${ }^{2}$ Quesada E. 1923c, 9.
} 
tancial entre el periodismo de la segunda mitad del siglo XIX y la primera del XX; en aquel afloraba el vulgarismo, el solecismo y el estilo desparejo; en este se estampan formas límpidas y cultas.

Y en el éxito de esta saludable evolución del idioma nacional, es de estricta justicia declarar que el mérito principal le corresponde al diario La Nación, pues fue el primero que dio al asunto toda la importancia que le correspondía... ${ }^{1}$

Casi al mismo tiempo que Quesada decreta el fin de la querella, Borges y Macedonio Fernández fundan Proa, mientras Oliverio Girondo, desde París, escribe a su amigo y poeta Carlos de la Púa, exhortando a los americanos a tener fe en nuestra fonética, pues

[...] hemos sido nosotros, los americanos, los que hemos oxigenado el castellano, haciéndolo un idioma respirable, un idioma que puede usarse cotidianamente y escribirse de "americana», con la «americana» nuestra de todos los días $[. . .]^{2}$

\section{3. La lengua de Eurindia}

A partir del $1^{\circ}$ de octubre de 1922, en su suplemento dominical, el diario La Nación comienza a publicar Eurindia, ensayo que Ricardo Rojas concibió a modo de una estética sobre las culturas americanas. El concepto «Eurindia» le viene, por aquellos años, como una revelación: ante las dos corrientes espirituales que constituyen América - la indígena y la europea, que han marchado paralelas o yuxtapuestas, sin llegar a fusionarse-, Eurindia intenta la reunión y la síntesis. No rechaza la vertiente europea: la asimila; no reverencia la americana: la supera. Toma lo mejor de ambas. Busca refundir el misterio legendario de los indios, la emoción pampeana de los gauchos y la generalidad idiomática de los españoles en una conciencia estética que contenga todo y lo proyecte hacia lo universal. Es, por tanto, la unidad de las fuerzas artísticas más vitales de lo autóctono y lo foráneo; lo anterior y lo posterior a la Conquista. Eurindia, para Rojas, es el reencuentro hospitalario de las razas; el despertar de un nuevo hombre consciente de su americanidad blanqueada. Eurindia, finalmente, es más bien una posibilidad, una deidad guiadora y, por momentos, un destino inevitable que ya se empieza a realizar.

\footnotetext{
${ }^{1}$ QuesadA E. 1923c, 57-58.

${ }^{2}$ GIRONDO 1924.
} 
Como el programa de esta obra es vastísimo, los temas abordados son diversos, pero uno se esgrime como central: la lengua, a la que consagra siete capítulos directos. Me detendré, previamente, en la tesis general del libro.

Rojas concibe dos grandes períodos culturales en América: antes y después de la colonización. Allí se produce un sismo continental. Este choque entre lo indiano americano y lo exótico europeo es el punto de partida de una historia que tiene, primero, a los indios precolombinos vencidos por los conquistadores españoles; luego, a estos vencidos por los gauchos americanos; quienes, más tarde, serán vencidos por los nuevos inmigrantes europeos. Por último, estos serán superados por un nuevo americanismo, que no anulará estas herencias, sino que las ensamblará en síntesis eurindiana.

Estas etapas políticas tienen sus correlatos literarios: el folclore indígena, primero; luego, el clasicismo colonial; más tarde, la poética de los gauchescos; a los que le siguió el cosmopolitismo de los modernos. Una nueva literatura surgirá, finalmente, al realizarse Eurindia, pues es, ante todo, una nueva conciencia estética. Sobre este anhelo, Rojas encuentra la reconstrucción de la nación; llama bárbaros al indianismo y al exotismo concebidos de forma separada, que fue, a menudo, el modo en que se los concibió; pero son una civilización futura si, finalmente, se reúnen en comunión.

Hecha esta mención sobre la tesis general de la obra, podemos deducir cuál es su percepción de la lengua en esa civilización euroindia. En primer lugar, la lengua aparece como el instrumento principal para su realización y triunfo; pues se revela como el signo más relevante de la nacionalidad americana y de cada una de las naciones que la conforman. Pero Rojas, a diferencia de Quesada, encuentra al idioma como un problema, al que formula de la siguiente manera: «La literatura argentina no se halla escrita en idioma argentino» ${ }^{1}$. Parte, así, de asumir que no componemos nuestros libros «en lengua creada por nosotros mismos», sino que somos herederos de un castellano traído a América por extraños, situación que ha generado una querella resumible en tres posturas: en primer lugar están los que entendieron que, si se quería tener una literatura nacional, se debía formar un idioma nacional; en segundo lugar, los que concluyeron en que, si nuestro idioma es común a varios pueblos hispanoamericanos, no somos una nación; y por último, los que, hallando que nuestro idioma era el castellano, encontraron natural que los pueblos de América continuaran siendo una colonia literaria de España. Luego menciona a Juan María Gutiérrez, a Calixto Oyuela y a

${ }^{1}$ Rojas 1922, 3. 
Lucien Abeille como sendos pregoneros de estas tres soluciones que, al estar planteadas equívocamente, soslayarían el problema fundamental.

Como se ve, Rojas conoce la querella en torno al idioma nacional, la reduce a tres corrientes y las juzga, finalmente, desacertadas; pues cree que el problema del idioma debe ser resuelto en una reflexión integral de la cultura americana. Veamos.

El problema del idioma argentino debe plantearse en el contexto integral de la cultura nacional: «Estamos, pues, en una atmósfera de sutiles fuerzas espirituales, más que ante las voces muertas de un simple glosario» ${ }^{1}$. De modo que al concebir el problema del idioma como algo más vasto que el ámbito de las palabras, traza una nueva síntesis de la querella, pero no al modo de Costa Álvarez o Quesada, relevando sus episodios y sus textos, sino revisando el proceso que ha sufrido la lengua en América, al que, detallado ya en la Historia de la literatura argentina, presenta ahora en forma de sinopsis filológica:

[...] primer fenómeno: la difusa poliglotía precolombina, cuyas voces han quedado en la toponomía o en la nomenclatura botánica y zoológica de las regiones; segundo fenómeno: la convivencia del castellano con los idiomas aborígenes, de los cuales tomó numerosos vocablos para usos y costumbres locales; tercer fenómeno: rápida extinción de las lenguas vernáculas menos importantes y predominio del quichua, el guaraní y el araucano adoptados por sínodos y concilios como lenguas más aptas para la conversión de los indios al cristianismo; cuarto fenómeno: caracterización de un habla vulgar en las campañas, proveniente del romance medieval, densamente impregnado de folklore aborigen; quinto fenómeno: paulatina extinción actual de las lenguas americanas más generales, por la difusión democrática de la prensa, la educación primaria y el servicio militar obligatorio; sexto fenómeno: sobrevivencia del castellano culto en las ciudades, como lengua literaria y política de las Naciones hispanoamericanas; séptimo fenómeno: contaminación del castellano moderno por la inmigración cosmopolita y la cultura universal, en conflicto con el casticismo académico. Este sucinto esquema, típico para la Argentina, podría aplicarse a otras Naciones americanas, donde se reproduce, con asombroso sincronismo, análogo proceso. ${ }^{2}$

\footnotetext{
${ }^{1}$ ROJAS 1922, 3.

${ }^{2}$ ROJAS 1922, 3.
} 
Presentando estos fenómenos, Rojas busca demostrar que, nos guste o no, el castellano es la lengua que se habla en Argentina y en la que se ha escrito nuestra literatura; por tanto, se trata de nuestro idioma nacional, y, en tanto tal, es el vínculo de nuestras tradiciones y el instrumento irremplazable de nuestra nacionalidad.

Ahora bien, ese castellano que nos llega de España, alcanza su cariz propio en el genio de cada uno de los pueblos que lo adopta; un cariz que se revela en el léxico, la prosodia, la semántica y la construcción verbal; un cariz que enseña las marcas de las lenguas indígenas, que no son marcas de degradación sino de enriquecimiento. Se trata, por tanto, del castellano peninsular en otra geografía, hablado por hombres de otra psicología, plasmándose en una literatura sensible a otros asuntos y ocupada en otros temas. Pero este castellano - al que encuentra erróneo llamar español- nos viene de afuera tanto como al resto de las regiones peninsulares, que, habiendo tenido sus propias lenguas vernáculas, terminaron adoptándolo también como lengua común. Pero incluso a los mismos castellanos les llega como herencia, pues nacen ya en una lengua que ha sido forjada por sus antepasados.

Los españoles de hoy escriben en castellano por aprendizaje tradicional, como los americanos de hoy. No hemos «creado» nosotros el idioma, pero ellos tampoco. Lo crearon antepasados comunes en un largo período de la Edad Media, cuya cronología es muy difusa. En realidad, españoles y americanos expresamos nuestro pensamiento en un nuevo latín que varía según las épocas, las regiones, los caracteres, los géneros y las escuelas. ${ }^{1}$

Resulta muy interesante este movimiento de Rojas, porque nos pondría a todos, frente a la lengua, ante la misma situación: herederos por igual de un patrimonio común.

En esta composición idiomática de Eurindia, Rojas no le teme a la presencia indígena en el castellano, sino a la presencia cosmopolita, como lo había expresado en La restauración nacionalista. Cree en el encuentro de lenguas, pero solo en el de las lenguas americanas con el castellano, no el de este con el francés, el italiano o el inglés. Si un encuentro fortalece y realiza la nacionalidad, el otro la degrada y envilece. O para ser más preciso, la hospitalidad del castellano para con el resto de las lenguas europeas, requiere que ellas, al ingresar en él, se castellanoamericanicen.

\footnotetext{
${ }^{1}$ Rojas 1922, 3.
} 
De modo que el paniberismo que Rojas anhela para América se realizará del común esfuerzo filológico de españoles y americanos; el castellano común, al cual Rojas imagina conteniendo las singularidades nacionales, se nutriría de los aportes de ambos continentes. Llama, finalmente, a la construcción de una gramática histórica y de un nuevo diccionario que dé cuenta de esta reunión eurindiana. Para esto, Rojas cree que hace falta renovar los estudios filológicos e ingresar de lleno en las nuevas corrientes científicas. Elogia, así, los esfuerzos de Cuervo en Colombia; de Lenz en Chile; pero en especial de Ramón Menéndez Pidal y sus discípulos en España. Este reconocimiento reviste un gran interés, porque debe consignarse como un notable antecedente del Instituto de Filología de la Universidad de Buenos Aires, que, por orden de Rojas, será concedido a Américo Castro, un filólogo de la escuela de Menéndez Pidal. Ya en Eurindia (cap. XVI), Rojas entiende que no hay en el Plata hombres que estén enterados de la nueva escuela filológica, única capaz de encarar científicamente los problemas de la lengua; y advierte, además, la necesidad de formarlos.

Esta entrega de Eurindia, del día 29 de octubre, que contiene los capítulos que van del décimo al decimoséptimo, cierra con la siguiente aseveración:

El pueblo argentino - individualizado ya por su tierra, su tradición y su cultura - no necesita crearse una lengua nueva para manifestar su genio social, y al hacerlo en castellano pone en su literatura un contenido nuevo, distinto del de España y diverso del de otras naciones americanas. ${ }^{1}$

En 1924, Juan Roldán reedita Eurindia en España, en un solo volumen.

\section{4. Los Disparates de Monner Sans y el casticismo de Groussac}

El problema de la lengua no termina, prueba de ello es que Ricardo Monner Sans no descansa. En 1923 da a la estampa sus Disparates usuales en la conversación diaria, amonestaciones gramaticales de calaña similar a las Notas, que no debieran ser mencionadas aquí si no trajeran adosadas, al final, unos «Apéndices» epistolares de sumo interés. Se trata de dos cartas, una dirigida al Ministro de Instrucción

${ }^{1}$ Rojas 1922, 10. 
Pública (con fecha 22 de septiembre de 1915); otra, al entonces intendente de Buenos Aires, a quien se dirige con el título de «Alcalde Mayon», por llamársele en Madrid así. Estas dos cartas enseñan que Monner Sans pretendió hacer, de la cuestión idiomática, una cuestión de Estado. Al primero le recuerda que «deber es de todas las autoridades, y especialmente del Ministerio de Instrucción Pública, el de procurar que no se bastardee el heredado lenguaje» ${ }^{1}$; y que sería obra patriótica —y honra para el célebre manco- decretar que todas las obras que se piensen y deseen poner en manos de los jóvenes «sean sometidas previamente a la censura del Ministerio de Instrucción Pública». Al segundo, al «Alcalde Mayon», le suplica expedir una «Ordenanza municipal» que, a través de los siguientes puntos, imponga el respeto del patrio idioma:

$1^{\circ}$ - Que se revisen todos los letreros fijos de esta capital, disponiendo se retiren de la vista del público los que no estén en correcto castellano;

$2^{\circ}-$ Que no se puedan repartir por calles y plazas, ni pegar en las paredes, anuncios y prospectos que no hayan sido previamente aprobados por la Municipalidad, y

$3^{\circ}$ - Que con los mismos fines de cultura popular, se manden borrar de la pantalla de los cinematógrafos, leyendas y explicaciones que, por lo bárbaras, atentan contra el sistema nervioso de las personas cultas. ${ }^{2}$

Monner Sans confiesa que estas dos cartas, fusionadas en un único artículo, fueron publicadas por el diario La Razón, el 6 de noviembre de 1922.

Aunque distante de Monner Sans, Paul Groussac tampoco descansa en su cruzada contra el criollismo. En la misma senda de su «Plan de estudios y programas...», de $1891^{3}$, al editarse en 1923 La divisa punгó - drama que ya había sido representado varias veces y le había deparado en el ocaso de su vida un renovado aplauso-, Groussac le adosa un «Prefacio» en el que confiesa haber dudado, al ponerse a escribir el texto, respecto del lenguaje o estilo más adecuado para el diálogo; había vacilado «entre el castellano castizo y el adulterado que aquí se usa, aun entre la gente culta que no ignora el español correcto». Siendo sus «fantoches» argentinos, cree justificado emplear las formas y locuciones «de nuestra jerga criolla», y

${ }^{1}$ MONNer SANS 1923, 95.

${ }^{2}$ MONNER SANS 1923, 102.

${ }^{3}$ CARBALlido 1891.

${ }^{4}$ Groussac 1923, XXI. 
consigna para los lectores o espectadores no argentinos lo que estima son nuestras principales desviaciones lingüísticas:

[...] para la fonética, en la confusión andaluza de la zo $c($ ante $e$ o $\imath$ ) con la s, así como de la ll con la $y$, pronunciadas en Buenos Aires como ge o gi francesas; y, para la analogía, en la conjugación viciosa de los verbos en la segunda persona del singular, debido a la sustitución pecaminosa de tú por vos; de ahí las formas híbridas: querés, poné, vení, etc., que son simples arcaísmos, encontrándose en los primeros siglos del idioma, especialmente en el lenguaje rústico. ${ }^{1}$

Al momento de estar a punto de editarse la obra, cambia de opinión y cree necesario corregir los diálogos para no aparecer pagando también su tributo "a este trasnochado "criollismo"»; pretende, así, presentar a los lectores extranjeros un texto expurgado, pero la impresión de La divisa ya había comenzado y no era posible emprender una corrección.

\footnotetext{
${ }^{1}$ Groussac 1923, XXI.
} 


\section{LA QUERELLA AL IRRUMPIR EL INSTITUTO DE FILOLOGÍA}

(1923 - 1926)

\section{1. El Instituto de Filología}

Quizá no haya que buscar en los libros de Ricardo Rojas su obra de mayor envergadura, con respecto a la querella de la lengua. Su obra mayor es la fundación del Instituto de Filología, que anheló durante mucho tiempo, que prometió fundar mientras era nombrado Decano de la Facultad de Filosofía y Letras, y cuya primera misión podría abreviarse en este propósito: la cuestión del idioma nacional dejará de ser una querella. El programa para lograrlo es vastísimo y cuenta con los primores de lo que se llamó la nueva escuela filológica.

Al hacerse cargo del decanato, abocado a la tarea de fundar el Instituto, Rojas advierte que la dirección de semejante institución solo podía ser dirigida por un europeo, y en caso que sea español, adscripto a la tradición inaugurada por Menéndez Pidal. Ningún argentino - pienso ante todo en Arturo Costa Álvarez- le inspiraba confianza; y aún no cree que pueda hablarse seriamente de una filología argentina. La búsqueda de un director concluye al dar con la persona que estimó más apropiada: Américo Castro, un hombre que, aunque nacido en Brasil, se trataba de pura cepa española. Castro, proveniente del célebre Centro de Estudios Históricos, no solo representaría el pensamiento de la nueva filología española, sino que además era hombre de confianza, discípulo dilecto y amigo de Menéndez Pidal.

El Instituto de Filología se inauguró formalmente el 6 de junio de 1923, en el anfiteatro de la Facultad de Filosofía y Letras de Buenos Aires. Ante un público numeroso - se encontraban presentes Marcó, ministro de Instrucción Pública, el doctor José Arce, rector de la Universidad, y el Marqués de Amposta, embajador de España- Ricardo Rojas, en calidad de decano, dio un discurso que, aunque eminentemente celebratorio, enseña todos los perfiles que tendrá el Instituto.

Rojas afirma que la filología no puede ser concebida como una verdadera ciencia sino hasta mediados del siglo XIX, y que en España se demoró hasta que llegara Menéndez Pidal, es decir, hasta los albores del siglo XX. Al presentar a Américo Castro aclara: «viene hacia nosotros como un generoso misionero de la nueva doctrina» ${ }^{1}$. Esta nueva doctrina en los estudios de la lengua ya no vie-

\footnotetext{
${ }^{1}$ ROJAS y CASTRO 1923, 9.
} 
ne a intervenir en la querella del idioma nacional, sino a desarmarla por efecto de los nuevos métodos científicos. No viene a discutir, pretende demostrar.

De la nueva y conciliadora doctrina, debiéramos decir, porque apenas se afronta con los instrumentos de la filología moderna el estudio del idioma, como él, español, va a hacerlo entre nosotros, americanos, el postrer motivo de controversia entre España y América desaparece, pues la verdadera ciencia del lenguaje desarma igualmente el dogma anacrónico de las academias metropolitanas y el instinto barbarizador de las repúblicas insurgentes. ${ }^{1}$

Rojas no cree que deba recriminársele haber elegido a un extranjero para dirigir un instituto nacional — recordemos los anhelos de La restauración nacionalista y de Eurindia - pues «si necesitamos traer del extranjero especialista de una ciencia que aquí no se cultiva o se cultiva por métodos equivocados, debemos traerlos» ${ }^{2}$. Justifica el haber elegido un filólogo español, además, en el hecho de poseer el vínculo común del idioma. La lengua de los argentinos — con esta idea cierra su oratoria - es la misma lengua que habla Castro, el que, luego de oír este discurso, sucede a Rojas en el uso de la palabra.

Castro refrenda la idea de que Menéndez Pidal origina en España los estudios científicos de la lengua, y celebra que los argentinos, sosegados ya los recelos de antaño, acepten el aporte que les puede dar un filólogo español, aporte que cree necesario explicitar. La misión que le compete, afirma, es hallar un justo medio entre dos tendencias contrarias: una, esgrimida por los devotos de la peculiaridad nacional del idioma; la otra celebrada por los casticistas. Una peca de neologista; la otra, de arcaizante. En palabras de Castro: «Ni "arrabaleros" o galiparlantes, ni fetichistas del incompleto diccionario de la Academia Española» ${ }^{3}$. En Argentina, los primeros habrían culminado en el libro de Abeille, que Castro encuentra felizmente derrotado.

La causa del idioma nacional, para Castro - y esto es decir, para la nueva escuela pidaliana-, ya se encuentra absolutamente superada: el idioma de los argentinos es el español. Puesto que ya no hay nada que atente contra la estructura del idioma, resta establecer cuáles son sus peculiaridades, ante todo las peculiaridades del

\footnotetext{
${ }^{1}$ ROJAS y CASTRO 1923, 9-10.

${ }^{2}$ Rojas y CASTRO 1923, 10.

${ }^{3}$ ROJAS y CASTRO 1923, 15.
} 
habla, y en especial aquellas que trasvasan el habla vulgar e impregnan el habla culta.

Lo que fundamentalmente preocupa al lingüista es determinar cómo han sido posible históricamente tales o cuales fenómenos, cuál es su extensión territorial, cuál su difusión a través de las distintas capas sociales y, en fin, en qué casos tales fenómenos de pronunciación, de léxico o de sintaxis, han llegado a adquirir carta de naturaleza en el habla de las personas cultas y en el estilo de los escritores más selectos. ${ }^{1}$

No obstante, Castro no sobreestima el poder de las academias, sabe que en el fondo las lenguas marchan ajenas a los dictámenes institucionales. La acción de una entidad como el Instituto, agrega, no será efectiva sin la ayudad de la literatura, la prensa, la oratoria. Cuanta mayor manifestación cultural ostente un pueblo, tanto mayores serán sus peculiaridades idiomáticas, al mismo tiempo que las reacciones tendientes a conservarlo inmóvil. El desafío, para Castro, es incidir en todo el entramado cultural; o dicho de otro modo, que todas las expresiones culturales del pueblo registren los ecos de la academia.

\section{2. Albor de la polémica entre Costa Álvarez y el Instituto de Filología}

Los hombres del flamante Instituto, urgidos por iniciar una nueva tradición de estudios lingüísticos en el Plata y obtener una pronta legitimación, debían tomar posición frente a la tradición lingüística que ya existía en Argentina, uno de cuyos referentes máximos era Arturo Costa Álvarez, quien no esperó ninguna declaración oficial de guerra para darse por enterado de que las hostilidades habían comenzado. En enero de 1924 embiste contra el Instituto en la revista Valoraciones, publicación platense que cederá cuantiosamente sus páginas a la polémica. El artículo tiene dos partes, una apologética, otra afrentosa; en la primera echa una mano a Juan B. Selva, a quien llamará «el estudioso argentino», en la segunda echa tierra a Américo Castro: «el catedrático importado». Soslayo la primera parte: la apología; me memoraré en la diatriba a Castro.

La polémica ya había empezado desde el momento que las autoridades de la universidad prescinden de los servicios que pudie-

\footnotetext{
${ }^{1}$ Rojas y CASTRO 1923, 19.
} 
ran dar un Selva o un Costa Álvarez. Desde ese momento, Costa Álvarez comienza a hacer un viraje en su posición, se vuelve, quizá, más argentinista y reelabora argumentos - algunos a veces a contrapelo de los que ya tenía impresos- que pretenden evidenciar la impropiedad que implica la radicación de filólogos españoles en el Plata. El planteo de Costa Álvarez es que ellos no atienden al dominio y cuidado de la lengua, sino al «anhelo espiritual de conocer su estructura»; son más teólogos que curas. Es este el primer obstáculo, pues lo que necesitaría la juventud universitaria argentina es más bien dominar la lengua, antes que estudiar sus orígenes; es decir, precisa más de gramáticos que de filólogos. Costa Álvarez, por el momento, no se quiere mostrar enteramente en contra de la nueva filología española — a la que no obstante encuentra como «secta de Menéndez Pidal» $\longleftarrow$, por lo que intenta atenuar el planteo agregando que solo la encuentra algo inapropiada para la realidad argentina, donde el saber se encara, antes que como un goce espiritual, como un medio de vida. La instalación de inquisiciones filológicas típicamente europeas iba, por tanto, a fracasar en Argentina. Esta es la apuesta de Costa Álvarez: demostrar que, a poco de fundarse el Instituto de Filología, ha fracasado. Llegó Américo Castro -a quien siempre se refiere y jamás nombra-, se puso al mando del Instituto, pero le fue mal:

Creyó que la Filología Española tenía suficiente prestigio para cautivar las voluntades argentinas, confió exclusivamente en tales fuerzas, desatendió el consejo de tener en cuenta nuestra idiosincrasia «desafecta al estudio desinteresado», y vino a reproducir en Buenos Aires y en La Plata el método de enseñanza madrileño. ${ }^{1}$

Para Costa Álvarez, Castro comienza dando sus cursos en aulas atestadas y los concluye monologando con bancos vacíos. El asidero de este planteo es que no puede estudiarse en América las fuentes del español, que están en España. Los textos paleográficos, los textos del castellano antiguo y del Siglo de Oro, no pueden desentrañarse mediando un océano. Lo que en todo caso se podría desarrolla en América es un estudio del castellano americano, del castellano colonial, de las lenguas indígenas. Luego, habiendo tanto aún por descubrir en América, en cuanto a cuestiones de la lengua, no es parte de nuestra idiosincrasia abocarnos específicamente a un tema, sino que tendemos a dar cuenta de la generalidad, a trazar una síntesis de conjunto. Aquí, Costa Álvarez tampoco quiere embestir

${ }^{1}$ Costa ÁlvVarez 1924, 145. 
de lleno contra la especialización, a la que cree necesaria, pero para otro momento. «Por esto, por la naturaleza del mundo en que vivimos, y no por petulancia, somos políglotos, polígrafos y politécnicos.»1

Este fracaso del que Costa Álvarez habla, sin embargo, pretende dirigirse hacia «la autoridad universitaria», pues ha sido ella la que ha invitado al catedrático extranjero a aventurarse en el Plata. A esta misma autoridad, entonces, le aconseja que «tanto por conveniencias prácticas como por razones ideológicas, al frente de este instituto argentino debe estar un argentino.... ${ }^{2}$

A estas impresiones responde quien está a punto de presentar una traducción de Max Leopold Wagner para el primer cuaderno del Instituto de Filología, Carlos M. Grünberg, para quien todo el planteo del «gramático platense» no es más que un ir preparándose la cama:

Sepa el señor Costa Álvarez que si, para desdicha de nuestra cultura universitaria, que tantos contrastes vive padeciendo, su cargo de director de biblioteca en una institución hípica de provincia se convirtiese, por arte de magia, pero de magia posible en este país extraordinario, en cargo de Director del Instituto de Filología, sepa, decimos, que sus actuales alumnos lo abandonaríamos en el acto. ${ }^{3}$

Costa Álvarez no responderá a Grünberg, pero no dejará de reescribir y publicar sus impresiones sobre el Instituto y los hombres que lo cortejan.

\section{3. Castro contra el dialecto argentino; Lugones en pro del idioma de los héroes}

Unos días más tarde, en La Nación, Américo Castro no responde a Costa Álvarez, sino a un remoto editorial del diario titulado «El dialecto argentino», en el que, por un lado, se aseveraba que, aunque no pudiera considerarse a ese dialecto como idioma nacional, no debía dudarse de su existencia; y por otro, se pedía la urgente opinión al respecto de un hombre como Américo Castro, «que tan elo-

\footnotetext{
${ }^{1}$ Costa Állvarez 1924, 146.

${ }^{2}$ Costa Állvarez 1924, 148.

${ }^{3}$ GRÜNBerg 1924, 8.
} 
cuentes pruebas nos ha dado de su saber profundo y de su clarísimo criterio» ${ }^{1}$.

El deseo es concedido en el mismo diario La Nación, el 20 de abril de 1924, en un artículo que Castro prefiere formular como interrogación: «¿Dialecto argentino?». Para Castro, dialecto puede ser una forma peculiar de lenguaje que no alcanzó prestigio literario; puede ser, también, una forma que gozó de una importancia literaria que ya no ostenta; o bien puede ser un habla poliforme y dividida que nunca haya rebasado el grado rudimentario de los idiomas rústicos. Hecha esta disquisición: «Me apresuraría a decir que el dialecto argentino no existe» ${ }^{2}$. $\mathrm{Al}$ invocarse la expresión dialecto argentino, para Castro, no se hace más que pensar en el habla familiar y popular de Buenos Aires; y confía en que las investigaciones que está llevando a cabo el Instituto de Filología demuestren, en breve, que de los diez millones de argentinos, tres cuartas partes no presentan muchos de los fenómenos que aparentemente constituyen peculiaridades respecto a los otros hispano hablantes.

Diez días más tarde, en el mismo diario, completa el planteo diciendo que lo que sucede con la lengua en Argentina no es muy distinto de lo que sucede en España; de modo que si cada aldea pretendiera reivindicar para sí un idioma distintivo, habría un idioma por cada una de ellas. Los argumentos de Castro buscan persuadir a través de la exposición y comparación de lo que él llama las peculiaridades lingüisticas, que son las mismas que lo harían tristemente famoso, tiempo después, al ser alcanzadas por las saetas borgeanas ${ }^{3}$.

En cuanto al léxico, Castro entiende que el lenguaje del Plata se caracteriza en cinco aspectos. Primero, por un relativo empobrecimiento, causado por el olvido de los sinónimos: «¿Por qué no puede el argentino aplicar a los diminutivos más que el sufijo ito, y se priva de poder decir "librico" o "librillo" como en todas partes? ${ }^{4}$ Segundo, por una gran cantidad de neologismos: «responsabilizan», «sesionan», etcétera. Tercero, por un buen número de indianismos: «baquiano», «bagual», «chancho», etcétera. Cuarto, por muchos galicismos. Quinto, por muchos italianismos y lunfardismos.

Luego de esto, Castro cree estar en condiciones de formular una gran conclusión:

${ }^{1}$ LANACIÓN 1923.

${ }^{2}$ CAstro 1924 a.

${ }^{3}$ Cf. Borges 1941.

${ }^{4}$ Castro 1924b. 
De la observación de muchos hechos y del examen de muchas opiniones se desprende la idea de que las peculiaridades del habla del Plata son más psicológicas que lingüísticas. Suprímase la creencia de que los argentinos tienen una manera de hablar sui géneris, y se habrá suprimido el noventa por ciento de las pretendidas particularidades argentinas. ${ }^{1}$

La idea es extraordinaria y certera, solo que está formulada de tal modo que Castro, aunque asegura que la cuestión de la lengua argentina es de dimensión psicológica, no deja de pensarla en su dimensión estrictamente lingüística. También Unamuno había llegado a una conclusión similar: el problema de la lengua en Argentina es más de orden moral que lingüístico. Aquí radica el problema a develar: ¿por qué los argentinos pretendimos, sin ostentar bases lingüísticas que lo sustenten, un idioma que no sea llamado español? Castro no responde a esto, pero su modo impugnador con que se refiere a la lengua en el Plata, en cambio, nos da la pauta para entenderlo.

Leopoldo Lugones, que venía investigando sobre etimologías y para el cual el problema de la lengua en América constituía un pilar en sus tesis sobre el payador, lee atentamente los dos artículos de Castro y encuentra que muchas voces a las que comúnmente se las llama «indianismos» —Castro había citado algunas- no son más que auténticas voces castellana, de origen peninsular. Lugones -que de paso responde a muchos que lo creen un hispanófobobusca demostrar que el pretendido dialecto argentino, al menos si por él se entiende el bañado en voces arcaicas, no es más que «buen castellano, y aun del mejor, como que se trata del castellano de la Conquista: el idioma de los héroes, no atildado todavía por el humanismo» ${ }^{2}$. Las diferencias, por tanto, con el idioma peninsular, es que el americano conserva voces - épicas para Lugones- que España ya no pronuncia.

\section{4. El «nuevo idioma de la Argentina» de Del Valle Inclán y el diccionario de Montoliu}

Poco tiempo después, en 1925, el escritor español Ramón del Valle Inclán vuelve de su extenso viaje por Latinoamérica y busca residencia en Vigo. Un grupo de amigos e intelectuales lo acoge y le

\footnotetext{
${ }^{1}$ CASTRO 1924b.

${ }^{2}$ LugONES 1924.
} 
arma una recepción. Al momento de hablar, a Del Valle Inclán le parece oportuno pronunciarse sobre el idioma español y su vínculo con América:

Las pampas son un vasto océano de trigo donde nace el pan de la humanidad y donde se elabora el nuevo idioma español que romperá la cárcel hermética del castellano actual, que ha de hacerse más flexible, más vivo y más sonoro. El verbo de América será, quiéralo Dios, para el castellano lo que lo fueron los romances de las colonias romanas para el latín anquilosado del señor del mundo. ${ }^{1}$

Se suma, así, a los que preanuncian una dialectización de la lengua. Su opinión respecto de la Argentina, sin embargo, está alentada por la presunción de que se trata de un país que es y seguirá siendo agrícola y ganadero, hecho que lo lleva a pensar que ese «nuevo idioma de la Argentina» será de pastores y labradores; es decir, surgirá de la llanura pampeana y las montañas, no de Buenos Aires, de donde — afirma - solo se puede esperar, como de cualquier ciudad, «el argot de la canalla y las germanías». Luego, al deducir que en el interior del país conviven armónicamente distintos idiomas y razas, preanuncia además que ese nuevo idioma será el producto de la fusión de esas mismas realidades.

Estas palabras de Del Valle Inclán, que vuelven sobre lo que Cuervo había advertido en las postrimerías del siglo XIX, agradan en Buenos Aires al poeta Francisco Luis Bernárdez, quien las saluda en el periódico Martín Fierro, ahondando en la influencia que la geografía ejerce sobre los idiomas. Ahora bien, para que el paisaje termine de modelar un idioma propio en Argentina, concluye Bernárdez, es necesario la presencia de una densa conciencia de la nacionalidad, conciencia que, estima, se está consumando. La «argentinidad» estaría dejando de ser un término de especulación intelectual y haciéndose carne en el pueblo y en la nueva literatura. La tendencia de la nueva generación hacia lo autóctono y lo que él llama «criolledad» es tal que, inevitablemente

[...] el idioma llegará a su hora, cuando nuestra manera de sentir la vida sea lo suficientemente fuerte para exigir un instrumento expresivo tan fuerte y tan propio como ella. Nuestro papel, mientras tanto, es el de preparar el camino para ese que ha de venir y que el autor de Eurindia llama mesiánicamente: el Esperado. ${ }^{2}$

\footnotetext{
${ }^{1}$ Cf. Pesqueira 1925.

${ }^{2}$ BERNÁRdEZ 1925, 5.
} 
Un día antes que aparezca la nota de Francisco Luis Bernárdez, el diario La Nación publica una interesante entrevista al catalán Manuel de Montoliu, instalado ahora en Buenos Aires y flamante sucesor de Agustín Millares Carlo en el cargo de director del Instituto de Filología. El proyecto más ambicioso de Montoliu, y por el cual lo entrevistan, es su pretensión de un diccionario dialectal argentino, construido a partir del modelo de los léxicos suizos semejantes. Pero no es esto lo curioso, sino que las opiniones de Montoliu son las del último Cuervo, es decir, las de un lingüista que termina creyendo en la dialectización del castellano en América. Montoliu no la desea, y está en Buenos Aires para ayudar a evitarla, ocupando un lugar reservado para hombres que conduzcan la unificación de la lengua española en el mundo, y no obstante no puede evitar decir que

[...] el período evolutivo que ahora atraviesa el castellano en la Argentina viene a ser un equivalente moderno del que pasó el latín en los pueblos colonizados por Roma, antes de convertirse en las actuales lenguas románicas. ${ }^{1}$

Quizá a raíz de esta preocupación de Montoliu por registrar los argentinismos, en el nuevo número de Martín Fierro, ahora en forma algo más virulenta, el escritor Pablo Rojas Paz se pregunta por el significado del vocablo «hispanoamericanismo»:

¿Qué significa esta palabra? ¿Qué índole de manifestaciones sociales e intelectuales caen bajo esta denominación? No es ni un concepto geográfico, ni político, ni étnico, ni idiomático. Y decimos idiomático porque tener un idioma independiente debe ser uno de nuestros problemas fundamentales de cultura. No nos quedaremos hablando el castellano del 1500, ¿o pensará alguien que viene a enseñarnos castellano el analfabeto que llega de inmigrante? Creo que no es necesario decir porqué no es un problema étnico ni político. Como no es nada real, preciso, sincero, sirve de tema literario para congresos y juegos florales. Se nos acusa que estamos echando a perder el idioma. Se dice que Chile y Perú poseen un idioma más puro que nosotros. ¿Qué es esto de cuidar al idioma como a un raquítico que se enferma con el aire? ¿De qué idioma se trata? Nos legaron por casualidad de navegantes equivocados, un idioma de hierro. ¿Quién nos impedirá fundirlo para hacer de él lo que nos

${ }^{1}$ LANACIÓN 1925. 
plazca? El castellano es un idioma medio asfixiado al que nosotros hacemos respiración artificial. ${ }^{1}$

Rojas Paz embiste contra España, muy en el tono con que lo hicieron los románticos del Salón Literario, o mejor dicho, a favor de Argentina, al que encuentra el menos español de los países sudamericanos. En el concepto «hispanoamericanismo», Rojas Paz busca desentrañar la anacrónica pretensión de España de influir en el espíritu argentino, pero no de la España de Unamuno, Marañón y Cajal, sino la de Primo de Rivera, la tradición, el rey, la raza y el hispanoamericanismo, pues es de esta España de donde llega. Este planteo preanuncia la polémica que, en 1927, enfrentará a los articulistas de Martín Fierro con los de La Gaceta Literaria, de Madrid, y que dotará a la querella de uno de los momentos más álgidos.

\section{5. «La mala suerte» de Costa Álvarez}

Atendiendo siempre a las recomendaciones de Menéndez Pidal, sucede a Américo Castro, en el cargo de Director del Instituto de Filología, Agustín Millares Carlo, en 1924; y a este, como ya he mencionado, Manuel de Montoliu, en 1925. Son los primeros pasos de la institución; Costa Álvarez los encuentra suficientes para volver a cargar contra ella. En noviembre de 1925 compondrá «La mala suerte del Instituto de Filología», una suerte de biografía que busca resaltar los lunares del Instituto. El planteo es sumamente interesante y se inscribe en la genealogía de pensamientos que advierten el peligro de convertir a la ciencia en reductos compartimentados que, profesionalizados hasta la hipertrofia y hábiles en generar nuevas especialidades, redundan en una forma de vicio intelectual. Costa Álvarez entiende que una nueva generación de catedráticos, parricida de la anterior, se ha condensado filosóficamente en un «idealismo cientificista». El cientificismo, concepto que no duda en endilgar a los nuevos filólogos del Instituto,

[...] es lo que fue en lo antiguo el gnosticismo con respecto a la teología: un tablado endeble pero ostentoso, con superestructura monumental, toda de yeso, construido en la cumbre misma del Areópago para ofrecer estrado conspicuo al que, saturado de saber, ha resuelto considerarse superior a los mejores $[. . .]^{2}$

\footnotetext{
${ }^{1}$ ROJAS PAZ 1925.

${ }^{2}$ Costa Álvarez 1925, 108.
} 
Este es el corazón de la crítica: acusar al Instituto de tramar un saber tan ostentoso como inservible. Inservible al menos para la Argentina, que es el escenario a partir del cual deben pensarse los proyectos intelectuales en el país, y sobre todo los vinculados a la lengua.

Son términos injuriosos los que Costa Álvarez enlista contra la «nueva generación»: «pequeño acopio de tecnicismos», «cuantiosa dosis de desparpajo», «monserga pedantesca», «fraseología hueca», «glosolalia pueril». Todo esto haría parecer al estudio de la lengua «dividido, analizado, sutilizado y sintetizado, aunque debajo de esta retícula superficial el tema está intacto» ${ }^{1}$ Para Costa Álvarez, esta nueva tendencia entre los docentes universitarios, sensible solo ante la minucia, aún no ha advertido que, al asignar un valor absoluto a la especialidad y haciendo de ella una especie de religión o metafísica, «el sentido de la relación se atrofia» logrando que el intelectual no lo sea más que a medias.

Ahora bien: como el agnosticismo, también el cientificismo es de naturaleza sectarista, está dividido en círculos que, al parecer independientes, son en realidad las diversas logias de una misma masonería, constituidas para ayudarse entre ellas fraternalmente. ${ }^{2}$

A estas apreciaciones las sigue una breve reseña de los primeros pasos del Instituto, a partir del desempeño y producción de sus directores: aquí aparece narrada la «mala suerte»: el que no quedó dando clases solo (Castro), se puso a hacer paleografía (Millares Carlo) o un diccionario dialectal argentino (Montoliu).

Temo que estos señores directores nos están tomando el pelo; porque el primero de ellos había hablado largamente el año anterior, desde La Nación de abril 20 y abril 30, para afirmar de una manera rotunda y terminante que no había ningún dialecto argentino. ${ }^{3}$

Ana Julia Darnet, secretaria del Instituto y aludida tangencialmente por Costa Álvarez, responde en el próximo número de Valoraciones $^{4}$ apelando un poco a la indignación, otro poco al elogio hiperbólico de sus hombres agraviados. Ni enfrenta lo sustancial de la crítica de Costa Álvarez, ni parece disponer de los recursos estilís-

${ }^{1}$ Costa Álvarez 1925, 109.

${ }^{2}$ COSTA Álvarez 1925, 109.

${ }^{3}$ Costa Álvarez 1925, 112-113.

${ }^{4}$ DARNET 1926. 
ticos para hacerlo. La redacción de la revista, al decidir publicar la nota, cree necesario adosar un epígrafe donde confiesa cierto desequilibrio: «El señor Costa Álvarez espera un contendor de otra laya».

El Instituto vuelve a referirse al hecho a mediados de 1926, en el primer Boletín, en cuyas líneas introductorias, Ángel J. Battistessa, «técnico encargado», advierte que

[...] el mejor indicio —el indicio local — de que no andamos muy lejos de la consecución de nuestro propósito, es la actitud de inofensiva agresividad que, ante la posición renovadora del Instituto, han asumido, desde la fundación del mismo, uno o dos representantes de ese sector —naturalmente susceptible y tradicionalmente iracundo- de nuestro medio intelectual $[\ldots]^{1}$

Battistessa no nombra jamás a Costa Álvarez, pero no hay duda de que es uno de esos «representantes» y una vez lo llama «conspicuo gramático de capital de provincia». Se trata de un breve prólogo que vuelve trasparente la discusión entre la filología local y la europea: al finalizar, Battistessa confiesa que las páginas del Boletin están abiertas a las personas que «colaboren» con el Instituto o «simpaticen» con él; estos conceptos ameritaban una nota al pie que acomodó el propio Battistessa: colaborar o simpatizar no solo significa la aquiescencia benévola y el aplauso fácil, sino, y se prefiere, el juicio severo y la crítica oportuna, «siempre que esta y aquel sepan exteriorizarse, eso sí, en reparos de índole estrictamente técnica» ${ }^{2}$. Digo que este prólogo torna transparente una discusión, porque lo que Costa Álvarez reprocha de la nueva escuela es, justamente, que se pronuncia sobre la lengua en Argentina desde una visión «estrictamente técnica».

El contendor que pedían los editores de Valoraciones, no obstante, aparecerá recién en 1927, cuando el Instituto ostente un director como el joven Amado Alonso, cuyo golpe radica en la novedad de su enfoque (Croce, Vossler), así como su fuerza inusitada. A Costa Álvarez no le alcanzaría la vida para responder: muere en 1929; algunos llegaron a decir, a causa de la presión de estos azotes $^{3}$.

\footnotetext{
${ }^{1}$ BATTISTESSA $1926,7$.

${ }^{2}$ BATTISTESSA 1926, 8.

${ }^{3}$ Para seguir la polémica entre Costa Álvarez y Alonso ver AlONso 1927, AlONSO 1929a y AlONSO 1929b.
} 
No es lugar, aquí, para ahondar en las polémicas que suscitó la nueva escuela de filólogos en Argentina; basta con mencionar esta que tuvo a Costa Álvarez como protagonista, porque su suerte, en parte, fue la suerte que corrió la querella de la que se ocupa esta tesis. Resuelto el Instituto de Filología a constituirse como la voz autorizada - en muchos casos con argumentos convincentes-, soterra a Costa Álvarez y graba, en su epitafio, la expresión «idioma nacional».

\section{6. Henríquez Ureña y la tesis del descontento y la promesa}

Al pensar la literatura de América, el dominicano Pedro Henríquez Ureña advierte rápidamente el problema del idioma, pues si es evidente que hay un idioma en común con España, igual de evidente es, afirma, que ese idioma adquiera un color, un matiz y un tono distintos en cada región. Sobre la base de un idioma común, por tanto, no hay que temer - y hasta es necesario- revitalizar las distinciones: «¿Sería de creer que, mientras cada región de España se define con rasgos suyos, la América española se quedara en nebulosa informe, y no se hallara medio de distinguirla de España?» ${ }^{1}$ De modo que, ante la existencia de «dos tendencias»: una que haría a los americanos «llenos de carácter», otra que los haría «pájaros sin matiz, peces sin escamas», Henríquez Ureña estaría muy cerca del planteo de Andrés Bello y de Ricardo Rojas: hace falta americanizar, pero sin romper lanzas con España; dar con el cariz que distinga idiomáticamente a los americanos, sin recurrir al separatismo; ahondar en nuestra fisonomía propia, sin tender a los credos nacionalistas.

Un año más tarde, el 28 de agosto de 1926, lo encontramos a Pedro Henríquez Ureña conferenciando en la Asociación Amigos del Arte, en Buenos Aires, donde despliega su sugerente tesis de «El descontento y la promesa». Lejanas ya las guerras independentistas y el vigor romántico que las había estetizado, irrumpió en la América española un descontento que se dio en llamar modernismo, una insurrección que Ureña estima que fue necesaria. Las nuevas juventudes inquietas se habrían irritado contra sus mayores y ofrecido a trabajar seriamente en busca de «nuestra expresión genuina», concepto que a Henríquez Ureña desvela y al que redescubre en los términos que expongo a continuación.

\footnotetext{
${ }^{1}$ HenríqueZ UReÑa 1925, 248.
} 
La expresión en la América española se encuentra tironeada por dos extremos: los europeizantes, por un lado, que afrancesan su español y llegan, en casos, a reemplazarlo por el francés; los hispanizantes, por otro, «enfermos de locura gramatical» e hipnotizados por todo lo español que no haya sido trasplantado a suelo americano. La solución de Ureña se separa de ambos y está formulada en términos de promesa. Para un catalán o un gallego, la necesidad de diferenciarse del castellano casi no reviste problema: se expresan en catalán o en gallego. Para el hispanoamericano no es tan simple, pues no se ha llegado a conformar una lengua ni un dialecto tal que puedan ser esgrimidos como reemplazo. Volver a las lenguas indígenas, para Ureña, no es una solución: es recluirse en el calor que pueda dar un puñado de lectores - eso si el escritor lograra aprender alguna de las cien lenguas vernáculas y hacer, luego, algo con alguna de ellas-; crear idiomas propios, por otro lado, es una nube que, finalmente, se ha disipado en la paulatina conformación de cierta unidad hispanohablante entre España y América. «No hemos renunciado a escribir en español, y nuestro problema de la expresión original y propia comienza ahí..» ${ }^{1}$

He aquí la promesa, o mejor dicho, la esperanza que formula Ureña, ya que no hemos abandonado el español, nuestra expresión necesita doble vigor para imponer su tonalidad, para que cada nación dé con su cariz propio.

El compartido idioma no nos obliga a perdemos en la masa de un coro cuya dirección no está en nuestras manos: solo nos obliga a acendrar nuestra nota expresiva, a buscar el acento inconfundible. Del deseo de alcanzarlo y sostenerlo nace todo el rompecabezas de cien años de independencia proclamada; de ahí las fórmulas de americanismo, las promesas que cada generación escribe, solo para que la siguiente las olvide o las rechace, y de ahí la reacción, hija del inconfesado desaliento, en los europeizantes. ${ }^{2}$

Cierra esta conferencia con una inquietante reflexión que, algo profética, preanuncia la discusión que más adelante enfrentará a $L a$ Gaceta literaria, de Madrid, con los porteños de Martín Fierro. Ureña afirma que las letras en Hispanoamérica, desde el despertar que están teniendo en el Río de la Plata, marchan a buen puerto y viajan seguras. Esa certeza de mejoría, que trocará en espeso oro lo que ahora es solo insinuación de riqueza, no debe temer al sello ajeno

\footnotetext{
${ }^{1}$ Henríquez Ureña 1926, 21.

${ }^{2}$ Henríquez Ureña 1926, 31-32.
} 
del idioma, porque para entonces «habrá pasado a estas orillas del Atlántico el eje espiritual del mundo español» ${ }^{1}$.

${ }^{1}$ HenríQuez UReÑa 1926, 35. 


\section{DE GROSSMANN A LA NACIÓN}

$(1926$ - 1927)

\section{1. El patrimonio, de Grossmann}

En 1926, el Seminario de Cultura y Lenguas Románicas de la Universidad de Hamburgo publica Das ausländische Sprachgut... ${ }^{1}$ (El patrimonio lingüistico extranjero en el español del Río de la Plata: una contribución al problema de la lengua nacional argentina), libro cuyo comentario debe principiar por una breve mención de su autor, Rudolf Grossmann, de quien se tiene aún en Argentina un conocimiento austero, inversamente proporcional a la relevancia de su obra.

Grossmann nació en Rosario, en julio de 1892, y aunque su infancia estuviera atada al río Paraná, recibió un influjo cotidiano de su padre alemán. Así, repartido espiritualmente entre dos mundos distintos, desde chico aclimató su oído y su boca a dos lenguas que, en igual tenor, le resultaban familiares. Fue desde aquella temprana edad, quizá, que comenzó a crecer en él una incesante inquietud por el sentido y forma de las palabras; por los diccionarios y las gramáticas; por la literatura y los idiomas. No disponer de un buen diccionario bilingüe alemán-español que se amoldara a su peculiaridad americana fue - confesará más tarde - una ausencia y un punto de partida. En 1919, ya en Alemania y formado en los rudimentos de las ciencias del lenguaje, comenzó sus actividades en el Instituto Iberoamericano de Hamburgo, del cual se constituirá con el tiempo en uno de sus referentes. Cuatro años más tarde, de regreso en Argentina, comenzó a tomar las anotaciones y registros fonéticos que le servirán de base para Elpatrimonio, con el cual obtendrá una cátedra universitaria. Consolidado en sus saberes lexicográficos y director, más tarde, del Instituto Iberoamericano, colaborará con el músico y filólogo Rudolf J. Slabý en el Diccionario de las lenguas española y alemana ${ }^{2}$, obra que en poco tiempo pasa a constituirse en el diccionario hispanogermano por antonomasia, y que el propio Grossmann completa algunos años después al publicar la segunda parte ${ }^{3}$. Conferencista en 1952 en el Instituto de Letras de Rosario, al cual estaba adscripto, regresará luego a su familiar Hamburgo para componer la que quizá sea, no su obra más famosa, sino la más extraor-

\footnotetext{
${ }^{1}$ GROSSMANN 1926.

${ }^{2}$ GrossmanN y SLABÝ 1932.

${ }^{3}$ GrossmanN y SlabÝ 1937.
} 
dinaria: Historia y problemas de la literatura latinoamericana ${ }^{1}$, un solo volumen de unas minuciosas setecientas cincuenta páginas que revelan una vida consagrada al estudio del mundo cultural latinoamericano. Ese interés había aflorado ya en el El patrimonio, cuya tesis paso a detallar.

Sin ánimo querellante, Rudolf Grossmann viene a dar su dictamen en relación a esta disputa que estaba a punto de cumplir cien años. También él intenta demostrar que no existe nada suficientemente relevante que ponga en peligro la unidad del español usual de la Argentina. Esto, que es la médula de su tesis, puede ser leído como alegato en contra de Idioma nacional de los argentinos, libro que, aunque ya cree perimido, intenta refutar. ¿No habían sido varias ya las refutaciones que pesaban sobre esta obra de Abeille? Sin duda Grossmann las conoce y las cita; solo que faltaba la refutación que se opusiera a Abeille en su mismo campo: el empírico; y en su misma lengua: la lingüística europea de principios de siglo XX. Ni las ironías de Miguel Cané; ni el ninguneo de Paul Groussac; ni la desautorización de Ernesto Quesada, entre otras tantas impugnaciones, le habrían bastado a Grossmann, quien casi no se referirá a Abeille, ni a su condición de francés, ni a sus supuestos intereses personales o francófilos. Grossmann procurará desarmar su programa filológico —al que llamará «trabajo pesudocientífico»—, y obtener, de un planteo similar, conclusiones opuestas. Abeille, en 1900, — por vías que entiende lingüísticas, psicológicas y raciales - cree estar ante la gestación de un idioma nacional argentino; Grossmann, en 1926 por las mismas vías - cree estar ante el fin de esa posibilidad. Abeille inaugura su tesis anunciando la formación de una nueva raza en América: la raza argentina. Grossmann concluye la suya apelando a una idea similar: «...se ha formado en Argentina una nueva raza, la llamada raza euro-argentina... $\rangle^{2}$.

Una primera radiografía de El patrimonio revela que el interés de Grossmann también se divide en dos partes: una historiográfica, referida a la cuestión de la lengua en Argentina, parte que es a la vez la más delgada del libro; otra empírico-lingüística, a la que consagra el flanco más gordo. Para resumir la primera se remite a voces que estima autorizadas y triunfantes en la polémica. Busca, en cambio, explayarse en la segunda, porque cree que es allí donde debe dar, no ya la disputa, sino la demostración fehaciente de que no existe amenaza extranjera del español en Argentina. Referiré brevemente ambas partes.

\footnotetext{
${ }^{1}$ GrossmanN 1969.

${ }^{2}$ Grossmann 1926, 333.
} 
El libro comienza hablando de los componentes lingüísticos del español americano, a los que divide en tres grupos predominantes: el vocabulario nativo, aportado por los americanos originarios; el vocabulario español, incorporado por los primeros colonizadores; y el vocabulario extranjero, introducido por inmigrantes no españoles ${ }^{1}$. Luego de observar el desenvolvimiento de estos componentes, Grossmann llega a la conclusión de que, así como las lenguas nativas no han influido en el español americano - excepto por un número ínfimo de voces, a las que llama «americanas»—, las lenguas no españolas, si bien dejaron y aún dejan un «patrimonio lingǘstico extranjero» de cierta importancia, no ponen en peligro la unidad del español en Argentina. Este patrimonio es, por su envergadura, el que Grossmann disecciona en su estudio; y del que no se puede esperar - concluye- que surja una nueva lengua.

Si bien Grossmann contempla la posibilidad de que se formen, muy a largo plazo, nuevas lenguas en América - como cree que lo ha previsto, además de Rufino José Cuervo, el mismo Rodolfo Lenz $^{2}$-, no cree que actualmente el español en América atraviese un proceso de dialectización. Descansa su certeza en las fundamentaciones hechas, principalmente, por Miguel de Toro y Gisbert (1912), y Ramón Menéndez Pidal (1918), filólogos que Grossmann aprecia y encuentra, a diferencia de Abeille, como verdaderos hombres de ciencia.

La adscripción a la tesis unificacionista de Menéndez Pidal es, a la vez, una adscripción a la labor de su escuela en el Río de la Plata. Grossmann no anhela sumarse a la querella en torno al idioma nacional, pues para él ya no hay querella, esto es, la cuestión de la lengua dejó de ser — después de las intervenciones de Toro y Gisbert y de Menéndez Pidal — un asunto polémico. De modo que, al referirse al movimiento autonomista de la lengua ${ }^{3}$ lo hará como si se tratase de un movimiento superado. Con los trabajos de Toro y Gisbert, Menéndez Pidal y Américo Castro, entre otros, Grossmann cree que «se ha pronunciado la última palabra sobre el costado filológico del problema» ${ }^{4}$, único costado que le queda al asunto.

\footnotetext{
${ }^{1}$ Cf. Grossmann 1926, I, 1

2 Grossmann se refiere a LENZ, Rudolf, «Beiträge zur Kenntnis des Americanospanischen», en Zeitschrift für Romanische Philologie. Band XVII. Halle, Gustav Gröber, 1893, pp. 188-214. Pero ya he referido en el presente ensayo (cf. Primera Parte, V. 1.) que Lenz no ve una futura formación de lenguas en América.

${ }^{3}$ Cf. Grossmann 1926, I. 2.

${ }^{4}$ Grossmann 1926, 74.
} 
Si bien Grossmann no cree en la existencia de un «idioma argentino», no puede dejar de llamar a su objeto de estudio «idioma argentino» (argentinisches Idiom), o bien «uso argentino de la lengua» (argentinischer Sprachgebrauch); a veces lo llamará «español argentino» (Argentinisch-Spanisches), a veces «lengua local» (heimische Sprache); también recurrirá a la expresión «lengua nacional argentina» (argentinische Nationalsprache) o simplemente «el argentino» (das Argentinische). En esta paradoja también incurre uno de los libros en que Grossmann más se respalda: El problema del idioma nacional, de Ernesto Quesada, quien tampoco quiso oír hablar más de un idioma semejante. No obstante, Grossmann no ignora que Argentina dispone de varias regiones léxicas, de modo que aquello que se llama «idioma argentino» (aclara) se restringirá a la región del Río de la Plata, denominación que comprende a Buenos Aires, Santa Fe, Entre Ríos, Corrientes y Uruguay. A ese idioma lo llamará, a la vez, «idioma corriente» (Verkehrsidiom) y de uso común entre los que viven en esa región del Plata. No duda, a la vez, en llamarlo «argentino», porque entiende que se ha constituido en el patrón idiomático para el resto de las provincias argentinas.

En el parágrafo quinto, Grossmann se asienta en la fe de que aún no se ha reunido una bibliografía acerca de los estudios de la lengua argentina, carencia que intenta remediar dando una de su propia faena. Alista, entonces - divididos en dos grupos que a la vez se confunden: «Aportes y Tratados», por un lado; «Diccionarios y Glosarios», por otro- una serie de textos de distintas naturalezas: notas querellantes sobre la cuestión del idioma nacional, polémicas sostenidas en los diarios, estudios filológicos, gramáticas, diccionarios especiales, minucias lexicográficas, etcétera. Este listado, notablemente incompleto y asolado por el predominio del descuido y la errata, quizá solo intente demostrar al lector que el tema tratado ostenta un corpus dilatado y una tradición.

Concluido este inventario, y presto a enunciar su impresión sobre lo que llama «El problema de la lengua nacional argentina», Grossmann entiende que el primero en desarrollar el concepto de una lengua especial argentina fue Sarmiento, sobre la base de un sentimiento antiespañol y una mala lectura de los trabajos de Andrés Bello. En párrafo siguiente, afirma que la oposición formal consciente al castellano fue, no obstante, señalada inicialmente por Juan María Gutiérrez y su círculo, «quienes deben ser considerados entonces como los auténticos creadores de la orientación separatista

\footnotetext{
${ }^{1}$ Cf. Grossmann 1926, I. 6.
} 
en el movimiento del "Idioma nacional argentino"»". Estas aseveraciones son menos curiosas por lo inexactas que por revelar que Nuestra lengua, libro que Grossmann encuentra indispensable para pensar estos problemas, es a la vez un libro del cual prescinde para formarse una idea sobre ellos. Recordemos que uno de los esfuerzos de Costa Álvarez, acaso el más relevante de su libro, fue quitar el sayo de «separatistas» a Esteban Echeverría, a Juan Bautista Alberdi, a Domingo F. Sarmiento y a Juan María Gutiérrez.

Teniendo en su escritorio a Nuestra lengua - donde la historia de la querella idiomática se relata con más cuidado- y a su disposición la biblioteca del Instituto Iberoamericano de Hamburgo, la biblioteca de Ernesto Quesada y la biblioteca del Museo Mitre, en Buenos Aires, Grossmann aligera la lectura de todos los materiales reunidos y resume la historia de la polémica idiomática como quien apresura un asunto preliminar y anecdótico para adentrarse con dedicación en la cuestión de fondo, cuestión a la que tratará con cierto celo alemán.

He dicho que una radiografía del libro de Grossmann revela que consta de dos partes, una que se ocupa fugazmente de la historia polémica del autoctonismo, otra que se consagra a la demostración lingüística de su inexistencia; sugerí, además, que la primera es asaz indolente; notablemente esmerada, la segunda. Agrego, ahora, que la indolencia con que Grossmann se refiere a la disputa idiomática enseña lo que piensa de ella; y que, por tanto, se trata de un descuido deliberado: no encuentra provechoso demorarse en una historia de las ideas lingüística en Argentina, sino en un análisis de la influencia extranjera, último aspecto a descifrar para comprobar que el español local no se encuentra amenazado. El paso siguiente, en el programa grossmanniano, es demostrar por qué la Argentina está libre de esta amenaza.

En el parágrafo undécimo, dedicado al «gran proveedor de bienes espirituales foráneos», Grossmann se muestra entusiasta con la actividad que desarrolla la prensa, pues encuentra que los diarios más importantes de Buenos Aires: La Prensa, La Nación, La Razón, así como periódicos provinciales - La Capital, por ejemplo, de Rosario-, escriben «un estilo ejemplarmente puro». La tendencia de estos periódicos al purismo y a su enseñanza —influencia pedagógica que encuentra mucho más fuerte que la del libro-, persuade a Grossmann de que la acción corruptora del extranjerismo retrocede progresivamente, al punto que es dable esperar que desaparezca por completo.

\footnotetext{
${ }^{1}$ Grossmann 1926, 70.
} 
Rechazados por insuficientes entonces los ensayos tendientes a formar una lengua nueva en Argentina, en el capítulo cuarto advierte que si, acaso alguna otra amenaza se avizora, es la que se deduce no ya de la presencia de extranjerismos, sino de la cuantiosa inmigración extranjera, a partir de la cual se constituyen, aunque frágiles e inconstantes, lenguas mixtas. Debido a que en algunas regiones del Plata estas lenguas mixtas preanuncian la constitución de un estado nuevo de la lengua,

[...] la pregunta que nos interesa especialmente en el marco de nuestro trabajo es, entonces, si no es quizás justamente aquí donde podría avistarse el germen de un nuevo idioma nacional argentino $[\ldots]^{1}$

Responde que no. La inconstancia, rasgo característico de las mismas, las haría prácticamente incapaces de constituirse en lenguas estables. Por otro lado, quienes las hablan van progresivamente renegando de ellas, como sucede con el ítalo-argentino, que aspira a hablar bien el español como modo de ascenso social en su nueva patria. Tres razones más agrega Grossmann para aseverar esto: primero, la diversidad cuantitativa de las lenguas mixtas; segundo, una cierta inferioridad cualitativa en los portadores de las más difundidas entre ellas; tercero

[...] la por demás poderosa fuerza de asimilación del país y de la lengua argentina, que hace aparecer ya a todos los hijos de extranjeros como absolutamente bilingües — con escasas excepciones- - y a todos los nietos como ya solo monolingües en español. ${ }^{2}$

Confeccionado el marco a partir del cual Grossmann formula sus tesis, enunciaré, ahora, sucintamente, las conclusiones a las que arriba:

$1^{\circ}$ Dividido en tres el componente léxico en América: el nativo americano, el extranjero no español y el español; es este último la lengua nacional de la Argentina (cf. I. 1.).

$2^{\circ}$ No hay ninguna realidad léxica que preanuncie un divorcio entre el español peninsular y el argentino; y es de esperar que esta unidad tienda a ser cada vez más uniforme (cf. I. 1.).

$3^{\circ}$ Mientras la más baja lengua coloquial sudamericana sigue desviándose aún en alguna medida del español castizo, la diferencia

\footnotetext{
${ }^{1}$ Grossmann 1926, 283.

${ }^{2}$ GrossmanN 1926, 284.
} 
entre la lengua del sudamericano culto y el español culto se ha visto reducida en su uso escrito a un mínimo (cf. I. 2.).

$4^{\circ}$ Grossmann encuentra necesario distinguir, claramente, la diferencia que existe entre el «neologismo» y el «extranjerismo». El primero corresponde a un préstamo que ha incorporado la acentuación, grafía y flexión nativas; el segundo es lo hablado, escrito y flexionado por cada individuo más o menos según su buen criterio, formación o gusto, aunque su integración general en la lengua aún no ha tenido lugar. El «neologismo», por tanto, se encuentra, lingüísticamente, claramente fijado; el «extranjerismo» no (cf. II. 7.). Por tanto, el patrimonio lingüístico extranjero introducido a través de la mediación intelectual (libro, prensa, etc.) obtiene su vigencia en el argentino preferentemente en la forma del "neologismo"; el "extranjerismo" se encuentra muy raramente en el ámbito intelectual (cf. II. 13.).

$5^{\circ}$ «A través de la sola importación del vocabulario extranjero por vías intelectuales, el carácter de la lengua argentina no es modificado en tan gran medida como para que, por este medio, pudiera ir adoptando la forma de un idioma autónomo» ${ }^{1}$ (cf. II. 13.).

$6^{\circ}$ Los neologismos que penetran en el argentino a través de la mediación intelectual están extendidos más o menos en igual medida en los restantes territorios hispanohablantes. De modo que, al reunir estos neologismos en un lexicón, se obtendrá un diccionario internacional, nunca uno especial para los argentinos (cf. II. 13.).

$7^{\circ}$ Los neologismos se conservan en la lengua durante mucho tiempo, encontrándose, preferentemente, en la lengua literaria y en la lengua conversacional culta. No obstante, contra ambos peligros (permanencia duradera en el léxico; preferencia por parte de la vanguardia intelectual) operan corrientes contrarias, como por ejemplo el purismo de los grandes periódicos, o la creciente difusión de buenas obras originales españolas en el Plata (cf. II. 13.).

$8^{\circ}$ «La importación lingüística material extranjera, de modo similar a la intelectual, se hace efectiva casi solamente en el vocabulario. Consecuentemente, puede obrar modificaciones solo sobre esta parte del idioma argentino, no así sobre la sintaxis, que debe ser vista junto a aquel como componente esencial de un idioma autónomo» ${ }^{2}$ (cf. III. 29.).

$9^{\circ}$ Esta presencia léxica extranjera, lejos de constituirse en una unidad que rivaliza de igual a igual con el español, se caracteriza por su variación, movilidad e inconstancia (cf. IV. 32.).

\footnotetext{
${ }^{1}$ Grossmann 1926, 127.

${ }^{2}$ GrossmanN 1926, 257.
} 
$10^{\circ}$ El español de la Argentina, a causa de su contacto con el patrimonio lingüístico extranjero, se encuentra expuesto, más que el español de cualquier otro lugar del mundo, a una serie de influencias que lo hacen distintivo del español de la Península. «A esto debe, sin embargo, objetarse que en el marco total de las manifestaciones lingüísticas, esta influencia extranjera es tan escasa que jamás podría hablarse ya a partir del estado actual del argentino, sobre la base de los mencionados procesos, de una nueva lengua especial» ${ }^{1}$ (cf. V. 36.).

$11^{\circ}$ Para Grossmann, finalmente, ningún otro pueblo del mundo, aparte del norteamericano, ha sabido subsumir lo extranjero tan rápidamente en su modo de ser nacional como el argentino. La lengua argentina, en este sentido, mantiene frente a la ofensiva del material lingüístico extranjero la misma fuerza de absorción que el país (cf. V. 36.).

Estas son las conclusiones a las que Grossmann arriba a partir de sus investigaciones lingüísticas. No obstante, y para respaldar aun más su demostración de que el español de la Argentina se encuentra unido íntimamente al español del resto del mundo, hace una última referencia del problema, esta vez de carácter psicológico. En el parágrafo 37, asevera que el posicionamiento «racialpsicológico del argentino» (Die rassenpsychologische Einstellung des Argentiners), al que cree algo más desarrollado que el del resto de los sudamericanos, toma de lo extranjero solo aquello que le resulta práctico para el progreso de su propia cultura. Superada la etapa de vivir del préstamo, se afirma cada vez más sobre lo propio. El argentino - para Grossmann - tiende a convertir en patrimonio nacional todo lo que absorbe. Todo el vínculo que, no obstante, mantiene aún con lo extranjero es equiparable a los límites que le opone en pro de reafirmar su espíritu de nacionalidad. «La conciencia nacional del argentino, de por sí ya fuertemente desarrollada, se encuentra, pues, en continuo fortalecimiento» ${ }^{2}$. Estos límites, como ha intentado demostrar, se observan en las distintas formas en que se rebela ante las influencias lingüísticas extranjeras.

\section{2. Primeras glosas de El patrimonio}

Excepto para aquellos lectores que reunieran la triple condición de hallar el libro, leer alemán y estar interesados por la cuestión filoló-

\footnotetext{
${ }^{1}$ Grossmann 1926, 332.

${ }^{2}$ GrossmanN 1926, 336.
} 
gica argentina, el esfuerzo de Grossmann fue a dar a un anaquel vedado. No obstante, quienes seguían de cerca la discusión lo saludan en distintos medios.

La primera reseña de El patrimonio quizá sea la que el filólogo norteamericano Aurelio M. Espinosa (1927) presenta a la revista Language. A pesar de las falencias que encuentra en el libro - una de las cuales es haber tomado como parámetro de la particularidad léxica rioplatense la lengua esgrimida en el periódico El Fogón, que no es un «specimens of popular speech»- Espinosa lo celebra abiertamente: «Dr. Grossman has done a distinct service to Romance scholarship...» ${ }^{1}$. Luego asevera que Grossmann establece con su estudio, finalmente, una voz autorizada con respecto a la discusión del idioma nacional de los argentinos. El énfasis que pone en el carácter científico del trabajo es, a la vez, énfasis reprobatorio al trabajo de Abeille, al que llama «ridiculous book». No obstante Espinosa, que ya había escrito un Studies in New Mexican Spanish, advierte que aquellas peculiaridades dialectales que comúnmente se consideran propias de algún país hispanoamericano son comunes a todo el mundo de habla hispana, incluida España. Por tanto cree que el español se encuentra mucho más unificado de lo que Grossmann lo presenta; y aquello que este llama «argentinismo», a menudo, no es más que una variante común al español.

Sin conocer aún esta glosa de Espinosa, al publicar «El castellano en Argentina» (1927), Arturo Costa Álvarez —notoriamente en sintonía con la glosa de Espinosa- se refiere a El patrimonio como una obra erudita y resuelta científicamente, y afirma de su autor «que ha preferido subir al mirador de la cultura para descubrir la trascendencia social del caso, en vez de tenderse en el suelo para detallar microscópicamente las particularidades del fenómeno» ${ }^{2}$. Aunque también lo celebra y lo encuentra un trabajo definitivo sobre la cuestión del idioma nacional, no puede dejar de objetar algún aspecto del mismo:

Es lástima que esta obra, tan interesante por su tesis cultural como importante por la documentación que ofrece, resulte inexacta en algunas de sus referencias históricas, deficiente en su información bibliográfica, errónea en muchas de sus etimologías indígenas, e incorrecta cuando toma por documentos lingüísticos los artificios chuscos del escritor plebeyo $[\ldots]^{3}$

\footnotetext{
${ }^{1}$ EsPinOSA 1927, 20.

${ }^{2}$ Costa Állvarez 1927, 192.

${ }^{3}$ Costa Álvarez 1927, 193.
} 
Sin embargo, nada de esto la empaña, porque Costa Álvarez, quizá el mayor cruzado en contra de Abeille y los abeillistas, encuentra en Grossmann un aliado bien pertrechado. Ambos aspiran a la unidad lingüística en Argentina; ambos creen que la querella por la autonomía de la lengua ha sido superada; ambos se reconocen, mutuamente, el protagonismo que han tenido en el triunfo de esa batalla.

En noviembre del mismo año (1927), Américo Castro escribe unas líneas en La Nación, refrendando la opinión de Espinosa. Castro siente el deber de señalar que la gran mayoría de extranjerismos que Grossmann recoge en su libro son tan «típicamente argentinos como yo soy rey de Cambodge». Es en esto donde ve que zozobra, no solo Grossmann, sino los que, como él, trabajan la peculiaridad léxica hispanoamericana. También para Castro, lo que comúnmente se considera propio de una región no es sino un hecho general del idioma español. Castro conjetura que el criterio seguido por Grossmann para hallar extranjerismos en el español del Río de la Plata es no hallarlos en el Diccionario de la Academia (14 a edición); criterio que encuentra harto peligroso: «todos saben que millares de palabras y acepciones corrientes quedan siempre fuera del léxico de aquella corporación madrileña» ${ }^{2}$.

A mediados del año siguiente (1928), en la revista platense $V a$ loraciones, Costa Álvarez amplía su juicio sobre El patrimonio. En primer lugar advierte que la influencia extranjera en el castellano argentino sirvió, durante muchos años, ya sea para que unos («los conservadores») alertaran sobre una degeneración idiomática que había que reprimir, ya sea para que otros («los revolucionarios») la alegaran para demostrar la evolución del «idioma propio». No obstante, advierte que esta influencia extranjera jamás había sido estudiada: «todos se conformaban con la afirmación dogmática de la existencia de esa contaminación, pensando cómodamente que, si se formulaba, era porque alguien se había tomado el trabajo de comprobarla» ${ }^{3}$. Grossmann, por tanto, vendría a terminar con esta creencia: «De afuera nos llega ahora un libro, cuya importancia reconocerán nuestros pocos filólogos, y nuestros muchos aficionados a la filología improvisada.... ${ }^{4}$

\footnotetext{
${ }^{1}$ CAstro $1927 b$.

${ }^{2}$ CASTRO $1927 \mathrm{~b}$.

${ }^{3}$ Costa Álvarez 1928a, 241.

${ }^{4}$ Costa Álvarez 1928a, 241.
} 
A pesar de estos auspicios, que son refrendados con algunas transcripciones del libro, Costa Álvarez cree necesario señalarle sus errores: unos de detalle, debidos en su mayor parte a la circunstancia de que Grossmann habría recurrido a informaciones de segunda mano; otros dos de bulto: uno histórico y otro científico. El primero es decir que Sarmiento «"fue el primero que desarrolló la idea de un idioma privativo argentino" y que a Gutiérrez "se le considera entre los verdaderos promotores de la tendencia separatista en la evolución del idioma nacional argentino"»'; el error científico, a su vez, es que para presentar ejemplos del «habla del analfabeto criollo o extranjero», el autor hace gran número de transcripciones del periódico El Fogón.

Los acogedores juicios de Espinosa, Costa Álvarez y Castro no alcanzaron, no obstante, para que el libro se volcara al español, hecho que, ochenta y dos años más tarde, consuma la Biblioteca Nacional de la Argentina.

\section{3. Polémica entre La Gaceta literaria y Martín Fierro}

El primero de enero de 1927 aparece en Madrid La Gaceta Literaria, de Ernesto Giménez Caballero. Ese primer número, aunque prologado por José Ortega y Gasset, no logra la repercusión que logará, en cambio, el octavo, aparecido en abril, a causa de un efusivo editorial de su secretario, Guillermo de Torre. La nota, que es también una arenga, exhorta a poner las cosas derechas y reconocer que España, más precisamente Madrid, debe ser reconocida como capital espiritual e idiomática de Ibero-América, expresión que escribo en cursiva por ser el centro de la disputa. De Torre entiende que llamar «Latinoamérica» a esta extensión continental es injustificado y contrario a los intereses de España.

No hay, a nuestro juicio, otros nombres lícitos y justificados para designar globalmente - de un modo exacto que selle los tres factores fundamentales: el primitivo origen étnico, la identidad lingüística y su más genuino carácter espiritual—a las jóvenes Repúblicas de habla española, que los de Iberoamérica, Hispanoamérica o América española. ${ }^{2}$

\footnotetext{
${ }^{1}$ Costa Álvarez 1928a, 243-244.

${ }^{2}$ TORRE 1927.
} 
Él preferiría, no obstante, llamarla «América hispanoparlante», pues el idioma, más que cualquier otra cosa, es lo que liga a estas tierras con España. Detrás del «latinismo», conjetura, se traman «turbias maniobras anexionistas» por parte de Francia e Italia, robándole a España su derecho histórico con respecto a América. Al latinismo, además, se suma la pretensión anglosajona, que avanza política y culturalmente. «iBasta ya de tolerar pasivamente esa merma de nuestro prestigio...! $\rangle^{1}$

Frente a los «excesos y errores del latinismo», el «monopolio galo» y la «imantación que ejerce París», De Torre llama a polarizar la atención de los intelectuales hispanoparlantes, a reafirma «la valía de España» y a asumir que Madrid es el único lugar que puede y debe erigirse como epicentro cultural y «meridiano» de la cultura hispana en el mundo.

En el Río de la Plata, este editorial, leído por los jóvenes martinfierristas, se toma como un presente griego; y a mitad de año, casi emulando el célebre rechazo de Gutiérrez a la Academia, responden colectivamente en las páginas de Martín Fierro tras el título: «Un llamado a la realidad. ¿Madrid, meridiano intelectual de Hispano-América?» Por orden de aparición gráfica, el primero que desenvaina es Pablo Rojas Paz, quien denuncia que, ya sea Norte América, detrás de su «panamericanismo»; ya sea Francia, con su «Latinoamérica»; ya España, con su «Hispanoamérica», se pretende, «bajo una mala actitud de concordia», imperar en «Sud América». (Este, estimo, es el nombre que muchos de ellos preferirían adoptar para el sur del continente.) La intención de España de constituirse en la Meca intelectual de los sudamericanos, según Rojas Paz, bien podría cuadrar para países que gusten de la tiranía, o en pueblos como Perú o Bolivia, que se jactan de hablar un español del 1600; «pero nosotros ya hemos progresado mucho, tanto que no podemos decir en qué idioma hablamos» ${ }^{2}$. Nuestro articulista no se contenta con señalar un hecho, sino que proclama un anhelo: «Nuestra ilusión debe ser la de echar a perder de tal manera el castellano que venga un español y no entienda nada de lo que digamos» ${ }^{3}$. Para Rojas Paz, Argentina ya no se liga a España sino a través de una tradición artificiosa. Cree que es signo de potencia espiritual que un pueblo transforme el idioma heredado al punto de convertirlo en otro: «Nosotros estamos organizando un idioma para nosotros solos y de

\footnotetext{
${ }^{1}$ TORRE 1927.

${ }^{2}$ ROJAS PAZ 1927.

${ }^{3}$ ROJAS PAZ 1927.
} 
aquí nos vendrá la libertad» ${ }^{1}$. También cree que Argentina no está buscando un meridiano; está hallando su destino.

Detrás de él, y enojando el rostro, le siguen Ricardo E. Molinari, Ildefonso Pereda Valdés y Nicolás Olivari, quienes, en la misma página, dedican al asunto brevísimas líneas; el primero cree una veleidad lo de «Madrid, meridiano intelectual de Hispano-América»; el segundo encuentra más correcto un enunciado que señale como meridiano a Buenos Aires, si se ha de tener en cuenta el verdadero interés de los escritores americanos; el tercero amerita un apartado. Olivari es menos hospitalario con La Gaceta; partiendo de la premisa de que España no tiene ningún interés intelectual para ellos, reclama - aunque concede que lo tenga Italia y Francia- el derecho de pensarse vírgenes de toda influencia. Para Olivari, España es un mal recuerdo, y la desdeña al punto de desconocerla: «Hablamos su lengua por casualidad, pero la hablamos tan mal que impertinentemente nos estamos haciendo un idioma argentino» ${ }^{2}$. Ese desaire, a la vez, contiene un pronóstico de divorcio: «Dentro de unos pocos años nos tendrán que traducir si quieren gozar de nuestro lírico influjo» ${ }^{3}$.

En la página siguiente, Santiago Ganduglia agrega, al conjunto de rechazos espirituales, el aspecto económico, vislumbrando en los españoles un apremio mercantil: «Al final del cuento se sabe que $L a$ Gaceta Literaria se preocupa por la mayor exportación del libro español» ${ }^{4}$. Luego, echando leña al fuego, llama a los argentinos a ser un pueblo moderno, esto es, a alejarse de España y virar, si se quiere, hacia Norte América y Francia; pero ante todo a hondar en la identidad cultural que se ha gestado en Argentina. «Nosotros somos dueños de una recia fisonomía intelectual. Nos hemos acuñado un espíritu propio. Somos insurrectos de España.. ${ }^{5}$

Raúl Scalabrini Ortiz, quien también se alista, descree de un término como «Hispanoamérica» $y$, por tanto, del vínculo establecido por el idioma. Adelantando la idea de que diversas corrientes de oro confluyen en el Plata (idea que expandirá en El hombre que está solo y espera), agrega: «Nuestros glóbulos rojos hablan varios idioma y responden a tradiciones distintas y antagónicas [...]. Hablamos en castellano, actuamos en inglés, gustamos en francés y pensamos...

\footnotetext{
${ }^{1}$ Rojas Paz 1927.

${ }^{2}$ Olivari 1927.

${ }^{3}$ Olivari 1927.

${ }^{4}$ GANDUGLIA 1927.

${ }^{5}$ GANDUGLIA 1927.
} 
pero, ¿es que nosotros pensamos?». ${ }^{1}$ Opina también Lisardo Zía, quien no cree que sea posible desligar la identidad cultural de un pueblo de su paisaje. El paisaje de España, afirma, «se reduce al de España misma: un pentágono. Cinco lados que encierran cinco perspectivas. El paisaje de América es, quizá, la suma de todos los horizontes» ${ }^{2}$.

También responde Jorge Luis Borges:

Madrid no nos entiende. Una ciudad cuyas orquestas no pueden intentar un tango sin desalmarlo; una ciudad cuyos estómagos no pueden asumir una caña brasilera sin enfermarse; una ciudad sin otra elaboración intelectual que las greguerías; una ciudad cuyo Irigoyen es Primo de Rivera; una ciudad cuyos actores no distinguen a un mejicano de un oriental; una ciudad cuya sola invención es el galicismo -a lo menos, en ninguna otra parte hablan tanto de él-; una ciudad cuyo humorismo está en el retruécano; una ciudad que dice «envidiable» para elogiar ¿de dónde va a entendernos, qué va a saber de la terrible esperanza que los americanos vivimos? ${ }^{3}$

Pero había algo más que Borges quería hacer: mofarse. En complicidad con Carlos Mastronardi (firman la broma: Ortelli y Gasset), imaginan a un criollo hablándole a un meridiano, encontrado en una fiambrera:

Aquí le patiamo el nido a la hispanidá y la escupimo el asao a la donosura y le arruinamo la fachada a los garbanzeli [...] Espiracusen con plumero y todo, antes que los faje. Che meridiano: hacete a un lao, que voy a escupir. ${ }^{4}$

Anoto estos argumentos para evidenciar en el espíritu de los martinfierristas una tendencia a estimar que el español de la Argentina no solo se distingue del español peninsular, sino que busca en esa distinción su renovación y expansión espiritual. Estos jóvenes no pueden dejar de hablar de una esperanza, a la invocan a modo de enseña, de mascarón de proa. Ese idioma argentino en el que piensan, antes que una realidad léxica es una tarea (cuando no se percibe ya como una realidad) que se consumará en la reunión generosa de todas las lenguas que se conversan y leen en Buenos Aires; tarea que, a la vez, pretende reunir todos los intereses estéticos y filosófi-

${ }^{1}$ SCALABRINI ORTIZ 1927.

${ }^{2}$ ZIA 1927.

${ }^{3}$ BORGES 1927a.

${ }^{4}$ Ortelli y Gasset (Borges - Mastronardi) 1927. 
cos que pasean por Buenos Aires. No creo que prime en ellos un rechazo a España; prima el entusiasmo que les genera la realidad literaria de América. Como si estuvieran redimiendo el anhelo de los románticos, más que un no a lo español, los aviva un sí al cosmos que se asentó en Argentina, que en ellos se representa como una tierra de promisión. No es, a su vez, la primera vez que el periódico se refiere a la querella de la lengua. Recordemos aquellas intervenciones de Francisco Luis Bernárdez (1925), y de Pablo Rojas Paz (1925).

En agosto de 1927, Guillermo de Torre viene a vivir a la Argentina, y tiempo después se casará con Norah Borges. La anécdota no es irrelevante. Guillermo de Torre demostrará que su anhelo de reconquistar América no era retórico. Toda La Gaceta Literaria lo había salido a despedir. Francisco Ayala escribe:

El día 25 embarca en Barcelona nuestro Secretario, Guillermo de Torre, con rumbo a Buenos Aires [...] Va «a fundirse» con aquella prolongación ideal de una España nueva, más vital, más musculosa y cosmopolita que es Suramérica. A «fundirse» sin «confundirse». En tipo de amante más que de espectador $[. . .]^{1}$

Esa fundición de españoles en Argentina no solo terminará con el temor de que París se constituya en eje de atracción espiritual, sino que horadará aún más los intentos separatistas en el idioma. Ayala ya lo sugiere en esta misma nota: «Con Amado Alonso nuestro redactor filológico — ya al frente del "Instituto" porteño de Filología, y ahora con Guillermo de Torre, La Gaceta Literaria siente el entusiasmo de los amplios desdoblamientos espirituales» ${ }^{2}$.

La polémica meridiana continúa, aunque a los efectos de ahondar en la biografía de la querella, basta con lo apuntado ${ }^{3}$.

\footnotetext{
${ }^{1}$ AYALA 1927.

${ }^{2}$ AYALA 1927.

${ }^{3}$ Cf. VV. AA., «Un debate apasionado. Campeonato para un meridiano intelectual. La selección argentina Martín Fierro (Buenos Aires) reta a la española Gaceta Literaria (Madrid). Gaceta Literaria no acepta por golpes sucios de Martín Fierro que lo descalifiquen. Opiniones y arbitrajes.», en La Gaceta Literaria, ibérica, americana, internacional. Letras, artes, ciencia. Periódico quincenal (1 y 15 de cada mes). Año I, $\mathrm{N}^{\circ}$ 17. Madrid, $1^{\circ}$ de septiembre, p. 3. Ver también VV. AA., en Martín Fierro. Periódico quincenal de arte y crítica libre. Número doble, Año IV, No 44-45. Buenos Aires, 31 de agosto - 15 de noviembre, pp. 1, 10, 11-12.
} 


\section{4. Xul Solar y sus «Apuntes de neocriollo»}

Xul Solar parece no haber querido ser indiferente a la querella ni dejar indemne el idioma español. Pintor, astrólogo y lúdico, ilustró los primeros libros de ensayos de Jorge Luis Borges (seis viñetas para El idioma de los argentinos). La afinidad entre ambos los unió, además, en la común batalla por un nuevo español en América: las ilustraciones de Xul Solar apelan al lenguaje y al combate, y debemos deducir que él también consideró que la guerra por la independencia continuaba en el terreno de los adjetivos y los símbolos. En los años 20, aunque Xul Solar no despliega aún todos los pormenores de su proyecto cósmico-lingüístico, ya comienza a dibujar la silueta de lo que pronto será el neocriollo, una mezcla que, teniendo por base al español, a los astros y a los números, pretende recibir los aportes del portugués, el alemán, el inglés y cualquier otra lengua que puje por integrarse a la ocurrencia. La picardía de Xul Solar no es su artefacto lingüístico (intentos de lenguas artificiales se registran desde tiempos bíblicos), sino anunciarlo como novedad.

Borges, si bien lo aplaudió bastante, no concibió el idioma nacional como un collage de lenguas, sino como un idioma capaz de expresar los misterios y fortunas de los demás idiomas: imaginó y anheló un español que aloje generosamente las fuerzas ajenas, y que dio en llamar, por los años veinte, idioma de los argentinos. Pero la querella había llegado a tal punto que es comprensible que Borges creyera oportunos los viñetazos proales de Xul Solar. Si bien los detalles los diferenciaban, los unía el común criterio de abrir el español al mundo, o mejor aun, que el mundo entero cupiera en el español.

Aunque publicados algunos años más tarde, Xul Solar compone en 1925 unos "Apuntes de neocriollo» ${ }^{1}$ de tal forma que ya ensaya la contracción (alfín), el uso abundante del apóstrofo (incomod'algo), la elisión ( $p$ a doqier), la reforma ortográfica (la $y$ por la $i$ es la más notoria), la invención de palabras (nubiplanos) y el empleo cuantioso de neologismos y voces tomadas directamente de otras lenguas. La sintaxis es española, pero todo lo demás es tan de Xul Solar que sugiere pensar que se trata de una lengua que le pertenece. Un escueto glosario de anexo parecería querer hacer legible el texto: confiesa que sür significa sobre; g'ral, en general; man, humano; chi, chico; dootri, en otra parte; c'len, caliente, etc. Una muestra de neocriolllo será publicada por primera vez en 1927, en Martín Fierró ${ }^{2}$. La lengua arti-

\footnotetext{
${ }^{1}$ Xul SOLAR 1931.

${ }^{2}$ Xul SOLAR 1927a.
} 
ficial de Xul Solar está en movimiento; se trata de una empresa que, por su naturaleza, no puede concebir una gramática. Parecería una mera humorada críptica si no fuera que se está poniendo a prueba un programa lingüístico que, cuanto menos, no carece de antecedentes ni de cierta osadía.

El primer y más ferviente convencido de este curioso idioma es el propio Xul Solar, pues insistirá por largos años con su defensa y propagación. Así, en oportunidad de publicar la traducción de unos aforismos del poeta y traductor alemán Christian Morgenstern, versión que compone en neocreol, adosa una breve «Nota del traductor», donde afirma:

Ya empiezan usarse el presente de indicativo i el presente de subjuntivo con sendas mismas desinencias (de $1^{\mathrm{a}}$ cónjuga) unicónjuga $\mathrm{i}$ a las palabras largas se les amputa: cion i miento $i$ a veces: dad, por inútiles y feos. ${ }^{1}$

Más allá de las varias reivindicaciones que le propinó el propio Xul Solar, no se sabrá más nada de se neocriollo; del idioma que entrevió Borges, en cambio, sabemos que ha servido para escribir infinidad de obra, entre ellas la del mismo Jorge Luis Borges.

Leopoldo Marechal, que ironizó sobre muchas de las invenciones de Xul Solar, no olvidó punzar en la lengua del Neocriollo. Recuérdese aquel diálogo en que el astrólogo Schultze afirma, refiriéndose a ella, que

[...] será el órgano del gusto y de la expresión a la vez, y estará dominada por Mercurio. Tendrá la forma de una cinta larga y flexible, como la de los osos hormigueros; y el Neocriollo la meterá en todas partes, ávido de sabores. ${ }^{2}$

No por satíricas estas líneas dejan de representar fielmente la esperanza que Xul Solar depositaba en su lengua neocriolla. Aunque Marechal no abogó jamás por una lengua tal y solo se detuvo en ella para urdir chanzas, Cortázar — he aquí un feliz malentendido-, al reseñar el Adán, creyó que su autor gestaba una lengua nueva:

Estamos haciendo un idioma, mal que les pese a los necrófagos y a los profesores normales en letras que creen en su título. Es un idioma turbio y valiente, torpe y sutil, pero de creciente propiedad para nuestra expresión necesaria. Un idioma que no necesita del lunfar-

\footnotetext{
${ }^{1}$ XUL SOLAR 1927b.

${ }^{2}$ Marechal 1948, p. 119.
} 
do (que lo usa, mejor), que puede articularse perfectamente con la mejor prosa «literaria» y fusionar cada vez mejor con ella - pero para irla liquidando secretamente y en buena hora. ${ }^{1}$

Cortázar creyó que en el Adán de Marechal surgía un idioma renovado que, aunque vacilante y a menudo temeroso, se trataba del mayor aporte idiomático de la literatura argentina «desde los experimentos (jtan en otra dimensión y en otra ambición!) de su tocayo cordobés» ${ }^{2}$. Es probable que esos experimentos remitan a La guerra gaucha.

\section{5. El futuro idioma en Borges y el «estado de gracia» de Castro}

El 11 de junio de 1927, el matutino porteño Crítica, de Natalio Botana, inicia una encuesta bajo un díscolo y único título: «¿legaremos a tener un idioma propio?», a la que responden sucesivamente Enrique Larreta, José Antonio Saldías, Ricardo Rojas, Víctor Mercante, Last Reason (Máximo Sáenz), Roberto J. Payró, Félix Lima, Jorge Luis Borges, Manuel Gálvez, Enrique García Velloso, Arturo Costa Álvarez, Alberto Nin Frías, Arturo Cancela, Alberto Gerchunoff, José María Monner Sans y Florencio Garrigós (hijo). La formulación prospectiva de la pregunta parecería informar de cierta premisa de los editores, pues, en tanto idioma posible, se presume hasta el momento su inexistencia.

De todas estas respuestas — que pueden abreviarse entre quienes lo creen o no venidero, por un lado; y quienes lo abogan o combaten, por otro- es notable la respuesta de Borges, pues se trata del anticipo de lo que más tarde será su conferencia sobre el idioma de los argentinos. Borges cree comprender el derecho argentino de forjar un idioma propio, pero sabe que no basta con que el reclamo sea legítimo: «Jurídicamente, nadie nos quitará el derecho de tener un idioma propio: la cosa es tenerlo» ${ }^{3}$. No teme a la presencia de un idioma argentino y hasta lo desea; solo que ese idioma, aunque propio, nada tiene que ver con una jerga, con un dialecto, con un recorte del idioma español. Se trata, por el contrario, de un español amillonado y audaz; apto para la conversación distendida como para los sofisticados procedimientos retóricos; un español

\footnotetext{
${ }^{1}$ CORTÁzAR 1949, 173.

${ }^{2}$ CORTÁzAR 1949, 173.

${ }^{3}$ BORGES 1927b.
} 
que sepa hablar lo local y lo americano, sin afectación; que no tema ahondar (y acertar) en temas de la filosofía, de la cosmología y de todas las ramas del arte. El idioma argentino que Borges predica tiene más de promesa que de actualidad; es más un deber que un deseo. Es esto lo que intenta decir cuando aclara que se trata del idioma profetizado y preconizado por Echeverría, por Alberdi, por Gutiérrez, por Sarmiento. Es este, a la vez, el mojón borgeano en la querella: reclamar un idioma nacional, pero para lograr un idioma superior.

Creo en el idioma argentino. Creo que es deber de cada escritor (nuestro y de todos) el aproximarlo. Para ese fin, nos basta considerar el español como una cosa apenas bosquejada y muy perfectible. Sintamos todos esa urgencia de innovación, sintámonos vivir en América y ya estará iniciada nuestra aventura. Digamos cosas que no le queden chicas a Buenos Aires y hablaremos idioma nuevo que será nuestro. ${ }^{1}$

Corresponsal en Buenos Aires del periódico La Nación, de Santiago de Chile, un tal Federico Vergara Vicuña, de seguro ignorando los resultados de la encuesta, toma velozmente partido sobre el asunto y afirma: «en Argentina ya no se habla el español: se habla el argentino» ${ }^{2}$. Ignoro quién sea este Vergara Vicuña, pero lo cito pues, al igual que él, muchos intelectuales se han formado esa impresión al visitar Buenos Aires y al estar en contacto con fenómenos que son los que intento desentrañar en esta tesis.

Poco tiempo después, en La Nación de Buenos Aires, Américo Castro sobrevuela la discusión en torno al meridiano y vuelve, a propósito de la encuesta de Crítica, sobre la cuestión del idioma argentino, aunque ahora agrega elementos que son relevantes y que enseñan que algo del aspecto sustancial del problema le fue revelado. En su nueva concepción, habría en Argentina un afán y una inquietud vitales que se sobreponen a la reflexión, luego de lo cual afloraría, «como un ágil efebo, bello y poderoso, la afirmación de la propia, peculiar e irreductible existencia» ${ }^{3}$. Esta aspiración a la propia, peculiar e irreductible existencia, que a simple vista podría parecer banal, le resulta maravillosa, pues garantiza una tensión esencial y necesaria.

\footnotetext{
${ }^{1}$ BORGES $1927 b$.

${ }^{2}$ Vergara Vicuña 1927.

${ }^{3}$ CAstro 1927a.
} 
Sin eso, ¿qué habría sido de las naciones de Hispano América? La idea de una lengua propia, exclusiva para la Argentina, por absurda que sea, es un reflejo de ese estado optativo, estado de gracia, ya que sin él las naciones se mueren. ${ }^{1}$

Aflora, así, el Américo Castro más interesante, el que se decide, aunque más no sea por un momento, a observar todo lo extralingüístico que tiene la peculiaridad argentina. Este viraje, traído en forma esporádica, reubica la discusión en la senda inaugurada por Unamuno, que es la exégesis más sugestiva e interesante.

El apetecer una lengua propia es un rasgo que hallamos en varios países de América. El hecho pide ser comprendido en conexión con toda la cadena de luchas y afanes que dieron origen a esas nuevas naciones. $^{2}$

Castro no ahondará en esta dimensión cultural del problema idiomático, y en nuevas intervenciones retomará el aspecto más débil de sus planteos, aquel que acusa a Buenos Aires de hablar incorrectamente y que lo harán pasar a la historia —al menos en el recuerdo argentino- como un alarmista.

\section{6. La Nación y los nuevos horizontes de Tirso Lorenzo}

El 17 de octubre de 1927, a través de un artículo titulado «El vínculo del idioma», los editores del diario La Nación se pronuncian sobre la intención de la Real Academia Española de reunir en Sevilla, aprovechando la próxima Exposición Iberoamericana, a todos los delegados de las filiales correspondientes. Advertido de que motiva a la corporación proyectar un gran diccionario hispanoamericano, el diario porteño imprime su opinión:

Siendo la lengua castellana una propiedad común de todos cuantos la usamos como idioma nacional, y constituyendo a la vez el vínculo más precioso, eficaz y positivo entre ellos, podemos ocuparnos del asunto en propiedad, y así lo hemos efectuado cada vez, atribuyéndole con esto, por otra parte, su primordial importancia. ${ }^{3}$

\footnotetext{
${ }^{1}$ CASTRO 1927a.

${ }^{2}$ CASTRO 1927a.

${ }^{3}$ LA NACIÓN 1927.
} 
Luego de esta declaración de principios, el editorial formula el deseo de que los delegados americanos formen parte permanente de la corporación, pues no basta con suministrar esporádicamente informes sobre el léxico en América y esperar, sin ciencia mediadora, todo de Madrid. «Ya contiene el último léxico demasiada broza así acogida.... ${ }^{1}$ Los hombres de La Nación parecen ya estar persuadidos del nuevo carácter científico de la lengua, que se pregona en esos años, pues lo enfatizan en este editorial y lo pretenden en la próxima construcción del diccionario, para evitar, afirman, que los celos regionalistas pretendan hacer pasar por indigenismo lo que es puro castellano. Luego, tienen necesidad de aclarar — sobre todo a los españoles- que no existe un idioma hispano-americano:

El castellano de América y el de España constituyen una misma entidad, salva la pronunciación: unidad preciosa que a todos nos interesa conservar. El pretendido «idioma argentino» en formación es, por ejemplo, una fantasía. ${ }^{2}$

Unos días más tarde, también en La Nación, Avelino Herrero Mayor —otro de los herederos del preceptismo idiomático de Monner Sans- en carta al director del diario, le reconoce toda la labor que hace en pos de defender la pureza de la lengua castellana, y se le ocurre formar, en auxilio de la santa misión, una «cofradía de los hablantes, en contra de los "prevaricadores del buen lenguaje"»". La idea se la habría dado el consabido Américo Castro, en una misiva que le enviara por esos días y que Herrero Mayor reproduce en forma textual:

¿No podríamos crear una Liga para la defensa del habla argentina, de la hermosa habla acriollada, americana, tradicional (y neologista), fundida en gramática y riqueza con la panhispánica? ${ }^{4}$

No es desmedido este reconocimiento de Herrero Mayor al diario La Nación, pues no hubo diario argentino que haya cedido tanto sus páginas en pos de custodiar la unidad de la lengua. En la misma edición del 21 de octubre, publica el escritor español José María Salaverría, que ya lo había hecho varias veces en relación a estos temas; esta vez advierte que en Buenos Aires, la gente bien

\footnotetext{
${ }^{1}$ LA NACIÓN 1927.

${ }^{2}$ LA NACIÓN 1927.

${ }^{3}$ Herrero MAYOR 1927.

${ }^{4}$ HerRero MAYOR 1927.
} 
nacida llega a hablar, incluso, tan correcto como en España ${ }^{1}$. En la edición del día anterior se publica una carta de José León Suárez², presidente del Ateneo Ibero-Americano, en la cual se confiesa el enorme agrado que ha causado en el Ateneo el editorial «El vínculo del idioma», del 17 de octubre.

Un poco después de la nota de Herrero Mayor, siempre en el mismo diario, escribe Tirso Lorenzo, alentado por la siguiente incógnita: «نSe habla bien o se habla mal el castellano en la República Argentina?»3. Habría, para él, dos tendencias extremas: una «deleznable», que aspira a ver declinar el castellano hacia un «idioma nacional, propio, característico»; otra purista y académica, la de los que «andan siempre con el código bajo el brazo». Si la primera no traspasa los límites de «una ideología precaria e inconsistente», la segunda es impulsada por «intransigentes empedernidos». La respuesta a la pregunta formulada, por tanto, suele tenerse de antemano, según uno sea un criollista o un purista. Lorenzo, para responder, pretende situarse en el medio, pues no se hablaría un castellano perfecto (ese castellano que cree se habla en Madrid), pero tampoco uno tan mal que merezca ser llamado dialecto. Encuentra al castellano en Argentina con las «amenazas» propias de cualquier idioma vigoroso y en ascenso. Pero hay más:

En la Argentina no solo se conserva el castellano con una perfección que sorprenderá a toda persona que quiera profundizar en la cultura hispanoamericana, sino que aquí, en Argentina, es donde seguramente cuenta el castellano con mejor ambiente y elementos más propicios para su florecimiento y su difusión. ${ }^{4}$

La voz de Lorenzo es, en este sentido, la de los que postulan que en Argentina se vela constantemente por la empresa heroica de cuidar la lengua, defendiéndola empeñosamente del cúmulo de «influencias extrañas». Es probable que Lorenzo acuerde con Herrero Mayor, con Castro, con Monner Sans, en lo que debe ser la lengua argentina, no en lo que es.

Pero su artículo tiene dos partes, o mejor dicho, parecería estar escrito por dos hombres distintos. Si el primero habla de custodiar la lengua de presencias extrañas, el segundo anuncia una especie de milagro idiomático operando en Argentina. Veamos: el castellano

\footnotetext{
${ }^{1}$ SALAVERRÍA 1927.

${ }^{2}$ LEÓN SUÁREZ 1927.

${ }^{3}$ LORENZO 1927.

${ }^{4}$ LORENZO 1927.
} 
en América, agrega en esta segunda parte, «lejos de decaer o enviciarse, se robustece, se enriquece, se universaliza sin las trabas que en la Península le oponen la tradición y la disciplina académica» ${ }^{1}$. De modo que su pensamiento va, rápidamente, girando hacia un planteo similar al de los románticos del siglo XIX, pues al promediar el artículo exalta la apertura de las lenguas en pos de evolucionar al unísono con el mundo moderno y consumar su ideal expresivo: «el arcaísmo idiomático es un léxico de museo», llega a decir. Los horizontes de los que habla son los de América, particularmente los de Argentina, a la que estima a la cabeza de la pujanza americana, pujanza que, al ensanchar su vida, ensancha y enriquece la vida de la lengua. Este ensancharse supone, naturalmente, incorporar elementos vitales nuevos (elementos que en las primeras columnas de la nota había advertido peligrosos). Este Lorenzo del final, por último, anuncia que

[...] en América el idioma castellano se universaliza, enriqueciendo su estructura por el aporte de conceptos y expresiones vividas y sentidas en la inquietud espiritual de sociedades nuevas. ${ }^{2}$

Estas son algunas de las notas con que diariamente La Nación mantenía la querella en perfecto estado de salud. Esta década del 20, sobre todo, es en la que el diario se muestra más entusiasta con ella, y un relevamiento exhaustivo de ese entusiasmo podría componer un capítulo aún mucho más vasto.

\footnotetext{
${ }^{1}$ LORENZO 1927.

${ }^{2}$ LORENZO 1927.
} 


\section{DE LA TESIS CONVERSACIONAL DE BORGES AL ÚLTIMO LIBRO}

DE COSTA ÁLVAREZ

(1928)

\section{1. Borges y la tesis conversacional}

En su decimonovena sesión ordinaria, el Instituto Popular de Conferencias del diario La Prensa cedió su estrado a Jorge Luis Borges, que para entonces ya ostentaba cierta merecida fama por sus opiniones en temas linderos a los que ahora presentaba bajo el nombre de «El idioma de los argentinos». Sucedió el 23 de septiembre de 1927. Al día siguiente, al publicarla, el diario confiesa que, «a causa de una afección en la vista», Borges pidió al señor Manuel Rojas Silveyra que leyera por él. Están presente Carlos Ibarguren; los vocales del Instituto, Enrique Uriburu y Arturo Capdevila; el embajador de México, Alfonso Reyes; el ministro de Santo Domingo, Tulio M. Cestero; y los señores Ángel J. Battistessa, Manuel Rojas Silveira y Arturo Costa Álvarez. El texto de Borges principia declarando el estado actual de la querella:

Dos influencias antagónicas entre sí militan contra un habla argentina. Una es la de quienes imaginan que esa habla ya está prefigurada en el arrabalero de los sainetes; otra es la de los casticistas o españolados que creen en lo cabal del idioma y en la impiedad o inutilidad de su refacción. ${ }^{1}$

Esta dicotomía es asaz parcial, pues Borges sabe que existe otra dimensión del problema, menos lexical y más vasta, pero por ahora la calla, acaso porque algo de ella aflorará en la solución final que le asestará al problema.

De todas las influencias que confluyen en esta conferencia está muy presente Gutiérrez, a quien no nombra, y están también Unamuno y Quesada - la obra que más acogida recibe es Nuestra lengua, de Arturo Costa Álvarez, de donde Borges toma el diagnóstico de la querella y de donde se persuade, quizá, de que se encuentra polarizada. Costa Álvarez había escrito, refiriéndose al pueblo argentino, que «una parte de él estropea el castellano en la lengua vulgar, en el guirigay de los escritores plebeyos y en la jerga de los barbáricos; otros, los académicos o disciplinados, lo reverencian en

${ }^{1}$ Borges 1927c, 136. 
el altar de la gramática y del diccionario...» ${ }^{1}$. El planteo de Costa Álvarez había sido también el planteo bifronte de Rojas, al darle la bienvenida a Américo Castro, que vendría a superar dicha dicotomía con el poder sanador de la nueva escuela. El mismo Castro lo enuncia con términos mucho más equivalentes: «Ni "arrabaleros" o galiparlantes, ni fetichistas del incompleto diccionario de la Academia Española» ${ }^{2}$. Este planteo, a la vez, tiene mucho del célebre «Prólogo» de Bello a su Gramática de 1847; allí también se presentan dos tendencias igualmente afectadas, «la avenida de neologismos de construcción, que inunda y enturbia mucha parte de lo que se escribe en América...» y el «purismo supersticioso» ${ }^{3}$. De modo que podemos aseverar que el diagnóstico de Borges se trata más bien de una percepción que, cada tanto, alguien sentía la necesidad de reeditar.

Presentar dos posiciones encontradas - la jergal arrabalera y la suntuosa que emana del lexicón español- le sirve a Borges para su plan de señalarlas ineptas ante el mentado idioma nacional. Una le parece caricatural y falaz; la otra, mendaz y fantasmagórica. Siendo ambas impostadas, a una la juzga pseudoplebeya; a la otra, pseudohispánica.

Arturo Costa Álvarez no había querido oír hablar de «lengua privativa», «idioma nacional», «lengua patria», pero tituló a su criatura: Nuestra lengua. Borges - a diferencia de De Vedia, Cané, Quesada, Groussac y el mismo Costa Álvarez, a quienes menciona como embates definitivos contra el «dialecto chúcaro y receloso»- no siente escozor al decir «idioma argentino», ni teme al reunir ambos vocablos. Este idioma — ajeno tanto a lo jergal, como a lo puristale resulta un hecho comprobable en la intimidad de la conversación argentina. La expresión «idioma argentino» lo complace solo para investigar el palpitar de la patria, tono y énfasis de una expresión que, aunque distintiva, no es inhábil para ser entendida en cualquier parte de España.

Equidistante de sus copias, el no escrito idioma de los argentinos sigue diciéndonos, el de nuestra pasión, el de nuestra casa, el de la confianza, el de la conversada amistad. ${ }^{4}$

\footnotetext{
${ }^{1}$ Costa Álvarez 1922, 72.

${ }^{2}$ Rojas y CASTRO 1923, 15.

${ }^{3}$ BELLO 1847, 11-12.

${ }^{4}$ BORGES 1927c, 145.
} 
Sin llegar a ser un animismo, Borges encuentra una singularidad argentina en la voz coloquial, más precisamente en la confidencia. En este Borges de los años 20, más que un idioma argentino, existe una forma argentina de expresarse en español. Si en Quesada el idioma nacional es el castellano culto y escrito, en Borges está en la boca, no en el libro; es una intimidad más que una grafía; se intuye, no se lee; es de carácter emocional, no lingüístico. Si hay alguna distinción en el habla argentina - y para Borges sí la hay, de donde emana el fuero íntimo de la patria- solo puede ser oída.

No resulta extraño entonces que Borges adopte, por estos años — atento sin duda a los consejos de Vicente Rossi- una ortografía respetuosa de la oralidad. Un tal Tobías Bonesatti, en Nosotros $^{\prime}$, recusará sus dos primeros libros de ensayo (Inquisiciones y El tamaño de mi esperanza) por la ortografía: apócopes de la $d$ final («verdá», «seguridá», «hermandá»), síncopas («trascrita») y cambios de $x$ por $s$ («estendido», «esplicable»), modificaciones todas desautorizadas por la Academia. Borges responde apelando a criterios fonetistas, confesando cierta inconstancia en la pronunciación argentina de la $d$ final, así como una preferencia a suplantar, en ciertas palabras, la $x$ por la s: «La solución es de casi escandalosa facilidad: escribo estendido y esplicable por pronunciarlo así, y examen y excelencia por esa misma todojustificadora razón» ${ }^{2}$.

En Rossi, ahora que vuelvo sobre él, hay algo que a Borges le produce muchísimo entusiasmo: «estoy previendo que este ahora inaudito y solitario Vicente Rossi va a ser descubierto algún día, con desprestigio de nosotros sus contemporáneos y escandalizada comprobación de nuestra ceguera» ${ }^{3}$. La cursiva en descubierto es oportuna, no porque la predicción se fuera a comprobar, sino porque Rossi se mueve en las catacumbas, y nadie se da por enterado de sus ritos y ceremonias. Borges prevé un reconocimiento venidero que atenuará las incorrecciones habituales de Rossi: «Nadie ha sido inhabilitado para la gloria por causa de incorrección.... ${ }^{4}$, pero sabemos, y también lo sabía Borges, que en Rossi esa incorrección gramatical y ortográfica es la forma natural del idioma rioplatense que preconiza. El celo de Rossi por una corrección ortográfica llega al punto de idear un sistema propio.

Borges advierte en este artículo que el criterio que podría emplearse para refutar las tesis rossistas serviría por igual para desbara-

\footnotetext{
${ }^{1}$ BONESATTI 1928.

${ }^{2}$ BORGeS 1928b, 152.

${ }^{3}$ BORGES 1928c.

${ }^{4}$ BORGES 1928c.
} 
tar las pretensiones casticistas, pues, en su cosmovisión del problema de la lengua en Argentina, lo central no es de carácter filológico, sino de «esperanza criolla». Borges lamenta que Rossi esté bregando por un idioma propio en el terreno léxico; en ese terreno, «es curioso que lo tengamos tan callado a ese idioma distinto» ${ }^{1}$.

\section{2. La prédica de Rossi}

Bastante tiempo después de publicado su Teatro nacional rioplatense, Vicente Rossi vuelve tangencialmente sobre la querella de la lengua en 1926, al publicar Cosas de negros, libro que, conforme reza su portada, indaga sobre los «orijenes del tango y otros aportes al folklore rioplatense». Sus tesis idiomáticas, adscriptas a las de Lucien Abeille, y su ortografía siguen intactas, aunque enfatizará, por un lado, la idea de una tradición rioplatense desvinculada de España y, por otro, la idea de un «idioma propio en jestacion»: «los pueblos rioplatenses crean, renuevan y adoptan, mejorando; mientras sus intelectuales reaccionan tercamente $\rangle^{2}$. Lo ofende, además, que se diga por ahí que el idioma nacional de los argentinos es el lunfardo. «No se hace, ni hacemos nosotros, idioma con argot, sinó con el uso, abuso, creacion y adopcion de vocablos.... $\rangle^{3}$

Mencionaré, ahora, otros tres aspectos que asoman en este texto de 1926, y que componen las conjeturas de Rossi sobre la lengua. Uno es el del recelo. Al igual que Gutiérrez, que jamás dejó de sospechar una pretensión de reconquista en América, Rossi siente que detrás de los diccionarios de argentinismos y americanismos supervisados por España se cuela un nuevo virreinato de la lengua en el Río de la Plata. Otro aspecto, que adoptará Borges para componer su contribución a la querella, remite a una concepción animista de la lengua. Rossi encuentra que del alma nacional, del interior autóctono del Río de la Plata, surgió una pronunciación singular. No es que él la haya descubierto, sino que quiere deducir un idioma autóctono de esa pronunciación.

Con el solo hecho de haberle quitado al idioma de los castellanos su molesto énfasis y su pringosa pronunciacion, sin alterar sus vocablos, hemos hecho otro idioma; eso deben tener bien «en mien-

\footnotetext{
${ }^{1}$ BORges 1928c.

${ }^{2}$ Rossi 1926, 401.

${ }^{3}$ Rossi 1926, 401.
} 
tes» aquellos que nos hacen el chiste aleman del «lunfardo» idioma nacional. ${ }^{1}$

El tercer aspecto remite al problema de la tradición, a la que encuentra enteramente desligada de Europa, porque no cree que la tradición pueda resistir traslados lejanos, ni viajar, ni dar saltos de un hemisferio a otro. Para Rossi es más fuerte el vínculo que se pueda establecer entre naciones vecinas que entre aquellas ligadas por la historia. Descree que el idioma establezca un lazo de unión espiritual: «Estamos cansados de saber que los paises de América no han evidenciado nunca afinidades históricas, lingüísticas ni de ningun otro jénero; viven ignorándose mutuamente» ${ }^{2}$. El idioma, estima, no da raza ni nacionalidad; así como el «hogar castellano» le resulta una figura literaria y un lugar común.

A partir de 1927, devenido ya en filólogo americanista y polemista matrero, Vicente Rossi convierte sus esbozos idiomáticos en doctrina independentista. Asociado con un tal Almanzor Medina, comienza a publicar los Folletos Lenguaraces, misceláneas reflexiones sobre la lengua y la lexicografía. El atributo lenguaraz, no remite a la versatilidad de manejar varias lenguas, sino a la de esgrimir solo una, aunque de modo picaresco. Los folletos - procurando demostrar la existencia de un idioma nacional rioplatense- aparecen como la antítesis de las Notas al castellano en la Argentina, de Ricardo Monner Sans. Donde estas excomulgan una voz local, poniendo en su lugar el equivalente castizo; aquellos deportan una voz Real, por hallarla ausente en el habla del Río de la Plata o mal definida. Pero no solo se opondrán a los consejos de Monner Sans, sino también a la Academia Española, a su Diccionario y al Instituto de Filología.

Los tres primeros folletos son meramente lexicográficos. El cuarto, ya en el año 1928, contiene una Introducción de carácter crítico, a cargo de Almanzor Medina, hombre de una prosa notablemente superior a la de Rossi. El quinto folleto es escrito enteramente por Medina y ofrece un enorme interés. Almanzor Medina advierte que la idea de que en Argentina se habla mal es una especie de extorsión para que se hable una lengua extranjera: el castellano; «no tienen presente - agrega - que hablando mal se han formado todos los lenguajes humanos; que es inevitable hablar mal para llegar a hablar bien creando un idioma propio» ${ }^{3}$. Ese hablar mal, para Medina, no es hablar lunfardo, jerga a la que llama «clave de voces jita-

\footnotetext{
${ }^{1}$ Rossi 1926, 403.

${ }^{2}$ Rossi 1926, 405.

${ }^{3}$ MEDINA 1928, 9.
} 
no-castellanas académicas», de uso en el hampa. Casi en los mismos términos en que lo formularon los románticos, infiere que es el pueblo quien, ajeno a diccionarios y academias, forma y sanciona su lengua nacional. Unido a Vicente Rossi en la cruzada contra los castellanistas y los meridianos, entonces, procurará refutar, ante todo, la concepción idiomática que Ricardo Rojas presenta en La restauración nacionalista; es decir, el dominio de la lengua castellana en la América hispana:

Un «ilustre restaurador» nacionalista, al fundar e inaugurar el Instituto de Filolojía en la Universidad de Buenos Aires, para entregarnos al protectorado lingüístico de Castilla, declara en una curiosa arenga antinacionalista, que con «la Lengua» se habían exterminado 200 idiomas autóctonos americanos...!1

Rojas había afirmado que el español era hablado como lengua nativa por cien millones, aproximadamente, en América, Filipinas y España. Este tipo de afirmaciones a Medina le resultan «globos de jabón»; y acomoda, luego, tres observaciones que cree necesarias:

$1^{2}$. Estos folletos han dicho repetidas veces que no existe un idioma «español» sinó varios, y por lo tanto debe decirse «castellano» cuanto de este se trate.

$2^{a}$. No es «la Lengua» idioma nativo en ninguna parte de América; como se verá en seguida, apenas un 15 por ciento de las poblaciones llamadas hispanoparlantes hablan un derivado castellano. Nunca lo fué en Filipinas; allí el idioma nativo y nacional fué siempre el Tagalo. Tampoco «la Lengua» es en Hispania idioma nativo, sinó escasamente para un cuarto de su poblacion.

$3^{2}$. Cien millones de hispanoparlantes...! Esto merece capítulo aparte. $^{2}$

El folleto se demora, luego, en ensombrecer esta cifra y en completar la diatriba en contra de Ricardo Rojas, extendiéndola a los académicos correspondientes de la lengua, a quienes Medina llama «entregadores». Ese cargo, el de correspondiente, le resulta indigno y logrado, a menudo, a través de pleitesía y vasallaje: «Nos consta que a estos académicos, los de la Real, en privado y para "moverse a risa", les quitan la "n": académicos de la legua... Muy lójico es reirse de los que a ello se prestan» ${ }^{3}$. En la guerra de desdenes entre

\footnotetext{
${ }^{1}$ Medina 1928, 12-13.

${ }^{2}$ MEDINA 1928, 13-14.

${ }^{3}$ Medina 1928, 20.
} 
los lingüistas locales y los llegados de España, Vicente Rossi y Almanzor Medina se sientan a la mesa de Arturo Costa Álvarez, con quien tienen muy pocas cosas en común.

A partir del sexto número, publicado aún en el año 28, los Folletos están escritos enteramente por Vicente Rossi, llevan por título «Idioma Nacional Rioplatense (Arjentino-Uruguayo)» y pretenden constituirse en una serie de «evidencias» de este mismo idioma. Mencionaré únicamente este sexto número, subtitulado «Primera evidencia», a partir del cual se puede deducir toda la serie. Un encendido epígrafe en la tapa acompaña el folleto:

Levante el espíritu nacional! / Propague que en tierras del Plata se llame "Nacional" al lenguaje; siempre Nacional! / Todo lo nuestro es producto de nuestra intelijencia, de nuestro esfuerzo, del esfuerzo nacional; no permita a nadie que lo ponga en duda. / A nadie debemos nada $[\ldots]^{1}$

A pesar de la expresión «idioma de los arjentinos», Rossi cree más exacto llamarlo «idioma nacional rioplatense». Este ser rioplatense, dotado de una lengua distintiva, jamás aparece definido territorialmente. Ignoro si creerá formada una nación con este nombre, pues no se referirá jamás a ello; del mismo modo que no se puede saber si estima que La Plata, Buenos Aires, Rosario y Montevideo, son igual de rioplatenses que Tucumán, Mendoza y Tierra del Fuego.

Ya desde sus primeros trabajos, Rossi estigmatizó a sus adversarios llamándolos «derrotistas»: los academicistas, los puristas y la castellanomanía en general, es decir, aquellos adversos a un idioma nacional. Para refutarlos, no obstante, se mete en el peligroso terreno de los porcentajes:

Estos Folletos Lenguaraces propagan que el Idioma Nacional Rioplatense «es el que hablamos y escribimos actualmente», con un porcentaje propio del «80 por ciento sobre sus orijenes». ${ }^{2}$

Para evidenciar esta cifra cree haber hallado una forma «infalible e irrebatible»: selecciona al azar algunas páginas del Diccionario de la Real Academia (trabaja con la edición de 1925), copia las definiciones de los vocablos que allí aparecen y, como mencioné, las impugna, ya porque encuentra de ascendencia americana lo que la

\footnotetext{
${ }^{1}$ Rossi 1928, cf. en la tapa.

${ }^{2}$ Rossi 1928, 6-7.
} 
Academia establece como de estirpe europea, ya porque serán voces vigentes en España, pero nunca en el Plata.

Rossi ya tiene en su mesa de lectura la conferencia ofrendada por Borges (1927c), pieza a la que, junto con el libro de Abeille (1900), encuentra como únicos trabajos dignos de ser mencionados. De modo que en el anhelo rossista de menoscabar la autoridad del Diccionario Real, unas líneas borgeanas le vendrán de perlas, aquellas en que Borges relativiza la «riqueza del castellano» si ha de juzgársela por las abundantes voces que en el diccionario se estampan, pues solo viven allí, como «espectáculo necrolójico deliberado», mientras se ausenta en todas las bocas.

No obstante, las evidencias impresas por Rossi — pedestal sobre el que afirma un idioma apartado de España - adolecen de un error elemental: presuponen que el léxico de los españoles es el que consta en el Diccionario. Rossi soslaya que muchas de las voces anotadas por la Academia resultaban extrañas a un rioplatense, igual que a un español. El error de Rossi, en todo caso, es creer demasiado en el Diccionario, exhortando a los lectores a no creer en él.

Esta efervescencia porcentual, sumada al brío de pancarta con que inflama los folletos restantes, menoscaban su independentismo idiomático. No obstante sigue dando a la estampa sus folletos. En el décimo, quinta de sus «Evidencias», Rossi encuentra oportuno hacer un «Balance». Es el que aquí reproduzco en sus puntos más curiosos:

Hemos demostrado (y estamos siempre prontos para agregar lo que faltara a esas demostraciones:

- La necesidad cívica de fundar la Academia del Idioma Nacional Rioplatense, por la intelectualidad arjentina-uruguaya, que editaria nuestro lexico, en el cual lo castellano que por aqui existiese, ocuparia el lugar que le corresponda, bien honroso por cierto, eliminando la anacronica autoridad del academico cambalache poliglota.

- La enorme superioridad, por multiples condiciones de tecnica y de estetica, del lenguaje rioplatense sobre el castellano.

-Que el Idioma Nacional Rioplatense es el que hablamos y escribimos, con un porcentaje medio del 500\% sobre el castellano.

- Que el Idioma Nacional Rioplatense fué notado con esplendido éxito en la culta Hollywood, oyendo hablar a un cronista arjentino (enviado de un rotativo porteño castellanista), que permitió lo confundieran con el español.1

\footnotetext{
${ }^{1}$ Rossi 1929, 49-51.
} 
En el Folleto 23, la diatriba de Rossi decae ya en parangones voceados con énfasis compadrón. Nótese que el idioma que preconiza parece ser muy hombruno:

Se desahogan infantilmente: contra nuestro varonil, hermoso i espresivo «vos», que quieren sustituir con los afeminados «tú» $\mathrm{i}$ «ti»; contra nuestro varonil «seseo», para sustituirlo con el maricon «zezeo»; contra nuestra pronunciacion varonil de «ll»» e «yy», que quieren canbiemos por la añoñada castellana; contra nuestro espresivo i sencillo «ustedes», para adoptar el insolito i áspero «vosotros»; contra nuestro machaso «sos», lindo, terminante i sonoro, para usar la mariquita «eres» $[\ldots]^{1}$

\section{3. Carriegos, un nuevo heredero de Abeille}

El año 1928, como vemos, llega con diversos acontecimientos ligados a la querella de la lengua; también es el año en que el filólogo y gramático correntino Ramón C. Carriegos edita El porvenir del idioma español en la República Argentina, en Tandil, ciudad donde residió y ejerció la docencia durante muchos años. Se trata de unos ensayos lexicográficos, a excepción del primero: «El casticismo en la Argentina», donde Carriegos, sin mencionar el trabajo de Lucien Abeille, se afilia a su tesis autonomista.

El ensayo no es ni extenso ni exhaustivo; por momentos adquiere forma proverbial y fragmentaria, coronando su descompostura, las erratas que atestan, en general, toda la edición. No obstante estos lamparones, sus intenciones se pueden adivinar. Lejos del ideal de pureza idiomática, en primer lugar, Carriegos encuentra natural que las lenguas populares devengan en lenguas nacionales, como sucedió en España, que termina por aceptar la lengua vulgar que esgrimió Cervantes; como sucedió en Italia, que eleva a oficial la lengua de Dante; como sucedió en Francia, que llama finalmente cultas las lenguas de Molière, Racine y Rabelais. Con expresiones parecidas a las de Abeille, Carriegos refrenda la idea de que cada pueblo - así como ostenta una geografía irrepetible- desarrolla una psicología tan singular que termina por hablar una lengua propia. El «idioma argentino», signado por un sentimiento de grandeza nacional, procura sentir, pensar, querer e imaginar en forma distinta al idioma ibérico.

\footnotetext{
${ }^{1}$ Rossi 1939, 88-89.
} 
En segundo lugar, Carriegos intenta postular que el casticismo no solo es indeseable, sino que también es imposible; y al igual que Gutiérrez y Alberdi, señala que el arribo de distintas influencias culturales termina por flexibilizar el oído y la inteligencia. El idioma en Argentina se habría impregnado del francés a tal punto que solo a costa de quedarnos mudos sería posible limpiarlo. En apoyo de esta tesis, cita algunas líneas de Unamuno y de Quesada, a quienes, estimo, no se los podría hermanar en lo sustancial con la idea autonomista de Carriegos. Unamuno entiende que en Argentina se pretenda una lengua nacional, pero no la auspicia. Quesada pone en evidencia el galicismo en el Río de la Plata, pero lo condena.

Carriegos parte de la idea de que nuestro país, a diferencia de España, es cosmopolita; luego: «el castellano en la Argentina se encuentra evolucionado en un medio distinto al de su procedencia» ${ }^{1}$. A su vez, cree que este castellano en la Argentina, al que llama «idioma nacional», se evidencia en el léxico: «siete mil quinientos vocablos», a los que clasifica de la siguiente forma: americanismos: mil; argentinismos propiamente dichos: cinco mil; frases y refranes: dos mil quinientos. Estos números, que lo acercan a la contaduría de Vicente Rossi, le resultan relevantes, pues considera que Shakespeare se valió solo de quince mil palabras para tramar su obra; mientras que a Milton le bastaron ocho mil para acabar la suya. En el caso del «idioma argentino», Carriegos advierte que se encuentra aún en formación; pero su destino es el que anunció Rufino J. Cuervo, a quien cita para coronar su tesis:

[...] la unidad solo existirá en el diccionario, será ilusoria, y la separación real del vocabulario será cada vez más honda entre los que creen hablar una misma lengua. ${ }^{2}$

No es el primer trabajo que Carriegos presenta sobre el tema; en 1904 había publicado El idioma argentino, un libro de observaciones críticas a la Gramática, de la Real Academia Española; luego, en 1910, Minucias gramaticales; tres años más tarde, Apostillas lexicográficas. En 1913, además, publica Carbonada periodística, donde ya se ocupa del problema del casticismo; y Necedades periodísticas, donde opina sobre las polémicas en torno a los diccionarios. Arturo Costa Álvarez, que halló y comentó una buena cantidad de publicaciones pertenecientes a Carriegos le despachará un juicio adverso:

\footnotetext{
${ }^{1}$ Carriegos 1928, 18.

${ }^{2}$ Carriegos 1928, 22. Cf. Cuervo 1904, 33.
} 
Este escritor no ha podido encarar nunca las particularidades de la lengua con un criterio definido: ora trata de demostrar que tenemos un idioma propio, ora nos hace ver que hablamos castizamente... y de este modo nos predica a la vez la licencia y la observancia... El barco sin brújula no va a ninguna parte; está a merced de las olas y del viento. ${ }^{1}$

\section{4. La Babel de Capdevila}

Durante la década del 20, en el diario La Prensa, el escritor Arturo Capdevila publicó una serie de artículos vinculados estrechamente a la querella de la lengua en Argentina. Recién en 1928 se reúnen y publican todos bajo el título Babel y el castellano. He demorado el comentario de estos artículos para realizar uno de conjunto sobre el libro.

Sus propósitos relevantes son cuatro: $1^{\circ}$, enunciar el orgullo que el autor siente por el castellano; $2^{\circ}$, demostrar que es el idioma que habla Argentina; $3^{\circ}$, vilipendiar el voseo, al que llama «mazacote», «gazapo», «ignominiosa fealdad», «viruela», «verdadera mancha del lenguaje argentino»; $4^{\circ}$, preanunciar el porvenir conquistador del idioma de Cervantes, que estima, no tardará en América en purificarse del todo. El primer propósito es emotivo; el último, más que imperial, imperito; el segundo es elocuente; el tercero, un dislate. Me ocupo del dislate.

Luego de rastrear el origen del voseo en América —un texto reciente de Henríquez Ureña le sirve de lazarillo— resume el estado de la cuestión, en cuyos puntos principales afirma que, ya en los primeros tiempos de la Conquista, el vos sonaba con demasiada familiaridad o con un aire despectivo u hostil; que en todo el siglo XVI no cesa de acentuarse el carácter despectivo o muy familiar del voseo, hasta que a fines del siglo XVII prevalece el tú en toda España; que el mapa de América se divide en dos zonas bien definidas: una en que se tutea y otra en que se vosea, aquella es el tercio del continente, esta comprende las dos terceras partes restantes; que el voseo en la actualidad se desconoce totalmente en España. Este resumen, descanso de un rodeo de dos capítulos sobre el tú y el vos, concluye en la inofensiva (definitiva y reveladora para Capdevila) conclusión:

\footnotetext{
${ }^{1}$ Costa Álvarez 1928b, 42.
} 
La total preferencia peninsular por el tuteo y su parcial adopción americana constituyen, sin disputa, un mismo fenómeno de cultura. Nada hay en él que sea étnico. Todo es cosa cultural. ${ }^{1}$

Capdevila procura que su resumen sea leído como una impugnación al voseo americano. Estima que no existe ninguna relación entre el vos que riega felizmente las páginas del Siglo de Oro, y el vos que envilece las costas del Río de la Plata. A un vos lo encuentra dorado; al otro, «ruin». Pero lo curioso viene luego, al estampar su conclusión del asunto: "No es que se deje de emplear el vos en la Península, porque vaya cayendo en desuso como tantas formas, como tantos giros idiomáticos. Se le deja de usar porque ofende» ${ }^{2}$. Curioso, digo, porque a Capdevila le basta con que ofenda en España para que ofenda también en Argentina; es decir, presume que el castellano aún se regula en, y pertenece a, España. (Nótese que el leísmo en «se le deja de usan», debiera condenarse si nos tomáramos muy a pecho aquello de usar bien el idioma. Pero el casticismo de Capdevila llega al punto de tomar por bueno hasta los vicios, si llegan de España.)

Luego, a medida que cesan los argumentos, crecen las imprecaciones, los porcentajes, los pronósticos. El simple cálculo que alega: dos terceras partes de Hispanoamérica vosea, parece no intimidarlo para creer que estos deben amoldarse a la tercera parte restante. ¿Cuál sería la razón por la que debiéramos volver al tuteo?: así lo quiere España. Ahora bien, ¿cuál es la verdadera razón por la que se impuso el tuteo en España? Nos lo informa el mismo Capdevila: dejó de lastimar el oído español, mientras que lo comenzó a herir el vos. De modo que, siguiendo este razonamiento, es la costumbre lo que hace apropiado uno u otro tratamiento. Luego, podríamos advertirle a Capdevila que, a principio del siglo XXI, decir tú en Buenos Aires ya es signo de afectación, es lo que hiere nuestros oídos.

Llegamos así al séptimo capítulo del libro, intitulado «El idioma en la Argentina», quizá el más endeble y confesional: «Cuando por el camino de una venerada memoria yo adopté el tú, siendo todavía muchacho, sentí como que se aclaraba mi espíritu» ${ }^{3}$. Capdevila confiesa, así, el momento en que su espíritu se ilumina: justo cuando se empieza a afectar. Unas líneas antes había aseverado: «Ni habla bien el que piensa mal ni piensa bien el que mal habla. Hablar

\footnotetext{
${ }^{1}$ CAPDeVila 1928, 89.

${ }^{2}$ CAPDEVILA 1928, 89.

${ }^{3}$ CAPDEVILA 1928, 102.
} 
así [voseando] es verdaderamente una caída en el caos» ${ }^{1}$. Después pronostica:

El día en que la mayoría de los hombres cultos se traten de tú en la Argentina (y ese día vendrá), el horrible voseo rioplatense no ha de ser sino una curiosidad del pasado y una ignominia más de los tiempos de Rosas. ${ }^{2}$

Al recibir el libro en Hendaya, en agosto de 1928, Miguel de Unamuno, que no era afecto al casticismo, le propina unas líneas elogiosas, quizá, porque «aún no he tenido tiempo más que de hojear ojeándolo» ${ }^{3}$. La carta se acomoda, luego, como prólogo.

Hombres como Capdevila, Ricardo Monner Sans, Juan B. Selva, Avelino Herrero Mayor, aciertan al buscar inspiración en textos mosaicos; pero desatinan al aferrarse al mito babélico para explicar los avatares de una lengua, que implicaría, por un lado, postular que hubo un momento originario de unidad lingüística que, por castigo divino, se desunió; por otro, que la tarea más loable de los hombres es retornar a ese estado unitario. Por último, Babel y el castellano busca respaldo en siete fragmentos del Diálogo de la Lengua, que se acomodan como epígrafes; estimo que están allí para refutarlo.

\section{5. Costa Álvarez y El castellano en la Argentina}

En diciembre de 1928, Arturo Costa Álvarez publica El castellano en la Argentina, destinado a poner punto final — ¡una vez más! — a la controversia sobre el idioma nacional. La empresa, aunque menos colérica, es similar a Nuestra lengua. Se compone de ensayos misceláneos repartidos en diez partes, de las cuales las primeras cinco abordan puntualmente el asunto de nuestra querella y ostentan una tesis de doble aspecto: por un lado, repudiar el programa autonomista del idioma; enarbolando, por otro, el ideal romántico de la emancipación. Veamos.

Costa Álvarez estima que las publicaciones en relación a la lengua en Argentina se caracterizan por un anhelo de emancipación de las formas castellanas, aunque expresado en castellano. Esto nos habría hecho resbalar, induciéndonos a pensar que, si desnaturalizábamos nuestro castellano mediante aportaciones extranjeras y

\footnotetext{
${ }^{1}$ CAPDEVILA 1928, 102.

${ }^{2}$ CAPDEVILA 1928, 109.

${ }^{3}$ UNAMUNO 1928, 11.
} 
vulgarismos nacionales, llegaríamos con el tiempo a tener un idioma propio.

Esta exaltación del sentimiento, aliada a nuestra tendencia atávica a resolver teóricamente los problemas prácticos, es lo que explica nuestra expresión «idioma nacional», nuestra cuestión de la lengua, nuestra afición al rebusco de etimologías indígenas, nuestra debilidad por el uso de expresiones jergales, y nuestra fabricación de vocabularios de argentinismos. ${ }^{1}$

Existiría, entonces, un anhelo de libertad en la causa del idioma, aunque mal conducido; y asevera que, a fuerza de localismos y extranjerismos, la lengua argentina no dejará de ser castellana. Lamenta, así, que en nuestros teóricos de la cuestión de la lengua no haya habido nunca estudio, sino «simplemente sentimiento...» El problema le resulta, por tanto, pasional; esto es, irracional. Y si otros disculpan a «nuestros teóricos» por esta razón, Costa Álvarez no:

Es corriente juzgar con benigna tolerancia a tales trabajos, porque se considera que sus defectos son solo de detalle. Mi disentimiento con este criterio es absoluto, porque el vicio de tales trabajos es orgánico $[\ldots]^{2}$

Esta nueva publicación de Costa Álvarez insiste en que la causa del idioma nacional acabó a principios de siglo, siendo Nuestra lengua - libro del cual adosa, en generoso Apéndice, 45 juicios que lo celebran - , la obra que narra la derrota y sella un juicio definitivo en favor de la unidad del castellano. Esta cuestión, estima, no ha tenido, durante los últimos veinte años, sino valor histórico y anecdótico:

Al fin se ha reconocido que la cuestión del idioma privativo no es una cuestión de hecho sino de anhelo, y de anhelo extraviado; y su discusión se sigue ahora con desgano, porque la dialéctica no hace sino repetir los lugares comunes del caso. ${ }^{3}$

La observación reviste cierta curiosidad, pues hubiera convenido a Costa Álvarez que la causa del idioma nacional no hubiera caducado, para librar a su nuevo libro del absurdo de pelear contra

${ }^{1}$ Costa Álvarez 1928b, 17.

${ }^{2}$ Costa Álvarez 1928b, 18.

${ }^{3}$ Costa Álvarez 1928b, 19-20. 
un espectro. No son pocas las páginas que consagra a rematar al muerto, y son tan encendidas que cualquier lector pensaría que el muerto goza de muy buena salud. Cito, como ejemplo, el programa que, a su juicio, deberían proponerse las autoridades escolares:

Demostrar al maestro, con la exposición de nuestros antecedentes históricos, cómo hemos estado perdiendo el tiempo con la quimera de emanciparnos de nuestra lengua heredada mediante la creación de un idioma privativo; hacerle ver cuánto más patriótico, cuánto más cómodo y cuánto más digno es abrazarnos al castellano como a cosa propia $[. . .]^{1}$

¿Qué necesidad había de convencer a los maestros de que debían abandonar el fervor por una causa perdida? ¿Si el idioma nacional ya era historia y anécdota al componer Nuestra lengua, a qué viene a oponerse, seis años más tarde, El castellano en Argentina, contra qué lucha; o mejor dicho, a qué le teme ahora?

El segundo aspecto de estos ensayos, aquel que enarbola el ideal romántico de la emancipación, reviste mayor valor por lo siguiente. Todo el repudio de Costa Álvarez a las pretensiones autonomistas no le impidieron adscribir al ideal emancipador de la lengua en América, que sería, para él, tomar el dominio del diccionario y la gramática, no para hacer otros sobre la base de distinciones y localismos, sino sobre el principio de soberanía americana de la lengua. Dominar la lengua americana implicaría estudiarla y ejercerla libre del afán jergal del criollista, y libre de la rutina dogmática de la academia monárquica. Este ideal es el que encuentra en Echeverría, Alberdi, Gutiérrez, Sarmiento y López; y es, quizá, en lo que se diferencia este nuevo libro de su hermano mayor, Nuestra lengua, en retomar el programa emancipador de los románticos y encausarlo, no hacia un idioma nacional, sino hacia un diccionario y una gramática que nazcan de la entraña filológica americana, para establecer la comunión o la diferencia, cuando sea necesario; la regla o la excepción, cuando lo mande el uso culto; lo aconsejable o repudiable, cuando lo auspicie la ciencia.

Costa Álvarez es el hombre que más ha estudiado la querella del idioma nacional y quien más bibliografía ha atesorado sobre el asunto. En su biblioteca privada, donada a la Biblioteca Pública de la Universidad de La Plata, podemos hallar el mayor número de ejemplares sobre el tema y hasta valiosas cartas personales. Digo esto porque, al ser tan sensible a estos problemas, advierte prematu-

\footnotetext{
${ }^{1}$ Costa Álvarez 1928b, 61.
} 
ramente la trascendencia del joven Borges, que acababa de presentar El idioma de los argentinos. Costa Álvarez le dedica un acápite titulado «Albores de argentinismo», que es una pieza preciosa por intuir y preanunciar, ya en 1928, que el Borges de El idioma devendrá en el de Otras inquisiciones. Es decir, comprende la promesa borgeana de redención de la lengua y le concede unas líneas premonitorias. No ignoro las que Scalabrini Ortiz consagró a Borges, en 1926 (en El Diario, de Paraná), que también lo anuncian; pero no llegan a tener el carácter visionario de estas que ahora destaco: «Los gramáticos lo llamarán neólogo; la cultura ve en él un ideólogo, para el cual la lengua no debe tener formas rígidas sino flexibles, y adaptables a todas las presiones del sentir y del pensar...» ${ }^{1}$ Hay otro aspecto, además, que advierte Costa Álvarez: la dimensión animista de la lengua que indaga Borges, para quien no existe una gramática argentina sino un ánima, que toma todo lo que la circunda, en primer lugar la lengua. Costa Álvarez interpreta el corazón de la tesis borgeana del idioma y lo saluda:

[...] me alegro de que en nuestro campo de estudios del castellano haya surgido una luz como esta, que, al proyectarse sobre gramatiquerías y lexiquerías, traspasa las formas externas de la lengua para poner de manifiesto el núcleo ideal que encubren. ${ }^{2}$

Y así como encuentra el espinazo de El idioma de los argentinos, encuentra el de Babel y el castellano, al que solo acompaña en su anhelo de ver unificada la lengua en Argentina, pues no cree que esa unificación deba erigir su capital en España:

A mí me parece que los argentinos no nos hemos emancipado para andar requiriendo la tutela espiritual de la madre patria, como la criatura que se arrepiente de alguna rebeldía $[\ldots]^{3}$

Por último, Costa Álvarez rechaza el cambio de castellano por español, que aflora en la última edición del diccionario académico. $\mathrm{Al}$ trueque lo encuentra político, más que lógico, pues sería el modo que España pretende aquietar los celos provincianos y el peligro separatista. Arturo afirma que los americanos nada tenemos que ver con esa disputa peninsular, ni debemos tomar posición adoptando servilmente el rebautizo.

\footnotetext{
${ }^{1}$ Costa Álvarez 1928b, 96.

${ }^{2}$ Costa Állvarez 1928b, 96.

${ }^{3}$ Costa Álvarez 1928b, 99.
} 
Nuestra lengua es la que en el siglo XVI importaron los colonizadores, procedentes de lo que se llamaba «el reino de Castilla» - $\mathrm{y}$ esa lengua no era ya el dialecto de Castilla sino el idioma del reino- por tanto, nuestra lengua seguirá llamándose «el castellano», por respeto a la Historia. ${ }^{1}$

${ }^{1}$ Costa Állvarez 1928b, 118. 


\section{RESUMEN}

En el siguiente resumen intentaré mencionar los momentos neurálgicos de cada capítulo, luego del cual formularé una serie de conclusiones generales.

PRIMERA PARTE (1828-1900)

\section{LOS PRECURSORES: CASTICISTAS Y ROMÁNTICOS (1828-1838)}

La querella del idioma en Argentina surge de un intento casticista. Antes que los románticos comenzaran a hablar de independencia idiomática, Juan Cruz Varela, a mediados de 1828, llama la atención sobre el mal trato del castellano en Argentina e inaugura un problema: el del idioma nacional.

La Generación del 37 dotó a la querella de nuevos enfoques: polemizó con España; abrazó principios tendientes a postular al pueblo soberano en todo; reconsideró aquellos idiomas permeables a los neologismos, es decir, poco castizos; procuró americanizar la cultura; bregó por la emancipación de la expresión; y conjeturó que, así como en Europa se formaron lenguas neolatinas, en América, desprendida ya del dominio peninsular, se formarían lenguas neoamericanas.

En julio del año 37, en Buenos Aires, ya había publicado el Fragmento preliminar al estudio del derecho. El ensayo podría haberse soslayado aquí si, en su «Prefacio», no afloraran ya las tesis alberdianas sobre el idioma. Para Alberdi, la emancipación urgida en 1810 ha dejado a los argentinos la enorme tarea de forjar una nación; pero esta nación no surgirá si no se ahonda, a partir de una conciencia propia, en la realidad argentina. Luego, no habrá un pensamiento propio si no se escribe y conversa en una lengua propia. Alberdi estima que la misión de su generación es teñir de color local, americano, a todos los elementos culturales que constituyen la nación, incluso, y ante todo, la lengua. De modo que recusa a los que piensan que, entre americanos, se debe escribir un español castizo. Señala que acusar una prosa americana de poco castiza, o de muy galicada, es ignorar con creces el espíritu preferido por el americano. El galicismo no sería barbarismo, sino síntoma de progreso. Alberdi, 
que ya había recibido reproches por su lengua, no cree que ésta deba identificarse con la lengua española, pues no se siente español, sino argentino. La existencia de esta entidad, Argentina, basta para que todo se impregne de su naturaleza distintiva. A cada nación, una lengua. La lengua de Argentina no es, entonces, la de España; es hija de ella, sin ser por eso la nación española.

Juan María Gutiérrez es un caso especial, porque su discurso durante la apertura del Salón Literario, a mediados del año 37, hace que la querella adquiera mayor repercusión pública. Su preocupación fundamental se ciñe al carácter que debe adquirir la cultura argentina, preocupación que lo lleva a revisar el pasado de la misma. La primera conclusión a la que arriba es que América, cuyas culturas precolombinas se desarrollaban como cualquier otra cultura de esplendor, se conmovió ante la conquista e interrumpió su desenvolvimiento intelectual autóctono. Pasó a convertirse en hija adoptiva de España, de quien tomó sus costumbres, su ciencia, su literatura y su lengua. Pero España, se lamenta Gutiérrez, no ha dado un solo hombre de nota, un solo descubrimiento memorable, una sola idea que le pertenezca o que sea útil. Es esta misma España la que, desdeñando el saber, queda absorta ante el escenario natural y social de América: todo le resulta exótico, todo inconmensurable.

Con la literatura española sucede lo mismo. Gutiérrez no encuentra libros gestados e impresos en lengua castellana que despierten interés a un espíritu culto; y confiesa que ha leído, por inclinación y por necesidad, los clásicos españoles, sin que casi nada lograra conmoverlo. Ante este diagnóstico, Gutiérrez clama divorciarnos de la tradición española, así como nos divorciamos de su política monacal. Incita a declararnos libres de esta herencia infausta; aunque aclara:

Quedamos aún ligados por el vínculo fuerte y estrecho del idioma; pero éste debe aflojarse de día en día, a medida que vayamos entrando en el movimiento intelectual de los pueblos adelantados de la Europa. Para esto es necesario que nos familiaricemos con los idiomas extranjeros, y hagamos constante estudio de aclimatar al nuestro cuanto en aquéllos se produzca de bueno, interesante y bello. ${ }^{1}$

\footnotetext{
${ }^{1}$ GutiÉRREZ 1837, 154.
} 
II. SARMIENTO: LA POLÉMICA CON BELLO Y LA REFORMA ORTOGRÁFICA (1841-1870)

La polémica sarmientina principia con un opúsculo de Pedro Fernández Garfias, ex profesor del Instituto Nacional, publicado en el Mercurio, Valparaíso, el 27 de abril de 1842. Lleva el nombre de «Ejercicios populares de lengua castellana» e intenta reunir aquellas palabras que el uso americano ha adulterado o dotado de nuevos sentidos, diversos a los de España. Fernández Garfias pone en evidencia, entonces, la autonomía americana de la lengua. Sarmiento, componiéndole al opúsculo un prólogo de bienvenida, en la misma edición del Mercurio, lo acompaña en la siguiente reflexión: reflexión:

Convendría, por ejemplo, saber si hemos de repudiar en nuestro lenguaje hablado o escrito, aquellos giros o modismos que nos ha entregado formados el pueblo de que somos partes, y que tan expresivos son, al mismo tiempo que recibimos como buena moneda los que usan los escritores españoles y que han recibido también del pueblo en medio del cual viven. ${ }^{1}$

Hasta aquí, adquiere la forma de una observación discreta, pero Sarmiento no quería decir solo esto, sino descoyuntar el tema de su tronco lexicográfico y rearticularlo en uno más político. De modo que agrega la idea de que el pueblo es soberano en las cuestiones del idioma, y lanza su célebre diatriba contra los gramáticos, a los que compara con un senado conservador, creado para resistir los embates populares, para conservar la rutina y las tradiciones. Asoma así, entonces, no solo la opinión, sino también el tono irritante con el cual Sarmiento querellará en cuestiones idiomáticas. Los gramáticos, agrega: «Son a nuestro juicio, si nos perdonan la mala palabra, el partido retrógrado, estacionario, de la sociedad habladora; pero como los de su clase en política, su derecho está reducido a gritar y desternillarse contra la corrupción, contra los abusos, contra las innovaciones». ${ }^{2}$

Luis Montt, al reproducir en el tomo primero de las Obras la polémica que suscita Sarmiento, agrega un artículo publicado en el Mercurio, firmado por Un quidam, detrás del cual, asevera, se esconde el políglota Andrés Bello. El quidam objeta al redactor del Mercurio (a

\footnotetext{
${ }^{1}$ SARMIENTO 1842, 209

${ }^{2}$ SARMIENTO 1842, 209.
} 
Sarmiento) la pretensión de atribuir al pueblo la plena soberanía del lenguaje; y juzga, además, irreverente su opinión sobre los gramáticos. Bello cree que, antes que un senado conservador, los gramáticos son el cuerpo sabio que evita que cada uno hable como «se le dé la gana». Son, por tanto, los custodios filosóficos de la lengua. Son, por lo tanto, los custodios filosóficos de la lengua.

De lo contrario —agrega—, admitidas las locuciones exóticas, los giros opuestos al genio de nuestra lengua y aquellas chocarreras vulgaridades e idiotismos del populacho, vendríamos a caer en la oscuridad y el embrollo, a que seguiría la degradación; como no deja de notarse ya en un pueblo americano, otro tiempo tan ilustre, en cuyos periódicos se ve degenerado el castellano en un dialecto español-gálico $[\ldots]^{1}$

¿A quién se refiere Bello al aludir a «un pueblo americano»?: a la Argentina, y más precisamente a la región del Río de la Plata, donde preanuncia, acaso por el clamor de «una libertad románticolicenciosa de lenguaje», la confusión babélica de las lenguas.

En enero de 1842, el entonces Ministro de Justicia, Culto e Instrucción Pública de Chile, Manuel Montt, nombra a Sarmiento en el cargo de Director de la Escuela Normal, recientemente fundada, y le encarga la composición de un método sencillo y eficaz para que los niños aprendan a leer. Abocado a estudiar el tema, Sarmiento descubre que los libros están impresos con distintos criterios ortográficos, y que no es coherente enseñar distintos criterios de lectura. Advierte, luego, que la diversidad de criterios convierte a la ortografía en algo irracional. Ésta ortografía se le representa al hablista español, y más gravemente al americano, como una ciencia oculta, o como un acertijo que solo develan los filólogos. A partir de antiguas reformas, entonces, compone una reforma ortográfica signada por la adopción del único criterio que estima válido: el fonético; esto es, escribir las palabras tal cual se pronuncian.

Sarmiento conoce bien los antecedentes del fonetismo, pero se nutre principalmente de las «Indicaciones sobre la conveniencia de simplificar i uniformar la ortografía en América», que Andrés Bello y el colombiano Juan García del Río habían publicado en Londres en 1823, en el primer número de la Biblioteca Americana. Las conclusiones de este trabajo, veinte años anterior al de Sarmiento, consisten, por un lado, en revitalizar la idea de que cada letra debiera tener un sonido distinto y cada sonido representarse por una sola letra;

${ }^{1}$ BeLLO 1842, 253. 
por otro, en ordenar la ortografía a partir de la pronunciación, no del uso corriente ni del origen de las palabras, que son los que la desordenan y la tornan contradictoria.

El 17 de octubre de 1843, heredero autoproclamado de esta reforma bellista, Sarmiento presenta su propia Memoria sobre ortografia americana, en la Facultad de Filosofía y Humanidades de la República de Chile, de la que ya es miembro. La década del cuarenta es un momento oportuno para presentar una reforma de este tenor, por tres razones principales: en primer lugar, no existe una ortografía uniforme; en segundo lugar, la Real Academia aparenta estar sensiblemente inactiva; por último, la Universidad de Chile, recientemente creada, estaba a punto de convertirse en un centro desde el cual se compusieran y propalaran una cantidad inestimable de libros. De modo que, dado este escenario, Sarmiento suma, a su urgencia por racionalizar la ortografía, el visceral encono hacia la Academia de España y el anhelo de que los próximos libros surtidos desde el sur ostenten ya la independencia ortográfica americana.

La reforma de Sarmiento, al radicalizar las diferencias americanas, expone su principal punto de escisión con el pensamiento de Bello, cuyo anhelo es, por el contrario, la unificación entre España y América. El ideal de Bello es la unidad panhispánica de la lengua; la de Sarmiento, en cambio, la independencia total y la unidad, solo, panamericana. Este prefiere una América bien lejos de España; aquel, bien cerca. Bello tomaba muchísimos recaudos en sus planteos gramaticales, por no desalentar su ideal integrador; Sarmiento, en cambio, vaticinaba que ni ahora ni en lo sucesivo tendremos en materia de letras nada que ver, «ni con la Academia de la lengua, ni con la nación española» ${ }^{1}$. Bello aprecia a la Real Academia; Sarmiento la ridiculiza y repudia. De aquí que, para neutralizar el desorden ortográfico que campea a uno y otro lado del océano, el simplificar de Bello tiene el sentido de unificar idiomáticamente las naciones de habla hispana; en Sarmiento, en cambio, el simplificar está ligado a diferenciar América de España. Existe un acuerdo, sin embargo, entre ambos: el estado actual de la composición gráfica de los libros no facilita ni la escritura ni la lectura: retrasa el avance de la civilización.

III. LA INTERVENCIÓN DE LA REAL ACADEMIA EN AMÉRICA (18701880)

En 1870 la Real Academia Española, preocupada por el divorcio que se está produciendo entre América y España, creó una Comi-

${ }^{1}$ SARMiento 1843, 13. 
sión de Academias Americanas con el fin de evitar una segregación idiomática; y en junta del 24 de noviembre de 1870 acordó autorizar la creación, del otro lado del Atlántico, de academias correspondientes. Al reseñar más tarde la iniciativa, Puente y Apezechea, entonces secretario de la Comisión, detalla los principios que los guiaba:

[...] si pronto, muy pronto, no se acude al reparo y defensa del idioma castellano en aquellas apartadas regiones, llegará la lengua, en ellas tan patria como en la nuestra, a bastardearse de manera que no se dé para tan grave daño remedio alguno. ${ }^{1}$

El interés de la Academia por reanudar los vínculos «violentamente rotos», además del carácter político que Puente y Apezechea niega, tiene otro interés de carácter geopolítico que no procura solapar, pues la recomposición de esos vínculos «va, por fin, a oponer un dique, más poderoso tal vez que las bayonetas mismas, al espíritu invasor de la raza anglo-sajona» ${ }^{2}$.

En marzo de 1871, el periódico América Latina publica el documento surgido de esa junta de 1870 y motiva la reacción, en primer lugar, de Alberdi, quien elabora desde Londres un documento que titula «De los destinos de la lengua castellana en la América antes española», y en el que denuncia que eso de recolonizar la literatura americana como medio eficaz para defender la lengua castellana no es más que un nuevo desatino de la Real Academia.

En diciembre de 1872, la Real Academia Española decide nombrar como miembro de la corporación, en calidad de correspondiente extranjero, a Juan María Gutiérrez, entonces rector de la Universidad de Buenos Aires. El diploma llega, tres años más tarde, acompañado del Reglamento de la institución y de sus Estatutos, cuyo punto primero afirma que los miembros de la corporación bregan por «cultivar y fijar la pureza y elegancia de la lengua castellana». A Gutiérrez le disgusta la invitación a convertirse en fijador y purista y rechaza el nombramiento inmediatamente. No escatima agradecimientos, pero informa al Secretario accidental, Aureliano F. Guerra y Orbe, y a través de él a toda la Academia, que no puede aceptar el nombramiento.

Esta carta, que se ha constituido en una de las piezas más preciosas dentro de la discusión en torno al idioma en Argentina, ni bien se publica es reproducida, grafica y oralmente, en cada rincón

\footnotetext{
${ }^{1}$ Puente y APEZECHeA 1873, 277.

${ }^{2}$ Puente y APEZECHeA 1873, 279.
} 
del Río de la Plata. La irreverencia de Gutiérrez atiza nuevamente la querella. Es casi la reedición de su encendido discurso inaugural del $37 \mathrm{y}$, como antaño, vuelven a esgrimirse adhesiones y diatribas.

En La Nación, el abogado y pedagogo Francisco Antonio Berra discute, en torno al rechazo del diploma, con el periodista e historiador Mariano A. Pelliza. Al mismo tiempo, una serie de diez cartas de Juan María Gutiérrez se publican en el periódico porteño La Libertad, para responder a las del escritor español Juan Martínez Villergas, publicadas en su semanario Antón Perulero. Hoy las conocemos como Cartas de un porteño, título bajo el cual las compila Ernesto Morales a partir del apelativo con que las firma Gutiérrez. La idea de un porteño enfatiza una pertenencia no tanto geográfica cuanto espiritual. Para ahondar en las razones de su denuncia, Gutiérrez rememora el origen servil de la Academia para con el Rey de España, que, con sus académicos correspondientes, sus gramáticas y diccionarios, infiltra los barcos de guerra. No olvida que Cuba aún clama por su independencia ni soslaya el reciente desembarco español en Valparaíso, que, anunciándose con fines «científicos», terminó quemando la ciudad y tomando las islas de Chincha. Para Gutiérrez, la distensión con España aún no ha llegado y, al fin y al cabo, él sigue siendo un hombre de la Revolución de Mayo, guerra que continúa librándose, ahora, por medios más filológicos, única vía que le queda a España para la Reconquista de América.

Desde París, en febrero del mismo año (1876), Juan Bautista Alberdi compone un nuevo ensayo, «Evolución de la lengua española», donde observa, no tanto la concepción idiomática de Gutiérrez, con la cual no parece tener grandes discrepancias, sino su percepción sobre la Academia. Alberdi, aunque cree limitado el poder de las instituciones de la lengua española, no las rechaza, e intenta persuadir a Gutiérrez de que ya no tiene sentido desdeñarlas. Lo que para uno entorpece el desarrollo del castellano en América, para el otro lo potencia. A Alberdi le interesa el asunto, no solo por estar involucrado un viejo compañero al que respeta, sino porque a él también lo han nombrado miembro correspondiente de la Real Academia y no ha seguido su ejemplo. Hay tres puntos que organiza este texto de Alberdi. En primer lugar, entiende que en la Academia conviven dos fuerzas antagónicas y complementarias: la conservadora y la reformista, que garantizan que la lengua sea siempre la misma y siempre distinta. En segundo lugar, al mismo tiempo que la Academia habla de «cultivar y fijar la pureza y elegancia de la lengua castellana», nombra, para que sean parte de su seno, hombres que ni la fijan ni la hacen más elegante. En tercer lugar, no 
habría que temer el ingreso de gramáticas y diccionarios, pues, antes que estos, son el comercio y la inmigración los grandes propagadores de los idiomas.

En 1877, el abogado, periodista y político Vicente G. Quesada asume como Ministro de Gobierno de la Provincia de Buenos Aires y expide, con fecha del 5 de marzo de ese mismo año, la primera circular oficial con respecto a la querella en torno a la lengua:

Persuadido que es necesario atender cuidadosa y esmeradamente la enseñanza de la lengua nacional, para impedir la anarquía que se va introduciendo en la ortografía, y conservar puro y correcto nuestro idioma, como cumple a todo pueblo culto, recomiendo a usted, de una manera especial, preste la mayor atención a su enseñanza, e impida que por descuido del profesor o por indolencia de los discípulos, crean que es permitido a gentes bien educadas, escribir incorrectamente su idioma e ignorar la gramática. ${ }^{1}$

\section{ACADEMIAS CORRESPONDIENTES Y DICCIONARIOS (1889-1892)}

Si salváramos las distancias del siguiente parangón, la nueva polémica que surge al cerrarse la década del 80 entre Rafael Obligado y Juan Antonio Argerich reedita la discusión sobre los académicos correspondientes y las academias sucursales de la española. Ahora es el publicista Argerich quien reedita el pensamiento rechazador de Gutiérrez; mientras que el poeta Obligado, a su vez, la aceptación de Juan Bautista Alberdi. Salvando las distancias, digo, porque, entre las muchas que se podrían establecer, la más evidente es que, tanto Obligado como Argerich bregan por la pureza y conservación del idioma.

La polémica se origina el 4 de agosto de 1889, a raíz de una entrevista publicada en La Prensa, donde Rafael Obligado asevera que la soberanía del idioma pertenece a España, y rendirle pleito homenaje sería cumplir un deber filial. Todo lo demás sería hacer lujo de «ridícula independencia» ${ }^{2}$. Luego, aludiendo al problema de las academias correspondientes, afirma no encontrarlas indeseables.

Antonio Argerich, sorprendido por las opiniones del autor del Santos Vega, a quien creía un patriota, escribe una carta el mismo día y la envía a La Nación. Creyéndolo ahora un converso, le pregunta

\footnotetext{
${ }^{1}$ Quesada 1877, 494.

${ }^{2}$ Obligado 1889a.
} 
qué fue de aquel poeta que bregaba por la independencia intelectual argentina:

[...] hete aquí que de pronto el señor ministro residente de España concibe la idea de establecer entre nosotros una sucursal de la que «fija, limpia y da esplendor» y Usted, en el campo de la doctrina crítica, se pasa con armas y bajeles al campo contrario [.... ${ }^{1}$

Argerich le advierte que la creación de una academia de la lengua española en América estaría destinada a morir por «falta de atmósfera», y por ser, al mismo tiempo que antipatriota, «inútil y descaminada». No obstante, dice todo esto sin querer que se lo confunda con un neologista; confiesa amar el idioma castellano y desear que se conserve incólume en América. Lo que Argerich objeta es, por un lado, la utilidad de las instituciones de la lengua; por otro, la legitimidad de las mismas en tierras que ya no gobiernan. Luego llama a los idiomas «organismos vivos», no sujetos al dictamen de las academias, sino a la inclemencia del lugar, el tiempo y el pueblo que los modela. La pureza por la que aboga, por tanto, remite a una pureza americana, sin injerencia de España. Si ha de formarse una academia, para Argerich debe ser argentina, «sin vasallajes de preocupaciones extranjeras», y que España acoja o rechace, si le place, lo que ésta diga.

Rafael Obligado le responde enviando a La Nación cuatro cartas, que serán publicadas el 7, 8, 9 y 11 de agosto. En ellas rechaza las acusaciones de traidor, y reconoce haber hablado de «autoridad» de España sobre la lengua, pero no de «soberanía»:

Fuera bien original y hasta ridículo que nosotros, o cualquiera república americana, que estamos balbuciendo una literatura propia, nos la echáramos de maestros ciruelas abrogándonos una supremacía que no nos hemos conquistado; porque esta autoridad se conquista, no con desearla, sino a fuerza de talento, prodigado en siglos de labor. ¡Quién nos diera a Cervantes, a Lope y a Calderón por acá, para decir a España: atrás, vieja inútil! ${ }^{2}$

Ese mismo año, 1889, en octubre, al reseñar un libro argentino, José Martí lanza su pertinaz «Gutiérrez, para no ser traidor, no quiso ser académico» ${ }^{3}$. Martí está asombrado de la transformación porteña y encuentra, a partir del libro de Juan Piaggio, la oportuni-

1 Argerich 1889.

${ }^{2}$ OBLIGAdo $1889 \mathrm{~b}$.

${ }^{3}$ MARTí 1889. 
dad para decirlo. Nunca ha visto una ciudad cambiar tanto como lo ha hecho Buenos Aires, en solo veinte años. Se sacó del costado, escribe, «el puñal de la tradición». Su juicio sobre lo que en ella está sucediendo es similar al que había expresado Gutiérrez al rechazar el diploma, pues advierte que la presencia extranjera, con sus lenguas, se cruza en Buenos Aires de tal modo que, valiéndose de la libertad y el progreso, produce beneficios espirituales. Esa reunión no es, para Martí, causa accidental y pasajera, sino voluntad de crear un pueblo donde se junten, bajo la presidencia latina, las fuerzas vivas del mundo. Esta confluencia extraordinaria no puede jamás consentir los anhelos académicos de fijar, pues la transformación idiomática que vive la ciudad no solo supone la presencia de lenguas europeas, sino de lo indígena y lo exótico, al punto que el idioma español, que no cree deba ser suplantado, torna en una forma descastizada.

Interesado por la querella y por la discusión del diccionario y las academias, Lucio V. Mansilla, también en 1889, le dedica al asunto una de sus causeries ${ }^{1}$, donde exhorta a los hombres en disputa a llegar a un acuerdo con la Academia Española y dotar a la lengua, finalmente, de un Diccionario que, no por ser del español, deje de ser americano. Mansilla cree que escritores como Bello, Baralt, Caro o Vicente Quesada no han buscado — al auspiciar la limpieza, la purificación y el ennoblecimiento de la lengua- someter el castellano de América al veto de la Academia peninsular, sino, por el contrario, inducir a esta a ir lentamente incorporando en su Diccionario oficial el caudal de voces forjadas al calor de la idiosincrasia americana. La propia España ostenta eruditos que, siguiendo esta tendencia, y sin abandonar el ideal casticista, quieren asimilar voces nuevas.

Dos años más tarde, en 1891, heredera de aquella circular de Vicente G. Quesada que pedía «atender cuidadosa y esmeradamente la enseñanza de la lengua nacional» ${ }^{2}$, se publica una circular de Juan Carballido, entonces Ministro de Instrucción Pública del gobierno de Carlos Pellegrini. En la circular se asevera que, más que la raza y las instituciones análogas, la «lengua común» constituye el mayor vínculo de fraternidad con el resto de los países hispanoamericanos. Esta «lengua común», no obstante, está seriamente amenazada por un proceso de dialectización; y no habría otro país más expuesto que Argentina a este peligro. La reforma, por tanto, decide intervenir en la dirección de la lengua. «Renunciemos —agrega Carballido- a vanagloriarnos con nuestras incorrecciones: como lo repite

\footnotetext{
${ }^{1}$ Mansilla 1889.

${ }^{2}$ QuesadA 1877, 494.
} 
expresamente el nuevo plan de estudios, no hay más idioma nacional que el castellano.» ${ }^{1}$

Algunos años más tarde, Paul Groussac se atribuirá la redacción de esta circular ${ }^{2}$, de modo que conviene leerla junto a las ideas que plasmará en 1897, al presentar Del Plata al Niágara. Todas estas extraordinarias notas de viaje están enriquecidas con valiosas observaciones sobre la lengua, sobre Andrés Bello, sobre la Real Academia Española. Al pasar por Lima, por ejemplo, Groussac alude de soslayo la polémica desatada por Gutiérrez:

En Lima se siente ahora como una recrudescencia de la palabrería pedantesca y vacía. Funciona solemnemente una «Academia de la Lengua», sucursal de la que elabora en Madrid tan exquisito diccionario. Para procrear una obra inspirada, para dar al fin con la originalidad y la vida, estos «excelentísimos» se cuelgan del pescuezo un abalorio y, puestos en cuclillas, formando rueda, teniendo cada cual en la mano su diploma de la academia matriz jse calientan al reflejo de una luna menguante! 3

\section{CONTRA EL PURISMO: DE LENZ A CUERVO (1893-1900)}

En una serie de notas publicadas a fines del año 1899, Unamuno embiste contra el purismo casticista y enuncia su tesis: «hay que hacer el español internacional con el castellano, y si este ofreciese resistencia, sobre él, sin él o contra él $\rangle^{4}$. Se trata de una tesis, a la vez, algo dramática, pues, siendo don Miguel vasco, postula la necesidad de que el vascuence muera en el castellano, para sobrevivir a través de él, del mismo modo que debía morir y sobrevivir el idioma nacional argentino. Estas muertes necesarias, sin embargo, debían suceder a condición de incidir en esa lengua mayor. La concesión de ser en otro debía hacerse para forjar un otro más vasto, un otro que deje de ser enteramente otro.

A fines de este mismo año (1899), en Buenos Aires, la Revista Nacional publica, de Ernesto Quesada, la primera entrega de «El problema de la lengua en la América española», una serie que luego aparecerá en un solo volumen bajo el nombre de El problema del idioma nacional. Ernesto Quesada, hijo del ya mencionado Vicente y

${ }^{1}$ CARBALlido 1891.

${ }^{2}$ Cf. Groussac 1900, 413.

${ }^{3}$ GroussaC 1897, 96-97.

${ }^{4}$ UNAMUNO 1899.

${ }^{5}$ QuesadA 1900. 
miembro correspondiente, a la sazón, de la Real Academia Española, señala aquí, ante todo, el profundo disgusto que le provocaron las tesis de Juan María Gutiérrez y se separa de ellas. Mientras que Quesada sintió el calor maternal de la Península; Gutiérrez, el fuego de sus cañones; uno cree que mantener lazos de cariño con ese tronco común no menoscaba la independencia; el otro percibe que esos lazos ofenden el legado de Mayo. En el lema académico fijar, Gutiérrez leyó detener, Quesada, en cambio, entendió que allí se decía precisar lo verdadero, lo conveniente para la lengua.

Pero este año, 1899, aun dispone de un hecho relevante para la querella, y probablemente sea el hecho más importante del año. El poeta argentino Francisco Soto y Calvo invitó a su casa al filólogo y lingüista colombiano Rufino José Cuervo, a quien le leyó, entre el agasajo y la conversación, su flamante Nastasio, una veintena de miles de versos que perfilan, sobre el escenario de la pampa, el drama de un gaucho al que, tras una vida dichosa, siguió la desgracia de perder su hogar, su mujer y sus hijos. Cuervo sintió, entre la emoción que le producían los versos, algo de nostalgia por lo que ellos le revelaban sobre el futuro de la lengua en América. Esos versos, para entenderse cabalmente, debían leerse con el auxilio de un glosario criollista, que el mismo Soto y Calvo anexaría al final. De modo que Cuervo ve confirmadas ciertas intuiciones que últimamente venían asediándolo: el idioma español, en América, se terminará separando del español peninsular. La escucha del Nastasio fue, para el célebre colombiano, como despedirse definitivamente de aquella esperanza de ver unida a la lengua que estimaba como una de «las mayores glorias que ha visto el mundo... ${ }^{1}$

Cuervo, luego, le escribe una carta, para expresarle la emoción que le causó su poema. En esas líneas, acaso sin prever la enorme repercusión que tendría, bosqueja una impresión que, al anexarse la carta como prólogo a la edición de Nastasio, será el umbral de otra polémica. Cuando los pueblos americanos, escribe allí Cuervo, se hallaban aún en el regazo de España, esta los dotaba de los bienes culturales y el vínculo con ella era íntimo y natural; luego vino la emancipación; luego, al imbuirse cada nación en sus asuntos e ignorar los ajenos, incluidos los de España, la influencia fue debilitándose cada día, y «fuera de cuatro o cinco autores cuyas obras leemos con gusto y provecho, nuestra vida intelectual se deriva de otras fuentes, y carecemos pues, casi por completo, de un regulador que garantice la antigua uniformidad $»^{2}$. Cuervo siente que el protectora-

\footnotetext{
${ }^{1}$ Cuervo 1899, X.

${ }^{2}$ Cuervo 1899, IX.
} 
do casticista, por el que tanto había bregado, ya no puede evitar que cada americano se apropie de lo extraño y extranjero como mejor le parezca. La idiosincrasia y el paisaje americanos, y las propias lenguas autóctonas, horadan la pureza de la lengua al punto de precisarse glosarios, si es que se ha de expresar lo más íntimo, lo familiar y local.

SEgUnda PARTE (1900-1928)

I. PolÉMiCA EN TORNO A LAS TESIS DE ABEILLE y CUERVO (19001903)

La obra de Lucien Abeille, en 1900, constituye una escisión tal que amerita pensarla como el inicio de un nuevo período. Lucien Abeille fue, como tantos franceses allegados al Río de la Plata, un entusiasta de la argentinidad. Radicado en Buenos Aires desde 1889, poco antes de cumplir treinta años intuyó en su nueva patria el nacimiento de algo que aún no conocía bien, pero que cree poder develar: la expresión local. En 1900 publica Idioma nacional de los argentinos. El libro, cuya tesis se puede inferir del título, presenta la siguiente taxonomía:

Cuatro opiniones condensan las teorías diversas que se han creado acerca de la lengua hablada en la República Argentina. Hay los que creen que el idioma nacional es simplemente el castellano; los que afirman que es solo un dialecto; los que sostienen que es una lengua genuinamente argentina; los que velan por el purismo castellano. ${ }^{1}$

Abeille es de la idea de cobijarse en la tercera, a la cual consagra los trece capítulos de su extenso volumen, donde discurre como un lingüista comparatista: el sánscrito, el griego, el latín, el inglés, el alemán; la fonética, la sintaxis, los léxicos, todo le sirve para confluir en la tesis de que en la Argentina se está forjando una nueva raza, de vida intelectual y moral propia, cuyo cariz distintivo es la claridad del pensamiento y la adopción de un idioma nacional que armoniza con él. Si esta nueva raza se sirviera de la lengua que heredó, la castellana, como es insuficiente para la expresión diáfana de su pensamiento, la raza argentina no se desarrollaría plenamente, pues estaría en contradicción su alma y el modo en que ella se expresa. Este

\footnotetext{
${ }^{1}$ ABEILLE 1900, XI.
} 
idioma, no obstante, por encontrarse aún en gestación, prefiere escribirlo en cursiva.

La fundamental novedad que reporta Abeille, estimo, no es tanto su tesis cuanto el modo de tratar la cuestión del idioma nacional, pues intenta demostrarlo filológicamente. Nadie hasta el momento había hecho un esfuerzo en este terreno; o al menos nadie lo había hecho de forma tan decidida. Abeille retira la querella del ámbito donde la libraron los románticos y somete al idioma a un examen disciplinar: la lingüística. No habla como escritor, político o abogado; habla como un profesional del lenguaje.

Esta novedad conlleva una gran paradoja para la causa abeilliana, porque todo lo que ella auspiciaba genera la aparición de antagonistas que la desmoronan con sus mismas armas. Hasta 1900, la disputa parecía no ameritar exceder el periódico o el folleto; al irrumpir Abeille, muñido de un aparato científico y una extensión inéditos, genera la propagación de una prosa refutadora que culmina en hombres como Ramón Menéndez Pidal y Amado Alonso. Refutadas, luego, las ideas lingüísticas que sustentaban a Abeille tarea de la que se encargará la nueva escuela filológica-, se desplomarán las conclusiones a las que esas ideas conducían. Es Abeille, paradójicamente, quien comienza la devastación del «idioma nacional de los argentinos». La cuestión de la lengua no deja de ser una querella, solo que ahora comenzará a disponer de un corpus bibliográfico que prescinde de considerarla como una lucha por la expresión y la emancipación cultural. Ese corpus comienza a ser escrito por lingüistas, que en la búsqueda de su propia legitimación piden que sea interpelado desde una inscripción similar en el «campo del saber». La novedad de Abeille, en síntesis, no reside en postular un idioma nacional, sino en confinarlo a una cuestión técnica.

Entre los que se alistan en defensa de la tesis de Abeille se encuentra, en primer lugar, el doctor Louis Duvau, profesor y director de Gramática Comparada en la Escuela Práctica de Altos Estudios de París, quien le envía a Abeille una carta, fechada en octubre de 1899, saludando la pronta aparición del libro y manifestando estar en todo de acuerdo con las premisas lingüística que lo guían. Luego saluda la tesis el ex presidente de la República, Carlos Pellegrini, a quien Abeille había dedicado el libro y citado, profusamente, como ejemplo de prosas escritas en idioma nacional de los argentinos. Carlos Olivera, después, elogiará a Abeille en la Tribuna, de Buenos Aires (7 de agosto de 1900) y se entusiasmará con la idea de ligar cada nación a una lengua privativa. También saludan la empresa de Abeille, dos años más tarde, un tal Ramón C. Linares, en El País (Bue- 
nos Aires, 1 de noviembre de 1902) y, desde las páginas de Caras y Caretas, Carlos Correa Luna.

Nombro estas bienvenidas porque son enumerables. No lo son, en cambio, las diatribas, que se alistan contra Abeille como si encarnara la peste del Apocalipsis. Es casi una regla que los refutadores de Abeille ignoren el contenido de su libro o cuanto menos su nombre de pila exacto. Quizá no sea el caso de Paul Groussac, quien no obstante, en oportunidad de refutar en un artículo la autoctonía de ciertos americanismos, castiga a Abeille con el desprecio $^{1}$. Pero el artículo no agota en esta nota al pie lo que tiene para decir con respecto a la querella; luego de discurrir sobre ciertas etimologías, Groussac ensaya dos tesis en torno a ella: una intenta desbaratar, en favor de la conveniencia de persistir en el castellano, la idea de un idioma nacional; la otra procura reencauzar a los románticos en la senda del casticismo. «La herencia que aconsejo a los argentinos conservar con respeto religioso es la de la lengua, que es la tradición viva de la raza.... ${ }^{2}$

También Miguel Cané, el mismo año, aboga por desligar a Juan María Gutiérrez de la genealogía que lo tendría como fundador principal del Idioma Nacional: «La acción del Doctor Gutiérrez ha sido generalmente mal entendida.... ${ }^{3}$. Luego advierte sobre la conveniencia de que la lengua persista inmutable en su estructura esencial; y recusa a Abeille por su condición de francés.

Más tarde, y con la excusa de impugnar el Nastasio, al que estima como un mero poema localista, Ernesto Quesada embiste contra toda forma de idioma nacional que no sea el castellano o, mejor aun, contra la pretensión de que su versión criollista se erija como tal. Publica, en 1902, «El criollismo en la literatura argentina» ${ }^{4}$, donde intenta demostrar que la gauchesca es, ya para principios del siglo XX, una impostura jergal, nada criolla (la cree andaluza) y mortecina. El castellano, entendió Quesada, contuvo a esos artificios como excentricidades que entonces (alba del siglo XX) solo podían ofrecer, por arcaicos, el valor del extrañamiento. El cocoliche y el lunfardo, que estima fueron la continuidad cronológica de la gauchesca, le resultan aún más escandalosos, y les teme por su vigencia y auge en las letras argentinas.

Algún tiempo después, Francisco Soto y Calvo, que ya leyó bastante crítica sobre su Nastasio, decide intervenir en la polémica;

${ }^{1}$ Cf. nota al pie en Groussac 1900, 387.

${ }^{2}$ Groussac 1900, 413.

${ }^{3}$ CANÉ 1900.

${ }^{4}$ Quesada 1902. 
pero elige como único antagonista a Ernesto Quesada, a cuyo ensayo encuentra erudito y meritorio, y aun así, equivocado en su punto central. En primer lugar, y como tesis que guía su réplica, estima que el criollismo no es una fuerza menor y degradada del lenguaje. Basta que la forma de la lengua sea la expresión de un sentimiento auténtico, para que sea apropiada. Para Soto y Calvo, la literatura nacional es una realidad incipiente y hay que juzgarla como tal, y disculparla, incluso, cuando procede como recién nacida. No es tiempo de censurar sus formas, sino de alentarlas. El «demiurgo argentino», así lo llama a Quesada, aconseja a los escritores: «rebuscar nuestro lenguaje, almidonarlo a la castellana, y prepararnos con él, bien descaracterizados y bien incoloros, la blanda almohada de la indiferencia universal, y la molicie en que duermen, los agotados, el sueño entorpecedor de la decadencia» ${ }^{1}$. Soto y Calvo — que sitúa la discusión en el lugar que estaba en 1837, restituyéndole su tono romántico- halla absurdo recriminar la ausencia de una idiosincrasia nacional, al mismo tiempo que se cercena y repudia sus formas incipientes.

II. DEL VIRAJE DE UNAMUNO A LA TESIS DE LA ESCISIÓN MORAL, DE MENÉNDEZ PidAL (1903-1918)

La carta que en enero de 1903 envía Miguel de Unamuno a Adolfo Casabal, entonces codirector de la revista Estudios, pretende reencauzar nuevamente la querella. Retomando las disputas nacidas a partir de la carta-prólogo de Cuervo y del estruendoso libro de Abeille, Unamuno retira el problema del recinto lingüístico y lo resitúa en el lugar donde lo habían puesto los románticos: el moral, pues cree intuir, en el clamor autonomista de los argentinos, un deseo legítimo de hacerse escuchar. Formula, así, una bisagra en torno a la querella.

Tiempo más tarde, en 1908, en Tucumán, el historiador y publicista Juan B. Terán interviene en la querella idiomática al publicar Estudios y notas, donde explicita que el lenguaje no es una revelación divina, sino una obra social. Sus leyes, por tanto, pueden conocerse siguiendo las de cualquier otro fenómeno social, es decir, las leyes de la evolución social. La lengua es, además, lo que más fielmente refleja y se acomoda a los movimientos del alma colectiva. Todo intento por detener este acomodamiento tiene algo de improcedente, algo de tendencia a estancar el despliegue espiritual de un pueblo.

\footnotetext{
${ }^{1}$ Soto y Calvo 1903, 291.
} 
Sus premisas son contrarias a un ideario purista de la lengua, al cual Terán estimó ajeno a la lingüística moderna.

Mientras tanto, Argentina está cerca del Centenario de la Revolución y crece la preocupación por actualizar el carácter nacional de la república. Ricardo Rojas, entonces, publica La restauración nacionalista. Rojas concibió, en este libro, que en el idioma patrio estaban los elementos espirituales más duraderos de la tradición nacional, el puente espiritual más firme con los antepasados y con España. La conservación de ese idioma era, por tanto, necesaria para la unidad espiritual e histórica a través del tiempo y para lograr el instrumento adecuado en la persecución de la hegemonía cultural en América. No duda en llamarlo idioma patrio; a veces utiliza el concepto de idioma nacional o el de idioma tradicional, que son, en esta obra, todos equivalentes, todas formas alternativas de idioma español, forma que, en cambio, evita por considerarla un error. Su revalorización de lo indígena y de las voces indígenas, que en La restauración ya ocupa un lugar relevante, no implica ceder absolutamente nada en la idea de que la lengua de Argentina es y debe ser el español. El problema no está en lo autóctono, sino en lo foráneo: en el francés, en el inglés, en el italiano. El enemigo número uno de la restauración que pretende Rojas es, entonces, el cosmopolitismo, entendido como la presencia extranjera que resiste argentinizarse. No pide la expulsión del inmigrante, pide que resigne su lengua materna ni bien pise suelo argentino.

La soledad en la que se encontraba Abeille desde que salió su Idioma se ameniza también en 1910, año en que Vicente Rossi presenta su Teatro nacional rioplatense y asegura que la forma de hablar de este teatro es la rioplatense; cosa que encuentra muy obvia y natural. Si el teatro, agrega, pretendiera hablar y pronunciar «castizo», precisaría dotarse de hombres y mujeres que supieran hacerlo, dotes que resultan muy afectadas en el Río de la Plata. A Rossi lo desvela la disputa con los puristas, que están, a su parecer, sitiando los escenarios en pro de hacerlos entonar de una manera equivocada.

En 1913 Lugones lee en público sus conferencias sobre El payador, una obra de propósito doble: por un lado, develar el sentido épico del Martín Fierro; por el otro, trazar una genealogía hercúlea para la raza argentina. En medio de su tesis, y haciéndolas armonizar con ella, Lugones enhebra sus apreciaciones sobre la lengua en Argentina. En primer lugar, persiste en advertir dos castellanos: uno español, otro americano; ambos perfectamente distinguibles. Esta es la base para postular que el castellano del gaucho, adaptado al suelo americano, constituye una lengua signada por una forma ar- 
caica. Pobre en su vocabulario, debido a la vida humilde y campestre, el gaucho tendió a la concisión y al laconismo, al realismo de la expresión y la filosofía práctica, a la elipsis y la simplificación de sus frases; vivificando la destreza derivativa de la lengua, convirtió en verbo todo aquello que necesitó verbalizar, y al faltar una literatura que imponga una preceptiva, discurrió con mayor libertad, y desarmó el humanismo que había latinizado y culteranizado al idioma.

Un año antes de que Lugones leyera sus conferencias, Ricardo Rojas inaugura en la Facultad de Filosofía y Letras de Buenos Aires la primera cátedra de Literatura Argentina (1912), cuya labor pedagógica e investigativa confluye en la publicación de su Historia de la Literatura Argentina. Al ocuparse de «El idioma de los conquistadores», Rojas procura especificar mejor de qué se trata el idioma argentino, pues es el idioma en que se escribe la literatura argentina. Ya había dicho que al llegar el castellano a América se encuentra en proceso de consolidación, pero al traerlo el conquistador, es decir el sermo vulgaris, se trata de un castellano que conserva aún muchas de las formas medievales, mucho de su vigor primitivo, anterior al Renacimiento, que es el modo en que vivía la lengua lejos de Castilla. De aquí que el castellano argentino esté lleno de arcaísmos y vulgarismos que afloran, por ejemplo, en la poesía gauchesca, poesía que Rojas encuentra genuinamente nacional. A este castellano aún medieval que llega a América se suma, luego, tras un proceso de canonización y latinización del idioma, el castellano culto, el sermus eruditus, reuniéndose ambos en la pluma de los escritores argentinos, quienes, al ensamblarlos, componen la literatura argentina. Hay, por tanto, en la lengua nacional, una vertiente popular y una culta. No cree que una valga más que la otra; cree, sí, que «en la armonía de ambas reside la plenitud de una cultura» ${ }^{1}$. Esta tesis volverá en Eurindia, ensayo del que me ocuparé más tarde.

No debo aún alejarme de los albores de 1910, pues en esos años, Miguel de Toro y Gisbert publica en París sus Americanismos, cuyo primer capítulo embiste «contra los fanáticos partidarios de una estrafalaria emancipación lingüística, que quisieran convertir el español de los argentinos en una lengua análoga al francés de los haitianos.... ${ }^{2}$. Esa estrafalaria emancipación remite principalmente al Idioma nacional de los argentinos.

Algunas de las ideas de Toro y Gisbert serán refrendadas, años más tarde, por Ramón Menéndez Pidal, al enviar una carta a sus amigos Aurelio M. Espinosa y Lawrence A. Wilkins, de los Estados

\footnotetext{
${ }^{1}$ Rojas 1917, 163.

2 TORO Y GISBERT [1912], 6.
} 
Unidos, a quienes saluda por el primer número de la revista Hispania. Los buenos augurios no vienen solos, traen adosadas dos tesis referidas a la querella. La primera se ocupa de la distinción entre el habla de España y el habla de Hispanoamérica; distinción que, para Menéndez Pidal, solo se encuentra en el habla popular, pues el habla culta está unificada a un lado y otro del océano. Todas las hablas populares, agrega, abundan en variaciones regionales, hecho que no debe conducir a estimarlas como lenguas nacionales. Las diferencias existentes en el habla popular de Hispanoamérica, por otra parte, son considerablemente menores a las que existen en España. El llamar «española» a la lengua remite, para Pidal, a esta superación de las variedades locales.

\section{PRIMERAS PERIODIZACIONES: COSTA ÁlVAREZ, QUESADA Y ROJAS (1922-1923)}

En 1922 el filólogo platense Arturo Costa Álvarez publica una serie de ensayos bajo el nombre de Nuestra Lengua, algunos de los cuales destina a biografiar la querella. Se trata del primer intento de periodización, justo cuando la controversia por el idioma está a punto de cumplir un siglo y ya hay algunos (acabamos de ver el caso de Menéndez Pidal) que la dan por muerta. El libro consta de un primer grupo de ensayos, «Los Idiomólogos», donde Costa Álvarez procura demostrar que Esteban Echeverría ha sido mal interpretado, y que, donde éste dijo ampliar y enriquecer la lengua, otros han leído barbarizar y arruinarla. Echeverría — según esta exégesis- no impugnaba la lengua de los conquistadores, sino cuando esta se disponía para la causa monárquica, arcaica y rutinaria. Todo el matiz americanista con que Echeverría forjó su lengua no debería presentarse, por tanto, como antecedente de la gauchesca ni de ninguna parla singular.

Demostrada la tergiversación que se hizo de Echeverría, Costa Álvarez sigue con Alberdi, Sarmiento y Gutiérrez, pues cree que ellos tampoco han predicado la desnaturalización del castellano, sino que habrían sufrido la misma adulteración que sufrió Echeverría. Esta idea de desligarlos de todo plan corruptivo de la lengua y quitarles el sayo de segregacionistas, esbozada ya en los artículos de Groussac y Cané, ambos de 1900, es la que Costa Álvarez desempolva para reavivar y nutrir de ejemplos.

La empresa desplegada en este libro convence a muchos: algunos la elogian en la prensa, otros la festejan en el estrado. A Ernesto Quesada lo motiva a tal punto que acomete una reescritura, 
La evolución del idioma nacional, enfatizando todo aquello que considera omisiones y distracciones. Compartiendo en lo substancial las tesis de Nuestra lengua, Quesada objeta un sinnúmero de detalles, convirtiendo a su opúsculo en una dilatada nota al pie, atestada de referencias nimias.

A partir del $1^{\circ}$ de octubre de 1922, en su suplemento dominical, el diario La Nación había comenzado a publicar Eurindia, ensayo que Ricardo Rojas concibió a modo de una estética sobre las culturas americanas. El programa de esta obra es vastísimo, pero uno de sus temas se esgrime como central: la lengua, a la que consagra siete capítulos. En primer lugar, la lengua aparece como el instrumento principal para la realización y triunfo de Eurindia; pues se revela como el signo más relevante de la nacionalidad americana y de cada una de las naciones que la conforman. Pero Rojas, a diferencia de Quesada, encuentra al idioma como un problema, al que formula de la siguiente manera: «La literatura argentina no se halla escrita en idioma argentino» ${ }^{1}$. Parte, así, de asumir que no componemos nuestros libros «en lengua creada por nosotros mismos», sino que somos herederos de un castellano traído a América por extraños, situación que ha generado una querella resumible en tres posturas: en primer lugar están los que entendieron que, si se quería tener una literatura nacional, se debía formar un idioma nacional; en segundo lugar, los que concluyeron en que, si nuestro idioma es común a varios pueblos hispanoamericanos, no somos una nación; y por último, los que, hallando que nuestro idioma era el castellano, encontraron natural que los pueblos de América continuaran siendo una colonia literaria de España. Luego menciona a Juan María Gutiérrez, a Calixto Oyuela y a Lucien Abeille como sendos pregoneros de estas tres soluciones que, al estar planteadas equívocamente, soslayarían el problema fundamental.

IV. LA QUERELLA AL IRRUMPIR EL INSTITUTO DE FILOLOGÍA (19231926)

Quizá no haya que buscar en los libros de Ricardo Rojas su obra de mayor envergadura, con respecto a la querella de la lengua. Su obra mayor es la fundación del Instituto de Filología, cuya primera misión podría abreviarse en el siguiente propósito: la cuestión del idioma nacional dejará de ser una querella. El programa para lograrlo es vastísimo y cuenta con los primores de lo que se llamó la nueva escuela filológica.

\footnotetext{
${ }^{1}$ ROJAS 1922, 3.
} 
El Instituto de Filología se inauguró formalmente en 1923, en el anfiteatro de la Facultad de Filosofía y Letras de Buenos Aires. Ante un público numeroso, Ricardo Rojas dio un discurso que, aunque eminentemente celebratorio, enseña todos los perfiles que tendrá el Instituto. Dirá, ante todo, que la filología no puede ser concebida como una verdadera ciencia sino hasta mediados del siglo XIX, y que en España se demoró hasta que llegara Menéndez Pidal, es decir, hasta los albores del siglo XX. Al presentar a Américo Castro, flamante director del Instituto, aclara: «viene hacia nosotros como un generoso misionero de la nueva doctrina». Esta nueva doctrina en los estudios de la lengua ya no viene a intervenir en la querella del idioma nacional, sino a desarmarla por efecto de los nuevos métodos científicos. No viene a discutir, pretende demostrar.

Rojas no cree que deba recriminársele haber elegido a un extranjero para dirigir un instituto nacional, pues «si necesitamos traer del extranjero especialista de una ciencia que aquí no se cultiva o se cultiva por métodos equivocados, debemos traerlos» $»^{2}$. Justifica el haber elegido un filólogo español, además, en el hecho de poseer el vínculo común del idioma. La lengua de los argentinos — con esta idea cierra su oratoria- es la misma lengua que habla Castro, el que, luego de oír este discurso, sucede a Rojas en el uso de la palabra.

Castro refrenda la idea de que Menéndez Pidal origina en España los estudios científicos de la lengua, y celebra que los argentinos, sosegados ya los recelos de antaño, acepten el aporte que les puede dar un filólogo español, aporte que cree necesario explicitar. La misión que le compete, afirma, es hallar un justo medio entre dos tendencias contrarias: una esgrimida por los devotos de la peculiaridad nacional del idioma; la otra celebrada por los casticistas. Una peca de neologista; la otra, de arcaizante. En palabras de Castro: «Ni "arrabaleros" o galiparlantes, ni fetichistas del incompleto diccionario de la Academia Españolas ${ }^{3}$. En Argentina, los primeros habrían culminado en el libro de Abeille, que Castro encuentra felizmente derrotado.

La causa del idioma nacional - para la nueva escuela - ya se encuentra absolutamente superada: el idioma de los argentinos es el español. Puesto que ya no hay nada que atente contra la estructura del idioma, resta establecer cuáles son sus peculiaridades, ante todo las

\footnotetext{
${ }^{1}$ Rojas y CAstro 1923, 9.

${ }^{2}$ ROJAS y CASTRO 1923, 10.

${ }^{3}$ Rojas y CASTRO 1923, 15.
} 
peculiaridades del habla, y en especial aquellas que trasvasan el habla vulgar e impregnan el habla culta.

Ya de lleno en sus funciones, Américo Castro responderá a un editorial del diario La Nación, titulado «El dialecto argentino», y lo hará preguntándose: «¿Dialecto argentino?». Para Castro, dialecto puede ser una forma peculiar de lenguaje que no alcanzó prestigio literario; puede ser, también, una forma que gozó de una importancia literaria que ya no ostenta; o bien puede ser un habla poliforme y dividida que nunca haya rebasado el grado rudimentario de los idiomas rústicos. Hecha esta disquisición: «Me apresuraría a decir que el dialecto argentino no existe» ${ }^{1}$. Diez días más tarde, en el mismo diario, completa el planteo diciendo que lo que sucede con la lengua en Argentina no es muy distinto de lo que sucede en España; de modo que si cada aldea pretendiera reivindicar para sí un idioma distintivo, habría un idioma por cada una de ellas. Castro cree estar en condiciones de formular una gran conclusión:

De la observación de muchos hechos y del examen de muchas opiniones se desprende la idea de que las peculiaridades del habla del Plata son más psicológicas que lingüísticas. Suprímase la creencia de que los argentinos tienen una manera de hablar sui géneris, y se habrá suprimido el noventa por ciento de las pretendidas particularidades argentinas. ${ }^{2}$

La idea es extraordinaria y certera, solo que está formulada de tal modo que Castro, aunque asegura que la cuestión de la lengua argentina es de dimensión psicológica, no deja de pensarla en su dimensión estrictamente lingüística. También Unamuno había llegado a una conclusión similar: el problema de la lengua en Argentina es más de orden moral que lingüístico. Aquí radica el problema a develar: ¿por qué los argentinos pretendimos, sin ostentar bases lingüísticas que lo sustenten, un idioma que no sea llamado español? Castro no responde a esto, pero su modo impugnador con que se refiere a la lengua en el Plata, en cambio, nos da la pauta para entenderlo.

\section{De GrossmanN a LA NACIÓN (1926-1927)}

En 1926, el Seminario de Cultura y Lenguas Románicas de la Universidad de Hamburgo publica El patrimonio lingüistico extranjero en el

\footnotetext{
${ }^{1}$ CASTRO 1924a.

${ }^{2}$ CASTRO 1924b.
} 
español del Río de la Plata: una contribución al problema de la lengua nacional argentina $^{1}$, del filólogo rosarino Rudolf Grossmann, quien, sin ánimo querellante, viene a dar su dictamen en relación a esta disputa que estaba a punto de cumplir cien años. También él intenta demostrar que no existe nada suficientemente relevante que ponga en peligro la unidad del español usual de la Argentina. Esto, que es la médula de su tesis, debe ser leído como alegato al Idioma nacional de los argentinos, que, aunque Grossmann cree ya ocioso ocuparse de él, intenta refutar. ¿No habían sido varias ya las refutaciones que pesaban sobre esta obra de Abeille? Sin duda, Grossmann las conoce y las cita; solo que faltaba la refutación que se opusiera a Abeille en su mismo campo: el empírico; y en su mismo código: la lingüística. Ni las ironías de Miguel Cané; ni el ninguneo de Paul Groussac; ni la desautorización de Ernesto Quesada, entre otras tantas impugnaciones, le habrían bastado a Grossmann, quien casi no se referirá a Abeille, ni a su condición de francés, ni a sus supuestos intereses personales o francófilos. Grossmann procurará desarmar el programa filológico abeilliano y obtener, de un planteo similar, conclusiones opuestas. No es un trabajo surgido del seno del Instituto de Filología, pero va en ese sentido.

A mediados de abril de 1927, La Gaceta Literaria, de España, trae un efusivo editorial titulado «Madrid, meridiano intelectual de Hispano-América», firmado por Guillermo de Torre, y en el que se exhorta a poner las cosas derechas y reconocer que Madrid debe ser reconocida como capital espiritual e idiomática de Ibero-América, expresión que escribo en cursiva por ser el centro de la disputa. Guillermo de Torre preferiría, no obstante, llamarla «América hispanoparlante», pues el idioma, más que cualquier otra cosa, es lo que liga a estas tierras con España.

En el Río de la Plata, este editorial es leído por los jóvenes martinfierristas y se toma como un presente griego. A mitad de año, casi emulando el célebre rechazo de Gutiérrez a la Academia, responden colectivamente en las páginas de Martín Fierro. El primero que desenvaina es Pablo Rojas Paz, quien denuncia que la intención de España de constituirse en la Meca intelectual de los sudamericanos bien podría cuadrar a países que gusten de la tiranía, o en pueblos como Perú o Bolivia, que se jactan de hablar un español del 1600; «pero nosotros ya hemos progresado mucho, tanto que no podemos decir en qué idioma hablamos» ${ }^{2}$. Para Rojas Paz, Argentina ya no se liga a España sino a través de una tradición artificiosa.

\footnotetext{
${ }^{1}$ Grossmann 1926.

${ }^{2}$ ROJAS PAZ 1927.
} 
Cree que es signo de potencia espiritual que un pueblo transforme el idioma heredado, al punto de convertirlo en otro: «Nosotros estamos organizando un idioma para nosotros solos y de aquí nos vendrá la libertad $\iota^{1}$. También cree que Argentina no está buscando un meridiano; está hallando su destino.

En la página siguiente, Raúl Scalabrini Ortiz, quien también se alista, descree de un término como «Hispanoamérica» y, por tanto, del vínculo establecido por el idioma. Adelantando la idea de que diversas corrientes de oro confluyen en el Plata (idea que expandirá en El hombre que está solo y espera), agrega: «Nuestros glóbulos rojos hablan varios idioma y responden a tradiciones distintas y antagónicas [...]. Hablamos en castellano, actuamos en inglés, gustamos en francés y pensamos... pero, ¿es que nosotros pensamos?». ${ }^{2}$

En el espíritu de los martinfierristas existía una tendencia a estimar que el español de la Argentina no solo se distingue del español peninsular, sino que busca en esa distinción su renovación y expansión espiritual. Estos jóvenes no pueden dejar de hablar de una esperanza, a la que invocan a modo de enseña, de mascarón de proa. Ese idioma argentino en el que piensan, antes que una realidad léxica es una tarea (cuando no se percibe ya como una realidad) que se consumará en la reunión generosa de todas las lenguas que se conversan y leen en Buenos Aires; tarea que, a la vez, pretende reunir todos los intereses estéticos y filosóficos que pasean por Buenos Aires. No creo que prime en ellos un rechazo a España; prima el entusiasmo que les genera la realidad literaria de América. Como si estuvieran redimiendo el anhelo de los románticos, más que un no a lo español, los aviva un sí al cosmos que se asentó en Argentina, que en ellos se representa como una tierra de promisión.

En este mismo orden de preocupaciones, en junio de 1927, el matutino porteño Crítica, de Natalio Botana, inicia una encuesta bajo un díscolo y único título: «¿Llegaremos a tener un idioma propio?», a la que responden sucesivamente Enrique Larreta, José Antonio Saldías, Ricardo Rojas, Víctor Mercante, Last Reason (Máximo Sáenz), Roberto J. Payró, Félix Lima, Jorge Luis Borges, Manuel Gálvez, Enrique García Velloso, Arturo Costa Álvarez, Alberto Nin Frías, Arturo Cancela, Alberto Gerchunoff, José María Monner Sans y Florencio Garrigós (hijo). La formulación prospectiva de la pregunta parecería informar de cierta premisa de los editores, pues, en tanto idioma posible, se presume hasta el momento su inexistencia.

\footnotetext{
${ }^{1}$ Rojas Paz 1927.

${ }^{2}$ SCALABRINI ORTIZ1927.
} 
De todas estas respuestas — que pueden abreviarse entre quienes lo creen o no venidero, por un lado; y quienes lo abogan o combaten, por otro- es notable la respuesta de Borges, pues se trata del anticipo de lo que más tarde será su conferencia sobre el idioma de los argentinos. Borges cree comprender el derecho argentino de forjar un idioma propio, pero sabe que no basta con que el reclamo sea legítimo: «Jurídicamente, nadie nos quitará el derecho de tener un idioma propio: la cosa es tenerlo» ${ }^{1}$. No teme a la presencia de un idioma argentino y hasta lo desea; solo que ese idioma, aunque propio, nada tiene que ver con una jerga, con un dialecto, con un recorte del idioma español. Se trata, por el contrario, de un español amillonado y audaz; apto para la conversación distendida como para los sofisticados procedimientos retóricos; un español que sepa hablar lo local y lo americano, sin afectación; que no tema ahondar (y acertar) en temas de la filosofía, de la cosmología y de todas las ramas del arte. El idioma argentino que Borges predica tiene más de promesa que de actualidad; es más un deber que un deseo. Es esto lo que intenta decir cuando aclara que se trata del idioma profetizado y preconizado por Echeverría, por Alberdi, por Gutiérrez, por Sarmiento. Es este, a la vez, el mojón borgeano en la querella: reclamar un idioma nacional, pero para lograr un idioma superior.

Creo en el idioma argentino. Creo que es deber de cada escritor (nuestro y de todos) el aproximarlo. Para ese fin, nos basta considerar el español como una cosa apenas bosquejada y muy perfectible. Sintamos todos esa urgencia de innovación, sintámonos vivir en América y ya estará iniciada nuestra aventura. Digamos cosas que no le queden chicas a Buenos Aires y hablaremos idioma nuevo que será nuestro. ${ }^{2}$

VI. DE LA TESIS CONVERSACIONAL DE BORGES AL ÚlTIMO LIBRO DE Costa Álvarez (1928)

En su decimonovena sesión ordinaria, el 23 de septiembre de 1927, el Instituto Popular de Conferencias del diario La Prensa cedió su estrado a Jorge Luis Borges, que para entonces ya ostentaba cierta merecida fama por sus opiniones en temas linderos a los que ahora presentaba bajo el nombre de «El idioma de los argentinos». El texto principia declarando el estado actual de la querella:

\footnotetext{
${ }^{1}$ BORGES 1927a.

${ }^{2}$ Borges 1927a.
} 
Dos influencias antagónicas entre sí militan contra un habla argentina. Una es la de quienes imaginan que esa habla ya está prefigurada en el arrabalero de los sainetes; otra es la de los casticistas o españolados que creen en lo cabal del idioma y en la impiedad o inutilidad de su refacción. ${ }^{1}$

Esta dicotomía es asaz parcial, pues Borges sabe que existe otra dimensión del problema, menos lexical y más vasta, pero por ahora la calla, acaso porque algo de ella aflorará en la solución final que le asestará al problema. Presentar dos posiciones encontradas - la jergal arrabalera y la suntuosa que emana del lexicón español_ le sirve a Borges en su plan de señalarlas igualmente ineptas para el mentado idioma nacional. Una le parece caricatural y falaz; la otra, mendaz y fantasmagórica. Siendo ambas impostadas, a una la juzga pseudoplebeya; a la otra, pseudohispánica.

A diferencia de De Vedia, Cané, Quesada, Groussac y Costa Álvarez, a quienes menciona como embates definitivos contra el «dialecto chúcaro y receloso», Borges no siente escozor al decir «idioma argentino», ni teme al reunir ambos vocablos. Este idioma le resulta un hecho comprobable, cuya existencia - ajena tanto a lo jergal, como a lo purista - apela a la inquisición de una pasión conversada de la intimidad argentina. La expresión «idioma argentino» lo complace solo para investigar el palpitar de la patria, tono y énfasis de una expresión que, aunque distintiva, no es inhábil para ser entendida en cualquier parte de España.

Equidistante de sus copias, el no escrito idioma de los argentinos sigue diciéndonos, el de nuestra pasión, el de nuestra casa, el de la confianza, el de la conversada amistad. ${ }^{2}$

Sin llegar a ser un animismo, Borges encuentra una singularidad argentina en la voz coloquial, más precisamente en la confidencia. En este Borges de los años 20, más que un idioma argentino, existe una forma argentina de expresarse en español. Si en Quesada el idioma nacional es el castellano culto y escrito, en Borges está en la boca, no en el libro; es una intimidad más que una grafía; se intuye, no se lee; es de carácter emocional, no lingüístico. Si hay alguna distinción en el habla argentina - y para Borges sí la hay, de donde emana el fuero íntimo de la patria- solo puede ser oída.

\footnotetext{
${ }^{1}$ BORges 1927b.

${ }^{2}$ BORGES 1927b.
} 
Por entonces, devenido ya en filólogo americanista y polemista matrero, Vicente Rossi convierte sus esbozos idiomáticos en doctrina independentista. Asociado con un tal Almanzor Medina comienza a publicar los Folletos Lenguaraces, misceláneas reflexiones sobre la lengua y la lexicografía. Estos folletos - procurando demostrar la existencia de un idioma nacional rioplatense- aparecen como la antítesis de las Notas al castellano en la Argentina, de Ricardo Monner Sans. Donde estas excomulgan una voz local, poniendo en su lugar el equivalente castizo; aquellos deportan una voz peninsular, por hallarla ausente en el habla del Río de la Plata o mal definida. Pero no solo se opondrán a los consejos de Monner Sans, sino también a la Academia Española, a su Diccionario y al Instituto de Filología.

Los tres primeros folletos son meramente lexicográficos. El cuarto, ya en el año 1928, contiene una Introducción de carácter crítico, a cargo de Almanzor Medina, quien compondrá el quinto folleto, de enorme interés para la querella. Medina advierte que la idea de que en Argentina se habla mal es una especie de extorsión para que se hable una lengua extranjera: el castellano; «no tienen presente - agrega - que hablando mal se han formado todos los lenguajes humanos; que es inevitable hablar mal para llegar a hablar bien creando un idioma propio» ${ }^{1}$. Ese hablar mal, para Medina, no es hablar lunfardo, jerga a la que llama «clave de voces jitanocastellanas académicas», de uso en el hampa. Casi en los mismos términos en que lo formularon los románticos, infiere que es el pueblo quien, ajeno a diccionarios y academias, forma y sanciona su lengua nacional. Unido a Vicente Rossi en la cruzada contra los castellanistas y los meridianos, entonces, procurará refutar ante todo la concepción idiomática que Ricardo Rojas presenta en La restauración nacionalista; es decir, el dominio de la lengua castellana en la América hispana.

Contrario a Rossi y a Medina, el escritor Arturo Capdevila publicó, también en la década del 20, en el diario La Prensa, una serie de artículos vinculados estrechamente a la querella. Recién en 1928 se reúnen y publican todos bajo el título Babel y el castellano. Sus propósitos relevantes son cuatro: $1^{\circ}$, enunciar el orgullo que el autor siente por el castellano; $2^{\circ}$, demostrar que es el idioma que habla Argentina; $3^{\circ}$, vilipendiar el voseo, al que llama «mazacote», «gazapo», «ignominiosa fealdad», «viruela», «verdadera mancha del lenguaje argentino»; $4^{\circ}$, preanunciar el porvenir conquistador del idio-

\footnotetext{
${ }^{1}$ Medina 1928, 9.
} 
ma de Cervantes, que estima, no tardará en América en purificarse del todo.

Como la polémica estaba cumpliendo un siglo de vida, en diciembre de 1928, Arturo Costa Álvarez publica El castellano en la Argentina, destinado a poner punto final — juna vez más! — a la controversia sobre el idioma nacional. La empresa, aunque menos colérica, es similar a Nuestra lengua, y en cuanto a la querella ostenta una tesis bifronte: por un lado, repudiar el programa autonomista del idioma; enarbolando, por otro, el ideal romántico de la emancipación. Costa Álvarez estima que las publicaciones en relación a la lengua en Argentina se caracterizan por un anhelo de emancipación de las formas castellanas, aunque expresado en castellano. Esto nos habría hecho resbalar, induciéndonos a pensar que, si desnaturalizábamos nuestro castellano mediante aportaciones extranjeras y vulgarismos nacionales, llegaríamos con el tiempo a tener un idioma propio. Existiría, entonces, un anhelo de libertad en la causa del idioma, aunque mal conducido; $y$, a fuerza de localismos y extranjerismos, la lengua argentina no dejará de ser castellana. Lamenta, por esto, que en nuestros teóricos de la cuestión de la lengua no haya habido nunca estudio, sino «simplemente sentimiento...» El problema le resulta, por tanto, pasional; esto es, irracional.

Esta nueva publicación de Costa Álvarez insiste en que la causa del idioma nacional acabó a principios de siglo, siendo Nuestra lengua la obra que narra la derrota y sella un juicio definitivo en favor de la unidad del castellano. Esta cuestión, estima, no ha tenido durante los últimos veinte años sino valor histórico y anecdótico: «Al fin se ha reconocido que la cuestión del idioma privativo no es una cuestión de hecho sino de anhelo, y de anhelo extraviado» ${ }^{1}$. La observación reviste cierta curiosidad, pues hubiera convenido a Costa Álvarez que la causa del idioma nacional no hubiera caducado, para librar a su nuevo libro del absurdo de pelear contra un espectro. No son pocas las páginas que consagra a rematar al muerto, y son tan encendidas que cualquier lector pensaría que el muerto goza de muy buena salud. Cito, como ejemplo, el programa que, a su juicio, deberían proponerse las autoridades escolares:

Demostrar al maestro, con la exposición de nuestros antecedentes históricos, cómo hemos estado perdiendo el tiempo con la quimera de emanciparnos de nuestra lengua heredada mediante la creación de un idioma privativo; hacerle ver cuánto más patriótico, cuánto

\footnotetext{
${ }^{1}$ Costa Álvarez 1928, 19-20.
} 
más cómodo y cuánto más digno es abrazarnos al castellano como a cosa propia... ${ }^{1}$

¿Qué necesidad había de convencer a los maestros de que debían abandonar el fervor por una causa perdida? ¿Si el idioma nacional ya era historia y anécdota al componer Nuestra lengua, a qué viene a oponerse, seis años más tarde, El castellano en Argentina, contra qué lucha; o mejor dicho, a qué le teme ahora?

El segundo aspecto de estos ensayos, aquél que enarbola el ideal romántico de la emancipación, reviste mayor valor por lo siguiente. Todo el repudio de Costa Álvarez a las pretensiones autonomistas no le impidieron adscribir al ideal emancipador de la lengua en América, que sería, para él, tomar el dominio del diccionario y la gramática, no para hacer otros sobre la base de distinciones y localismos, sino sobre el principio de soberanía americana de la lengua. Dominar la lengua americana implicaría estudiarla y ejercerla libre del afán jergal del criollista, y libre de la rutina dogmática de la academia. Este ideal es el que encuentra en Echeverría, Alberdi, Gutiérrez, Sarmiento y López; y es, quizá, en lo que se diferencia este nuevo libro de su hermano mayor, Nuestra lengua, en retomar el programa emancipador de los románticos y encausarlo, no hacia un idioma nacional, sino hacia un diccionario y una gramática que nazcan de la entraña filológica americana.

\footnotetext{
${ }^{1}$ Costa Álvarez 1928, 61.
} 


\section{CONCLUSIONES}

Como he mencionado en la «Introducción», la formación identitaria de la Argentina se ha erigido, en buena medida, a partir de la querella en torno a la lengua que hablamos los argentinos. Esta querella consta de dos períodos: uno signado por la necesidad de adquirir una identidad cultural emancipada; otro urgido por resolver el problema idiomático desde su aspecto estrictamente gramatical y empírico. El primer período concibió la «cuestión de la lengua» como una querella de dimensión política; el segundo reclamó convertirla en un asunto científico, liberado del fragor controversial. Uno es eminentemente ontológico; el otro anheló ser eminentemente lingüístico. Uno fue disputa de nuestros políticos, publicistas y poetas; el otro fue informes y tratados de filólogos y lexicógrafos. Si para el primero son considerados héroes un Alberdi, un Gutiérrez, un Sarmiento; para el segundo lo son un Rufino J. Cuervo, un Rudolf Grossmann, un Amado Alonso.

De estos dos períodos solo se puede establecer sus orígenes; pues no concluyen aún, ni se anulan por completo. El segundo se agrega al primero y convive con él, aunque procure superarlo; el primero brega por no ser acallado, aunque a veces se encuentre hostigado y a punto de claudicar. No son bloques inexpugnables, ni carecen de fisuras y filtraciones.

El primero se inicia en 1828, con el ensayo de Juan Cruz Varela sobre «Literatura Nacional», y tiene sus motivos más característicos durante el siglo XIX. El segundo viene de la mano del siglo $\mathrm{XX}$, con Idioma nacional de los argentinos (1900), de Lucien Abeille, y sus estelas llegan hasta el día de hoy. Abeille puede considerarse una bisagra entre la vieja forma de estudiar las lenguas —ligada a la herencia del romanticismo y a la ciencia decimonónica-, y la nueva forma, de carácter ya lingüístico, que en España se desarrollaba en los albores del siglo XX y encuentra en Ramón Menéndez Pidal a su patriarca. Aunque Abeille no llega a pertenecer a esta escuela, se trata del primer intento de formar un programa filológico (con gramática y léxico incluidos) para el idioma argentino.

Estos dos períodos, no obstante, tuvieron como horizonte común dilucidar — ya sea desdeñándolo, ya sea enarbolándolo— el idioma nacional, el idioma patrio, la lengua argentina... modos alternativos 
con que se ha aludido siempre a un mismo problema: la cuestión de la lengua en Argentina.

He compuesto la presente tesis en torno a estas dos vertientes, que llegan, en la década de 1920, a su máxima expresión. Tomo como punto de partida el año 1828, porque es allí cuando aparecen los primeros artículos que estimo relevantes. Concluye en 1928, cien años más tarde, por ser el año más activo de la querella (cuatro libros de enorme relevancia se publican este año), luego del cual aminora, como si se tratara de la paz que deja tras de sí el último estampido de una extendida batalla. El alcance exacto de un siglo no redunda más que en una mera coincidencia cronológica.

La querella de la lengua en Argentina nace ligada al ideario de la emancipación política, la independencia cultural y la búsqueda de una expresión propia. A principios del siglo XX, con el avance de la lingüística moderna y la profesionalización de los saberes, se produce en ella un corrimiento, pierde poco a poco su carácter querellante y recibe el trato impersonal e indolente de las distintas disciplinas de la lengua. El científico se presenta como aquel que no discute, sino que demuestra, y en nombre de la pertinencia con que deben tratarse estos temas sugiere al político, al historiador, al literato y al poeta que se abstengan de expedirse sobre el tema. Hombres como Cuervo o Grossmann no se presentan como polemistas, sino como técnicos.

El siglo XX le sugiere al siglo XIX que se calle. La cuestión se retira del ámbito vasto de la cultura para confinarse al laboratorio y al aula de seminario; va del ámbito de los problemas nacionales, al de los departamentos y simposios. La pregunta por el idioma propio dejará de ser la pregunta por la identidad nacional, y pasará a ser la pregunta por el entramado interno de la lengua. Este proceso de compartimentación y desdramatización de los saberes se presenta como el tránsito del mal saber al buen saber, como un tránsito inevitable, necesario y final.

Triunfante el modelo no beligerante de abordar la lengua, la cuestión del idioma nacional comienza a menguar, pues su esencia radicaba, justamente, en su carácter polémico. En este nuevo planteo, un Alberdi o un Gutiérrez quedan desautorizados, no para hacer política o literatura, sino para hacer ciencia; la cuestión de la lengua ya es un botín de los expertos. La querella, antes unida a los anhelos de emancipación, queda en manos de los lingüistas. 
Concluida la avanzada de las ciencias del lenguaje sobre las voces no profesionalizadas, con la fundación del Instituto de Filología se inicia una nueva disputa, ahora en el interior de la propia comunidad científica. Las apreciaciones de Amado Alonso sobre otros colegas evidencia el hecho: «Nadie ha negado a Costa Álvarez el derecho, ni nadie le ha impedido el ejercicio de ser superficial y anticientífico» ${ }^{1}$. Nadie se lo ha negado, es verdad, porque han logrado que la voz de Costa Álvarez, con todos sus derechos intactos, pierda por completo el sentido de existir. Que hable, que hable..., dijo algún filólogo por ahí, nunca logrará un asiento en nuestro Instituto. Muerto Costa Álvarez, quizá en el doble sentido del término, Alonso iza su banderín de avanzada y escribe: «Verdad que a la llegada de filólogos extranjeros, aquel hombre se revolvía con el odio santo con que el curandero acoge a los primeros médicos» ${ }^{2}$.

Es muy probable que la obra de Menéndez Pidal supere en estima el valor a la de Costa Álvarez, pero esto tiene intersticios y remite a asuntos extralingüísticos. No es un proceso científico decretar la muerte completa de una obra. De hecho, el método infalible del doctor Castro tuvo sus peculiaridades.

El predominio de una de las fuerzas en pugna redunda en un nuevo golpe a la cuestión del idioma nacional. La querella, no obstante, no muere, pero decae. De Abeille no se sabe más nada, Xul Solar termina como personaje en una novela de Marechal, Rossi se hace gaucho matrero, los libros de Carriegos no se encuentran ni siquiera en Tandil, donde sus antiguos paisanos lo confunden con un poeta arrabalero de Buenos Aires.

Convertida la querella en un problema disciplinar, pierde interés general y gana la inquietud de camarilla: el diario le cierra sus páginas y se las abre la revista especializada; a ningún nuevo ex presidente se le ocurre pronunciarse frente a este problema; los abogados se mudan de pleito; los escritores opinan fugaz y tímidamente, presumiendo que la lengua ya no es asunto suyo.

III

Como expresé en la «Introducción», el concepto de idioma nacional designó, en Argentina, tanto una lengua privativa, como su contrario: la lengua común de todas las naciones de habla hispana; a menudo se empleó para referir una mera entonación rioplatense, a

${ }^{1}$ AlONSO 1929a, 140.

${ }^{2}$ Alonso 1929b, 175. 
menudo como sinónimo de gauchesco, lunfardo, cocoliche o cualquiera otra jerga; también fue una variante de castellano y de español, como lo usa Ricardo Rojas. Muchas de las diatribas contra el idioma argentino, entendido ahora como una lengua privativa, llevan por nombre esta misma forma o formas parecidas: «idioma nacional» (Vicente G. Quesada), «lengua nacional» (Miguel de Toro y Gisbert), «nuestra lengua» (Costa Álvarez), como si el esmero por refutar la existencia de algo no pudiera prescindir de que, al menos, ese algo tiene un nombre.

Creo que debemos llamar idioma nacional, por tanto, al pleito que en Argentina se dio en torno a esta misma expresión. Ya ligada a la independencia nacional, a una identidad espiritual, a una gramática distintiva o a una lengua de la conversación y la amistad, el idioma argentino ha sido una disputa; más que una morfología o un léxico, su naturaleza es la polémica. Aun si en Argentina se hubiera hablado siempre igual que en Madrid, la querella por la lengua no hubiera prescindido de los textos que hoy ostenta.

Excepto el insólito estudio de Lucien Abeille, nadie se atrevió a esbozar la gramática de este idioma; excepto los esfuerzos lenguaraces de Vicente Rossi por evidenciar un léxico rioplatense, nadie ha logrado convencer de un vocabulario exclusivo de los argentinos; excepto el sueño cósmico-lingüístico de Xul Solar, nadie se ha expresado en neocriollo. La explicación es sencilla: el idioma nacional es de carácter ético. Las pocas y naturales distinciones fonéticas y morfológicas han servido de telón de fondo, nunca han sido lo sustancial, aunque se haya intentado, a menudo, plantear lo sustancial por medio de ellas. Bajo la expresión idioma nacional, los polemistas argentinos intentaron llamar la atención sobre otro aspecto de su existencia. Idioma nacional es, por tanto, la metáfora de un pleito que remite a la constitución espiritual de esta nación.

De todas las querellas que tuvo Argentina - cuyos nombres han adoptado, a menudo, la forma de la antinomia: ciudad-campo, cosmopolitas-provincianos, unitarios-federales, americanismoespañolismo, europeísmo-criollismo, etcétera-, la querella de la lengua, con sus propias oposiciones, ha sido la más extendida en el tiempo, la que más voluntades ha congregado en torno suyo y la que ha atravesado a todas las demás.

\section{IV}

Si se comparara el español de la Argentina con el de España a lo largo de este siglo que he biografiado, lo que nos asombraría no es 
la disparidad, sino las semejanzas. De modo que si alguien, supongamos un italiano o un inglés, hubiera observado nuestra discusión sobre el idioma nacional creería, con razones, que ese idioma se trata más bien de una quimera; en esto Costa Álvarez tenía razón. La polémica que tuvimos los argentinos, la de la lengua, es en torno a una quimera. Esto en cuanto al objeto de la polémica, pero, en cuanto a la polémica en sí, al acto mismo de polemizar, ¿cuál sería la percepción? La polémica fue desplazando a la quimera al punto de ser más relevante que ella. No tuvimos un idioma nacional, pero tuvimos una disputa por él; o dicho de otro modo, nuestro idioma nacional fue la forma en que llamamos a una disputa. Nada de ella resulta baladí, si entrevemos en sus pliegues la discusión por una renovación cultural, la modelación de una identidad nacional, el anhelo de una expresión aún más vital que la ostentada a principios del siglo XIX.

En la construcción de la Argentina - no me refiero a una geografía, o a un Estado, sino a la construcción imaginaria de la nación- hemos dado con varias formas de su expresión más íntima; la del idioma fue la más publicada y la que más sedimentaciones ha generado en la constitución de la identidad. Nuestra singularidad, en todo caso, fue intentar constituirnos en torno a un pleito ficcional; como si hubiéramos puesto nuestras mejores energías en recuperar, lanza en mano y grito de malón, una isla que sospechábamos sumergida, que jamás hemos visto, pero que nos resultaba imprescindible.

¿Fue la invención de esta quimera un ejercicio ocioso? Ciertamente que no. Buscando una singularidad se dio con una singularidad, solo que de forma distinta. Pretendimos una marca identitaria en la lengua, pero, al cabo de advertir que no dejábamos de hablar español, nuestra marca se iba confinando a la pretensión. ¿'Tuvo esta quimera un basamento gramatical? Ciertamente, y basta para ello presentar, entre otras particularidades, el voseo. Pero ni un vos, ni un che, ni mil voces paganas hacen una lengua. Cualquier ciudad populosa podría, con más elementos, pedir una para sí; sin embargo no la piden y he ahí la distinción. Excepto Buenos Aires, ninguna otra ciudad americana de habla hispana extendió un pleito hasta estas dimensiones. ¿Qué se buscaba? Nos lo dijo al oído un vasco que hablaba español: queríamos ser oídos. Queríamos hablar español, pero que esa lengua nos hablara, nos dijera cosas nuestras, nos conmoviera. No queríamos una lengua prestada.

¿Éramos conscientes los argentinos que estábamos discutiendo la existencia de una entelequia? Algunos sí, otros no, no importa; 
esto no era lo relevante, lo relevante era que discutíamos, y en la discusión íbamos dando con la talla de nuestra expresión propia. Un enorme esfuerzo hicieron Quesada, Groussac, Alonso y tantos otros en demostrar que no había tal idioma argentino. Y triunfaron una y mil veces, y hasta hubiera bastado con páginas más simples y austeras para lograrlo, solo que derribaban al fantasma equivocado, al que andaba desvalido y sin culpa. El otro espectro, algo más inasible y vital, mudaba de un lugar a otro y se alimentaba de sus verdugos para subsistir, crecer y expandirse. El alimento del idioma nacional fue las saetas que sistemáticamente le endilgaron.

Así, nuestro idioma nacional no fue tanto una disposición del habla, cuanto una predisposición a confrontar las preferencias del habla. Del mismo modo que no fue lo que alguien pudo haber dicho de él, sino la sumatoria de cosas que se dijeron. No bastaría un texto inobjetable para postular su existencia; bastó el sin fin de intervenciones que lo modelaron.

A menudo, cuando se pedía una lengua propia, no se trataba de una lengua distinta, sino propia, es decir, que se la pudiera esgrimir sin pedir permiso, ni tener que preguntar a otra ciudad si se la estaba empleando con elegancia. Una lengua propia remitía a apropiarse de la lengua, a permitir que se asimilara a la nueva tierra, al nuevo temperamento y tono de quienes la empuñaran. ¿No era, acaso, nuestra lengua materna? No se trataba de buscarle otro nombre, sino de que, al llamarla, resonara también en sus entrañas el carácter americano y argentino. El pleito por el nombre, como aquel que remitió a una singularidad gramatical, no fue sino un modo de exhortar a la lengua para que se hendiera, para que entrara en su seno la variedad que la constituía de hecho. Todas las intervenciones, desafortunadas u oportunas, deben ser repensadas a partir de este clamor. Cada vez que España objetó una voz argentina, el brío autonomista se hinchó.

Ahora bien, ¿es el argentino el único que querelló sobre la lengua? Acaso no haya país del mundo que no haya imaginado, aunque sea una vez, un idioma privativo para sus paisanos. La singularidad argentina es haber hecho de esta querella un énfasis, una duración, una objeción permanente; haberla convertido en una cuestión de Estado. No hay rasgo distintivo en este país que no haya remitido a la pregunta: «¿cómo decirlo?» La Argentina no es ninguna raza ni nacionalidad —ha dicho en algún lugar Osvaldo Lamborghini-, sino puro estilo y lengua. Esta tesis, que aquí concluyo, ha nacido impregnada de esa convicción. 


\section{BIBLIOGRAFÍA}

ABEILLE, Luciano

1900 Idioma nacional de los argentinos. Con una introducción del Dr. Louis Duvau. Paris, Libraire Ėmile Bouillon.

1901 Idioma nacional de los argentinos: Antinomia lingüistica insoluble. Conferencia dada en los salones del Círculo Militar, el 26 de noviembre de 1900. Buenos Aires, Local del Círculo Militar.

AlBERDI, Juan Bautista

1837 Fragmento preliminar al estudio del derecho acompañado por una serie numerosa de consideraciones formando una especie de programa de los trabajos futuros de la inteligencia argentina. Buenos Aires, Imprenta de la Libertad, julio. A partir de AlBERDi, J. B., Obras Selectas. Nueva edición ordenada, revisada y precedida de una introducción por el doctor Joaquín V. González. Tomo VIII. Escritos Jurídicos. Volumen $1^{\circ}$. Buenos Aires, Librería «La Facultad» de Juan Roldán, 1920.

1838a «Álbum alfabético», en La Moda. Buenos Aires, 17 y 31 de marzo. Citado a partir de la versión que consta en AlBERDi 1986, 199-211.

1838b «Emancipación de la lengua», en El iniciador. Montevideo, 1 de septiembre. Citado a partir de la versión que consta en ALBERDI 1986, 224-231.

1838c «Enseñanza del idioma», en El iniciador. Montevideo, 15 de noviembre. Citado a partir de la versión que consta en ALBERDi 1986, 218-223.

1871 «De los destinos de la lengua castellana en la América antes española». Fechada en Londres, marzo de 1871. Se publica por primera vez en AlBERDI, Juan Bautista (1898) Escritos póstumos, Tomo VI: Ensayos sobre la sociedad, los hombres y las cosas de Sud-América. Buenos Aires, Manuel Alberdi, Imp. Alberto Monkes, pp. 165-180.

1876 «Evolución de la lengua española». Fechado en París, febrero de 1876. Citado a partir de ALBERDI, Juan Bautista (1898) Escritos póstumos, Tomo VI: Ensayos sobre la sociedad, los hombres y las cosas de Sud-América. Buenos Aires, Manuel Alberdi, Imp. Alberto Monkes, pp. 181-210.

1900 «Mi vida privada...» XI, en Escritos póstumos, Tomo XV: Memorias y documentos. Buenos Aires, Francisco Cruz, pp. 294-296.

1986 Escritos satíricos y de crítica literaria. Prólogo y notas de José A. Oria. Buenos Aires, Academia Argentina de Letras. («Figarillo»)

Alonso, Amado

1927 «Lingüística espiritualista», en Síntesis. Artes, ciencias y letras, Año I, No 8. Buenos Aires, diciembre, pp. 227-236.

1929a «La filología del Sr. Costa Álvarez y la filología», en Sintesis. Artes, ciencias y letras. Año II, No 23. Buenos Aires, abril, pp. 125-141.

1929b «Sobre el difunto Costa Álvarez», en Sintesis. Artes, ciencias y letras. Año III, No 26. Buenos Aires, julio, pp. 175-178. 
ARgERICH, Juan Antonio

1889a «Por la negativa. La sucursal de la Academia» (Carta a Rafael Obligado), en La Nación. Buenos Aires, 6 de agosto, p. 1.

1889b «El entierro de la sucursal» (Carta a Rafael Obligado), en La Nación. Buenos Aires, 14 de agosto, p. 1.

ASOCIACIÓN DE ESCRITORES Y ARTISTAS ESPAÑOLES

1892 IV Centenario del Descubrimiento de América. Congreso Literario HispanoAmericano organizado por la Asociación de escritores y artistas españoles e iniciado por su presidente el Excm. Sr. D. Gaspar Núñez de Arce. 31 de octubre a 10 de noviembre de 1892. Madrid, Establecimiento tipográfico de Ricardo Fe, 1893.

AyAla, Francisco

1927 «Madrid = España. 3 Raids literarios. Guillermo de Torre.», en La Gaceta Literaria, ibérica, americana, internacional. Letras, artes, ciencia. Periódico quincenal (1 y 15 de cada mes). Año I, Número 16. Madrid, 15 de agosto, p. 1.

BALCARCE, Florencio

1837 «Carta de Florencio G. Balcarce a Félix Frías», fechada en París, el 29 de octubre de 1837. Citado a partir de la versión publicada en ECHEVERRÍA 1940, 294-298.

BATTISTESSA, Ángel J.

1926 «Nuestro Boletín», en Boletín del Instituto de Filología. Tomo I, N¹-2. Buenos Aires, Universidad de Buenos Aires, Facultad de Filosofía y Letras, enero-junio.

BAYO, Ciro

1906 «Vocabulario de provincialismos argentinos y bolivianos» («Prólogo»), en Revue Hispanique. Recueil consacré à l'étude des langues, littéraures et de l'bistoire des pays castillans, catalans et portugais, ririgé par $\mathrm{R}$. Foulché-Delbosc, Tome XIV. New York, The Hispanic Society of America; Paris, Librairie C. Klincksieck, pp. 241-249.

1910 «Prólogo» en Vocabulario criollo-español sud-americano. Madrid, Librería de los sucesores de Hernando, pp. 5-7.

BELLO, Andrés

1842 «Ejercicios populares de la lengua castellana», en Mercurio. Valparaíso, 12 mayo. Citado a partir de SARMIENTO 1887, 249-257. (Un quídam) 
1847 «Prólogo» a la Gramática de la lengua castellana, destinada al uso de los americanos. Santiago de Chile, Imprenta de El Progreso, Plaza de la Independencia, No 9, abril. Citado a partir de BELLO, Andrés (1951) Obras completas, Tomo IV: Gramática. Prólogo de Amado Alonso. Caracas, Venezuela, Ediciones del Ministerio de Educación.

1848 «Biblioteca de autores clásicos españoles» en El Araucano, No 948. Santiago, 6 de octubre. Citado a partir de BELlo, Andrés (1956) Obras completas de Andrés Bello, Tomo IX: Temas de crítica literaria. Caracas, Venezuela, Ministerio de Educación, pp. 738-740.

BELLO, Andrés y GARCía DEL Río, Juan

1823 «Indicaciones sobre la conveniencia de simplificar i uniformar la ortografía en América», en La biblioteca americana, o miscelánea de literatura, artes $i$ ciencias. Tomo I. Londres, pp. 50-66. El texto se reedita, modificando apenas su redacción, en El Repertorio Americano, Tomo I. Londres, octubre de 1826, pp. 27-41.

BERNÁRDEZ, Francisco Luis

1925 «El futuro idioma argentino», en Martín Fierro. Periódico quincenal de arte y crítica libre. Segunda Época, Año II, No 16. Buenos Aires, 5 de mayo, pp. $4-5$.

BERrA, Francisco Antonio

1876a «La lengua castellana» (Artículo Comunicado - Carta al director de La Nación), en La Nación. Buenos Aires, 14 de enero, p. 1.

1876b «La lengua castellana» (Artículo Comunicado), en La Nación. Buenos Aires, 25 de enero, p. 1.

1876c «La lengua castellana» (Artículo Comunicado), en La Nación. Buenos Aires, 4 de febrero, p. 1.

BLOMMAERT, Jan (ed.)

1999 Language Ideological Debates. Berlin, New York, Mouton de Gruyter.

BOnesatTI, Tobías

1928 «Lápiz y margen», en Nosotros. Revista mensual de letras, arte, historia, filosofia y ciencias sociales. Año XXII, Tomo LIX, No 225/226. Buenos Aires, febrero-marzo, pp. 246-248.

BORGES, Jorge Luis

1927a «Un llamado a la realidad. ¿Madrid, meridiano intelectual de Hispano América? Sobre el meridiano de una gaceta.», en Martín Fierro. Periódico quincenal de arte y crítica libre. Número doble, Año IV, $\mathrm{N}^{\circ} 42$. Buenos Aires, 10 de junio - 10 de julio, p. 7. 
1927b (Respuesta a la Encuesta de Crítica: «iLlegaremos a tener un idioma propio?»), en Crítica. Buenos Aires, 19 de junio.

1927c «El idioma de los argentinos», en La Prensa. Buenos Aires, 24 de septiembre. Citado a partir de BORGES 1928a.

1928a El idioma de los argentinos. Ilustraciones de Xul Solar. Buenos Aires, Seix Barral-Biblioteca Breve, diciembre de 1994.

1928b «Sobre pronunciación argentina», en Nosotros. Revista mensual de letras, arte, historia, filosofía y ciencias sociales. Año XXII, Volumen LX, No 227. Buenos Aires, abril, p. 152.

1928c «Idioma Nacional Ríoplatense, por Vicente Rossi (Folletos lenguaraces, 6)», en Síntesis, Año 2, No 18. Buenos Aires, noviembre, p. 361.

1941 «Américo Castro: La peculiaridad lingüistica rioplatense y su sentido bistórico», en Sur. Revista mensual publicada bajo la dirección de Victoria Ocampo, Año $\mathrm{X}, \mathrm{N}^{\circ}$ 86. Buenos Aires, noviembre, pp. 66-70.

CANÉ, Miguel

1876 «Un nuevo libro del Dr. Gutiérrez», en GuTIÉRREZ 1918.

1900 «La cuestión del idioma», en La Nación. Buenos Aires, 5 de octubre. Citado a partir de CANÉ 1903, 61-70.

1902 «El criollismo», carta abierta al Dr. Ernesto Quesada, en La Nación. Buenos Aires, 11 de octubre.

1903 Prosa ligera. Con una introducción de Martín García Mérou. Buenos Aires, La cultura argentina, 1919.

Capdevila, Arturo

1928 Babel y el castellano. Prólogo de Miguel de Unamuno. Buenos Aires, Losada, 1940.

CARBALLIDO, Juan

1891a «Plan de estudios y programas. Circular. Ministerio de Instrucción Pública.» (A los señores rectores de colegios nacionales), en La Nación. Buenos Aires, 21 de abril, p. 1. Paul Groussac se atribuye la redacción de esta circular. Cf. GROUSSAC 1900, 413.

$1891 \mathrm{~b}$ «Plan de estudios y programas. Circular. Ministerio de Instrucción Pública.» (A los señores rectores de colegios nacionales), en La Nación. Buenos Aires, 22 de abril, p. 1. Paul Groussac se atribuye la redacción de esta circular. Cf. GrousSAC 1900, 413.

CARriegos, Ramón C.

1928 «El casticismo en la Argentina», en El porvenir del idioma español en la República Argentina. Frases i palabras criollas. Tandil F. C. S., El Imparcial, pp. 15-27.

Castro, Américo 
1924a «¿Dialecto argentino? I», en La Nación. Buenos Aires, 20 de abril.

1924b «Sobre dialecto argentino. II», en La Nación. Buenos Aires, 30 de abril.

1927a «En torno al posible idioma argentino», en La Nación. Buenos Aires, 18 de septiembre.

1927 «Un libro alemán sobre argentinismos», en La Nación. Buenos Aires, 6 de noviembre.

CORREa LunA, Carlos

1902 «La cuestión del criollismo», en Caras y Caretas. Semanario festivo, literario, artístico y de actualidades. Año V, $\mathrm{N}^{\circ} 213$. Buenos Aires, 1 de noviembre, p. 38 .

CORTÁZAR, Julio

1949 «Leopoldo Marechal: Adán Buenosayres», en revista Realidad. No 14. Buenos Aires, marzo-abril. Citado a partir de CORTÁzAR, Julio (1994) Obra crítica / 2, Edición de Jaime Alazraki. Madrid, Alfaguara, pp. 167176.

\section{Costa Álvarez, Arturo}

1922 Nuestra lengua. Buenos Aires, Sociedad Editorial Argentina, noviembre.

1924 «El estudioso argentino y el catedrático importado, ante la autoridad universitaria» en Valoraciones. Revista Bimestral de Humanidades, Crítica y Polémica. Órgano del Grupo de Estudiantes Renovación de La Plata. Año I, No II. La Plata, enero, pp. 137-149.

1925 «La mala suerte del Instituto de Filología» en Valoraciones. Revista Bimestral de Humanidades, Crítica y Polémica. Órgano del Grupo de Estudiantes Renovación de La Plata. No 8. La Plata, noviembre, pp. 108-115.

1927 «El castellano en la Argentina», en Nosotros. Revista mensual de letras, arte, historia, filosofía y ciencias sociales. Número Aniversario. Año XXI, Tomo LVII, No 219-220. Buenos Aires, agosto-septiembre, pp. 189-219.

1928a «Rudolf Grossmann: Das ausländische Sprachgut im Spanishcen des Río de la Plata. Ein Beitrag zum Problem der argentinischen Nationalsprache», en Valoraciones. Revista Bimestral de Humanidades, Crítica y Polémica. Órgano del Grupo de Estudiantes Renovación de La Plata. No 12. La Plata, mayo, pp. 241-244.

1928b El castellano en la Argentina. La Plata, Talleres de la Escuela San Vicente de Paúl, diciembre.

Cuervo, Rufino José

1885 Apuntaciones críticas sobre el lenguaje bogotano. Cuarta edición notablemente aumentada. Chartres, Imprenta de Duran.

1899 «Señor D. Francisco Soto y Calvo», en Nastasio. Chartres, Imprenta de Durand, pp. VII-X.

1901 «El castellano en América», en Bulletin Hispanique, Tome III. Vol. III, $\mathrm{N}^{\circ} 1$. Bordeaux, Feret \& fils, éditeurs, janvier-mars, pp. 35-62. 
1903 «El castellano en América», en Bulletin Hispanique, Tome V, Nº1. Bordeaux, Feret \& fils, éditeurs, janvier-mars, pp. 58-77.

1904 «Prólogo», en GaGINI, Carlos (1919) Diccionario de costarriqueñismos. Segunda edición. San José de Costa Rica, pp. 11-35. Está fechado en París, abril de 1904.

1947 El castellano en América. Precedido de un estudio sobre Rufino José Cuervo por Rodolfo M. Ragucci. Buenos Aires, El Ateneo.

DARNET, Ana Julia

1926 «La buena suerte del Instituto de Filología» en Valoraciones. Revista Bimestral de Humanidades, Crítica y Polémica. Órgano del Grupo de Estudiantes Renovación de La Plata. Nº 9. La Plata, marzo, pp. 263-267.

Del Valle, José and Gabriel-Stheeman, Luis (eds.)

2002 The Battle over Spanish between 1800 and 2000. Language ideologies and Hispanic intellectuals. London and New York, Routledge. Hay una versión en español Del VAlle, José y GABRIEL-STHEeman, Luis (eds.) (2002) La batalla del idioma: La intelectualidad hispánica ante la lengua. Madrid-Frankfurt, Iberoamericana-Vervuert, 2004.

DíAz SALAZAR, Diego (Miguel Toledano)

1911 «Justificación», en Vocabulario argentino. Neologismos, refranes, frases familiares, etc. usados en la Argentina. Buenos Aires-Barcelona, Editorial Hispano-Argentina, pp. 7-15.

Di Tullio, Ángela Lucía

2003 Políticas lingüisticas e inmigración. El caso argentino. Buenos Aires, Eudeba.

DUVAU, Louis

1899 «Monsieur et cher Confrère», en ABEILLE, Luciano (1900) Idioma nacional de los argentinos. Paris, Libraire Ėmile Bouillon, pp. XVII-XXIV.

ECHEVERRÍA, Esteban

1834 Los consuelos. Buenos Aires, Imprenta Argentina.

1837 Rimas de Esteban Echeverría. Buenos Aires, Imprenta Argentina.

1846 Dogma Socialista de la Asociación de Mayo, precedido de una ojeada retrospectiva sobre el movimiento intelectual en el Plata desde 1837. Montevideo, Imprenta del Nacional. Citado a partir de ECHEVERRía 1940.

1874 Obras completas de D. Esteban Echeverría. Tomo V. Con notas y explicaciones por don Juan María Gutiérrez. Buenos Aires, Edición Carlos Casavalle.

1940 Dogma Socialista. Edición crítica y documentada. Prólogo de Alberto Palcos. La Plata, Universidad Nacional de La Plata (Biblioteca de Au- 
tores Nacionales y Extranjeros referente a la República Argentina, Volumen II).

ENNIS, Juan

2008 Decir la lengua. Debates ideológico-lingüisticos en la Argentina desde 1837. Sprache, Identität, Kultur. Band 2. Internationaler Verlag der Wissenschaften, Peter Lang, Frankfurt.

EsPINOSA, Aurelio M.

1927 «Das ausländische Sprachgut im Spanishcen des Río de la Plata, by Rudolph Grossman», en Language. Volumen 3, No 1. Linguistic Society of America, marzo, pp. 20-25.

ESTRADA, Carlos A.

1902 «Carta al Dr. Ernesto Quesada», en El Tiempo. Buenos Aires, 21 de octubre. Citado a partir de RUBIONE 1983, 239-242.

EsTUdios (Adolfo Casabal y Tristán Achaval Rodríguez)

1903 «Notas de actualidad», en Estudios, Año II, Tomo IV. Buenos Aires, Imprenta y Casa Editora de Coni Hermanos, pp. 238-239; 340-341; 352-356.

GANDUGLIA, Santiago

1927 «Un llamado a la realidad. ¿Madrid, meridiano intelectual de Hispano América? Buenos Aires, metrópoli», en Martín Fierro. Periódico quincenal de arte y crítica libre. Número doble, Año IV, No 42. Buenos Aires, 10 de junio - 10 de julio, p. 7.

GARZÓN, Tobías

1910 «Introducción», en Diccionario argentino ilustrado con numerosos textos. Publicado bajo los auspicios de la Comisión Nacional del Centenario de la Revolución de Mayo y de la Universidad Nacional de Córdoba (República Argentina). Barcelona, Imprenta Elzeviriana de Borrás y Mestre, pp. V-XI.

GirONDO, Oliverio

1924 «Carta abierta a "La Púa"», en Martín Fierro. Periódico quincenal de arte y crítica libre. Segunda Época, Año 1, No 2. Buenos Aires, 20 de marzo, pp. 4-5.

GONZÁLEZ, Joaquín V. 
1900 «La escuela nacional», en Patria, Capítulo V. Buenos Aires, Félix Lajouane, pp. 57-72.

Grossmann, Rudolf

1926 Das ausländische Sprachgut im Spanischen des Río de la Plata. Ein Beitrag zum Problem der argentinischen Nationalsprache. En Mitteilungen und Abhandlungen aus dem Gebiet der romanischen Philologie. Publicado por el Seminar für romanische Sprachen und Kultur. Tomo VIII. Hamburgo. VI + 224 páginas. Citado a partir de GrossmanN 2008 [1926].

1969 Geschichte und Probleme der Lateinamerikanischen Literatur. München, Max Hueber Verlag. Hay traducción al español: Grossmann, Rudolf (1969) Historia y problemas de la literatura latinoamericana. Traducción de Juan C. Probst. Madrid, Ediciones de la Revista de Occidente, 1972.

2008 El patrimonio lingüistico extranjero en el español del Río de la Plata. Estudio

[1926] preliminar de Fernando Alfón. Traducción y notas de Juan Ennis. Colección Los Raros, No 20. Buenos Aires, Biblioteca Nacional, diciembre.

GrossmanN, Rudolf y SLABÝ, Rudolf J.

1932 Diccionario de las lenguas española y alemana. Wörterbuch der spanischen und deutschen Sprache. I. Español-Alemán. Spanisch-Deutsche. Leipzig, Bernhard Tauchnitz.

1937 Diccionario de las lenguas española y alemana. Wörterbuch der spanischen und deutschen Sprache. II. Alemán-Español. Deutsche-Spanisch. Leipzig, Bernhard Tauchnitz.

Groussac, Paul

1882 «Ensayo histórico sobre el Tucumán», en Memoria histórica y descriptiva de la Provincia de Tucumán. Primera Parte. Historia, 1400-1870. Buenos Aires, Imprenta de M. Biedma, pp. 1-254.

1897 Del Plata al Niágara. Buenos Aires, Administración de la Biblioteca.

1900 «A propósito de americanismos», en Anales de la Biblioteca. Publicación de documentos relativos al Río de la Plata con introducciones y notas de P. Groussac, director de la Biblioteca Nacional. Tomo I. Buenos Aires, Imprenta y Casa Editora de Coni Hermanos, pp. 385-417.

1923 «Prefacio» a La divisa punzó. Buenos Aires, Jesús Menéndez e hijo, 21 de septiembre, pp. IX-XXIII.

GRÜNBERG, Carlos M.

1924 «Un gramático», en Martín Fierro. Periódico quincenal de arte y crítica libre. Segunda Época, Año I, No 3. Buenos Aires, 15 de abril, pp. 5-8.

GUTIÉRREZ, Juan María

1837 «Fisonomía del saber español: cuál deba ser entre nosotros», en Diario 
de la Tarde, $\mathrm{N}^{\circ}$ 1813. Buenos Aires, 14 de julio, pp. I-II. Citado a partir de WeInBerg, Félix (1958) El salón literario de 1837. Con escritos de M. Sastre - J. B. Alberdi - J. M. Gutiérrez - E. Echeverría. Colección «El pasado argentino», dirigida por Gregorio Weinberg. Buenos Aires, Hachette, 1977, pp. 145-157.

1871 Estudio sobre las obras y la persona del literato y publicista argentino D. Juan Cruz Varela. Buenos Aires, Imprenta y Litografía de Mayo.

1876a «Carta al señor secretario de la Academia Española», en La Libertad. Buenos Aires, 5 de enero. Citado a partir de GUTIÉRREZ 2003, 67-74.

1876b «Carta Primera», en La Libertad. Buenos Aires, 22 de enero. Citado a partir de GuTIÉRREZ 2003, 89-98.

1876c «Carta Segunda», en La Libertad. Buenos Aires, 23 de enero. Citado a partir de GuTiÉRREZ 2003, 99-105.

1876d «Carta Sexta», en La Libertad. Buenos Aires, 28 de enero. Citado a partir de GuTIÉRREZ 2003, 125-130.

1876e «Carta Décima», en La Libertad. Buenos Aires, 6 de febrero. Citado a partir de GuTIÉRREZ 2003, 169-182.

1876f [Se trata de una carta privada enviada a un amigo de Chile, fechada el 6 de marzo de 1876]. La publica Benjamín Vicuña Mackenna en Chile. Relaciones Históricas. Colección de articulos i tradiciones sobre asuntos nacionales, $2^{a}$ serie. Santiago de Chile, Rafael Jover, 1878, p. 976.

1918 Juan Cruz. Varela. Su vida. Sus obras. Su época. Buenos Aires, Casa Vaccaro, La Cultura Argentina.

1942 Cartas de un porteño. Polémica en torno al idioma y a la Real Academia Española, sostenida con Juan Martínez Villergas, seguida de "Sarmienticidio". Prólogo y notas de Ernesto Morales. Buenos Aires, Editorial Americana.

2003 Cartas de un porteño. Polémicas en torno al idioma y a la Real Academia Española. Colección Nueva Dimensión Argentina. Dirigida por Gregorio Weinberg. Estudio preliminar de Jorge Myers. Buenos Aires, Taurus.

HenríQuez Ureña, Pedro

1925 «Caminos de nuestra historia literaria», en Valoraciones. Revista Bimestral de Humanidades, Crítica y Polémica. Órgano del Grupo de Estudiantes Renovación de La Plata. No 6. La Plata, junio, pp. 246-252.

1926 «El descontento y la promesa» (Conferencia pronunciada en la Asociación Amigos del Arte, de Buenos Aires, el 28 de agosto de 1926) en La Nación. Buenos Aires, 29 de agosto. Citado a partir de HenríqueZ UREÑA [1928] 11-35.

[1928] Seis ensayos en busca de nuestra expresión. Buenos Aires - Madrid, Babel (Biblioteca Argentina de Buenas Ediciones Literarias).

HERNÁNDEZ, José

1879 La vuelta de Martín Fierro. Buenos Aires, Librería del Plata.

HERrero Mayor, Avelino

1927 «El vínculo del idioma», en La Nación. Buenos Aires, 21 de octubre. 
1923 «El dialecto argentino», en La Nación. Buenos Aires, 11 de noviembre. Arturo Costa Álvarez anota al margen de un recorte de este editorial: «Supe accidentalmente, el 14 de diciembre de 1928, por Julio Piquet mismo, que este suelto había sido obra suya». Cf. Sala Arturo Costa Álvarez (SACA) $140-25$, en la Biblioteca Pública de la Universidad Nacional de La Plata.

1925 «Se ha planeado una importante obra filológica. Habla el Dr. Montoliu», en La Nación. Buenos Aires, 4 de mayo.

1927 «El vínculo del idioma», en La Nación. Buenos Aires, 17 de octubre, p. 4.

LABOV, William

2001 Principles of linguistic change II. Social factors, Cambridge-Oxford, Blackwell.

LARRA, Mariano José de

1828 «Donde las dan las toman», en El Duende Satírico del Día. Cuaderno Quinto. Madrid, Imprenta de D. L. Amarita, 31 de diciembre. Citado a partir de la edición Obras de D Mariano José de Larra (Fígaro). Edición y estudio preliminar de Carlos Seco Serrano. Biblioteca de autores españoles. Tomo 127. Volumen 1. Madrid, Ediciones Atlas, 1960.

1835 «El álbum», en La Revista Española... Mensajero de las Cortes, Nº 64, 3 de mayo, «Boletín del 3 de mayo. Costumbres». Firmado: «Fígaro». Citado a partir de LARRA 1997.

1836 «Literatura», en El Español, N $\mathrm{N}^{\circ}$ 79, 18 de enero. Firma con el pseudónimo Figaro. Citado a partir de LARRA 1997.

1997 Figaro. Colección de artículos dramáticos, literarios, políticos y de costumbre. Edición de Alejandro Pérez Vidal. Biblioteca clásica 92. Barcelona, Crítica.

LENZ, Rodolfo

1893 «Nacionalidad y lenguaje», en Revista Nacional. Segunda Serie, Año Sexto, Tomo XVII. Buenos Aires, Entrega de $1^{\circ}$ de enero, pp. 35-47.

1894 Ensayos filológicos americanos. I: Introducción al estudio del lenguaje vulgar de Chile, en Anales de la Universidad, Tomo 87. Santiago de Chile, Imprenta Cervantes, pp. 113-132. Sigo la edición que hace la misma imprenta, el mismo año, en forma de folleto. 15 páginas.

1899 Memoria sobre las tendencias de la enseñanza del idioma patrio en Chile, Imprenta Cervantes.

LEÓN SUÁREZ, José

1927 «El vínculo del idioma», en La Nación. Buenos Aires, 20 de octubre. 
LiNARES, Ramón C.

1902 «Idiomas», carta al Sr. Profesor Abeille, en El País. Buenos Aires, 1 de noviembre.

LÓPEZ, Vicente Fidel

1800 «Introducción», en CALANDrelLI, Matías (1880) Diccionario FilológicoComparado de la Lengua Castellana. Precedido de una introducción del Dr. Don Vicente Fidel López. Volumen 1. Buenos Aires, Imprenta de «Obras clásicas», pp. V-XXIX.

1883 «Geografía histórica del territorio argentino», en Historia de la República Argentina. Su origen, su revolución y su desarrollo politico basta 1852. Tomo I, Capítulo VI. Buenos Aires, C. Casavalle.

LORENZO, Tirso

1927 «Los nuevos horizontes del idioma», en La Nación. Buenos Aires, 13 de noviembre.

LUGONES, Leopoldo

1910 «Castellano, Idiomas Extranjeros y Matemáticas», en Didáctica, Capítulo XIII. Buenos Aires, Otero y Cía., pp. 246-265.

1916 El payador. Hijo de la pampa. Tomo primero [único]. Capítulo VI. Buenos Aires, Otero \& Co. Impresores, julio.

1924 "Algo respecto a "indianismos"», en La Nación. Buenos Aires, 1 de mayo.

MANSILLA, Lucio V.

1889 «Académicos de número, honorarios, correspondientes y electos», en Entre-nos. Causeries del jueves. Libro IV. Buenos Aires, Casa Editora de Juan A. Alsina. Citado a partir de Mansilla, Lucio V., Entre-nos (Causeries del jueves) II. Grandes Escritores Argentinos. Tomo XXXIII. Director: Alberto Palcos. Buenos Aires, El Ateneo, 1930, pp. 56-68.

MARECHAL, Leopoldo

1948 Adán Buenosayres, en Obras completas, Tomo III. Las novelas. Buenos Aires, Perfil Libros, 1998, p. 119.

MARTÍ, José

1889 «Tipos y costumbres bonaerenses, por Juan A. Piaggio», en El Partido Liberal. México, 3 de octubre. Citado a partir de MARTí, José (1948) Obras Completas. Edición popular, conmemorativa del Cincuentenario de su muerte. Prólogo y Síntesis biográfica por M. Isidro Méndez. Volumen II. Tomo I: Hispanoamericanos - Nuestra América - Escenas Mexicanas - 
Escenas Europeas. La Habana, Cuba, Editorial Lex, pp. 359-364.

MARTíNEZ VILLERGAS, Juan

1876a «Amor con amor se paga I», en Antón Perulero. Periódico satírico de política y literatura. Año I, No 7. Buenos Aires, jueves 13 de enero, pp. 1 y 4. Citado a partir de GuTIÉRREZ 2003, 75-79.

1876b «Amor con amor se paga II», en Antón Perulero. Periódico satírico de política y literatura. Año I, No 8. Buenos Aires, jueves 20 de enero, pp. 1 y 4. Citado a partir de GuTIÉRREZ 2003, 80-84.

1876c «Amor con amor se paga III», en Antón Perulero. Periódico satírico de política y literatura. Año I, No 9. Buenos Aires, jueves 27 de enero, p. 1. Citado a partir de GuTIÉRREZ 2003, 85-88.

MEDinA, Almanzor

1928 Las falsas papilas de «La lengua». (Folletos Lenguaraces, 5). Río de la Plata, Imprenta Argentina.

MENÉNDEZ PIDAL, Ramón

1918 «La lengua española», carta a los señores Aurelio M. Espinosa y Lawrence A. Wilkins. Publicada en revista Hispania, Volumen I, No I. California, Universidad de Stanford, febrero, pp. 1-14.

MONNER SANS, Ricardo

1903 Notas al castellano en la Argentina. Con un prólogo de Estanislao Severo Zeballos. Buenos Aires, Imprenta Carlos Parral. Citado a partir de Monner SAns, Ricardo (1903) Notas al castellano en la Argentina. $3^{a}$ edición. Prólogo y acotaciones de José María Monner Sans. Colección Estrada, Volumen Trigésimoquinto. Buenos Aires, Ángel Estrada, 1944.

1923 Disparates usuales en la conversación diaria. Primera Serie. Buenos Aires, Agencia General de Librería y Publicaciones.

MOREL-FATIO, Alfred

1900 [Reseña del libro de Abeille] en Romania. Recueil Trimestriel consacrè a l'étude des langues et des littératures romanes publié par Paul Meyer et Gaston Paris, $N^{\circ} 113$, Tome XXIX. Paris, Librairie Émile Bouillon, Éditeur, janvier, p. 486.

OBLIGADO, Rafael

1889a [Entrevista a Rafael Obligado], en La Prensa. Buenos Aires, 4 de agosto.

1889b «Por la afirmativa. Cuestión casera. I» (Carta a Juan Antonio Argerich), en La Nación. Buenos Aires, 7 de agosto, p. 1. 
1889c «Por la afirmativa. Cuestión casera. II» (Carta a Juan Antonio Argerich), en La Nación. Buenos Aires, 8 de agosto, p. 1.

1889d «Por la afirmativa. Cuestión casera. III» (Carta a Juan Antonio Argerich), en La Nación. Buenos Aires, 9 de agosto, p. 1.

1889e «Por la afirmativa. Cuestión casera. IV» (Carta a Juan Antonio Argerich), en La Nación. Buenos Aires, 11 de agosto, p. 1.

1890 «Rafael Obligado, académico» (Carta al secretario perpetuo de la Academia española, Sr. Tamayo y Baus), en La Nación. Buenos Aires, 16 de enero.

OLIVARI, Nicolás

1927 «Un llamado a la realidad. ¿Madrid, meridiano intelectual de Hispano América? Madrid, meridiano intelectual Hispano América.», en Martín Fierro. Periódico quincenal de arte y crítica libre. Número doble, Año IV, $\mathrm{N}^{\circ}$ 42. Buenos Aires, 10 de junio - 10 de julio, p. 6.

Olivera, Carlos

1900 «El idioma nacional de los argentinos», en Tribuna. Buenos Aires, 7 de agosto. Citado a partir de RUBIONE 1983, 62-66.

Oyuela, Calixto

1903 «Del espíritu nacional en la lengua y en la literatura» [Conferencia dada en el Colegio Nacional Norte, el 21 de septiembre de 1903], en Estudio literario, Tomo II. Buenos Aires, Academia Argentina de Letras, pp. 223-251.

PellizA, Mariano A.

1876a «La lengua española», en La Nación. Buenos Aires, 19 de enero, p. 1.

1876b «La lengua española», en La Nación. Buenos Aires, 29 de enero, p. 1.

PESQUeIRA, Joaquín

1925 «D. Ramón del Valle Inclán habla del futuro idioma argentino», en La Nación. Buenos Aires, 18 de marzo, p. 1.

Puente y ApeZeCheA, Fermín de la

1873 «Academias americanas correspondientes de la española», en Memorias de la Academia Española, Tomo IV. España, Imprenta y Estereotipia de Rivadeneyra, 1873, pp. 274-289.

QUeSADA, Ernesto

1900 El problema del idioma nacional. Buenos Aires, Revista Nacional.

1902 «El criollismo en la literatura argentina», en Estudios, Año I, Tomo III. 
Buenos Aires, Coni Hermanos, julio y agosto, pp. 251-322 y 396-453. Citado a partir de la edición que Coni Hermanos hace el mismo año en un volumen aparte.

1923a «La evolución del idioma nacional», en Nosotros. Revista mensual de letras, arte, historia, filosofía y ciencias sociales. Año XVII, Tomo XLIII, No 164. Buenos Aires, enero, pp. 5-31.

1923b «La evolución del idioma nacional (Conclusión)», en Nosotros. Revista mensual de letras, arte, historia, filosofía y ciencias sociales. Año XVII, Tomo XLIII, No 165. Buenos Aires, febrero, pp. 175-207.

1923c La evolución del idioma nacional. Buenos Aires, Imprenta Mercatali. 68 páginas. Se trata de la reedición de QueSADA 1923a y QuesADA 1923b, en forma de opúsculo. 1923 es el año que se imprime en la tapa, el que Quesada afirma estar escribiendo (cf. página 46) y el que se deduce de la información bibliográfica brindada en página 68. El pie de imprenta, sin embargo, en lo que quizá deba considerarse un error, data 1922.

QUESADA, Vicente G.

1877 a «Circular del ministro Vicente G. Quesada», en La República. Buenos Aires, 7 de marzo. Citado a partir de QUESADA 1877b, 494.

$1877 \mathrm{~b}$ «El idioma nacional», en Las bibliotecas europeas y algunas de la América latina, con un Apéndice sobre el Archivo General de Indias en Sevilla, la Dirección de Hidrografía y la Biblioteca de la Real Academia de la Historia en Madrid, Tomo I, Capítulo VIII, Punto IX. Buenos Aires, Imprenta y Librerías de Mayo, pp. 490-503.

1903 «El idioma castellano y las lenguas indianas», en Estudios, Año II, Tomo V. Buenos Aires, Coni Hermanos, pp. 7-27.

\section{REAL ACADEMIA ESPAÑOLA}

1870 [Resoluciones de la junta del 24 de noviembre de 1870], en Memorias de la Academia Española, Año I, Tomo IV. España, Imprenta de Rivadeneyra, 1870.

1925 Diccionario de la lengua española. Décima Quinta Edición. Madrid, Calpe.

RENAN, Ernest

1882 Qu'est-ce qu'une nation?: conférence faite en Sorbonne, le 11 mars 1882. Paris, Calmann Lévy.

REVISTA ESPAÑOLA DE AMBOS MUNDOS

1853 REVISTA ESPAÑOLA DE AMBOS MUNDOS Tomo primero. Madrid, Establecimiento Tipográfico de Mellado.

ROJAS, Ricardo

1909 La restauración nacionalista. Informe sobre educación. Buenos Aires, Ministe- 
rio de Justicia e Instrucción Pública.

1917 Historia de la literatura argentina. Ensayo filosófico sobre la evolución de la cultura en el Plata. I Los gauchescos. Buenos Aires, Imprenta de Coni Hermanos.

1922 «Eurindia, un ensayo de Ricardo Rojas», en suplemento dominical de La Nación. Buenos Aires, 29 de octubre, pp. 3 y 10.

Rojas, Ricardo y CASTRO, Américo

1923 Instituto de Filología: Discursos pronunciados por el decano don Ricardo Rojas y por el profesor don Américo Castro en el acto inaugural, realizado el día 6 de junio de 1923. Buenos Aires, Instituto de Filología, Facultad de Filosofía y Letras, Universidad de Buenos Aires. Folleto de 23 páginas.

Rojas Paz, Pablo

1925 «Hispanoamericanismo», en Martín Fierro. Periódico quincenal de arte y crítica libre. Segunda Época, Año II, No 17 Buenos Aires, 17 de mayo, p. 2.

1927 «Un llamado a la realidad. ¿Madrid, meridiano intelectual de Hispano América? Imperialismo baldío.», en Martín Fierro. Periódico quincenal de arte y crítica libre. Número doble, Año IV, $\mathrm{N}^{\circ}$ 42. Buenos Aires, 10 de junio - 10 de julio, p. 6.

RossI, Vicente

1910 «El Lenguaje», en Teatro nacional rioplatense. Contribución á su análisis y á su bistoria. Río de la Plata, Imprenta Argentina de Beltrán y Rossi, pp. 119-126.

1926 «Idioma nacional de arjentinos y uruguayos», en Cosas de Negros. Los orijenes del tango y otros aportes al folklore rioplatense. Rectificaciones históricas. Río de la Plata, Imprenta Argentina, Nota complementaria 25, pp. 399-409.

1928 Idioma Nacional Rioplatense (arjentino-uruguayo). Primera evidencia. (Folletos Lenguaraces, 6). Río de la Plata, Imprenta Argentina.

1929 Táta - Mamá - Papá. Idioma Nacional Rioplatense. Quinta evidencia. (Folletos Lenguaraces, 10). Río de la Plata, Imprenta Argentina.

1939 Filolojía i Fololoría. Confabulacion Antiarjentinista. (Folletos Lenguaraces, 23). Río de la Plata, Imprenta Argentina.

Rubione, Alfredo V. E. (comp.)

1983 En torno al criollismo. Textos y polémicas. Estudio crítico y compilación por el profesor Alfredo V. E. Rubione. Biblioteca argentina fundamental. Serie contemporánea: Sociedad y Cultura. Las nuevas propuestas, 22. Capítulo 190. Buenos Aires, Centro Editor de América Latina.

SALAVERRíA, José María 
1927 «El castellano que hablamos», en La Nación. Buenos Aires, 21 de octubre.

SARMIENTO, Domingo Faustino

1841 «Un plan de educación de americanos en París», en La Bolsa. Chile, 15 de enero de 1841. Citado a partir de SARMiento, Domingo Faustino (1914) Obras de D. F. Sarmiento, Tomo XII: Educación común. Buenos Aires, Augusto Belín Sarmiento, pp. 179-190.

1842a «Ejercicios populares de la lengua castellana», en Mercurio. Valparaíso, 27 de abril. Citado a partir de SARMIENTO 1887, 208-211.

1842b «Contestación a Un quídam», en Mercurio. Valparaíso, 19 de mayo. Citado a partir de SARMIENTO 1887, 213-218.

1842c «Segunda contestación a Un quídam», en Mercurio. Valparaíso, 22 de mayo de 1842. Citado a partir de SARMIENTO 1887, 218-224.

1842d «El comunicado de Otro quidam», en Mercurio. Valparaíso, 3 de junio. Citado a partir de SARMIENTO 1887, 224-227.

1842e «Los redactores al Otro quídam», en Mercurio. Valparaíso, 5 de junio de 1842. Citado a partir de SARMIENTO 1887, 228-231.

1843a Memoria (Sobre ortografía americana) leída a la Facultad de Humanidades. Santiago de Chile, Imprenta de La Opinión, octubre. Citado a partir de SARMIENTO 1909, 1-50.

1843b «Primera carta al señor Minvielle», en Gaceta del Comercio. Valparaíso, 24 de octubre. Fechada en Santiago, 21 de octubre de 1843. Citado a partir de SARMIENTO 1909, 55-59.

1843 c «Cuarta carta al señor Minvielle», en Gaceta del Comercio. Valparaíso, 27 de octubre. Fechada en Santiago, 24 de octubre de 1843. Citado a partir de SARMIENTO 1909, 67-71.

1843d «Octava carta a don Rafael Minvielle», en Gaceta del Comercio. Valparaíso, 7 de noviembre. Fechada en Santiago, 4 de noviembre de 1843. Citado a partir de SARMIENTO 1909, 86-89.

1843e «Contestación al Mercurio, I», en Progreso. Santiago, 22 de noviembre. Citado a partir de SARMIENTO 1909, 89-92.

$1843 \mathrm{f}$ «Contestación al Mercurio, II», en Progreso. Santiago, 23 de noviembre. Citado a partir de SARMIENTO 1909, 92-97.

$1843 \mathrm{~g}$ «Contestación a un profesor de gramática», en Progreso. Santiago, 29 de noviembre. Citado a partir de SARMIENTO 1909, 97-115.

$1843 \mathrm{~h}$ «Nueva contestación al Mercurio», en Progreso. Santiago, 4 de diciembre. Citado a partir de SARMIENTO 1909, 126-132.

1844 «El informe presentado a la Facultad de Humanidades», en Progreso. Santiago, 21 de febrero de 1844. Citado a partir de SARMIENTO 1909, 145-174.

1849 «Biblioteca de autores españoles publicada por don Manuel Rivadeneyra», en Crónica. Santiago, 25 de marzo. Citado a partir de Sarmiento, Domingo Faustino (1885) Obras de D. F. Sarmiento, Tomo II: Artículos críticos i literarios 1842-1853. Santiago de Chile, Luis Montt, pp. 331-333.

1865 «La doctrina Monroe. Discurso de Recepción en la Sociedad Histórica de Rhode Island - Providence, EE.UU., 27 de octubre de 1865.» 
Citado a partir de Sarmiento, Domingo Faustino, Obras de D. F. Sarmiento, Tomo XXI: Discursos populares I. Buenos Aires, Augusto Belín Sarmiento, 1899, pp. 195-236.

1866 «Agricultor americano», en Ambas Américas. Revista de Educación, Bibliografia i Agricultura. Bajo los auspicios de D. F. Sarmiento, Volumen I. Nueva York, 1867, pp. 102-113.

1870 «Carta al Señor D. J. Rojas Paul, Ministro de Relaciones Exteriores de los Estados Unidos». Fechada en Buenos Aires, 11 de abril. Citado a partir de SARmiento, Domingo Faustino, Obras de D. F. Sarmiento, Tomo XLVII: Educar al soberano. Buenos Aires, Augusto Belín Sarmiento, 1900, pp. 5-24.

1872 «Carta al Señor D. José Posse». Fechada el 5 de septiembre. Citado a partir de SARmiento, Domingo Faustino, Obras de D. F. Sarmiento, Tomo LI, Papeles del Presidente (1868-1874). Parte Segunda. Buenos Aires, Augusto Belín Sarmiento, 1902, pp. 222-224.

1879a «Ortografía castellana», en La Educación Común. Buenos Aires, 1 de marzo. Citado a partir de SARMiento, Domingo Faustino (1914) Obras de D. F. Sarmiento, Tomo XXVIII: Conflicto $i$ armonias de las razas en América. $2^{a}$ parte póstuma. Buenos Aires, Augusto Belín Sarmiento, pp. 308-312.

1879b «Nuestros trigos III», en El Nacional. Buenos Aires, 22 de abril. Citado a partir de SARmiento, Domingo Faustino (1900) Obras de D. F. Sarmiento, Tomo XLI: Progresos jenerales. Vistas económicas. Buenos Aires, Augusto Belín Sarmiento, pp. 138-141.

1886 «El volapuck y el curso de lengua universal, II», en El Censor. Buenos Aires, 10 de junio. Citado a partir de SARMiento, Domingo Faustino (1900) Obras de D. F. Sarmiento, Tomo XLVI: Pájinas literarias. Buenos Aires, Augusto Belín Sarmiento, pp. 350-351.

1887 Obras de D. F. Sarmiento, Tomo I: Artículos críticos i literarios 1841-1842. Santiago de Chile, Luis Montt.

1899 «Una crítica española» (póstumo), en Obras de D. F. Sarmiento, Tomo XXIX: Ambas Américas. Buenos Aires, Augusto Belín Sarmiento, pp. 316-325.

1909 Obras de D. F. Sarmiento, Tomo IV: Ortografía, Instruccion Pública 18411854. Reimpresion. Paris, Belín Hermanos.

SASTRE, Marcos

1855 Ortografía Completa (Utilisima para todos los que deseen escribir correctamente sin necesidad del Diccionario). Tomo I. Buenos Aires, Imprenta de la Revista.

SCALABRINI ORTIZ, Raúl

1927 «Un llamado a la realidad. ¿Madrid, meridiano intelectual de Hispano América? La implantación de un meridiano. Anotaciones de sextante.», en Martín Fierro. Periódico quincenal de arte y crítica libre. Número doble, Año IV, No 42. Buenos Aires, 10 de junio - 10 de julio, p. 7. 
SEGOVIA, Lisandro

1911 «Introducción», en Diccionario de argentinismos, neologismos y barbarismos, con un apéndice sobre voces extranjeras interesantes. Obra publicada bajo los auspicios de la Comisión Nacional del Centenario. Buenos Aires, Imprenta de Coni Hermanos, pp. 5-12.

SElVA, Juan B.

1906 El castellano en América. Su evolución. La Plata, Talleres Gráficos Sesé y Larrañaga. Folleto de 88 páginas.

SOLAR, Alberto del

1889a «La Academia española y los americanos», en La Nación. Buenos Aires, 25 de agosto, p. 1.

1889b «Replico» (Carta a Juan Cancio), en La Nación. Buenos Aires, 5 de septiembre, p. 1.

1889c «Punto y coma» (Carta a Juan Cancio), en La Nación. Buenos Aires, 7 de septiembre, p. 1.

1889d Cuestión filológica. Suerte de la lengua castellana en América. Conferencia leída en el Ateneo de Buenos Aires. Buenos Aires, Félix Lajouane.

Soto y CALVO, Francisco

1903 «De la falta de carácter en la literatura argentina», en Estudios, Año II, Tomo IV. Buenos Aires, Imprenta y Casa Editora de Coni Hermanos, pp. 286-304.

TERÁN, Juan B.

1908 «Naturaleza del lenguaje», en Estudios y Notas. Tucumán, Edición de la Revista de Letras y Ciencias Sociales, pp. 122-151.

TORO y GisBert, Miguel de

[1912] Americanismos. París, Librería Paul Ollendorff, s. a. Deduzco que se trata de un trabajo de 1912 porque, en la página 15, Toro y Gisbert confiesa que han pasado 40 años del trabajo de Gaston Maspero: «Sur quelques singularités phonétiques de l'espagnol parlé dans la campagne de Buenos Aires et Montevideo», publicado en París, en 1872.

TORRE, Guillermo de

1927 «Madrid, meridiano intelectual de Hispano-América», en La Gaceta Literaria, ibérica, americana, internacional. Letras, artes, ciencia. Periódico quincenal (1 y 15 de cada mes). Año I, No 8. Madrid, 15 de abril, p. 1.

UGARTE, Manuel 
1910 El porvenir de la América española: la raza, la integridad territorial y moral, la organización interior. España, Valencia, Prometeo.

\section{UN LECHUGUINO}

1837 «Sr. Editor del Diario de la Tarde», en Diario de la Tarde. Buenos Aires, 2 de agosto. Citado a partir de ECHEVERRÍA 1940, 299.

UnAmunO, Miguel de

1899a «Contra el purismo I», en El Sol. Buenos Aires, 24 de octubre.

1899b «Contra el purismo II», en El Sol. Buenos Aires, 1 de noviembre.

1899c «Contra el purismo III», en El Sol. Buenos Aires, 8 de noviembre.

1899d «El pueblo que habla español», en El Sol. Buenos Aires, 16 de noviembre.

1901 «Sobre la lengua española», en Nuestro Tiempo, Año I, No 11. Madrid, noviembre, pp. 601-607.

1903 «Sobre el criollismo», carta al Señor doctor Adolfo Casabal, en El Tiempo. 6 de junio de 1903. Citado a partir de la edición que se reproduce en Estudios, Año II, Tomo V. Buenos Aires, Coni Hermanos, pp. 28-38.

1928 «Prólogo con verso», en CAPDEVILA 1928, 11-12

VALERA, Juan

1864 «Discurso de recepción en la Real Academia Española», en Estudios críticos sobre literatura, política y costumbres de nuestros días, Tomo II. Madrid, Librerías de A. Durán, pp. 262-305.

1900 a «Sobre la duración del habla castellana. Con motivo de algunas frases del Sr. Cuervo», en Los lunes de El imparcial. Madrid, 24 de septiembre. Citado a partir de Cuervo 1947, 37-47.

1900b «Carta a La Nación de Buenos Aires», en La Nación. Buenos Aires, 2 de diciembre. Citado a partir de Cuervo 1947, 49-52.

1902 «Carta a La Tribuna de México», en La Tribuna, N²76 y No 277. México, 31 de agosto y 2 de septiembre. Citado a partir de Cuervo 1947, 93-104.

VARELA, Florencio

1835 «Los Consuelos. Juicio crítico del doctor don Florencio Varela», en ECHEVERRÍA 1874, VIII-XXXVI.

1837 «Carta de Florencio Varela a Juan María Gutiérrez con referencia al "Salón Literario" y los discursos pronunciados el día de su apertura», fechada en Montevideo, el $1^{\circ}$ de agosto de 1837, publicada por primera vez en Antecedentes de la Asociación de Mayo, 1837-1939. Buenos Aires, Ed. Homenaje del H. Cosejo Deliberante de la Ciudad de Buenos Aires, 1939, pp. 15-22. Sigo la edición de ECHEVERRía 1940, 288-293. 
VARELA, Juan Cruz

1828 «Literatura nacional», en El Tiempo. Diario politico, literario y mercantil. $\mathrm{N}^{\circ}$ 36. Buenos Aires, 14 de junio. Página 2 y 3. Citado a partir de la edición Weinberg, Félix (1964) «Juan Cruz Varela, crítico de la Literatura Nacional», en Boletín de Literatura Argentina de la Facultad de Filosofía y Humanidades, Año 1, No 1. Córdoba, agosto, pp. 29-63.

VediA, Mariano de (Firma como Juan Cancio)

1889a «Fundo mi voto» (Carta a Alberto del Solar), en La Nación. Buenos Aires, 4 de septiembre, p. 1.

1889b «Sobre lo mismo» (Carta a Alberto del Solar), en La Nación. Buenos Aires, 6 de septiembre, p. 1.

1889c «Hasta la vista» (Carta a Alberto del Solar), en La Nación. Buenos Aires, 8 de septiembre, p. 1.

1900 [Sobre «El idioma nacional de los argentinos», de Carlos Olivera], en Tribuna. Buenos Aires, 30 de julio y 7 de agosto.

Vergara Vicuña, Federico

1927 «El nuevo idioma argentino», en La Nación. Santiago de Chile, 6 de julio.

WILDE, Eduardo

1904 «El idioma y la gramática», en Anales de la Facultad de Derecho y Ciencias Sociales, Tomo V. Buenos Aires, Imprenta y Casa Editora de Coni Hermanos, pp. 105-151.

XUL SOLAR

1927a «Despedida de Marechal», en «Notas de Martín Fierro», en Martín Fierro. Periódico quincenal de arte y crítica libre. Buenos Aires, Segunda Época. Año IV, N 37. Buenos Aires, 20 de enero, p. 8.

1927b «Algunos piensos cortos de Cristian Morgenstern» (Versión de Xul Solar), en Martín Fierro. Periódico quincenal de arte y crítica libre. Segunda Época. Año IV, No 41. Buenos Aires, 28 de mayo, p. 9.

1931 «Apuntes de neocriollo», en Azul. Revista de Ciencias y Letras. Año 2, N 11. Azul, agosto, pp. 201-205. Firma Xul Solá [sic]

ZEBALLos, Estanislao Severo

1903 «El castellano en América», en Notas al castellano en la Argentina, por Ricardo Monner Sans. Buenos Aires, Imprenta Carlos Parral. Citado a partir de MONNER SANS 1903, 3-40.

1878 La conquista de quince mil leguas. Estudio sobre la traslación de la frontera sud de la República al río Negro. Dedicado a los jefes y oficiales del ejército expedicionario. Segunda edición revisada y considerablemente aumentada por el 
autor. Buenos Aires, Establecimiento tipográfico a vapor de «La Prensa».

ZíA, Lisardo

1927 «Un llamado a la realidad. ¿Madrid, meridiano intelectual de Hispano América? Para Martín Fierro.», en Martín Fierro. Periódico quincenal de arte y crítica libre. Número doble, Año IV, $\mathrm{N}^{\circ}$ 42. Buenos Aires, 10 de junio 10 de julio, p. 7. 